\title{
Molekulardynamiksimulationen kraftmikroskopischer
}

\section{Einzelmolekülexperimente}

\author{
Dissertation \\ zur Erlangung des Doktorgrades \\ der Mathematisch-Naturwissenschaftlichen Fakultäten \\ der Georg-August-Universität zu Göttingen
}

vorgelegt von

Berthold Heymann

aus Hamburg

Göttingen 1999 
D7

Referent: Prof. Dr. E. Neher

Korreferentin: Prof. Dr. A. Zippelius

Tag der mündlichen Prüfung: 


\section{Inhaltsverzeichnis}

1 Einleitung 3

2 Die Methode der MD-Simulation $\quad 9$

2.1 Prinzip . . . . . . . . . . . . . . . . . . 10

2.2 Effiziente Simulationsmethoden ................ 13

2.3 Die Lösungsmittelumgebung . . . . . . . . . . . . . . . 16

2.4 Minimierung und Equilibrierung . . . . . . . . . . . . . 20

3 MD-Simulation kraftmikroskopischer Experimente $\quad 21$

3.1 Kraftmikroskopische Einzelmolekülxperimente . . . . . . . . . . 22

3.2 MD-Simulation kraftmikroskopischer Experimente . . . . . . . . . . 25

3.2.1 Das Simulationsverfahren . . . . . . . . . . . 25

3.2.2 Die Federkonstante in Dissoziationssimulationen . . . . . . . . . 26

4 Theorie zu Dissoziationsprozessen $\quad 31$

4.1 Modell zur Interpolation von Dissoziationskräften . . . . . . . . . . . 32

4.2 Allgemeine Theorie forcierter Dissoziationsprozesse . . . . . . . . . . 35

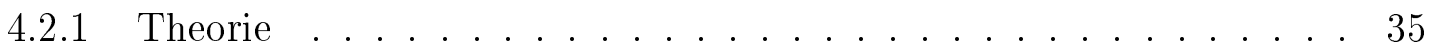

4.2 .2 Testrechnungen . . . . . . . . . . . . . . . 40

5 Dissoziationssimulationen zu AN02-Hapten $\quad 47$

5.1 Der AN02-DNP-Hapten-Komplex . . . . . . . . . . . . . 48

5.2 Das Simulationsmodell . . . . . . . . . . . . . . . 52

5.3 Minimierung und Equilibrierung . . . . . . . . . . . . 54

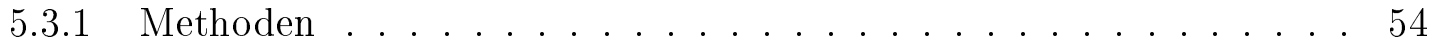

5.3 .2 Ergebnisse und Diskussion ................ 56 


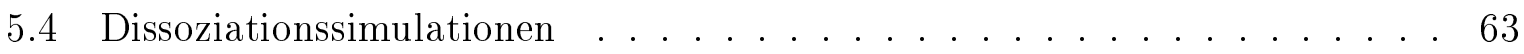

5.4.1 Das Simulationsverfahren ................ 64

5.4.2 Kraftprofile und Dissoziationskräfte . . . . . . . . . 67

5.4.3 Dissoziationspfade und Wechselwirkungen . . . . . . . . . . 72

5.4.4 Zusammenfassung und Diskussion . . . . . . . . . . . 90

5.4.5 Dissoziationsprozesse von zwei Mutanten . . . . . . . . . 91

6 Dehnungssimulationen von Polymermolekülen 101

6.1 Dehnungssimulationen von Polysacchariden . . . . . . . . . . . 102

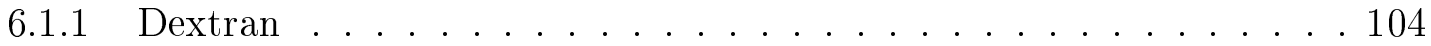

6.1.2 Cellulose und Amylose . . . . . . . . . . . . . . 111

6.1.3 Exkurs: Antikooperativität bei Amyloseübergängen . . . . . . . . . 120

6.2 Dehnungssimulationen von Polyethylenglykol (PEG) . . . . . . . . . . 132

6.3 Zusammenfassung der Dehnungssimulationen . . . . . . . . . . . 142

$\begin{array}{lll}7 & \text { Zusammenfassung } & 143\end{array}$

$\begin{array}{ll}\text { A Aminosäuresequenz von AN02 } & 145\end{array}$

$\begin{array}{lr}\text { Danksagung } & 149\end{array}$ 


\section{Kapitel 1}

\section{Einleitung}

Neue experimentelle Techniken, die in den letzten zehn Jahren entwickelt worden sind, ermöglichen es, inter- und intramolekulare Kräfte an einzelnen Molekülen zu messen [1,2]. Auf diese Weise sind etwa Kräfte zugänglich, die Motorproteine wie Myosin auf Aktinfilamente ausüben, um an ihnen innerhalb von Zellen entlangzuwandern und Vesikel hinund herzutransportieren [3]. Auch konnte die Kraft gemessen werden, welche die RNAPolymerase während der Transkription entlang eines DNA-Strangs schiebt [4], oder welche ein Flagellenmotor zu generieren in der Lage ist, um Bakterien mit Geschwindigkeiten von mehr als $50 \mu \mathrm{m} / \mathrm{s}$ voranzutreiben [5]. Desweiteren wurde kürzlich an zahlreichen Systemen untersucht, welche Kräfte erforderlich sind, um Proteine oder DNA-Stränge zu entfalten [6-16], Zucker- und andere Polymere zu dehnen [17-24] oder einzelne RezeptorLigand-Bindungen zu trennen [25-34]. In vielen Fällen dienten von außen angelegte, gerichtete Kräfte als Kontrollparameter für strukturelle Veränderungen innerhalb von Molekülen, etwa Konformationsübergängen in Proteinen oder die partielle Auffaltung von DNA-Doppelsträngen [35-39].

Ein Beispiel für diese kraftinduzierenden Einzelmolekülexperimente sind kraftmikroskopische Experimente. Ursprünglich diente das 1986 erfundene Kraftmikroskop dazu, Bilder von Halbleitern, Mineralien, Polymeren, Bio- und anderen Molekülen in nahezu atomarer Aufösung zu liefern [40,41]. Wie Abbildung 1.1 schematisch zeigt, wurde das Kraftmikroskop in jüngeren Anwendungen dann auch dazu verwendet, mechanische Kräfte an einzelnen Molekülen zu messen [7, 26, 27, 42]: Einzelne Rezeptor-Ligand-Komplexe werden über Polymerlinker zwischen Cantilever und Unterlage „eingespannt" und dann getrennt, indem Cantilever und Unterlage auseinandergezogen werden. Die dabei aufgewendete Zugkraft wird über die Auslenkung des Cantilevers aus seiner Gleichgewichtslage bestimmt.

Zwei Aspekte zeichnen derartige Messungen besonders aus. Zum einen können in den Einzelmolekülexperimenten individuelle Moleküle adressiert und an ihnen Messungen durchgeführt werden. Führt man viele solcher Experimente durch, erhält man eine Verteilung von Einzelmolekülmesswerten. Im Gegensatz dazu können in herkömmlichen Ensemblemessungen nur Ensemblemittelwerte für eine große Zahl von Molekülen bestimmt werden, so dass hier Informationen über die Messwertverteilung nicht zugänglich sind.

Zweitens werden in kraftinduzierenden Einzelmolekülexperimenten anstelle von Energien 


\section{Trennung eines Rezeptor-Ligand-Komplexes}

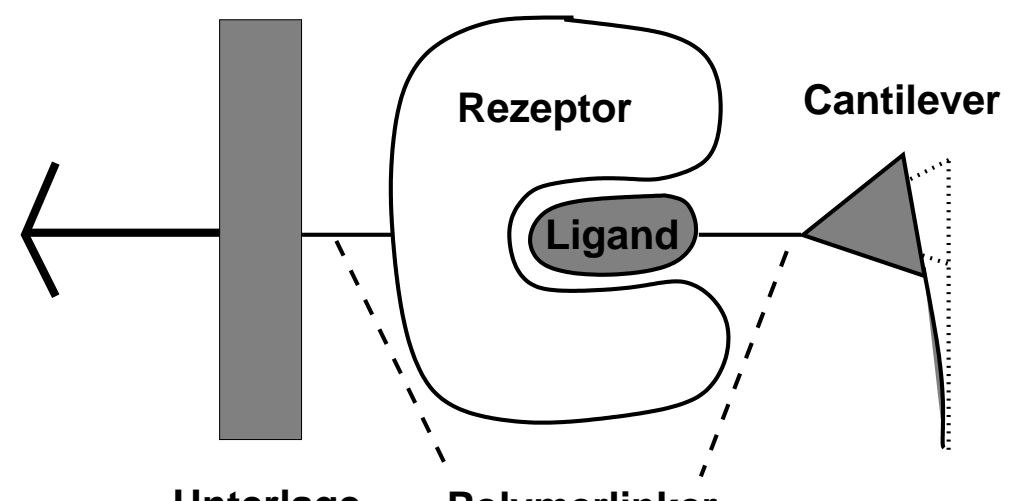

Unterlage Polymerlinker

Abbildung 1.1: Typische Vorgehensweise in kraftmikroskopischen Einzelmolekülexperimenten (Skizze). Ein Ligand wird über einen Polymerlinker an den Cantilever gebunden; ebenso wird der Rezeptor an einer Unterlage befestigt, die im Verlauf des Experiments mit konstanter Zuggeschwindigkeit vom Cantilever wegbewegt wird. Die dadurch auf den Rezeptor-Ligand-Komplex ausgeübte anwachsende Zugkraft wird über die Auslenkung des Cantilevers aus seiner Gleichgewichtslage registriert. Auf diese Weise kann die zum Zeitpunkt der Bindungstrennung ausgeübte Maximalkraft (die Dissoziationskraft) bestimmt werden.

Kräfte gemessen. Während man beispielsweise in kalorimetrischen Messungen die FreieEnergie-Differenz zwischen gebundenem und ungebundenem Zustand eines Ensembles von Rezeptor-Ligand-Komplexen bestimmt [43,44], misst man hier Bindungskräfte. Da diese im Gegensatz zur freien Energie keine thermodynamischen Zustandsgrößen sind, enthalten sie zusätzliche Informationen über den Verlauf der kraftinduzierten Prozesse, etwa über einen Bindungsmechanismus [25, 26].

Bereits vor einiger Zeit sind auf Molekulardynamik-(MD)-Simulationen [45-49] gestützte Methoden entwickelt und seitdem erfolgreich eingesetzt worden, mit deren Hilfe man in der Lage ist, sogar in solch komplexen und heterogenen Vielteilchensystemen wie Proteinen Freie-Energie-Differenzen zu berechnen [50-54], diese auf individuelle interatomare Wechselwirkungen und atomare Fluktuationen zurückzuführen und in verschiedene Energiebeiträge - etwa elektrostatische oder Van der Waals-Wechselwirkungen — aufzuschlüsseln. Ausgehend von atomar aufgelösten Proteinstrukturen, wie sie etwa durch Röntgenstreuexperimente oder Kernspinresonanzmessungen in schnell wachsender Zahl verfügbar werden, wird in solchen MD-Simulationen die atomare Dynamik numerisch berechnet, was die detaillierte theoretische Untersuchung mikroskopischer Wechselwirkungen und Fluktuationen gestattet.

Entsprechende Verfahren zur mikroskopischen Interpretation der neuen kraftinduzierenden Einzelmolekülexperimente gab es bis vor kurzem nicht. Solche Verfahren sind aber wichtig, da mechanische Kraftmessungen bisher keinen direkten Einblick in die atomaren Prozesse erlauben, die in den Molekülen unter Einwirkung der applizierten Kraft stattfinden. So sind etwa Informationen, auf welchem (geometrischen) Dissoziationsweg sich ein 
Ligand aus der Bindungstasche seines Rezeptors bewegt und welche Wechselwirkungen zwischen individuellen Ligand- und Rezeptoratomen den untersuchten Dissoziationsprozess bestimmen, experimentell nicht zugänglich. Desweiteren kann in der Regel nicht der gesamte Verlauf der Kraft auf einen Liganden während des Dissoziationsprozesses (das so genannte Kraftprofil) aufgelöst werden, sondern nur die Abreiß- oder Dissoziationskraft, also das Maximum des Kraftprofils. Auch können strukturelle Änderungen innerhalb eines Moleküls als Antwort auf die einwirkende Kraft gegenwärtig nicht in atomarer Auflösung detektiert werden.

Kürzlich wurde ein MD-gestütztes Verfahren zur Interpretation von kraftinduzierenden Einzelmolekülexperimenten unter Mitwirkung des Autors vorgeschlagen, entwickelt und erstmalig eingesetzt [55,56]. Am Beispiel der Streptavidin-Biotin-Dissoziation wurde nachgewiesen, dass dieses Verfahren es erlaubt, Dissoziationskräfte mit der experimentell erreichbaren Genauigkeit zu berechnen. Die Berechnung von Kraftprofilen erlaubte es außerdem, ein detailliertes Modell der atomaren Prozesse und Wechselwirkungen anzugeben, die für die bei der Trennung der Bindung gemessenen Kräfte verantwortlich sind. Inzwischen wurde diese Methode von mehreren Arbeitsgruppen auf zahlreiche Systeme erfolgreich angewendet [17,57-72] und kann als etabliert angesehen werden.

Die in der vorliegenden Arbeit beschriebenen Simulationen - die forcierte Dissoziation eines Antikörper-Hapten-Komplexes sowie die Dehnung von Polymermolekülen fußen auf diesem Simulationsverfahren, das in Kapitel 3 im Detail beschrieben wird. Prinzipiell ist unser Simulationsverfahren auf alle kraftinduzierenden Einzelmolekülexperimente anwendbar, wie etwa Experimente mit optischen oder magnetischen Pinzetten [73-76], Biomembran-Kraftmessungs-(BFP)-Experimente [77] oder kraftmikroskopische Einzelmolekülexperimente [25]. Hier wollen wir uns auf Letztere konzentrieren, da zu allen in der vorliegenden Arbeit untersuchten Systemen kraftmikroskopische Einzelmolekülexperimente durchgeführt wurden oder in Arbeit sind [17, 22, 24-26].

Die von uns vorgeschlagenen MD-Dissoziationssimulationen [55] zielen darauf ab, das vollständige Einzelmolekülexperiment möglichst detailgetreu zu simulieren. Entsprechend wird gerade dasjenige Ligandatom, das im kraftmikroskopischen Experiment mit der Spitze des Cantilevers verbunden ist, einem geeigneten Zugpotenzial unterworfen, das als Modell für den Cantilever dient. Während der Simulation wird dieses Zugpotenzial über die Simulationszeitspanne in Zugrichtung bewegt, so dass auf das Ligandatom eine ansteigende Zugkraft ausgeübt und dieser schließlich von seinem Rezeptormolekül getrennt wird. Auch hier bestimmen wir die Dissoziationskraft als die maximale Zugkraft, die der Ligand im Verlauf der Dissoziationssimulation erfährt.

In dieser Arbeit richtet sich unser Interesse zunächst auf das Phänomen der molekularen Erkennung in Rezeptor-Ligand-Komplexen. Dahinter verbirgt sich die Frage, wie sich in der ungeheuren molekularen Vielfalt eines jeden biologischen Systems bestimmte Moleküle gegenseitig erkennen und hochspezifisch miteinander reagieren. Auf Grund welcher atomarer Prozesse bindet ein Antikörper sein Antigen, ein Hormon sein Rezeptormolekül oder ein Enzym sein Substrat hochspezifisch? Wir wollen dies anhand eines Rezeptor-Ligand-Komplexes untersuchen, bei dem ein AN02-Antikörper spezifisch an ein spinmarkiertes Dinitrophenyl-(DNP)-Hapten bindet [78, 79].

Neben der Berechnung der Dissoziationskraft fragen wir bei unseren Dissoziationssimu- 
lationen nach dem Mechanismus der spezifischen Bindung zwischen AN02 und DNPHapten. Auf welchem Dissoziationspfad bewegt sich das Haptenmolekül aus der Bindungstasche des Antikörpers heraus und in welche spezifischen Wechselwirkungen tritt es mit den Aminosäuren der Bindungstasche im Verlauf des Dissoziationsprozesses? Ein besonderes Augenmerk liegt dabei auf der Frage, ob es einen eindeutigen Dissoziationspfad und eine eindeutige Folge von Wechselwirkungen während des Dissoziationsprozesses gibt oder ob eine signifikante Streuung zu beobachten ist. Wir stellen diese Frage vor allem vor dem Hintergrund der kürzlich bei einem noch nicht spezialisierten Antikörper gemachten Entdeckung, dass die Geometrie der Bindungstaschenregion auch durch weit entfernte Aminosäuren verändert werden kann [80] und dass somit die Konformationsflexibilität bei der Optimierung der Bindung eine zentrale Rolle spielt, was damit einhergehende signifikante entropische Beiträge nahelegt.

Neben der forcierten Dissoziation von Rezeptor-Ligand-Komplexen wurden in ähnlichen kraftmikropischen Experimenten die elastischen Eigenschaften einzelner Polymermoleküle untersucht [17, 18, 21, 22, 24], indem diese Moleküle zwischen Cantilever und einer Unterlage „eingespannt“ und anschließend auseinandergezogen wurden. Im Unterschied zu den Dissoziationsexperimenten interessierte hier der Verlauf der Zugkraft als Funktion der Ausdehnung des Polymers, der in der so genannten Kraft-Ausdehnungs-Kurve aufgezeichnet wurde. Diese Experimente zielten darauf ab, Materialeigenschaften auf molekularer Grundlage besser zu verstehen, da diese für die makroskopischen Eigenschaften von komplexen biologischen Systemen in hohem Maße mitverantwortlich sind. In Analogie zu der in Abbildung 1.1 schematisch gezeigten Vorgehensweise wurden am Lehrstuhl Gaub an der Universität München die strukturell einander sehr ähnlichen Polysaccharide Dextran, Amylose und Cellulose sowie das in vielen industriellen, biotechnischen oder klinischen Anwendungen [81, 82] vorkommende Polymermolekül Polyethylenglykol (PEG) mechanisch gedehnt. Dabei wurde für jedes Polymermolekül eine Kraft-Ausdehnungs-Kurve aufgezeichnet. Die Steigung entlang der Kraft-Ausdehnungs-Kurve ist ein Maß für die Elastizität des jeweiligen Polymers. Die Messungen an den Polysacchariden ergaben, dass minimale Unterschiede in der Verbrückung der Monomere zu dramatisch unterschiedlichen Elastizitätscharakteristiken führen können. Wie ist dies zu erklären?

Um diese Frage zu beantworten, haben wir MD-Simulationen durchgeführt (Kapitel 6), in denen diese Polymermoleküle in direkter Anlehnung an die kraftmikroskopischen Experimente gedehnt wurden. Es bot sich hier die Chance zu überprüfen, ob unser Simulationsverfahren auch auf den von einer Rezeptor-Ligand-Dissoziation sehr verschiedenen Prozess der mechanischen Dehnung einzelner Polymermoleküle anwendbar ist. Die Simulationen sollten Einblick in die Prozesse auf atomarer Ebene verschaffen, die für die kraftmikroskopisch gemessenen und aus den Simulationen abgeleiteten Elastizitäten verantwortlich sind. Das Hauptaugenmerk lag dabei auf der Frage, worin sich diese Prozesse auf Grund der unterschiedlichen Verbrückung in den einzelnen Polysacchariden voneinander unterschieden.

Im Gegensatz zu den Polysacchariden zeigt PEG in seiner Elastizitätscharakteristik eine starke Lösungsmittelabhängigkeit [24]. Hier sollten MD-Dehnungssimulationen aufklären, wie unterschiedliche Lösungsmittel auf die molekulare Struktur von PEG einwirken und somit die elastischen Eigenschaften beeinflussen. 
MD-Simulationen sind deswegen sehr gut sowohl für die forcierte Dissoziation von RezeptorLigand-Komplexen als auch für die Dehnung von Polymermolekülen geeignet, da sie die analogen Experimente ungewöhnlich genau nachbilden. Zum einen, weil man es in Simulation und Experiment mit Systemen identischer Größe zu tun hat: Der üblicherweise anzutreffende Nachteil, dass MD-Simulationen aus Rechenzeitgründen auf einzelne Makromoleküle und somit auf sehr viel kleinere Systeme als in vergleichbaren Experimenten beschränkt sind, fällt hier weg, da gerade Einzelmolekülexperimente simuliert werden. Zum anderen haben wir es mit identischen Observablen, nämlich Dissoziations- und Dehnungskräften zu tun, was einen direkten Vergleich zwischen Experiment und Simulation erleichtert.

Die einzig verbleibende Diskrepanz zwischen Experiment und Simulation sind die sehr unterschiedlichen Zeitskalen: Während kraftmikroskopische Experimente nur auf der Millisekundenzeitskala oder langsamer durchgeführt werden können, kann die atomare Dynamik in MD-Simulationen auf Grund des enorm hohen Rechenaufwands selbst auf Hochleistungsparallelrechnern nur für die Zeitspanne von maximal einigen Nanosekunden berechnet werden. Für die forcierte Dissoziation von Rezeptor-Ligand-Komplexes hat dies zur Folge, dass in der Simulation eine erheblich höhere Zuggeschwindigkeit als im kraftmikroskopischen Experiment gewählt werden muss, um den Liganden in der zur Verfügung stehenden Zeitspanne aus der Bindungstasche seines Rezeptors ziehen zu können.

Diese Diskrepanz zwischen Theorie und Experiment wirft die Frage auf, welchen Einfluss die Wahl der Zuggeschwindigkeit auf die gemessenen bzw. berechneten Dissoziationskräfte hat. Dass ein solcher Einfluss besteht, wurde inzwischen in zahlreichen Experimenten nachgewiesen [7,83-85]. Um trotz der Zeitskalendiskrepanz Theorie und Experiment vergleichen zu können, ist zunächst zu klären, welche physikalischen Mechanismen die beobachtete Abhängigkeit von der Zuggeschwindigkeit bewirken und wie sich diese beschreiben lassen (Kapitel 4).

Bereits in Ref. [55] wurden Reibung und aktivierte Prozesse auf Grund von thermischen Fluktuationen als die maßgeblichen Effekte benannt. Dort wurde, um berechnete mit gemessenenen Dissoziationskräften zu vergleichen, nur Reibung berücksichtigt, die eine lineare Abhängigkeit der Dissoziationskraft von der Zuggeschwindigkeit bewirkt; die Beschränkung auf Reibung war für den untersuchten, sehr stabilen Streptavidin-BiotinKomplex gerechtfertigt [68]. Im Allgemeinen, und insbesondere bei weniger stabilen Komplexen, wird die Dissoziationskraft durch thermisch aktivierte Prozesse verringert: Nach hinreichend langer Zeit führen diese ja ganz ohne extern angelegte Zugkraft zur spontanen Dissoziation. Wie auch vom Autor gezeigt wurde, ist zu erwarten, dass die Dissoziationskraft logarithmisch mit der Zuggeschwindigkeit anwächst [58, 68, 84, 86-88]. Im vierten Kapitel der vorliegenden Arbeit werden wir beide Effekte, Reibung und aktivierte Prozesse, in einem einfachen Modell kombinieren, das es erlaubt, den groben Verlauf des so genannten Kraftspektrums, in dem die Dissoziationskraft als Funktion der Zuggeschwindigkeit aufgetragen ist, zu beschreiben. Unter Zuhilfenahme der spontanen Dissoziationsrate können damit die auf der Nanosekundenzeitskala berechneten Dissoziationskräfte auf die Millisekunden- bis Sekundenzeitskala interpoliert und dadurch mit experimentell bestimmten Dissoziationskräften verglichen werden. Auf Grundlage dieses einfachen Modells werden wir die berechneten Dissoziationskräfte des AN02-DNP-Hapten-Komplexes (Kapitel 5) auf die experimentelle Zeitskala interpolieren, um somit zu einer Vorhersage 
für eine experimentelle Dissoziationskraft zu kommen.

Außer der Höhe der Aktivierungsbarriere, die sich direkt aus der spontanen Dissoziationsrate ergibt, bleiben hierbei allerdings Details der Energielandschaft, die die RezeptorLigand-Bindung beschreibt, zunächst unberücksichtigt. Eine genauere Betrachtung zeigt jedoch, dass der detaillierte Verlauf der Wechselwirkungsenergie zwischen Ligand und Rezeptor entlang des Dissoziationswegs in der Tat Einfluss auf die Feinstruktur des Kraftspektrums haben sollte. Tatsächlich wurde dies in BFP-Experimenten kürzlich beobachtet [83]. In einem eindimensionalen Diffusionsmodell wollen wir diesen Einfluss eingehend untersuchen und eine Theorie entwickeln, die es gestatten soll, für eine gegebene Energielandschaft das zugeordnete Kraftspektrum abzuleiten (viertes Kapitel). Wenn sich tatsächlich strukturelle Merkmale der Energielandschaft im Kraftspektrum widerspiegeln, dann sollte es sogar umgekehrt möglich sein, aus einem gemessenen Kraftspektrum die gesamte zugrunde liegende Energielandschaft zu rekonstruieren. Dies wäre insofern bemerkenswert, als man dann aus kraftinduzierenden Einzelmolekülexperimenten geringer Ortsauflösung dennoch Energielandschaften oder Kraftprofile mit atomarer Ortsauflösung erhalten kann.

Für den Spezialfall eines sehr weichen Zugpotenzials und unter der Annahme einer recht einfach strukturierten Energielandschaft ist eine solche Rekonstruktion für den ProteinLigand-Komplex Avidin-Biotin bereits gelungen [83]. Dabei wurden aus einem Spektrum von Dissoziationskräften, das in BFP-Experimenten über einen etwa fünf Größenordnungen überspannenden Bereich von Zuggeschwindigkeiten bestimmt wurde, drei Regimes in der Energielandschaft abgeleitet, die zuvor in MD-Simulationen beobachtet worden waren [58]. In der vorliegenden Arbeit zielen wir auf eine allgemeine Theorie ab, welche keine Voraussetzungen hinsichtlich der Beschaffenheit der Energielandschaft oder der Härte des Zugpotenzials macht.

Bevor wir im vierten Kapitel unsere Theorie zu kraftinduzierenden Einzelmolekülexperimenten entwickeln sowie in den Kapiteln fünf und sechs die Dissoziationssimulationen zu AN02-DNP-Hpaten und die Dehnungssimulationen zu Polymermolekülen beschreiben, werden wir im zweiten Kapitel die Methode der MD-Simulation einführen und kurz auf das verwendete parallele Simulationsprogramm EGO eingehen sowie, im dritten Kapitel, die Vorgehensweise in kraftmikroskopischen Einzelmolekülexperimenten und unser darauf aufbauendes Simulationsverfahren erläutern. 


\section{Kapitel 2}

\section{Die Methode der Molekulardynamiksimulation}

Die Methode der MD-Simulation wurde in der Literatur eingehend beschrieben; ein guter Übersichtsartikel ist etwa Ref. [89]. Hier soll lediglich das Prinzip skizziert und anschließend auf die Besonderheiten der hier durchgeführten MD-Simulationen — wie etwa die eingesetzten Methoden zur Effizienzsteigerung und die Beschreibung der Lösungsmittelumgebung - eingegangen werden. 


\subsection{Prinzip}

Die Methode der Molekulardynamiksimulation (MD-Simulation) dient dazu, die atomaren Bewegungen eines molekularen Systems von typischerweise $10^{3} \ldots 10^{5}$ Atomen über eine vorgegebene Zeitspanne zu berechnen. Wenn man dies exakt tun will, muss man die zeitabhängige Schrödinger-Gleichung für das Vielteilchensystem aus Elektronen und Atomkernen lösen. Dies ist jedoch bereits für sehr kleine Systeme, die aus mehr als zehn Atomen bestehen, zu aufwendig. Um auch größere molekulare Systeme, etwa ein Protein in seiner Lösungsmittelumgebung, über eine Zeitspanne von wenigstens einigen Nanosekunden simulieren zu können, sind drei Näherungsschritte erforderlich:

Zunächst werden die schnellen elektronischen Freiheitsgrade von den langsameren Kernfreiheitsgraden im Rahmen der Born-Oppenheimer-Näherung separiert [90,91]. Die daraus resultierende zeitunabhängige Schrödinger-Gleichung für die elektronische Dynamik, die parametrisch von den Kernpositionen abhängt, definiert die Eigenzustände des Elektronensystems. Somit lässt sich die Grundzustandsenergie des Elektronensystems als effektives Potenzial auffassen, das von der Position der Kerne abhängt und den Einfluss der elektronischen Dynamik auf die Bewegung der Atomkerne beschreibt.

Im zweiten Näherungsschritt wird dieses effektive Potenzial durch ein semiempirisches molekulares Kraftfeld approximiert, das aus einer großen Zahl einzelner Energiebeiträge zusammengesetzt ist, welche in einfacher funktioneller Form von den Kernkoordinaten abhängen. Diese Energiebeiträge tragen zum einen der chemischen Struktur des Systems Rechnung und beinhalten Bindungsstreck-, Bindungswinkel-, Torsions- und Extraplanarpotenziale, die näherungsweise die Eigenschaften kovalenter Bindungen beschreiben und deswegen auch bindende Wechselwirkungen genannt werden. Zum anderen werden die langreichweitigen nicht-bindenden Wechselwirkungen berücksichtigt, zu denen die elektrostatischen und Van der Waals-Wechselwirkungen gehören. Bindungsstreckungen und Bindungswinkel werden durch harmonische Potenziale beschrieben, deren Minimum dem Gleichgewichtsabstand zwischen zwei kovalent gebundenen Atomen bzw. dem Gleichgewichtsbindungswinkel von drei Atomen entspricht. Elektrostatischen Wechselwirkungen wird durch das Coulomb-Potenzial, Van der Waals-Wechselwirkungen und der PauliAbstoßing durch das Lennard-Jones-Potenzial [89] Rechnung getragen. Die Parameter, die man für das Kraftfeld benötigt - etwa Gleichgewichtsabstände zwischen kovalent gebundenen Atomen, Kraftkonstanten oder Partialladungen und Van der Waals-Radien für die einzelnen Atome - werden aus experimentellen Daten und quantenmechanischen Rechnungen an kleinen Molekülen etwa mit Hilfe des Self-Consistent Force FieldVerfahrens [92] gewonnen. Auf diese Weise wurde eine Reihe unterschiedlicher Kraftfelder [93-105] für verschiedene Klassen von Molekülen wie Proteine, DNA-Moleküle oder Kohlehydratverbindungen entwickelt.

Schließlich wird in einem dritten Näherungsschritt die Dynamik der Kerne klassisch beschrieben: Alle Atome im System werden als Punktmassen behandelt, die sich in dem gegebenen Kraftfeld $\mathbf{F}\left(\mathbf{r}_{1}, \ldots, \mathbf{r}_{N}\right)$ gemäß den Newtonschen Bewegungsgleichungen

$$
m_{i} \frac{d^{2}}{d t^{2}} \mathbf{r}_{i}=\mathbf{F}_{i}\left(\mathbf{r}_{1}, \ldots, \mathbf{r}_{N}\right)=-\nabla_{i} E\left(\mathbf{r}_{1}, \ldots, \mathbf{r}_{N}\right)
$$


bewegen, wobei $m_{i}$ und $\mathbf{r}_{i}$ Masse und Ort des $i$-ten Atomkerns $(i=1, \ldots, N), \mathbf{F}_{i}$ die Kraft auf Atom $i$ und $N$ die Anzahl der Atome sind.

Zur numerischen Integration der Newtonschen Bewegungsgleichungen hat sich die NystrømMethode zweiter Ordnung [106] bewährt. Für MD-Simulationen wurde dieses Verfahren 1967 erstmalig von L. Verlet eingesetzt [107], weswegen es auch als Verlet-Algorithmus bezeichnet wird. Der Verlet-Algorithmus approximiert die Lösung $\mathbf{r}_{i}$ von Gleichung (2.1) mit Hilfe der Rekursionsformel

$$
\mathbf{r}_{i}(t+\Delta t)=2 \mathbf{r}_{i}(t)-\mathbf{r}_{i}(t-\Delta t)+\frac{\mathbf{F}_{i}(t)}{m_{i}} \cdot(\Delta t)^{2},
$$

wobei $\Delta t$ die Integrationsschrittweite bezeichnet. Diese ist so zu wählen, dass sie im Vergleich zu der Periodendauer der schnellsten Freiheitsgrade klein ist. Letztere beträgt mit den Bindungsstreckschwingungen der Wasserstoffatome zwischen 10 und 20 Femtosekunden, so dass für die Integrationsschrittweite typischerweise ein bis zwei Femtosekunden gewählt werden.

Der Vorteil dieses Verfahrens liegt zum einen in seiner numerischen Stabilität und zum anderen darin, dass im Gegensatz etwa zum Runge-Kutta-Verfahren [108] nur eine Berechnung der Kräfte $\mathbf{F}_{i}$ zum Zeitpunkt $t$ erforderlich ist. Die Gesamtenergie konservativer Systeme bleibt bei Verwendung des Verlet-Algorithmus in sehr guter Näherung konstant [109].

Ausgehend von geeigneten Anfangspositionen und -geschwindigkeiten erhält man nach $L$ Integrationsschritten die Trajektorie $\left\{\mathbf{r}_{\mathbf{1}}(k \cdot \Delta t), \ldots, \mathbf{r}_{\mathbf{N}}(k \cdot \Delta t) ; k=0, \ldots, L\right\}$, die die atomare Dynamik des simulierten Systems über die Simulationszeitspanne beschreibt. Geeignete Anfangsstrukturen für kleine, einfach aufgebaute Moleküle (z.B. einfache Zuckerpolymere) können mit so genannten Molekül-Editoren auf dem Computer modelliert werden [110-113]; für große Biomoleküle wie Proteine ist man dagegen auf Strukturen angewiesen, die experimentell ermittelt wurden, meist mit Hilfe der Röntgenstrukturanalyse oder auch der Kernresonanzspektroskopie. Für Proteine existieren mittlerweile mehr als 10000 aufgelöste Strukturen in der Brookhaven Data Bank [114]. Die Wahl geeigneter Anfangsgeschwindigkeiten wird in Abschnitt 2.4 beschrieben.

Die erwähnten Näherungen zur Berechnung der atomaren Dynamik ziehen folgende Einschränkungen für MD-Simulationen nach sich [89]:

- Chemische Reaktionen können nicht beschrieben werden.

- Vorgänge bei niedrigen Temperaturen $(<10 \mathrm{~K})$ werden nicht adäquat beschrieben, da hier der quantenmechanische Charakter niederenergetischer Kernbewegungen zum Tragen kommt.

- Die Bewegung der leichten Wasserstoffatome wird in klassischer Näherung auch bei Raumtemperatur ungenau wiedergegeben.

Trotz dieser Einschränkungen können in MD-Simulationen viele Aspekte der Dynamik von Biomolekülen beschrieben werden [89]. Für die hier durchgeführten Dissoziations- 
bzw. Dehnungssimulationen, die in den Kapitlen 5 und 6 beschriebenen werden, spielen chemische Reaktionen keine Rolle, und die Simulationstemperatur betrug $300 \mathrm{~K}$. Auf die Frage, ob und wie die Beschreibung der leichten Wasserstoffatome verbessert werden muss, gehen wir weiter unten ein. 


\subsection{Effiziente Simulationsmethoden}

Die Berechnung der Trajektorie eines großen Systems ist sehr aufwendig. Dies gilt insbesondere dann, wenn alle langreichweitigen Paarwechselwirkungen exakt ausgewertet werden: In diesem Fall skaliert der Rechenaufwand quadratisch mit der Anzahl der Atome. Wollte man die Trajektorie eines Systems aus 50000 Atomen, etwa ein in Wasser gelöstes Protein, über eine Zeitspanne von einer Nanosekunde mit der exakten Auswertung aller Wechselwirkungsbeiträge berechnen, wären dazu etwa $6 \cdot 10^{16}$ Fließkommaoperationen erforderlich. Dies würde auf einer heutigen Hochleistungsworkstation mit einer praktisch erreichbaren Leistung von 100 MFLOP gut 20 Jahre in Anspruch nehmen. Um diese Zeit zu verkürzen, sind eine Reihe von effizienzsteigernden Algorithmen vorgeschlagen und implementiert worden. In dieser Arbeit wurde das MD-Simulationsprogramm EGO [115-117] verwendet, das über solche Algorithmen verfügt. Die wichtigsten dieser Algorithmen seien im folgenden kurz skizziert.

- Compound-Atome und SHAKE-Algorithmus: Wie weiter oben schon erwähnt, kann die Dynamik der leichten Wasserstoffatome in MD-Simulationen nicht korrekt wiedergegeben werden. Um den Einfluss der Wasserstoffatome auf die Dynamik des betrachteten molekularen Systems adäquat zu beschreiben, unterscheidet man typischerweise zwischen polaren und apolaren Wasserstoffatomen. Da die apolaren Wasserstoffatome nur schwach mit ihrer Umgebung wechselwirken, hat es sich als sehr gute Näherung erwiesen, sie implizit über so genannte Compund-Atome zu berücksichtigen [93]. In solchen Compound-Atomen sind das schwere Atom und die an ihm gebundenen Wasserstoffatome zu einem Atom zusammengefasst, wodurch sich eine modifizierte Partialladung sowie andere Van der Waals-Parameter ergeben. Diese Vorgehensweise ist sehr effizient, da dadurch die Anzahl der Atome auf etwa die Hälfte reduziert werden kann. Da die polaren Wasserstoffatome mit ihrer Umgebung insbesondere in Form von Wasserstoffbrücken in starke Wechselwirkungen treten und somit Struktur und Dynamik des Systems wesentlich beeinflussen, werden diese explizit simuliert. Hier wird üblicherweise ihr Abstand zu den schweren Atomen, an die sie gebundenen sind, mit Hilfe des in Ref. [118] vorgeschlagenen SHAKE-Algorithmus fixiert. Es gibt keine Hinweise darauf, dass dadurch die Beschreibung der physikalischen Eigenschaften des Systems beeinträchtigt wäre [119], und darüber hinaus kann damit die Rechenzeit etwa um den Faktor zwei reduziert werden [89].

- Parallelisierung: Ab etwa Mitte der achtziger Jahre wurden umfangreiche Anstrengungen unternommen, um MD-Simulationsprogramme effizient auf Vektorrechnern [120,121] oder Parallelrechnern [122-129] zu implementieren. Das MD-Simulationsprogramm EGO ist für den Einsatz auf Parallelrechnern konzipiert. Die Atome werden dabei so auf die einzelnen Prozessoren verteilt, dass zum einen der Datenaustausch zwischen den Prozessoren, der insbesondere zur Berechnung der langreichweitigen Wechselwirkungen erforderlich ist, minimal wird, und zum anderen die einzelnen Prozessoren möglichst gleichmäßig ausgelastet sind [115]. Wie sich die Rechenleistung durch die Verwendung von mehreren Prozessoren im Vergleich zu einem einzelnen Prozessor erhöht, d.h. wie gut das MD-Simulationsprogramm auf 
dem Parallelrechner skaliert, hängt neben der rechnerinternen Architektur und der Datenübertragungsrate auch von der Größe des simulierten Systems ab. Je größer das System ist, desto besser ist in der Regel auch die Skalierung, da dann der Kommunikationsaufwand zwischen den einzelnen Prozessoren relativ abnimmt und der limitierende Faktor die Einzelprozessorleistung ist. (So ist es wenig sinnvoll, ein kleines System auf sehr vielen Prozessoren zu simulieren.) Für die MD-Simulation eines aus rund 50000 Atomen bestehenden Systems hat sich auf dem Parallelrechner der Arbeitsgruppe, der aus 72 Prozessoren des Typs PowerPC mit einer Taktung von $300 \mathrm{MHz}$ besteht, die Verwendung von 16-Prozessor-Partitionen als geeignet erwiesen, was gegenüber der Einzelprozessorleistung eine Beschleunigung etwa um den Faktor 10 mit sich bringt.

\section{- Effiziente Berechnung langreichweitiger Wechselwirkungen:}

Zur exakten Berechnung der langreichweitigen Coulomb-Wechselwirkungen

$$
E_{\text {Coulomb }}=\sum_{\langle i, j\rangle} E_{\text {Coulomb }}^{i j} \sim \sum_{\langle i, j\rangle} \frac{q_{i} q_{j}}{r_{i j}}
$$

müssen alle interatomaren Paarwechselwirkungen berücksichtigt werden. Dabei skaliert der Rechenaufwand quadratisch mit der Anzahl der Atome. Entsprechend erstreckt sich die Summe in Gleichung (2.3) über alle Atompaare $\langle i, j\rangle$, wobei $r_{i j}$ deren Abstand und $q_{i}$ die Partialladung von Atom $i$ ist. Aufgrund des beschriebenen Skalierungsverhaltens wird bei zunehmender Systemgröße die Berechnung der Coulombkräfte rasch zum rechenzeitbestimmenden Schritt. Um hier den Rechenaufwand zu reduzieren, wird üblicherweise auf die cut off-Methode zurückgegriffen, bei der Paarwechselwirkungen zwischen Atomen, deren Abstand zueinander den cut off-Radius $r_{c u t}$ übersteigt, vernachlässigt werden [93]. Allerdings gibt es zahlreiche Hinweise, dass die vollständige Vernachlässigung von langreichweitigen Wechselwirkungen zwischen weit entfernten Atomen gerade in Proteinen zu Artefakten in der räumlichen Struktur sowie in den dynamischen Eigenschaften führen kann [130-133].

Um solche Artefakte zu vermeiden, greifen wir hier zur effizienten Berechnung der Coulomb-Wechselwirkungen auf die Kombination eines Mehrschrittverfahrens und einer Multipolmethode zurück:

- Mehrschrittverfahren: Hier wird der Befund ausgenutzt, dass in Proteinen die Kräfte, die auf ein gegebenes Atom auf Grund von Paarwechselwirkungen mit anderen Atomen wirken, im zeitlichen Verlauf desto geringere Fluktuationen aufweisen, je weiter die Atome voneinander entfernt sind [134-139]. Deswegen ist es eine gute Nährung, solche Kräfte, die aus Paarwechselwirkungen mit weit entfernten Atomen herrühren, nicht in jedem Integrationsschritt exakt zu berechnen, sondern auf Grundlage vorhergehender Kräfte zu extrapolieren. Je weiter die Atome entfernt sind, desto seltener ist eine exakte Berechnung erforderlich. Man definiert deshalb Distanzklassen, wobei die erste Distanzklasse die Atome in der direkten Umgebung des gegebenen Atoms enthält, während höhere Distanzklassen entferntere Atome beinhalten. In der $n$-ten Distanzklasse erfolgt eine exakte Berechnung der Kräfte alle $2^{(n-1)}$ Schritte. 
Dieses Verfahren bringt nur einen marginalen Verlust an Genauigkeit, aber eine weitere Beschleunigung etwa um den Faktor 7 [140].

- Multipolmethode: Anders als bei der cut off-Methode werden bei der Multipolmethode alle langreichweitigen Paarwechselwirkungen berücksichtigt. Ähnlich wie beim Mehrschrittverfahren werden bei der Multipolmethode die langreichweitigen Wechselwirkungen eines gegebenen Atoms mit den umgebenden Atomen für verschiedene Entfernungen unterschiedlich berechnet: Während für benachbarte Atome die Kräfte paarweise ausgewertet werden, fasst man weiter entfernte Atome in Cluster zusammen. Ein gegebenes Atom wechselwirkt nun mit solchen Clustern über deren Multipolentwicklungen [141]. Je nach Genauigkeitsanforderungen werden die Multipolentwicklungen nach einer bestimmten Ordnung abgebrochen. Bei der Berechnung der elektrostatischen Wechselwirkungen, wie sie in MD-Simulationen erforderlich ist, müssen auch höhere Multipolmomente berücksichtigt werden, da auf Grund der Existenz von Ladungen unterschiedlichen Vorzeichens niedrigere Multipolmomente verschwinden können. Die Größe der Cluster nimmt mit wachsendem Abstand hierarchisch zu: Cluster $n$-ter Ordnung sind aus Clustern $(n-1)$-ter Ordnung aufgebaut. Der Rechenaufwand zur Auswertung langreichweitiger Paarwechselwirkungen skaliert dadurch nicht mehr quadratisch mit der Anzahl $N$ der Atome - d.h. in der Ordnung $\mathrm{O}\left(N^{2}\right)$ - , sondern nur noch in der Ordnung $\mathrm{O}[N \log (N)][142]$. In der so genannten schnellen Multipolmethode (FMM, Fast Multipole Method) werden die Koeffizienten der Multipolentwicklung eines Clusters dazu verwendet, das Multipolmoment des Clusters der nächst höheren Ordnung zu berechnen, was als bottom-up-Strategie bezeichnet wird. Für hinreichend große Systeme skaliert der Rechenaufwand zur Auswertung der langreichweitigen Paarwechselwirkungen bei dem schnellen Multipolverfahren nur noch linear mit der Anzahl der Atome, d.h. in der Ordnung $\mathrm{O}(N)$ [143-145]. Für Proteine, die als Sequenzen von 20 unterschiedlichen Aminosäuren sehr kanonisch aufgebaut sind ${ }^{1}$, werden in der strukturadaptierten Multipolmethode (SAMM) die Atome entsprechend der proteinspezifischen Strukturmerkmale so in Cluster eingeteilt, dass die Multipolentwicklung bereits nach dem ersten nicht verschwindenden Multipolmoment abgebrochen werden kann, was den Rechenaufwand weiter reduziert. Während die mit der cut-off-Methode berechnete elektrostatische Wechselwirkungsenergie bei einem cut-off-Radius von $10 \AA$ um durchschnittlich $20 \%$ von der exakt berechneten abweicht, führt die in EGO implementierte strukturadaptierte Multipolmethode zu einer mittleren Abweichung von lediglich $1 \%$ [146].

Die hier skizzierten Algorithmen verkürzen in ihrer in EGO implementierten Form die Rechenzeit für die oben erwähnte Nanosekunden-Trajektorie bei Verwendung einer 16Prozessor-Partition des angesprochenen Parallelrechners von 20 Jahren auf etwa 2 Wochen.

\footnotetext{
${ }^{1}$ Die Eigenschaften der einzelnen Aminosäuren sind in Anhang A aufgeführt.
} 


\subsection{Die Lösungsmittelumgebung}

Viele Eigenschaften von Biomolekülen in ihrer nativen Lösungsmittelumgebung (z.B. Wasser mit Ionen in physiologischer Konzentration) unterscheiden sich häufig erheblich von denen in vacuo [147,148]; die meisten Proteine funktionieren nur in ihrer nativen Umgebung [148-151]. Hauptgrund sind hierfür die elektrostatischen Wechselwirkungen zwischen Protein und seiner wässrigen Lösungsmittelumgebung, die wegen des sehr polaren Charakters von Wassermolekülen (Dielektrizitätskonstante $\epsilon_{\mathrm{H}_{2} \mathrm{O}} \approx 80$ ) von besonderer Bedeutung sind.

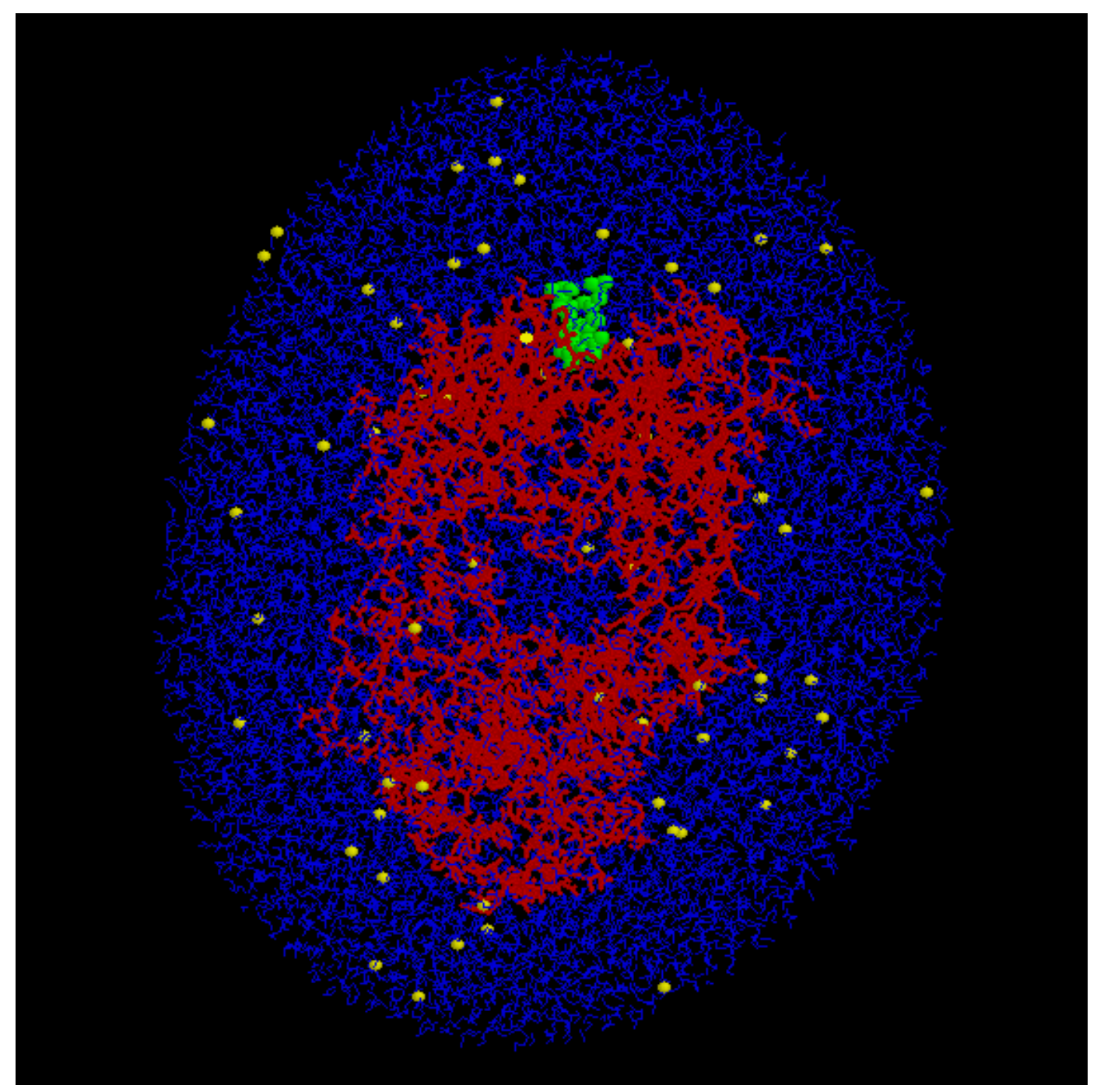

Abbildung 2.1: Simulationsmodell für den AN02-DNP-Hapten-Komplex (rot/grün) in einer Umgebung aus Wassermolekülen (blau) und Ionen in physiologischer Konzentration (gelb).

So ist es für eine realistische MD-Simulation von Biomolekülen oft unumgänglich, die Lösungsmittelumgebung adäquat zu berücksichtigen. Dies kann auf implizite oder explizite Weise geschehen. Um das Lösungsmittel implizit zu berücksichtigen, wurde eine 
Reihe von Kontinuumsmodellen entwickelt, bei denen die Eigenschaften der Lösungsmittelumgebung durch die Dielektrizitätskonstante $\epsilon_{L}$ bestimmt und das elektrostatische Potenzial an jedem Punkt des Simulationssystems (das aus den explizit simulierten Atomen besteht, z.B. einem Protein) durch näherungsweise Lösung der (linearisierten) PoissonBoltzmann-Gleichung berechnet werden [152-158]. In Langevin-Dynamiken enthalten die Kräfte zusätzliche Terme, die Reibung und Rauschen beschreiben, und auf diese Weise Lösungsmitteleffekten Rechnung tragen [159-161]. Solche Verfahren können allerdings lokale Wechselwirkungen (z.B. Wasserstoffbrücken) nicht beschreiben, welche jedoch, wie wir sehen werden, bei Rezeptor-Ligand-Bindungen [55,56] oder bei der Konformation von Polymermolekülen entscheidend sind (siehe dazu insbesondere Kapitel 6.2). Um auch solche Effekte zu berücksichtigen, haben wir bei den in dieser Arbeit simulierten Molekülen — dem AN02-Antikörper-Hapten-Komplex sowie verschiedenen Polymermolekülen — ein explizites Lösungsmittelmodell verwendet, wie es in Abbildung 2.1 beispielhaft gezeigt ist: Hier ist der AN02-Antikörper in ein Wassertröpfchen platziert worden, dessen atomare Dynamik explizit simuliert wird. Im Vergleich zu den impliziten Modellen ist hiermit wegen der erheblich größeren Atomanzahl ein höherer Rechenaufwand verbunden ${ }^{2}$. Für Wasser als das am weitesten verbreitete Lösungsmittel wurde eine Reihe unterschiedlicher atomarer Modelle entwickelt [162-164]. In den in dieser Arbeit beschriebenen MDSimulationen wurde auf das so genannte TIP3-Modell [164] zurückgegriffen, das zur Beschreibung von Protein-Wasser-Wechselwirkungen optimiert wurde und für das in dem verwendeten CHARMM-Kraftfeld Parameter zur Verfügung stehen [165].

Gewöhnlich ist die Wasserumgebung von realen Systemen sehr viel größer als das Simulationssystem, das aus Rechenzeitgründen meist auf einige $10^{4}$ Atome beschränkt bleiben muss. Deshalb ist man auf Verfahren angewiesen, die eine endliche Repräsentation eines aus mikroskopischer Sicht unendlich großen Systems ermöglichen [147]. Solche Methoden zielen darauf ab, das System so zu simulieren, als sei es seinerseits in ein sehr großes System eingebettet. Dazu wird überwiegend auf folgende Möglichkeiten zurückgegriffen:

1. die Einführung periodischer Randbedingungen,

2. die Verwendung eines geeigneten Randpotenzials.

Die erste Möglichkeit ist ein aus der statistischen Mechanik bekannter Ansatz [43], bei dem das betrachtete System als Einheitszelle praktisch von identischen Zellen umgeben ist. Dieser Ansatz hat den Vorteil, dass er das Problem des abrupten Materie-VakuumÜbergangs elegant umgeht und nicht sehr rechenaufwendig ist. Der Nachteil besteht zum einen darin, dass das Simulationssystem eine Form besitzen muss, mit der der Raum lückenlos und überlappungsfrei ausgefüllt werden kann, z.B. die eines Quaders oder eines abgeschnittenen Oktaeders [166]. Zum anderen muss die Wasserschicht zwischen dem gelösten Molekül und dem Rand der Einheitszelle hinreichend groß gewählt werden, um zu vermeiden, dass das gelöste Molekül mit seinen Abbildern in benachbarten Zellen in signifikante Wechselwirkungen tritt.

Die zweite Möglichkeit zur Behandlung der Grenzfläche des simulierten Systems sieht die Verwendung eines Randpotenzials vor. Das Ziel dabei ist, die Verdampfung von

\footnotetext{
${ }^{2}$ Für ein in eine Wasserumgebung eingebettetes Protein gehören typischerweise etwa $90 \%$ der Atome zum Lösungsmittel.
} 


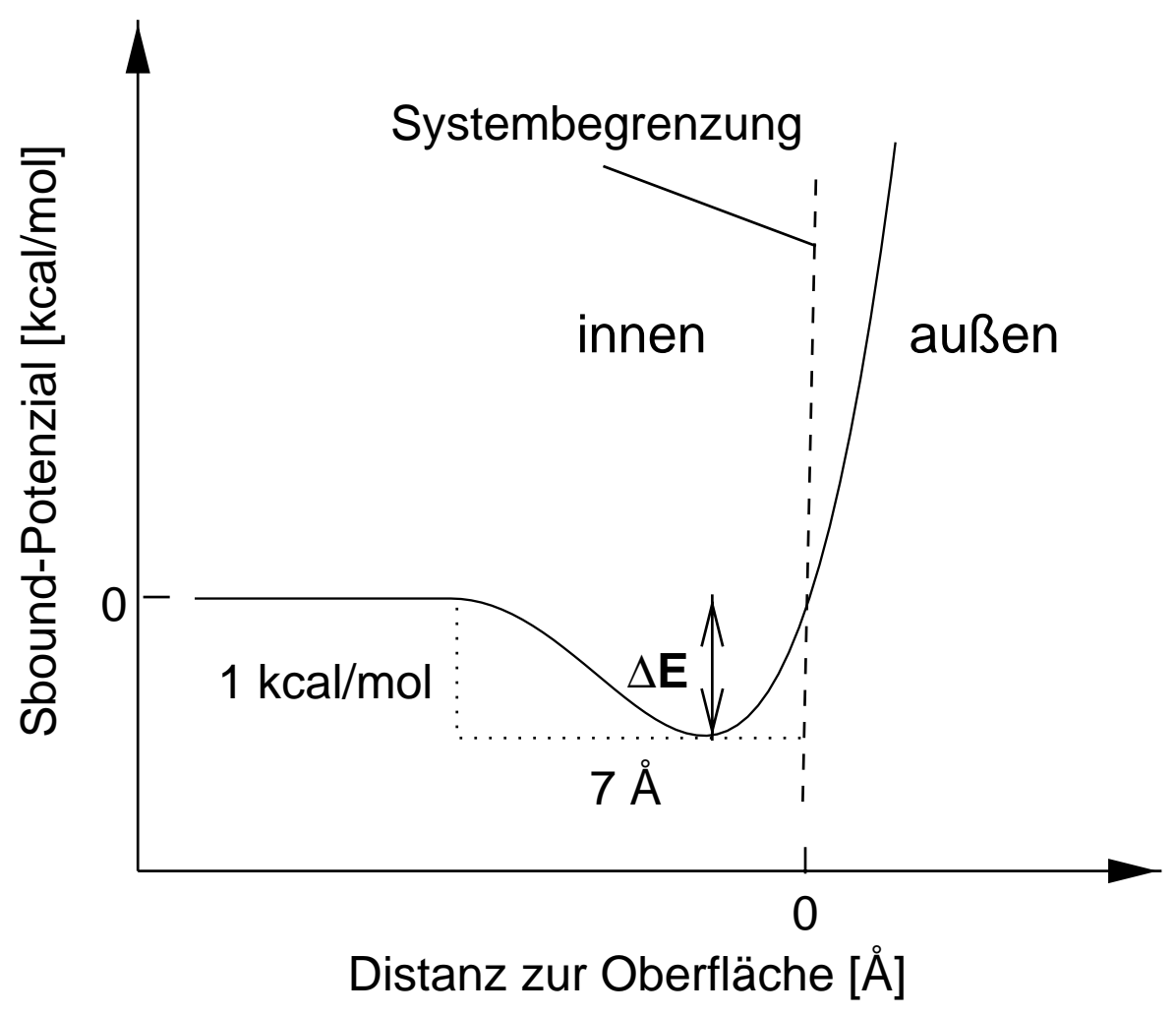

Abbildung 2.2: Sbound-Potenzial (durchgezogene Linie) als Funktion des Abstands der Moleküle von der Systemoberfläche (gestrichelte Linie). Das Sbound-Potenzial wird wirksam für Wassermoleküle, deren Abstand zur Systemoberfläche weniger als $7 \AA$ beträgt. Das Minimum des Sbound-Potenzials liegt bei $\Delta E=-1.0 \mathrm{kcal} / \mathrm{mol}$.

Lösungsmittelmolekülen von der Oberfläche des Systems zu verhindern, die Oberflächenspannung auszugleichen und die Effekte der außerhalb des Simulationssystems liegenden Lösungsmittelumgebung zu berücksichtigen. Ein solches Randpotenzial wird als SboundPotenzial bezeichnet $^{3}$. Es wurde erstmalig 1982 für die MD-Simulation von Argonatomen verwendet [167], dann in Ref. [168] auf Wasser als Lösungsmittel übertragen, durch ein quartisches Potenzial für sphärische Geometrien approximiert [169] und schließlich auf Systeme mit beliebiger konvexer Geometrie erweitert [170]. Abbildung 2.2 zeigt den Verlauf des in Ref. [170] vorgeschlagenen Sbound-Potenzials, auf das wir in den in dieser Arbeit beschriebenen MD-Simulationen zurückgegriffen haben und das die Form

$$
E_{\text {Sbound }}=\left\{\begin{aligned}
0 & : \quad d>d_{0} \\
\frac{1}{600} d_{\Delta}^{2}\left(d_{\Delta}^{2}-49\right) & : \quad d \leq d_{0}\left(d_{\Delta}=d_{0}-d\right)
\end{aligned}\right.
$$

hat. Dabei sind $d$ der Abstand von der Oberfläche des Systems und $d_{0}$ die Dicke der Randschicht, auf die das Potenzial wirkt, die nach Ref. [170] zu $7 \AA$ bestimmt wurde. Der vom Zentrum aus zunächst abfallende Teil des Potenzials (in der Abbildung nach rechts fortschreitend) bis zum Niveau $\Delta E=-1.0 \mathrm{kcal} / \mathrm{mol}$ dient insbesondere dazu, die Oberflächenspannung auszugleichen, die für sehr kleine Wassertropfen mit Radien bis zu $40 \AA$, wie sie in MD-Simulationen üblicherweise verwendet werden, auf Grund der starken Krümmung der Oberfläche zu Drücken von bis zu $50 \mathrm{MPa}$ führen würde. Der -

\footnotetext{
${ }^{3}$ Sbound steht für stochastic boundary.
} 
in der Abbildung weiter nach rechts fortschreitend - wieder ansteigende Verlauf soll die Wassermoleküle daran hindern, sich vom System zu entfernen. Der stochastische Anteil vom Sbound beschreibt die Kraftbeiträge, die von Fluktuationen und Reibungseinflüssen der Atome außerhalb des Simulationssystems herrühren. Derartige Rauschund Reibungskräfte stehen nach dem Fluktuations-Dissipations-Theorem miteinander in Beziehung [171] und sind von der Temperatur der Lösungsmittelumgebung abhängig. Auf diese Weise wirken die Kräfte wie ein Wärmebad, das das System umgibt [172].

Wir haben in unseren Simulationen deshalb auf das Sbound-Potenzial zurückgegriffen, da diese Methode beliebige konvexe Geometrien der Lösungsmittelumgebung zulässt und somit im Vergleich zu periodischen Randbedingungen für eine realistische Beschreibung der Lösungsmitteleffekte erheblich weniger Lösungsmittelmoleküle benötigt. Bei den in dieser Arbeit beschriebenen Simulationen zu AN02-Hapten sowie verschiedenen Polymermolekülen konnten damit bis zu $30 \%$ weniger Lösungsmittelmoleküle verwendet werden als es bei der Verwendung von periodischen Randbedingungen der Fall gewesen wäre.

Eingehende Voruntersuchungen haben ergeben, dass das Sbound-Potenzial diejenigen Wassermoleküle, die sich innerhalb des Wassertröpfchens mit einem Mindestabstand von $6 \AA$ zur Oberfläche befinden, gut beschreibt [173]. Die äußerste $6 \AA$-Schicht der Wasserumgebung zeigte dahingegen Randeffekte in Form von starken Dichteschwankungen und einer signifikanten Orientierungspolarisation, die durch das Sbound-Potenzial nicht gänzlich eliminiert werden konnten. Für die Größe der Wasserumgebung ergaben sich somit für uns die folgenden Kriterien: Zum einen sollten diejenigen Wassermoleküle, die in direkte Wechselwirkungen mit dem gelösten Molekül traten, nicht von den Artefakten am Rand des Simulationssystems betroffen sein. Zum zweiten sollte gewährleistet sein, dass der größte Teil der langreichweitigen elektrostatischen Wechselwirkungen des gelösten Moleküls mit den Wassermolekülen explizit berücksichtigt wurde. Das letzte Kriterium bestand darin, die Simulationssysteme aus Rechenzeitgründen so klein wie möglich zu gestalten. Diese Kriterien ließen uns jeweils eine Wasserumgebung als geeigent erscheinen, bei der ein minimaler Abstand von $12 \AA$ zwischen der Oberfläche des gelösten Moleküls und der Oberfläche des Wassertröpfchens nicht unterschritten wurde.

Der AN02-DNP-Hapten-Komplex (Kapitel 5) und die Polymermoleküle (Kapitel 6) wurden mit SOLVATE [174] in eine entsprechende Wasserumgebung platziert, das zur Anordnung der Wassermoleküle lokale Energieminimierungen durchführt. Außerdem wurden $\mathrm{Na}^{+}$- und $\mathrm{Cl}^{-}$-Ionen in physiologischer Konzentration gemäß der Debye-Hückel-Verteilung [175], die ihrerseits von der Anordnung der Ladungen des gelösten Moleküls abhängt, hinzugefügt. 


\subsection{Minimierung und Equilibrierung}

Minimierung und Equilibrierung dienen dazu, das Simulationssystem in einen Zustand mit solchen Atompositionen und -geschwindigkeiten relaxieren zu lassen, der dem nativen Gleichgewichtszustand bei einer vorgegebenen (z.B. physiologischen) Temperatur möglichst nahekommt und in dem die Energie gleichmäßig auf alle Freiheitsgrade verteilt ist.

Die Minimierung hat zum Ziel, das Simulationsssystem in eine Konfiguration zu überführen, die in guter Nährung einem lokalen Minimum in der Energielandschaft entspricht. Dies erweist sich häufig als nötig, da Röntgenstrukturen, die typischerweise als Ausgangspunkt von MD-Simulationen verwendet werden, oftmals Verspannungen, etwa deformierte Bindungs- oder Torsionswinkel, aufweisen. Eine Minimierung vermeidet, dass das System aus einer anfänglich höchst instabilen, energetisch ungünstigen Konfiguration in eine sehr unrealistische, weit von der Ausgangstruktur entfernte Konfiguration getrieben wird. Bereits geringfügige Überlappungen von Atomen würden auf Grund der Pauli-Abstoßung zu sehr hohen Van der Waals-Kräften führen, die ein rasches Auseinanderdriften der beteiligten Atome zur Folge hätten und das gesamte System destabilisieren würden. Ähnliches gilt für bereits geringfügig deformierte chemische Bindungen oder Bindungswinkel. Wegen der begrenzten Aufösung der experimentell bestimmten Strukturen, die bei der Röntgenstrukturanalyse unter Verwendung von guten Kristallen häufig zwischen 1.5 und 3 A liegt, sowie auf Grund der Platzierung des Moleküls in eine Lösungsmittelumgebung kann es leicht zu solchen lokalen Instabilitäten kommen. Geeignete Verfahren zur Energieminimierung des molekularen Systems sind Gradientenabstiegsverfahren oder eine Methode, in der die Dynamik zunächst stark gedämpft, die Integrationsschrittweite anfänglich sehr klein gewählt und die maximale Bewegung eines Atoms pro Integrationsschritt begrenzt wird. Bei dem hier verwendeten Simulationsprogramm EGO wird auf die zuletzt genannte Methode zurückgegriffen.

Die Equilibrierung dient dazu, das Simulationssystem durch Kopplung an ein Wärmebad auf eine vorgegebene Zieltemperatur zu bringen und bei dieser Temperatur relaxieren zu lassen. Diese Kopplung wird typischerweise dadurch bewerkstelligt, dass die Geschwindigkeiten aller Atome in jedem Integrationsschritt so reskaliert werden, dass die Zieltemperatur mit einer bestimmten Zeitkonstante angenähert wird [89,172]. Eine einfache Abschätzung aus der bekannten Wärmeleitfähigkeit für Wasser ergibt, dass Werte zwischen $1 \mathrm{ps}^{-1}$ und $10 \mathrm{ps}^{-1}$ geeignete Zeitkonstanten sind. Wie schon erwähnt, wirkt das (temperaturabhängige) stochastische Potenzial für die Wassermoleküle an der Systemoberfläche ebenfalls wie die Kopplung an ein Wärmebad.

Wie die in dieser Arbeit beschriebenen Simulationssysteme im Einzelnen minimiert und equilibriert wurden, wird in den Kapiteln 5 und 6, in denen wir die einzelnen Simulationen detailliert diskutieren, erörtert. 


\section{Kapitel 3}

\section{MD-Simulation kraftmikroskopischer Einzelmolekülexperimente}

In diesem Kapitel werden wir zunächst die prinzipielle Vorgehensweise in kraftmikroskopischen Einzelmolekülxperimenten erläutern. Es folgt eine ausführliche Beschreibung der Simulationsmethode dieser Einzelmolekülexperimente, die, wie schon einleitend erwähnt, nicht notwendigerweise auf kraftmikroskopische Einzelmolekülxperimente beschränkt ist. 


\subsection{Kraftmikroskopische Einzelmolekülxperimente}

Das 1986 von Binnig und anderen entwickelte Rasterkraftmikroskop [40] dient dazu, Bilder von einer Probe (z.B. Kristallen oder DNA-Molekülen) in nahezu atomarer Auflösung zu liefern. Dabei wird eine Nadel mit einer Spitze, die einen Durchmesser von lediglich einigen Atomradien aufweist, so über die Oberfläche einer Probe geführt, dass die dabei auftretende Pauli-Abstoßungskraft auf die Nadel und den sie tragenden beweglichen Hebel (den Cantilever) konstant bleibt. Da die Kraft direkt mit dem Abstand zwischen Nadel und Probe verknüpft ist, lässt sich über die Auslenkung des Cantilevers unmittelbar auf die Oberflächenbeschaffenheit der Probe schließen.

Seit Beginn der neunziger Jahre wird das Rasterkraftmikroskop auch eingestezt, um Kräfte zwischen einzelnen Molekülen zu messen. Hoh und anderen gelang es zum ersten Mal 1992, quantisierte Adhäsion ${ }^{1}$ zwischen der Rasterkraftmikroskopnadel und einer Glasoberfläche aufzulösen und dabei Kräfte im Bereich von $10^{-11} \mathrm{~N}$ zu messen, die sie auf einzelne molekulare Bindungen (etwa Wasserstoffbrücken) zurückführten [176].

In der Folge wurde diese Technik so verfeinert, dass Kraftmessungen an einzelnen Biomolekülen in ihrer nativen Umgebung vorgenommen werden konnten. So wurden etwa Dissoziationskräfte bestimmt, die zur Trennung von Rezeptor-Ligand-Komplexen erforderlich sind. Dies geschah zuerst für die sehr starke, nicht-kovalente Avidin- bzw. StreptavidinBiotin-Bindung [25-27, 177, 178], daraufhin für eine Vielzahl weiterer Rezeptor-LigandKomplexe [29-34,179-182]. Desweiteren wurden Entfaltungskräfte von Protein- und DNA-Molekülen [6-16,182] oder Elastizitäten von Zucker- und anderen Polymeren [17-24] gemessen.

Die Vorgehensweise bei solchen kraftmikroskopischen Einzelmolekülexperimenten ist in Abbilding 3.1 für die Kraftmessung an einem Rezeptor-Ligand-Komplex schematisch gezeigt. Der Ligand ist dabei in Form von Kugeln, der Rezeptor im Bändermodell gezeigt. An der Spitze des Cantilevers sind über flexible Polymerlinker (z.B. Polyethylenglykol) wenige Ligandmoleküle kovalent gebunden. Auf einer Unterlage unter dem Cantilever befinden sich, ebenfalls über einen Polymerlinker vermittelt, Rezeptormoleküle mit noch nicht besetzten Bindungsstellen. Während eines Kraftmessungsvorgangs wird zunächst die Unterlage auf den Cantilever zubewegt (in der Abbildung nicht gezeigt), so dass sich Bindungen zwischen Liganden und Rezeptoren ausbilden können (oftmals bildet sich genau eine einzige). Daraufhin wird die Unterlage in die entgegengesetzte Richtung mit konstanter Zuggeschwindigkeit zurückbewegt. Solange die wie sehr weiche Federn wirkenden Polymerlinker zwischen Ligand und Cantileverspitze bzw. zwischen Rezeptor und Unterlage noch nicht gestreckt sind, wirkt weder auf den Cantilever noch auf den RezeptorLigand-Komplex eine signifikante Zugkraft (diese Situation ist in der Abbildung links in (1) gezeigt). Sobald die Polymerlinker jedoch gestreckt sind (und die Rezeptor-LigandBindung noch intakt ist), beginnt die resultierende Zugkraft den Cantilever von seiner Gleichgewichtslage auszulenken (2) ). Die Auslenkung des Cantilevers wird über einen Laserstrahl registriert (in der Abbildung nicht gezeigt) und direkt über die bekannte Federkonstante des Cantilevers in eine Zugkraft übersetzt, welche dann, wie unten in der

\footnotetext{
${ }^{1}$ „Quantisierte Adhäsion“ bezeichnet lediglich die Beobachtung ganzzahliger Vielfacher einer Elementarkraft und nimmt nicht etwa Bezug auf quantenmechanische Effekte.
} 
Abbildung gezeigt, als Funktion der Verschiebung der Unterlage aufgetragen wird. Hält der Rezeptor-Ligand-Komplex der Zugkraft nicht mehr stand, reißt die Bindung und der Ligand bewegt sich aus der Bindungstasche des Rezeptors heraus (Pfeil), so dass die Zugkraft abnimmt und der Cantilever in seine Gleichgewichtslage zurückkehrt (3)). Die maximale Zugkraft, die während eines solchen Dissoziationsvorgangs beobachtet wird, wird als Abreißkraft oder Dissoziationskraft eines einzelnen Rezeptor-Ligand-Komplexes bezeichnet.

Die erzwungene Entfaltung von Proteinen oder DNA-Molekülen bzw. die Messung der Elastizität von Polymermolekülen läuft ähnlich ab. Auch hier wird das eine Ende des Moleküls an die Unterlage, das andere Ende an die Cantileverspitze kovalent gebunden, das Molekül gedehnt und dabei die Kraft als Funktion der Ausdehnung des Moleküls aufgezeichnet (Kraft-Ausdehnungs-Kurve). Die Steigung der Kraft-Ausdehnungs-Kurve ist ein Maß für die Elastizität des Moleküls.

Sowohl die forcierte Dissoziation von Rezeptor-Ligand-Bindungen als auch die Entfaltung bzw. die Dehnung von Polymermolekülen sind in kraftmikroskopischen Einzelmolekülexperimenten in der Regel reversibel, d.h. gerade getrennte Bindungen bilden sich bei nachfolgender Annäherung von Cantilever und Unterlage wieder aus bzw. entfaltete Proteine falten sich wieder in ihre native Konformation zurück, so dass forcierte Dissoziation, Entfaltung und Dehnung in der Regel mehrere hundert Mal hintereinander mit denselben Molekülen durchgeführt werden können [7,17,22,25,26]. 

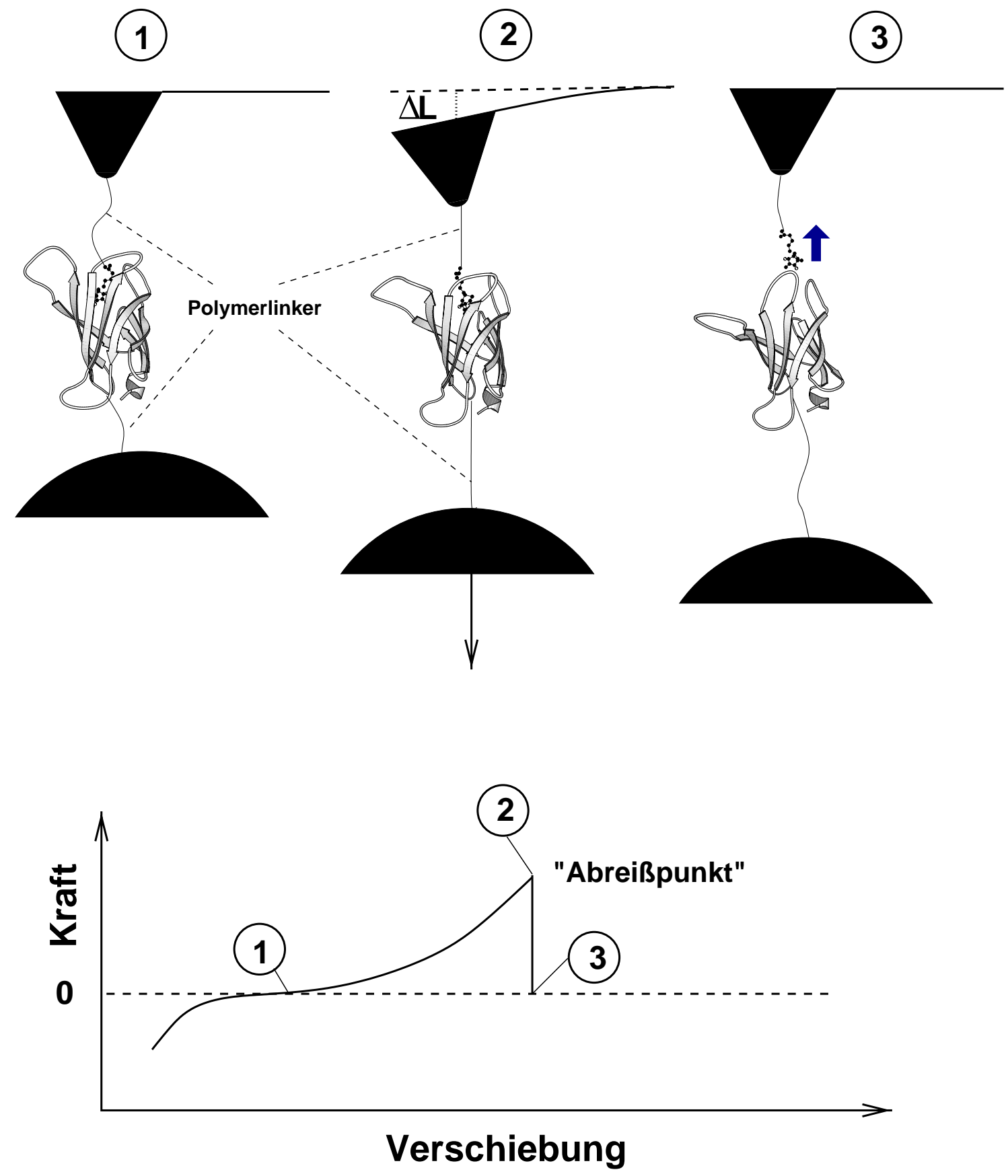

Abbildung 3.1: Schematisch gezeichneter Ablauf eines kraftmikroskopischen Einzelmolekülexperiments, in dem Rezeptor (Bändermodell) und Ligand (Kugeln) voneinander getrennt werden. Oben: Drei Schnappschüsse während des Dissoziationsvorgangs. In (1) befindet sich bereits ein Rezeptor-Ligand-Komplex zwischen Cantilever und der kugelförmigen Unterlage, jedoch sind die Polymerlinker noch nicht gestreckt, so dass auf den Komplex und auf den Cantilever keine Zugkräfte wirken. Nachdem in (2) die Unterlage nach unten bewegt wurde, sind die Polymerlinker gestreckt. Die resultierende Zugkraft führt zu einer Auslenkung des Cantilevers. In (3) ist der Rezeptor-Ligand-Komplex bereits getrennt, so dass keine Zugkraft mehr wirkt und der Cantilever in seine Gleichgewichtsposition zurückgekehrt ist. Unten: Auftragung der über die Auslenkung $\Delta \mathrm{L}$ des Cantilevers gemessenen Zugkraft als Funktion der Verschiebung der Unterlage. 


\subsection{MD-Simulation kraftmikroskopischer Einzelmo- lekülexperimente}

In dem folgenden Abschnitt wird die Methode der MD-Simulation kraftmikroskopischer Einzelmolekülexperimente beschrieben, die allen in dieser Arbeit diskutierten Simulationen zugrunde liegt. Die Methode zielt darauf ab, die kraftmikroskopischen Experimente möglichst detailgetreu nachzubilden. Dazu gehören die Modellierung des Cantilevers (einschließlich des Polymerlinkers), an dem der Ligand gebunden ist, sowie die Fixierung des Rezeptormoleküls. Darüber hinaus werden wir darlegen, nach welchen Kriterien wir in unseren Simulationen die Federkonstante des Cantilevers gewählt haben.

\subsubsection{Das Simulationsverfahren}

Abbildung 3.2 zeigt das Simulationsverfahren exemplarisch für einen Rezeptor-LigandKomplex. Der Cantilever des Kraftmikroskops sowie der Polymerlinker werden durch ein harmonisches Potenzial

$$
V_{\text {cant }}(t)=k_{0}\left[z_{\mathrm{A}}(t)-z_{\text {cant }}(t)\right]^{2} / 2
$$

beschrieben, das in der Abbildung durch eine Feder symbolisiert ist. Dieses harmonische Zugpotenzial wirkt gerade auf dasjenige Atom „A“ [dessen Position in Zugrichtung $z_{\mathrm{A}}(t)$ ist], das im kraftmikroskopischen Experiment über den Polymerlinker an den Cantilever gebunden ist. Das Potenzial $V_{\text {cant }}$ wirkt nur in Zugrichting $z$ (Pfeil); $k_{0}$ ist die Federkonstante des Cantilever/Polymerlinker-Systems, $z_{\text {cant }}(t)$ die Position des Minimums des Potenzials (Gleichgewichtslage des Cantilevers) entlang der Zugrichtung zum Zeitpunkt t. Dieses Minimum wird im Verlauf der Simulation kontinuierlich in Zugrichtung $z$ mit Zuggeschwindigkeit $v_{\text {cant }}$ bewegt,

$$
z_{\text {cant }}(t)=z_{\text {cant }}(0)+v_{\text {cant }} t
$$

wobei $z_{\text {cant }}(0):=z_{\mathrm{A}}(0)$ gewählt wird, so dass auf das Atom A zu Beginn einer Simulation keine Kraft ausgeübt wird. Die Zugkraft, die während einer Simulation auf Atom A auf Grund des Zugpotenzials wirkt, ergibt sich gemäß dem Hookeschen Gesetz zu

$$
F_{\text {cant }}(t)=k_{0}\left[z_{\mathrm{A}}(t)-z_{\text {cant }}(t)\right]
$$

Da das kraftmikroskopische Experiment in einem viskosen Medium auf einer Zeitskala stattfindet, die deutlich über der Periodendauer der Resonanzschwingung des Cantilevers liegt, spielen Trägheitskräfte eine vernachlässigbare Rolle. Damit auch in den Dissoziationssimulationen nicht Trägheitskräfte signifikant zu den Zugkräften beitragen, nehmen wir die Feder als masselos an.

Durch Auftragung der auf das Atom A ausgeübten Zugkraft $F_{\text {cant }}$ als Funktion der Cantileverposition $z_{\text {cant }}$ erhalten wir ein Kraftprofil. Das Maximum des Kraftprofils ordnen wir der Dissoziationskraft zu. 


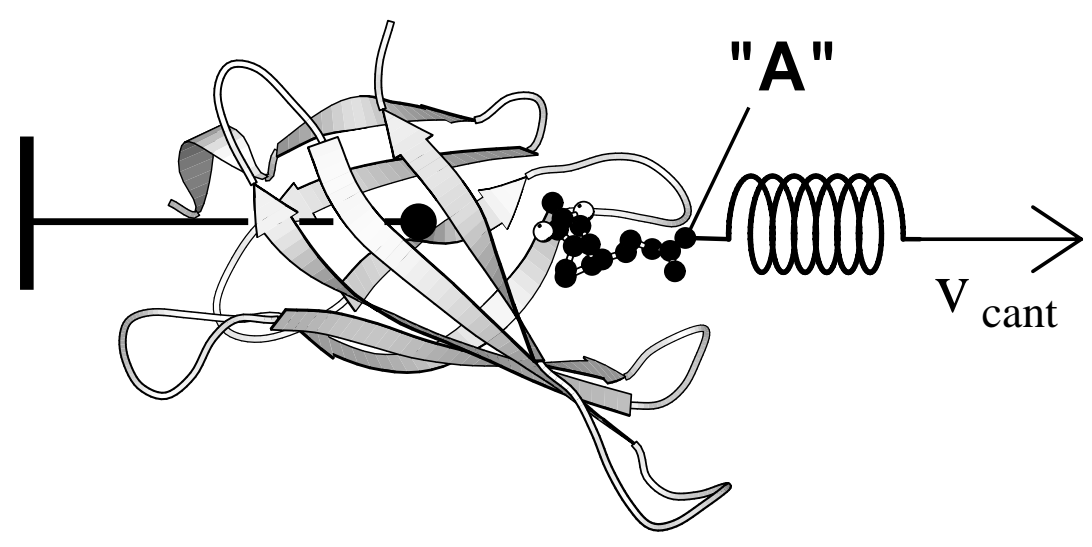

Abbildung 3.2: Verfahren zur Simulation kraftmikroskopischer Einzelmolekülexperimente zur forcierten Dissoziation von Rezeptor-Ligand-Komplexen. Cantilever und Polymerlinker werden durch ein harmonisches Potenzial beschrieben (symbolisiert durch eine Feder), das gerade an dasjenige Atom gekoppelt ist, das im Experiment mit dem Cantilever verbunden ist. Während der Simulation wird dieses Potenzial mit konstanter Zuggeschwindigkeit $v_{\text {cant }}$ in Zugrichtung bewegt, während der Schwerpunkt des Rezeptors fixiert ist.

Um zu vermeiden, dass sich während einer Dissoziationssimulation der gesamte RezeptorLigand-Komplex in Zugrichtung bewegt, halten wir den Schwerpunkt $\mathbf{R}(t)$ des Rezeptors mit einem steifen harmonischen Potenzial $V_{\mathrm{SP}}$ der Form

$$
\begin{aligned}
V_{\mathrm{SP}}(t) & =k_{1}[\mathbf{R}(t)-\mathbf{R}(0)]^{2} / 2 \mathrm{mit} \\
\mathbf{R}(t) & =\frac{1}{M} \sum_{i=1}^{N} m_{i} \mathbf{r}_{i}(t)
\end{aligned}
$$

ortsfest. Dabei ist $k_{1}$ eine Federkonstante, $\mathbf{r}_{i}(t)$ sind die Koordinaten für Atom $i, M$ ist die Gesamtmasse und $N$ die Anzahl der Atome des Rezeptors. Auf diese Weise ist gewährleistet, dass der Rezeptor keine Translationsbewegungen ausführen kann (insbesondere nicht in Zugrichtung). Die internen Freiheitsgrade - etwa die Bewegungen einzelner Aminosäuren - sind dabei kaum berührt (d.h. das System ist praktisch ungestört), und der Rezeptor bleibt als Gesamtes frei drehbar.

\subsubsection{Die Federkonstante in Dissoziationssimulationen}

Sowohl im kraftmikroskopischen Experiment als auch in der MD-Simulation müssen zwei Parameter festgelegt werden: die Federkonstante des Cantilevers, $k_{0}$, und dessen Zuggeschwindigkeit $v_{\text {cant }}$. Im Folgenden werden die Kriterien definiert und diskutiert, nach denen wir diese auch für unsere Simulationen kritischen Parameter gewählt haben.

Für die Wahl der Federkonstante des harmonischen Zugpozenzials in Dissoziationssimulationen ziehen wir drei Kriterien in Betracht. Zum einen muss gewährleistet sein, dass der Ligand in der zur Verfügung stehenden Simulationszeitspanne von seinem Rezeptor 
getrennt wird, zum zweiten ist eine möglichst hohe Auflösung des Kraftprofils, das im Verlauf der Simulation abgetastet wird, angestrebt, und zum dritten soll das System durch das Zugpotenzial möglichst wenig gestört werden. Da eine ausführliche Disskussion hierzu bereits in der Diplomarbeit des Autors [56] erfolgte, beschränken wir uns hier auf die wichtigsten Schlussfolgerungen.

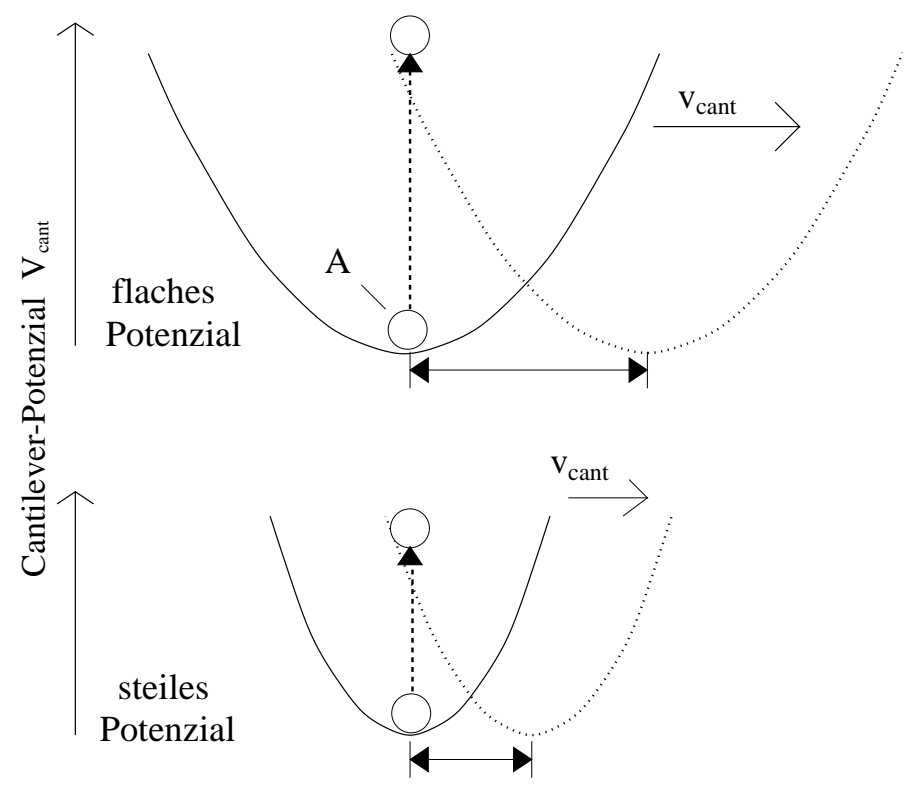

Abbildung 3.3: Vergleich von flachem (oben) und steilem (unten) harmonischem Zugpotenzial (weiche versus steife Feder). Für den Fall der flacheren Parabel ist eine größere Verschiebung nötig, um auf das Atom A eine vorgegebene Kraft - die einer bestimmten Neigung in der Parabel entspricht - wirken zu lassen. Damit diese Kraft innerhalb der zur Verfügung stehenden Simulationszeit erreicht wird, muss die Zuggeschwindigkeit $v_{\text {cant }}$ bei weicher Feder größer sein, wie es durch den längeren Pfeil angedeutet ist.

Wie Abbildung 3.3 zeigt, können Federkonstante und Zuggeschwindigkeit nicht unabhängig voneinander betrachtet werden: Je „weicher" die Feder ist, je flacher das parabelförmige Zugpotenzial $V_{\text {cant }}$ also verläuft, desto größer muss die Auslenkung des Atoms A vom Minimum dieses Potenzials sein, um eine gegebene Zugkraft wirken zu lassen. Soll innerhalb der zur Verfügung stehenden Simulationszeit $T_{0}$ (z.B. 5 ns) die Dissoziationskraft $F_{\text {Diss }}=k_{0} \cdot v_{\text {cant }} \cdot T_{0}$ erreicht werden, die zur Trennung des Komplexes nötig ist, muss mit weicherer Feder eine höhere Zuggeschwindigkeit gewählt werden als mit steiferer Feder.

Im Folgenden werden wir anhand von Abbildung 3.4 erläutern, welchen Einfluss die Wahl der Federkonstante $k_{0}$ auf den Verlauf des gemessenen bzw. berechneten Kraftprofils hat. Wir beschränken uns dabei zunächst auf die Dissoziation von Rezeptor-LigandKomplexen. In Bild A ist eine hypothetische Energielandschaft $U_{0}$ für den Dissoziationsprozess eines Rezeptor-Ligand-Komplexes eingezeichnet: Links befindet sich der energetisch günstigere gebundene Zustand und rechts der energetisch ungünstigere ungebundene Zustand. Um vom gebundenen zum ungebundenen Zustand zu gelangen, muss in diesem Energiebild der Weg von links nach rechts zurückgelegt werden. Die nötige Kraft, die auf das Atom A (und in der Folge auf den gesamten Liganden) mindestens wirken muss, um diese Potenzialdifferenz zu überwinden, erhält man aus der (negativen) ersten Ab- 
leitung der Energielandschaft entlang der Zugrichtung, in unserem Fall der z-Koordinate $z_{\mathrm{A}}$. Der Verlauf dieser Kraft $-F_{0}$, der im forcierten Dissoziationsprozess vom Cantilever abgetastet wird, ist in Bild B und $\mathrm{C}$ zu sehen (durchgezogene Linien).

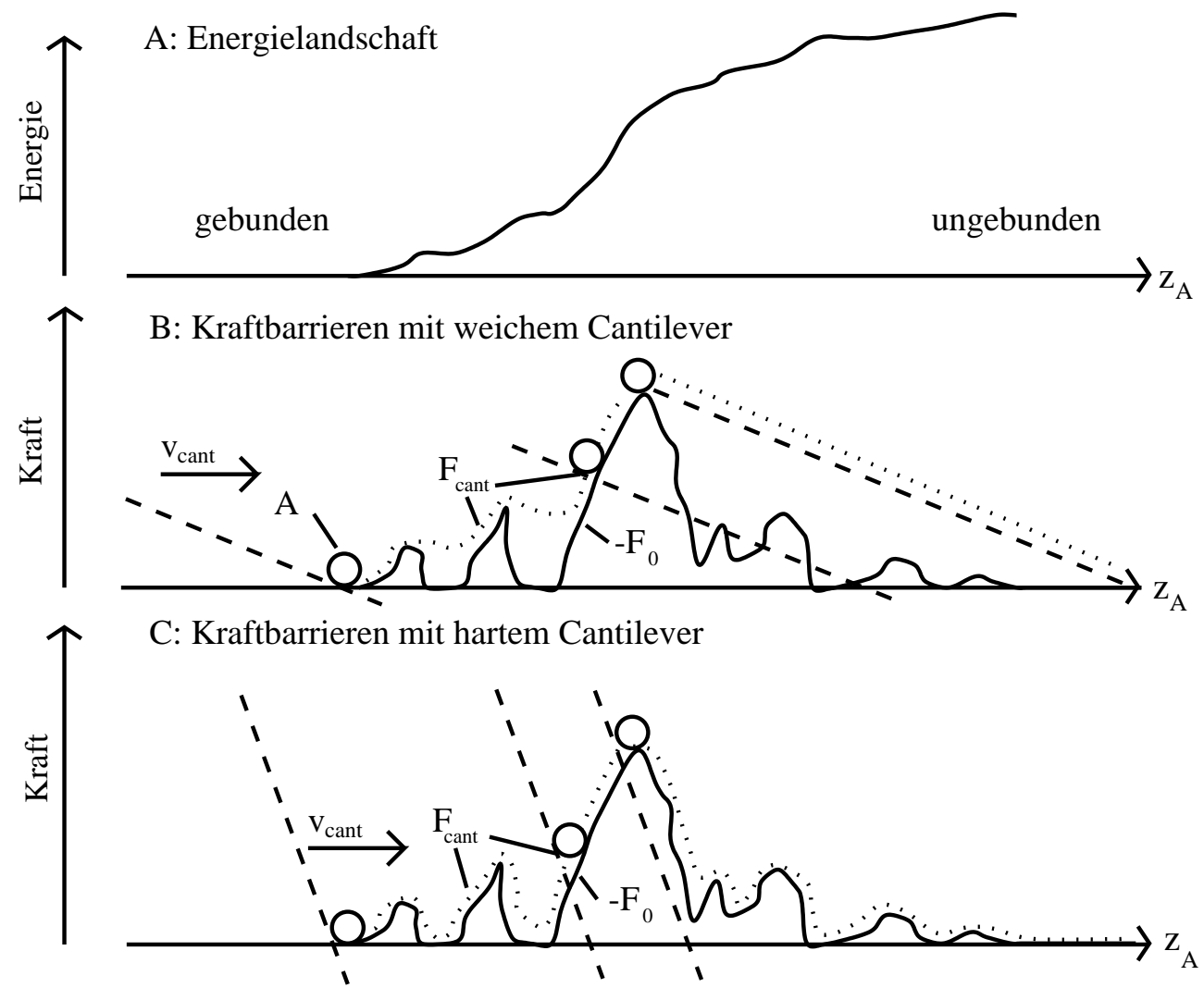

Abbildung 3.4: Skizze zur Erläuterung des Zusammenhangs zwischen Federhärte und erzielter Auflösung im Kraftprofil. Zur Beschreibung siehe Text.

Wenn in der Dissoziationssimulation die auf Atom A angelegte Zugkraft $F_{\text {cant }}$ - gezeigt anhand der gestrichelten „Kraftgeraden“ in der Abbildung — kleiner ist als $-F_{0}$, kann das Atom keine Dissoziationsbewegungen vollführen; es bleibt gleichsam an der Barriere „hängen“. Dies ist sowohl in Bild B als auch in Bild C in der jeweils mittleren der drei eingezeichneten Positionen des Atoms A zu sehen. Erst, wenn die Zugkraft $F_{\text {cant }}(z)$ die Kraft $-F_{0}(z)$ erreicht, wird diese Barriere überwunden (rechts eingezeichnete Positionen).

Dieser Effekt beschreibt die prinzipiell erreichbare Ortsauflösung: Eine kleine Federkonstante (Bild B), d.h. eine flach verlaufende Kraftgerade, hat zur Folge, dass das Atom A nach Überwindung einer Barriere vergleichsweise weit in Richtung des ungebundenen Zustands wandern muss, um die angelegte Zugkraft signifikant zu erniedrigen. Eine hohe Federkonstante (Bild C), die einer steil verlaufenden Kraftgeraden entspricht, bewirkt dagegen bereits bei kleinen Dissoziationsbewegungen von Atom A eine signifikante Erniedrigung der Zugkraft. Auf diese Weise kann es sein, dass Kraftbarrieren, die im Dissoziationsweg nach der höchsten Kraftbarriere liegen, mit einer weichen Feder nicht aufgelöst werden, da Atom A sich auf Grund der hohen Zugkraft gleichsam über diese Barrieren hinwegbewegt (gepunktete Linie im rechten Teil von Bild B). Mit einer steifen Feder können dagegen solche nachfolgenden Kraftbarrieren aufgelöst werden (gepunktete 
Linie in Bild C). Somit ist für eine hohe Abtastgenauigkeit eine steife Feder vorzuziehen.

Dabei ist allerdings zu bedenken, dass eine steife Feder die Bewegungsfreiheit des Atoms stärker einschränkt als eine weiche Feder, so dass vor dem Hintergrund der Störung des Systems eine weiche Feder zu bevorzugen wäre. Die Wahl der Federkonstante ist somit ein Kompromiss zwischen der Abtastgenauigkeit und der Störung des Systems. Für eine quantitative Abwägung dieser beiden Kriterien sei auf Abschnitt 5.4 verwiesen, in dem die Dissoziationssimulationen zum AN02-Hapten-Komplex beschrieben werden.

Für Dehnungssimulationen gelten diese Überlegungen zwar prinzipiell auch, doch sind sie da nicht relevant. In ihnen liegt das Hauptaugenmerk nämlich nicht darauf, Kraftbarrieren aufzulösen, sondern die Elastizität des betrachteten Polymermoleküls aus der Steigung der Kraft-Ausdehnungs-Kurve, in der die Zugkraft als Funktion der Polymerausdehnung aufgetragen ist, zu berechnen. Darüber hinaus können in kraftmikroskopischen Experimenten Kraft-Ausdehnungs-Kurven im Gegensatz zu Kraftprofilen direkt bestimmt werden, so dass es zur Vergleichbarkeit von gemessenen und berechneten KraftAusdehnungs-Kurven nahe liegt, in der Dehnungssimulation dieselbe Federkonstante zu wählen wie im analogen kraftmikroskopischen Experiment. 
30 KAPITEL 3. MD-SIMULATION KRAFTMIKROSKOPISCHER EXPERIMENTE 


\section{Kapitel 4}

\section{Theorie zur forcierten Dissoziation von Rezeptor-Ligand-Komplexen}

Nach den qualitativen Überlegungen zum Einfluss der Federkonstante auf die erreichbare Ortsauflösung soll nun untersucht werden, wie die Dissoziationskraft von RezeptorLigand-Komplexen von der Zuggeschwindigkeit $v_{\text {cant }}$ abhängt. Generell sollen hier, im Sinne der Ratentheorie, eindimensionale Landschaften freier Enthalpie/freier Energie $G(x)$ entlang einer vorgegebenen Reaktionskoordinate $x$ - etwa der Cantileverposition - betrachtet werden, um eine analytische Behandlung zu ermöglichen. Der Einfluss der übrigen zahlreichen Freiheitsgrade etwa eines Proteins wird dabei nicht vernachlässigt, sondern vielmehr über das geeignete Phasenraumintegral als implizit in der Freien-EnergieLandschaft berücksichtigt aufgefasst.

Im ersten Teil dieses Kapitels werden wir ein sehr einfaches Interpolationsmodell ableiten, das es erlaubt, Dissoziationskräfte, die in Dissoziationssimulationen auf der Nanosekundenzeitskala berechnet werden, auf die Millisekundenzeitskala zu übertragen und auf diese Weise mit experimentell bestimmten Dissoziationskräften direkt vergleichbar zu machen. Als Eingabeparameter geht hier lediglich die üblicherweise gemessene spontane Dissoziationsrate der betrachteten Rezeptor-Ligand-Bindung ein.

Im zweiten Teil dieses Kapitels wollen wir dann eine grundlegende Theorie zu forcierten Dissoziationsprozessen entwickeln. Im Zentrum des Interesses soll dabei der Zusammenhang zwischen der Gestalt der Freien-Energie-Landschaft bzw. des daraus abgeleiteten Kraftprofils $F(x)=-\partial_{x} G(x)$ einerseits und der Dissoziationskraft als Funktion der Geschwindigkeit der erzwungenen Dissoziation - des „Kraftspektrums“ $F_{\text {diss }}\left(v_{\text {cant }}\right)$ - andererseits stehen. Dabei interessiert uns, wie sich Details der Freien-Energie-Landschaft, die etwa eine Rezeptor-Ligand-Bindung beschreibt, in ihrem Kraftspektrum widerspiegeln. Gelänge nämlich eine solche Transformation zwischen Ort und Geschwindigkeit, dann sollte es möglich sein, aus einem gegebenen (experimentell ermittelten) Kraftspektrum die Energielandschaft entlang einer Reaktionskoordinate — teilweise oder vollständig — $\mathrm{zu}$ rekonstruieren. 


\subsection{Modell zur Interpolation von Dissoziationskräften}

In der Einleitung haben wir bereits auf die unterschiedlichen Zeitskalen in kraftmikroskopischen Experimenten und in MD-Simulationen hingewiesen. Um experimentell bestimmte und in den MD-Simulationen berechnete Dissoziationskräfte vergleichen zu können, müssen Effekte in Betracht gezogen werden, die eine Abhängigkeit der Dissoziationskräfte von der Zuggeschwindigkeit bewirken.

In den vergangenen Jahren hat man bereits Reibung und durch thermische Fluktuationen getriebene aktivierte Prozesse als die entscheidenden physikalischen Effekte erkannt, die die Dissoziationskraft von der Zuggeschwindigkeit abhängig machen [55, 58, 68, 84, 86-88]. Dabei führen Reibung zu einer linearen Abhängigkeit und aktivierte Prozesse zu einer logarithmischen Abhängigkeit.

Im Folgenden werden wir diese beiden Effekte kombinieren, um mit Hilfe eines einfachen Modells aus berechneten Dissoziationskräften auf der Nanosekundenzeitskala auf die zu erwartenden Dissoziationskräfte auf der Millisekundenzeitskala zu schließen. Entscheidend wird dabei das Hinzuziehen der (experimentell zugänglichen) spontanen Dissoziationsrate sein, welche diejenige Zuggeschwindigkeit angibt, unterhalb der die Dissoziation ohne von außen angelegte Kräfte erfolgt.

In unserem Modell setzt sich also die Dissoziationskraft $F_{\text {diss }}$ aus den beiden oben benannten Anteilen, Reibung und aktivierten Prozessen, zusammen:

$$
F_{\text {diss }}\left(v_{\text {cant }}\right)=F_{\mathrm{R}}\left(v_{\text {cant }}\right)+F_{\mathrm{A}}\left(v_{\text {cant }}\right)
$$

wobei $F_{\mathrm{R}}$ die Reibungskraft und $F_{\mathrm{A}}$ die durch aktivierte Prozesse bedingte Kraft ist.

Bisher durchgeführte Dissoziationssimulationen [55,56,68] zeigten für höhere Zuggeschwindigkeiten $\left(v_{\text {cant }}>5 \mathrm{~m} / \mathrm{s}\right)$ ein Regime, in dem eine lineare Abhängigkeit der Dissoziationskraft von der Zuggeschwindigkeit vorherrschte. Diese Abhängigkeit wurde mit Stokesscher Reibung beschrieben, bei der die Reibungskraft $F_{\mathrm{R}}$ für kugelförmige Objekte die Form

$$
F_{R}=6 \pi \eta r v=: \gamma v
$$

hat. Dabei sind $\eta$ die Viskosität für Wasser, $r$ und $v$ Radius bzw. Geschwindigkeit der Kugel und $\gamma$ der Reibungskoeffizient.

Zur Disskussion von aktivierten Prozessen betrachten wir ein Ensemble von forcierten Dissoziationsprozessen bei gegebener Zuggeschwindigkeit $v_{\text {cant }}$. Der Dissoziationspunkt sei der Ort in der Energielandschaft, an dem der Fluss der gerade dissoziierenden RezeptorLigand-Komplexe sein Maximum erreicht. Weiter führen wir ein (zeitliches) Intervall $\Delta T_{\text {trans }}$ ein, innerhalb dessen die meisten Komlplexe des Ensembles dissoziieren, und nehmen an, dass sich die Zugkraft $F_{\text {Zug }}$ auf die Komplexe innerhalb dieses Intervalls nicht signifikant ändert. Ihren Mittelwert im Intervall $\Delta T_{\text {trans }}$ bezeichnen wir mit $F_{\mathrm{A}}$. Unter dieser Voraussetzung kann, wie in Abbildung 4.1 illustriert, der Dissoziationsprozess beschrieben werden als das durch aktivierte Prozesse bedingte Überqueren einer FreienEnergie-Barriere $\Delta G^{\ddagger}$, die durch die Zugkraft $F_{\mathrm{A}}$ zu einer effektiven Barriere $\Delta G_{v}^{\ddagger}$ abgesenkt wird:

$$
\Delta G_{v}^{\ddagger}=\Delta G^{\ddagger}-L F_{\mathrm{A}}
$$


Hier ist $L$ die durchschnittliche Dissoziationslänge, definiert als die Auslenkung des Liganden von seiner Position im gebundenen Zustand entlang der Zugrichtung. (Der Index $v$ in Gleichung (4.3) bezieht sich auf von Null verschiedene Zuggeschwindigkeiten $v_{\text {cant }}$; der Index 0 wird im Folgenden für spontane Dissoziation verwendet, bei der $v_{\text {cant }}$ verschwindet.)

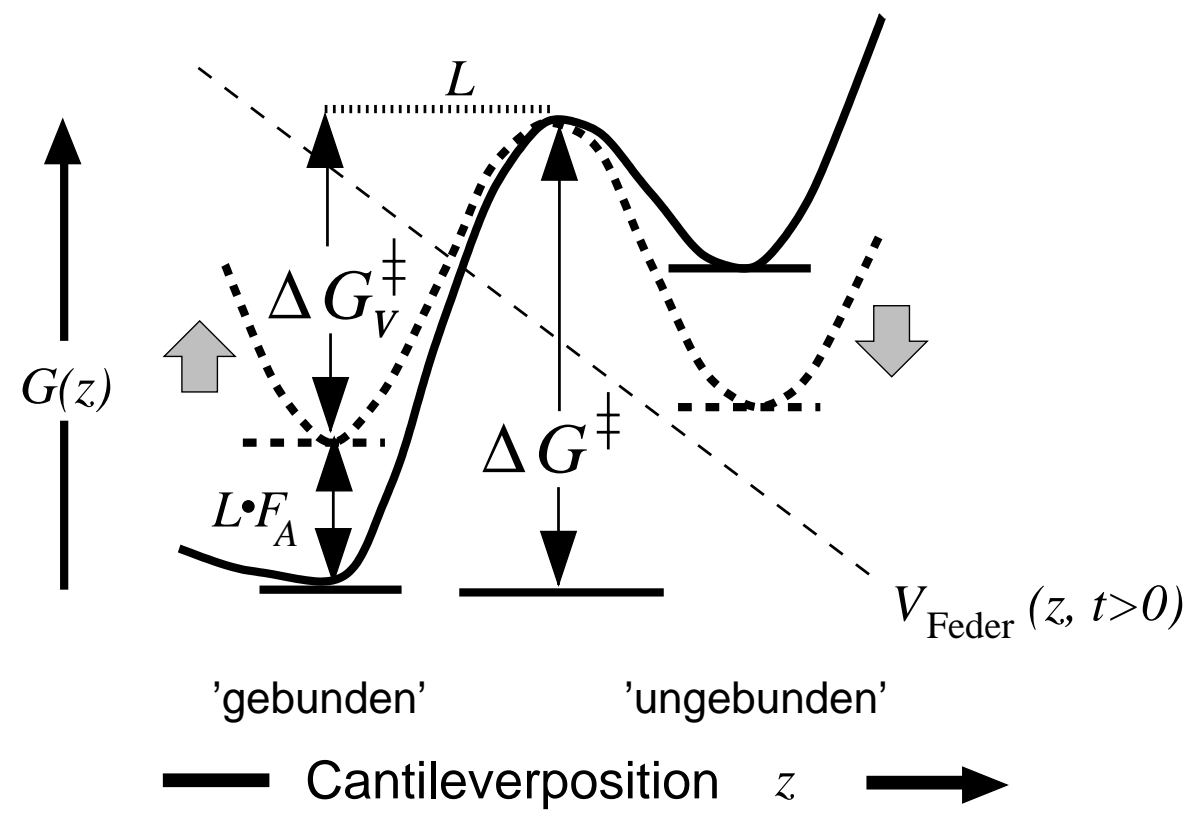

Abbildung 4.1: Skizze einer hypothetischen Energielandschaft, um den Einfluss eines externen, harmonischen Zugpotenzials zu erläutern. Die ursprüngliche Aktivierungsbarriere $\Delta G^{\ddagger}$ der ungestörten Energielandschaft (durchgezogene Linie) wird durch das Zugpotenzial $V_{\text {Feder }}$ um etwa $L \cdot F_{\mathrm{A}}$ erniedrigt, wobei $L$ die Dissoziationslänge und $F_{\mathrm{A}}$ die Zugkraft sind. Die effektive Energielandschaft (Summe aus ungestörter Energielandschaft und Zugpotenzial) ist anhand der gestrichelten Linie gezeigt. $\Delta G_{v}^{\ddagger}$ ist die verbleibende effektive Aktivierungsbarriere.

Um nun einen Ausdruck für $F_{\mathrm{A}}$ als Funktion der Zuggeschwindigkkeit $v_{\text {cant }}$ zu bekommen, führen wir zunächst eine innerhalb des Intervalls $\Delta T_{\text {trans }}$ gültige effektive (forcierte) Dissoziationsrate $k_{v}$ ein, die sich in der Kramers-Näherung [183] schreiben lässt als

$$
k_{v}=\omega_{0} \exp \left(-\frac{\Delta G_{v}^{\ddagger}}{k_{\mathrm{B}}}\right) .
$$

Hierbei ist $\omega_{0}$ der Kramers-Vorfaktor, der die Fluktuationen des Systems im gebundenen Zustand beschreibt, $k_{\mathrm{B}}$ ist die Boltzmann-Konstante und $T$ ist die Temperatur. Man beachte, dass $k_{v}$ durch $k_{v} \approx 1 / \Delta T_{\text {trans }}$ approximiert werden kann, da nach Definition innerhalb des Intervalls $\Delta T_{\text {trans }}$ die meisten Dissoziationen stattfinden. Wenn man die Schwankungsbreite $\Delta L$ der individuellen Dissoziationslängen $\Delta L:=v_{\text {cant }} \Delta T_{\text {trans }}$ einführt, kann die effektive Dissoziationsrate geschrieben werden als

$$
k_{v}=\frac{v_{\text {cant }}}{\Delta L}
$$


Für die spontane Dissoziationsrate verwenden wir ebenfalls die Kramers-Näherung:

$$
k_{0}=\omega_{0} \exp \left(-\frac{\Delta G^{\ddagger}}{k_{\mathrm{B}}}\right)
$$

Hier nehmen wir an, dass sich der Kramers-Vorfaktor $\omega_{0}$ in Gleichung (4.6) nicht wesentlich von dem in Gleichung (4.4) unterscheidet. Diese Annahme erwies sich in den bisher durchgeführten Dissoziationssimulationen als gerechtfertigt [68]. Somit ergeben Gleichungen (4.3) - (4.6) das angestrebte Resultat

$$
F_{\mathrm{A}}\left(v_{\text {cant }}\right)=\frac{k_{\mathrm{B}} T}{L} \ln \frac{v_{\text {cant }}}{k_{0} \Delta L}
$$

Die Kombination dieses Ausdrucks mit dem für die Reibungskraft $F_{\mathrm{R}}$ [Gleichung (4.2)] ergibt für die Dissoziationskraft

$$
F_{\text {diss }}\left(v_{\text {cant }}\right)=\gamma v_{\text {cant }}+\frac{k_{\mathrm{B}} T}{L} \ln \frac{v_{\text {cant }}}{k_{0} \Delta L}
$$

Dieses einfache Modell erlaubt es, auf Grundlage der Dissoziationskräfte, die in MDSimulationen auf der Nanosekundenzeitskala unter Verwendung von unterschiedlichen Zuggeschwindigkeiten berechnet wurden, die Dissoziationskraft für die experimentelle Zeit- (bzw. Zuggeschwindigkeits-)Skala abzuschätzen. Die justierbaren Parameter sind die Größen $L, \Delta L$ und der Rreibungskoeffizient $\gamma$. Die spontane Dissoziationskonstante $k_{0}$ wird als bekannt vorausgesetzt. 


\subsection{Allgemeine Theorie forcierter Dissoziationspro- zesse}

Das soeben beschriebene Modell dient dazu, ein aus MD-Simulationen abgeleitetes Kraftspektrum auf die experimentelle Zeitskala zu interpolieren. Nun wollen wir untersuchen, wie ein gemessenes Kraftspektrum ausgenutzt werden kann, um auf Details der Energielandschaft, die die Rezeptor-Ligand-Bindung beschreibt, zu schließen.

Wir haben bereits einleitend erwähnt, dass in Dissoziationsexperimenten bisher nur Dissoziationskräfte von Rezeptor-Ligand-Komplexen gemessen werden konnten [25, 26, 184], nicht aber Kraftprofile entlang einer Reaktionskoordinate. Diese konnten dagegen in MDSimulationen solcher Experimente [55,58,61,62,67] berechnet werden. Dies stellte sich für biologische Makromoleküle als überaus nützlich heraus, da die entsprechenden Kraftprofile eine Vielzahl von Barrieren aufwiesen, die intermolekularen Wechselwirkungen wie dem Brechen von Wasserstoffbrücken, Van der Waals-Kontakten oder Wasserbrücken zugeordnet werden konnten und auf eine entsprechend komplexe Energielandschaft schließen ließen $[55,58]$.

Bisherige theoretische Untersuchungen, die auf einfachen Modellen der Energielandschaft basieren [58,68, 84, 88, 185-187], haben bereits nahegelegt, dass über die Messung von Kraftspektren (dynamische Kraftspektroskopie) Kraftprofile auch experimentell direkt zugänglich sein sollten. Diese Erwartung wurde kürzlich durch Dissoziationsexperimente bestätigt, in denen der Avidin-Biotin-Komplex mit Hilfe der Biomembran-KraftmessungsTechnik (BFP) getrennt wurde, wobei der Bereich der verwendeten Zuggeschwindigkeiten etwa fünf Größenordnungen umfasste [83]: Für den Grenzfall einer sehr weichen Feder unter $0.01 \mathrm{~N} / \mathrm{m}$ und unter Annahme eines Zwei-Zustands-Modells [84, 88, 186] konnten drei Regimes in der Energielandschaft des Avidin-Biotin-Komplexes aufgelöst werden, die zuvor schon aus MD-Simulationen abgeleitet worden waren [58]. Dabei musste angenommen werden, dass diese Regimes gut von einander separiert sind.

Die Theorie zur Rekonstruktion von Kraftprofilen, die wir nun entwickeln wollen, soll keine Annahmen hinsichtlich der Energielandschaft erfordern. Darüber hinaus sollte sie sowohl auf BFP- oder Optical-Tweezer-Experimente, in denen weiche Federn verwendet werden, anwendbar sein, als auch auf Experimente, in denen vergleichsweise harte Federn verwendet werden (etwa kraftmikroskopische Experimente), die sich nicht mit dem ZweiZustands-Modell beschreiben lassen.

\subsubsection{Theorie}

Wie wir bereits in Abschnitt 3.1 gesehen haben, ist in typischen Dissoziationsexperimenten der Ligand über einen flexiblen Polymerlinker an eine „Feder“ (z.B. den Cantilever eines Kraftmikroskops) gebunden, die im Laufe des Dissoziationsprozesses von dem Rezeptormolekül wegbewegt wird und somit eine Zugkraft auf den Liganden ausübt.

Zur Beschreibung des Dissoziationsprozesses gehen wir, wie in Abbildung 4.2(a) illustriert, von einer Landschaft der (Helmholtzschen) freien Energie $U_{0}(x)$ aus ${ }^{1}$, die den Dis-

\footnotetext{
${ }^{1}$ Wir bezeichnen die freie Energie hier mit $U_{0}$, um Verwechslungen mit der Kraft $F$ zu vermeiden.
} 
soziationsprozess eines Rezeptor-Ligand-Komplexes entlang der Reaktionskoordinate $x$ (etwa der Abstand des Schwerpunkts des Liganden von dem seines Rezeptors) beschreibt.

Die auf den Liganden ausgeübte, externe Zugkraft $F_{\text {Feder }}(x, t)=-\partial_{x} V_{\text {Feder }}(x, t)$ wird beschrieben durch ein semiharmonisches Potenzial,

$$
V_{\text {Feder }}(x, t)=\left\{\begin{array}{rll}
\frac{1}{2} k(x-v t)^{2} & : & x<v t \\
0 & : & \text { sonst }
\end{array}\right.
$$

[gestrichelte Linien in Abbildung 4.2(a)], wobei $k$ die Kraftkonstante des Zugpotenzials ist.

Wir setzen hier ein semiharmonisches Potenzial an, da der flexible Polymerlinker, über den der Ligand an die Feder gebunden ist (siehe dazu Abschnitt 3.1), nur Zugkräfte auf den Liganden ausüben und ihn somit nicht in die Bindungstasche drücken kann.

Wie in Abbildung 4.2(a) durch den Pfeil angedeutet, wird das Zugpotenzial $V_{\text {Feder }}(x, t)$ mit konstanter Zuggeschwindigkeit $v=v_{\text {cant }}$ bewegt, so dass die Dissoziation des RezeptorLigand-Komplexes forciert wird. Ohne Beschränkung der Allgemeinheit definieren wir $x=0$ für das ungestörte System und nehmen an, dass das Zugpotenzial $V_{\text {Feder }}$ zum Zeitpunkt $t=0$ aktiviert wird.

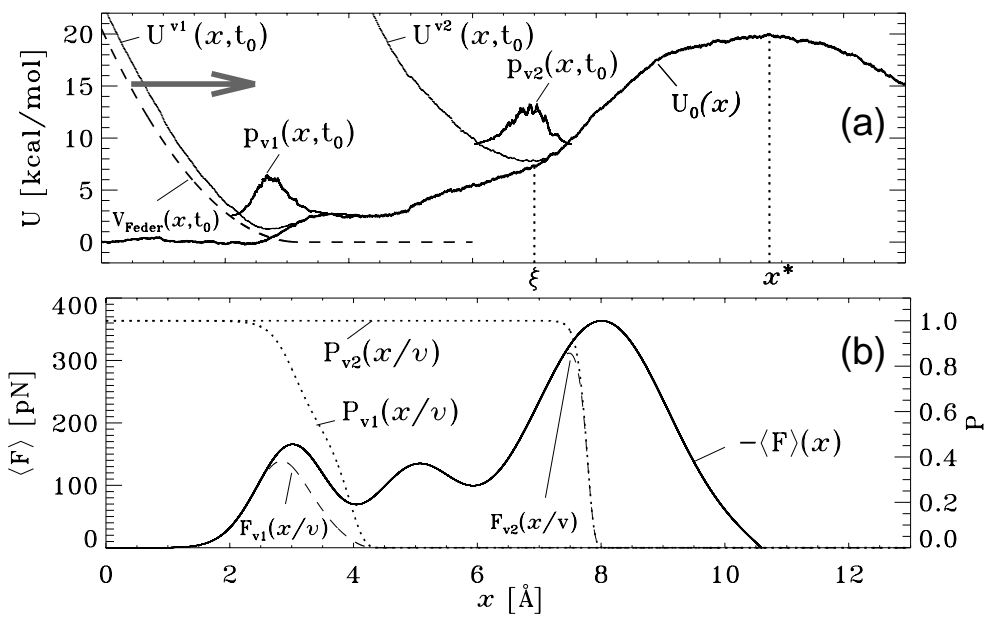

Abbildung 4.2: (a) Beschreibung von Einzelmolekül-Dissoziationsexperimenten mit einer zeitabhängigen Energielandschaft $U(x, t)$ (durchgezogene Linien) entlang einer Reaktionskoordinate $x$. $U(x, t)$ setzt sich aus zwei Beiträgen zusammen: der Freien-EnergieLandschaft $U_{0}(x)$ (fette Linie) des ungestörten Systems und dem externen Zugpotenzial $V_{\text {Feder }}(x, t)$, dem der Ligand unterworfen ist. (b) Der Anteil $P_{v}(t)$ der gebundenen Komplexe (gepunktete Linien) bestimmt, wie weit das Kraftprofil $F(x)$ entlang der Reaktionskoordinate bei gegebener Zuggeschwindigkeit $v$ abgetastet wird. Dabei markieren die gestrichelten Linien die effektiven Kraftprofile, die man für ein Ensemble von Einzelmolekül-Dissoziationsexperimenten mit der Zuggeschwindigkeit $v$ erhält.

Wir betrachten ein Ensemble von Einzelmolekül-Dissoziationsexperimenten und nehmen an, dass sich die Wahrscheinlichkeitsverteilung $\rho_{v}(x, t)$ der Reaktionskoordinate, die durch molekulare Bewegungen auf der Pikosekundenzeitskala dominiert ist, auf der experimentellen Zeitskalka $\tau$, die oberhalb von Millisekunden liegt, stets im Gleichgewicht befindet. 
In dieser quasistatischen Behandlung ist $\rho_{v}(x, t)$ durch den Boltzmann-Faktor

$$
\rho_{v}(x, t)=\frac{1}{Z} e^{-\beta\left[U_{0}(x)+V_{\text {Feder }}(x, t)\right]}
$$

gegeben, wobei $Z$ die Zustandssumme im Konfigurationsraum,

$$
Z=\frac{1}{h} \sqrt{\frac{2 \pi m}{\beta}} \int d x e^{-\beta\left[U_{0}(x)+V_{\text {Feder }}(x, t)\right]},
$$

und $\beta=1 / k_{B} T$ die reziproke thermische Energie ist. Führt man eine Zustandssumme $Z_{b}$ für die gebundenen Zustände $x<x^{*}$ ein, wobei $x^{*}$ die Position des Übergangszustands ist (vgl. Abbildung 4.2),

$$
Z_{b}=\frac{1}{h} \sqrt{\frac{2 \pi m}{\beta}} \int_{x<x^{*}} d x e^{-\beta\left[U_{0}(x)+V_{\mathrm{Feder}}(x, t)\right]},
$$

erhalten wir $\rho_{v}(x, t)=P_{v}(t) p_{v}(x, t)$, wobei $P_{v}(t)=Z_{b} / Z$ der Anteil der gebundenen Zustände und $p_{v}(x, t)$ die Verteilung der Reaktionskoordinate im gebundenen Zustand ist:

$$
p_{v}(x, t)=\frac{1}{Z_{b}} e^{-\beta\left[U_{0}(x)+V_{\text {Feder }}(x)\right]} .
$$

Mit Hilfe dieser Verteilung definieren wir Ensemblemittelwerte $\langle\ldots\rangle:=\int d x \ldots p_{v}(x, t)$ im gebundenen Zustand, z.B. die mittlere Position $\langle x\rangle(v, t)$ des Liganden.

Für Zuggeschwindigkeiten $v>0$ wird das Minimum von $U:=U_{0}+V_{\text {Feder }}$ kontinuierlich angehoben, wie es in Abbildung 4.2(a) skizziert ist, so dass die Barriere, die bei der Dissoziation überwunden werden muss, erniedrigt wird. Die Folge ist, dass der Fluss dissoziierender Komplexe $\partial_{t} P_{v}(t)$ über die Barriere ansteigt und $P_{v}(t)$ schneller abfällt als für $v=0$. Entsprechend wird die mittlere Übergangszeit reduziert, wie man anhand des nach der zeitabhängigen Ratentheorie bestimmten (Vorwärts-)Flusses über die Barriere [188],

$$
\partial_{t} P_{v}(t)=-\kappa k_{\mathrm{TST}}^{+} P_{v}(t)=-\omega_{0} P_{v}(t) e^{-\beta \Delta A(v, t)},
$$

sehen kann. Dabei ist $\kappa$ ein Transmissionskoeffizient, den wir als von $v$ unabhängig annehmen, und $\omega_{0}:=\kappa /(h \beta)$. Rückbindungsereignisse wurden vernachlässigt. Die freie Aktivierungsenergie kann als $\Delta A(v, t)=U\left(x^{*}, t\right)-A(v, t)$ mit $A(v, t)=-\frac{1}{\beta} \ln Z_{b}$ geschrieben werden. Aus Gleichung (4.9) folgt, dass $U\left(x^{*}, t\right)$ für $t<x^{*} / v$ unabhängig von $v$ [und identisch mit der Barrierenhöhe $U_{0}\left(x^{*}\right)$, siehe Abbildung 4.2(a)] ist und sonst mit $t$ ansteigt. Entsprechend unterscheiden wir ein Regime harter Feder mit $\tau<x^{*} / v$ von einem Regime weicher Feder mit $\tau>x^{*} / v$, wobei wir den Dissoziationszeitpunkt $\tau$ über $P_{v}(\tau)=\frac{1}{2}$ definieren.

Wäre $P_{v}(t)$ bekannt, könnte die über ein Ensemble von Dissoziationsexperimenten gemittelte Dissoziationskraft mit

$$
\left\langle F_{\mathrm{SM}}\right\rangle(v)=-\int_{0}^{\infty} d t \partial_{t} P_{v}(t) F_{\max }(v, t)
$$


identifiziert werden, wobei $F_{\max }(v, t):=\max _{t^{\prime}<t} F\left(v, t^{\prime}\right)$ ist und

$$
F(v, t)=\partial_{t} A(v, t) / v \text {. }
$$

Da $P_{v}(t)$ im allgemeinen sigmoid verläuft [siehe Abbildung 4.2(b)], kann die mittlere Dissoziationskraft in guter Näherung mit $\left\langle F_{\mathrm{SM}}\right\rangle(v) \approx F_{\max }(\tau)$ abgeschätzt werden. [Korrekturen erhält man, wenn man $P_{v}(t)$ in $t$ um $\tau$ entwickelt.] Das Minimum des Zugpotenzials befinde sich zum Zeitpunkt der Dissoziation bei $\xi=v \tau$. Unter Verwendung von Gleichung (4.16) und der Zeitableitung von $Z_{b}$ aus Gleichung (4.12) erhält man das verallgemeinerte Hookesche Gesetz,

$$
F(v, t)=k[v t-\langle x\rangle(v, t)],
$$

wenn man ein harmonisches Zugpotenzial zugrunde legt. Für ein semiharmonisches Potenzial gilt dies bis auf die Korrektur $-\left(1 / Z_{b}\right) \int_{v t}^{x^{*}} d x k(x-v t) \exp \left[-\beta U_{0}(x)\right]$. Wir werden diese Korrektur vernachlässigen, was eine gute Näherung ist, falls $F(v, \tau)$ größer ist als eine kritische Kraft $F_{c}:=k /\left[\beta^{2}\left(k^{2}+k_{0}^{2}\right)\right]^{1 / 4}$ mit $k_{0}=\partial^{2} U_{0}(x)$ bei $x=0$. Für $k \gg k_{0}$ (harte Feder) gilt für die kritische Kraft

$$
F_{c} \approx(k / \beta)^{1 / 2},
$$

für $k \ll k_{0}$ (weiche Feder)

$$
F_{c} \approx k /\left(\beta k_{0}\right)^{1 / 2},
$$

so dass sie für $k \rightarrow 0$ verschwindet.

Der entscheidende Schritt ist nun, von $v$ zu $\tau$ als den unabhängigen Parameter überzugehen und $\Delta A(v, t)$ in erster Ordnung in $t$ um $\tau \mathrm{zu}$ approximieren:

$$
\overline{\Delta A}(v, t):=\Delta A(v, \tau)+(t-\tau) \partial_{t} \Delta A(v, \tau) .
$$

Diese Approximation ist gültig innerhalb eines Dissoziationsintervalls $\tau-\Delta t<t<\tau+\Delta t$, in $\operatorname{dem}|\overline{\Delta A}(v, t)-\Delta A(v, t)|<1 / \beta$. Um die Notation zu vereinfachen, werden wir im Folgenden die $\tau$-Abhängigkeit nicht explizit notieren, d.h. $A(v, \tau) \equiv A(v)$.

Ersetzt man $\Delta A(t)$ in Gleichung (4.14) durch $\overline{\Delta A}(t)$, kann $P_{v}(t)$ analytisch gelöst werden:

$$
P_{v}(t)=\exp \left[\frac{\omega_{0}}{\beta \partial_{t} \Delta A(v)} e^{-\beta\left[\Delta A(v)+(t-\tau) \partial_{t} \Delta A(v)\right]}\right] .
$$

Wie $\overline{\Delta A}(t)$ ist auch $P_{v}(t)$ zunächst nur im oben definierten Dissoziationsintervall gültig. Eine nähere Betrachtung von $P_{v}(t)$ zeigt jedoch, dass, falls die Kräfte $\partial_{t} A(t) / v$ gleich oder größer der kritischen Kraft $F_{c}$ sind, $P_{v}(t)$ eine stark abfallende sigmoide Funktion ist, die bereits innerhalb des Dissoziationsintervalls dem Wert eins $(t<\tau)$ und dem Wert Null $(t>\tau)$ nahekommt. In diesem Fall ist $P_{v}(t)$ eine gute Näherung für die exakte Lösung von Gleichung (4.14) für alle $t \geq 0$.

Mit der Definition von $\tau, P_{v}(\tau)=\frac{1}{2}$, spezifiziert Gleichung (4.21) die freie Aktivierungsenergie zum Dissoziationszeitpunkt $\tau$ :

$$
\beta \Delta A(v)=-\ln \frac{-\beta \partial_{t} \Delta A(v) \ln 2}{\omega_{0}} .
$$


Da wir es später benötigen werden, weisen wir darauf hin, dass aus Gleichung (4.16)

$$
\frac{d A(v)}{d v}=F(v) \frac{d \xi}{d v}
$$

folgt.

Im Folgenden werden wir das Regime harter Feder und das Regime weicher Feder separat behandeln. Im Regime harter Feder bleibt die Position des Übergangszustandes unverändert, so dass $\partial_{t} U\left(x^{*}, \tau\right)$ verschwindet. Folglich haben wir $\partial_{t} \Delta A(v)=-\partial_{t} A(v)=$ $-v F(v)$, und wir erhalten aus Gleichung (4.22)

$$
\beta\left[A(v)-U_{0}\left(x^{*}\right)\right]=\ln \frac{\beta v F(v) \ln 2}{\omega_{0}} .
$$

Verwendet man Gleichung (4.23), dann bekommt man für die Ableitung von Gleichung (4.24) nach $v$

$$
\frac{d \xi}{d v}=\frac{1}{\beta v F(v)}\left[1+\frac{v}{F(v)} \frac{d F(v)}{d v}\right] .
$$

Gleichung (4.25) kann für jedes gegebene Kraftspektrum $F(v)$ numerisch gelöst werden. Aus $\xi(v)$ und dem gegebenen $F(v)$ kann nun ein Kraftprofil $F(\langle x\rangle)$ als Funktion der mittleren Reaktionskoordinate mit $\langle x\rangle=\xi(v)-F(v) / k$ [siehe Gleichung (4.17)] bestimmt werden. Vernachlässigt man die Anharmonizität von $V_{\text {Feder }}$, so besagen die Gleichungen (4.12) und (4.16), dass das rekonstruierte Kraftprofil eine Faltung des wahren Kraftprofils $F(x)$ mit einer Gaussfunktion der Breite $1 /(\beta k)^{1 / 2}$ ist.

Im Regime weicher Feder sind im Allgemeinen weder $x^{*}$ noch $U\left(x^{*}, \tau\right)$ konstant. Wenn man $Z_{b}$ aus Gleichung (4.12) verwendet, bekommen wir, falls $t>x^{*} / v$, für die Zeitableitung in Gleichung (4.22),

$$
\partial_{t} \Delta A(v)=k v \Delta x(v)+\left[k\left(\xi-x^{*}\right)-\partial_{x} U_{0}\left(x^{*}\right)\right] \partial_{t} x^{*}
$$

wobei

$$
\Delta x(v):=x^{*}-\langle x\rangle \quad .
$$

Da $U\left(x^{*}\right)$ definitionsgemäß ein Maximum ist, erhält man unter der Annahme, dass $U_{0}(x)$ stetig differenzierbar und endlich für große $x$ ist

$$
\partial_{x} U\left(x^{*}\right)=\partial_{x} U_{0}\left(x^{*}\right)-F(v)+k \Delta x(v)=0 .
$$

Somit verschwindet wegen Gleichung (4.17) der zweite Term in Gleichung (4.26), so dass aus Gleichung (4.22) folgt:

$$
\beta\left[A(v)-U_{0}\left(x^{*}\right)\right]-\frac{k \beta}{2}\left[\Delta x-\frac{F(v)}{k}\right]^{2}=\ln \frac{\beta k v \Delta x}{\omega_{0}} .
$$

In Analogie zum Regime harter Feder ordnet auch hier die Ableitung von Gleichung (4.29) nach $v$ dem Kraftspektrum $F(v)$ eine räumlichen Koordinate zu: im Regime harter Feder $\xi$, hier $\Delta x(v)$ :

$$
\beta \Delta x(v)\left[k \frac{d\langle x\rangle}{d v}+\frac{d F(v)}{d v}\right]=\frac{1}{v}+\frac{1}{\Delta x} \frac{d \Delta x}{d v},
$$


wobei die Gleichungen (4.23) und (4.28) verwendet wurden.

Um aus Gleichung (4.30) ein Kraftprofil als Funktion der Reaktionskoordinate $x$ abzuleiten, muss $\langle x\rangle$ als Funktion von $F(v)$ ausgedrückt werden. Dazu können Experimente innerhalb des Regimes harter Feder ausgenutzt werden, da hier jedem $F(v)$ ein $\langle x\rangle$ zugeordnet wird. Stehen solche Daten nicht zur Verfügung, kann $U(x)$ in der Umgebung des gebundenen Zustands harmonisch genähert werden, d.h. $\langle x\rangle(v)=F(v) / k_{0}$ mit $k_{0}$ wie oben definiert. Für letzteren Fall kann Gleichung (4.25) analytisch gelöst werden:

$$
\Delta x(v)=\left[v \eta \beta \int_{v}^{\infty} d v^{\prime} \frac{1}{v^{\prime}} \frac{d F\left(v^{\prime}\right)}{d v^{\prime}}\right]^{-1},
$$

wobei $\eta:=1+k / k_{0}$. Das Integral in Gleichung (4.31) konvergiert, wenn $F(v)$ ein Polynom in $\ln v$ ist. Wenn die Krümmung von $F(v) \equiv \tilde{F}(\nu)$ auf einer logarithmischen Skala der Zuggeschwindigkeit $\nu=\ln v / v_{0}$ klein ist, d.h. $d^{2} \tilde{F}(\nu) / d \nu^{2} \ll d \tilde{F}(\nu) / d \nu$, reduziert sich Gleichung (4.31) zu

$$
\Delta x(v)=\left[\eta \beta \frac{d \tilde{F}(\nu)}{d \nu}\right]^{-1},
$$

was für den Grenzfall $k \rightarrow 0$ das Resultat des Zwei-Zustands-Modells liefert, das in Ref. [88] abgeleitet und in Ref. [83] verwendet wurde.

Die Gleichungen (4.25) und (4.31) sind das Hauptresultat unserer Theorie. Sie erlauben es, aus einem gegebenen Kraftspektrum ein Kraftprofil zu berechnen. Durch Integration des Kraftprofils über die Reaktionskoordinate erhält man die gewünschte Energielandschaft.

\subsubsection{Testrechnungen}

Wir wollen zunächst illustrieren, wie für ein vorgegebenes Kraftprofil (Abbildung 4.3, oben) die Kraftspektren für unterschiedliche Federkonstanten im Regime weicher Feder (links) und im Regime harter Feder (rechts) aussehen. Dabei überprüfen wir gleichzeitig die Gültigkeit der Gleichungen (4.29) (weiche Feder) und (4.24) (harte Feder), indem wir die über sie berechneten Kraftspektren (durchgezogene dünne Linien) mit numerischen Lösungen der Ausgangsgleichungen (4.14) und (4.15) (Punkte), in die noch keine Näherungen eingehen, vergleichen.

Bevor wir auf den Vergleich von analytischen und numerischen Resulten kommen, wollen wir den Verlauf der Kraftspektren diskutieren. Für das Regime harter Feder (Abbildung 4.3, rechts) zeigen die Kraftspektren mit wachsender Federkonstante zunehmend ausgeprägte Plateaus. Wie es zu diesen Plateaus kommt, sei anhand der weiter oben gezeigten Abbildung 4.2 illustriert: Die links in der Energielandschaft (oben) und dem aus ihr abgeleiteten Kraftprofil (unten) skizzierte Situation beschreibt den Fall einer kleinen Zuggeschwindigkeit, in dem aktivierte Prozesse bereits zur Dissoziation des RezeptorLigand-Komplexes führen, als das Zugpotenzial $V_{\text {Feder }}$ erst ein kleines Stück entlang der Reaktionskoordinate verschoben wurde. Für eine solche Zuggeschwindigkeit wurde demzufolge erst ein kleiner Teil der Energielandschaft für $x>0$ rechts vom Minimum abgetastet, bis die Komplexe des Ensembles dissoziieren; die über ein Ensemble aus Einzelmolekülmessungen gemittelte Dissoziationskraft entspricht der maximalen Steigung der bis 

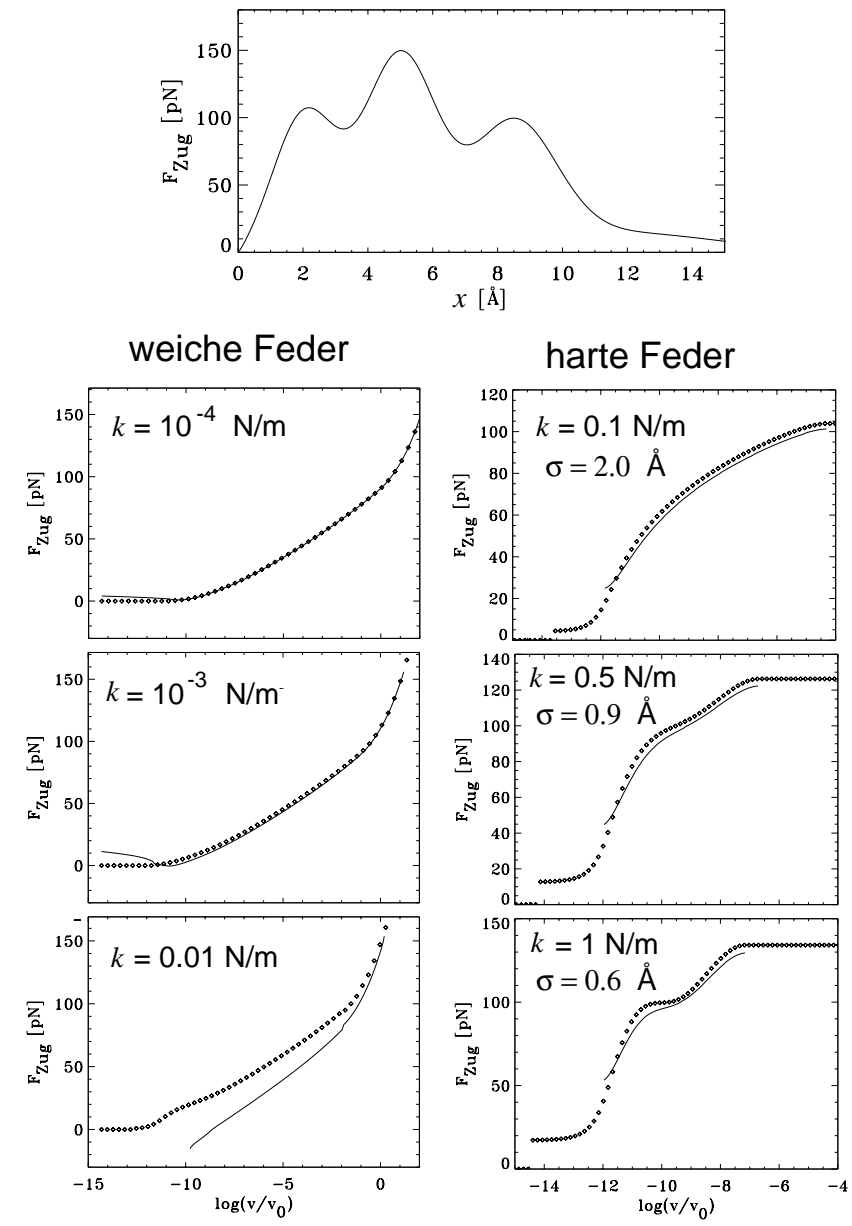

Abbildung 4.3: Oben: Gegebenes Kraftprofil, für das Kraftspektren zum Vergleich numerisch und analytisch nach den Gleichungen (4.29) und (4.24) abgeleitet wurden. Darunter: Kraftspektren für Federn mit kleiner Federkonstante $k$ (links) und für Federn mit größerer Federkonstante (rechts). Die durchgezogegenen Linien markieren die analytischen Resultate, die Punkte die numerische Lösung von Gleichungen (4.14) und (4.15). Zur weiteren Erklärung siehe Text.

hierhin abgetasteten Energielandschaft [Gleichung (4.15)]. Bei höheren Zuggeschwindigkeiten steht aktivierten Prozessen dagegen weniger Zeit zur Verfügung, um die Aktivierungsbarriere zu erniedrigen, so dass das Zugpotenzial weiter in Zugrichtung verschoben werden muss, bis es zur Dissoziation kommt; entsprechend wird hier ein größerer Teil der Energielandschaft abgetastet. Die mittlere Dissoziationskraft wächst mit zunehmender Zuggeschwindigkeit jedoch erst dann wieder an, wenn die Steigung in der Energielandschaft an der Stelle des Dissoziationspunktes die maximale Steigung des bereits bei kleineren Zuggeschwindigkeiten abgetasteten Teils der Energielandschaft übertrifft. Auf das Kraftprofil (Abbildung 4.2, unten) übertragen heißt das, dass der Verlauf des Kraftspektrums erst wieder ansteigt, wenn der Punkt erreicht ist, an dem die Kraft das bisherige lokale Maximum übersteigt. Die Plateaus im Kraftspektrum lassen sich somit den Maxima des Kraftprofils zuordnen. Lokale Maxima, die höheren Maxima (etwa dem globalen Maximum des Kraftprofils) folgen, spiegeln sich nicht im Kraftspektrum wider. So sind 
in dem in Abbildung 4.3 rechts unten gezeigten Kraftspektrum lediglich zwei Plateaus zu sehen, die den ersten beiden Maxima des Kraftprofils entsprechen, wohingegen das dritte (niedrigere) Maximum keinen Einfluss auf das Kraftspektrum hatte.

Desweiteren ist aus Abbildung 4.3 (rechts) erkennbar, dass die Kraftspektren für das Regime harter Feder um so strukturierter sind, je härter die Feder ist. Der Grund dafür ist, dass, wie weiter oben schon erwähnt, die Kraftspektren die Eigenschaften des mit $1 /(\beta k)^{1 / 2}$ geglätteten Kraftprofils widerspiegeln. Eine weichere Feder entspricht mithin einer stärkeren Glättung des Kraftprofils, wodurch Strukturinformation verloren geht. Die für das Regime harter Feder gewählten Federkonstanten von $k=0.1 \mathrm{~N} / \mathrm{m}, k=0.5 \mathrm{~N} / \mathrm{m}$ und $k=1 \mathrm{~N} / \mathrm{m}$ entsprechen Glättungsbreiten von $\sigma=2.0 \AA, \sigma=0.9 \AA$ bzw. $\sigma=0.6 \AA$.

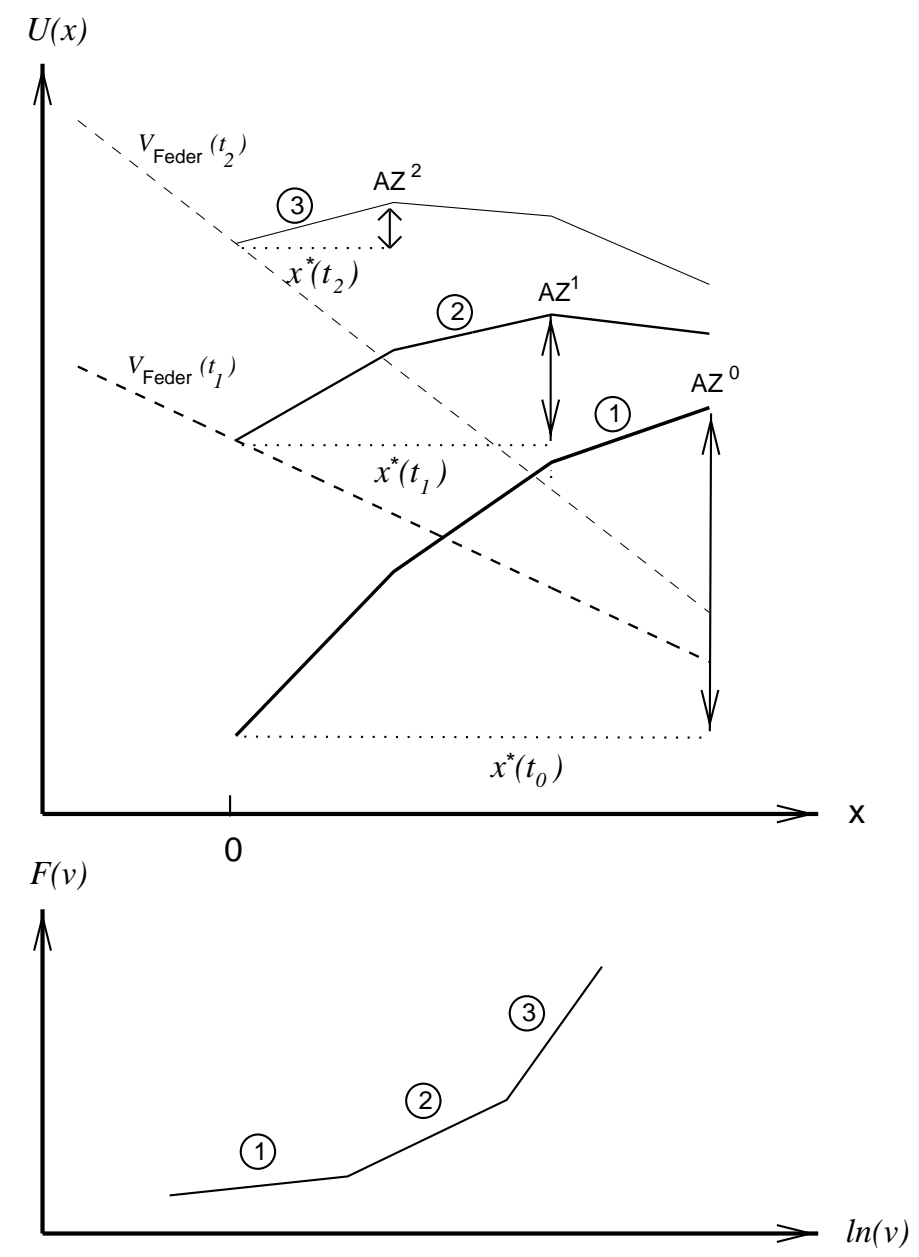

Abbildung 4.4: Wirkungsweise eines weichen Zugpotenzials. Oben: Die fett gezeichnete, ungestörte (hypothetische) Energielandschaft $U_{0}$ wird durch die Zugpotenziale $V_{\text {Feder }}\left(t_{1}\right)$ und $V_{\text {Feder }}\left(t_{2}\right)$ (gestrichelte Linien) modifiziert. Mit wachsendem Zugpotenzial wird der aktivierte Zustand AZ zu einem kleineren $x^{*}$ (d.h. nach links) verschoben. Unten: Kraftspektrum. Die mit Zahlen gekennzeichneten Bereiche können jeweils entsprechenden Abschnitten in der Energielandschaft zugeordnet werden.

Der Verlauf der Kraftspektren für das Regime weicher Feder ist qualitativ ein ganz anderer; für sein Verständnis sind zunächst einige Vorübelegungen nötig: Abbildung 4.4 (oben) 
zeigt eine hypothetische Energielandschaft, deren ungestörter Verlauf durch die fette Linie gekennzeichnet ist. Fügt man zu der ungestörten Energielandschaft ein weiches Zugpotenzial, das auf der Skala der Dissoziationslänge nahezu linear verläuft (gestrichelte Linien), hinzu, wird dadurch - im Unterschied zu einem harten Zugpozenzial — die gesamte Energielandschaft auf ein höheres Niveau gehoben (dünne durchgezogene Linien). Da das Zugpotenzial von links nach rechts abnimmt, wird die Energielandschaft in der Nähe des gebundenen Zustands bei $x=0$ stärker angehoben als in der Umgebung des aktivierten Zustands AZ an der Stelle $x^{*}>0$. Dies bedeutest, dass, sobald das Zugpotenzial die (negative) Steigung in der Nachbarschaft links vom aktivierten Zustand übertrifft, der aktivierte Zustand nach links verschoben wird, wodurch sich die effektive Dissoziationslänge $x^{*}(t)$ und demzufolge auch $\Delta x$ [siehe Gleichung (4.27)] verringert. Dies ist in der Abbildung im oberen Bild anhand der mittleren Kurve gezeigt, die aus der Summe der ungestörten Energielandschaft mit dem Zugpotenzial $V_{\text {Feder }}\left(t_{1}\right)$ (fette gestrichelte Linie) resultiert, und bei der sich der aktivierte Zustand $\mathrm{AZ}^{1}$ nunmehr bei $x^{*}\left(t_{1}\right)<x^{*}\left(t_{0}\right)$ befindet [entsprechend gilt $\Delta x\left(t_{1}\right)<\Delta x\left(t_{0}\right)$ ], sowie anhand der oberen Kurve (hier wirkt das Zugpotenzial $V_{\text {Feder }}\left(t_{2}\right)$, dünne gestrichelte Linie) mit dem aktivierten Zustand $\mathrm{AZ}^{2}$ an der Stelle $x^{*}\left(t_{2}\right)<x^{*}\left(t_{1}\right)$ [entsprechend $\Delta x\left(t_{2}\right)<\Delta x\left(t_{1}\right)$ ]. Da nach Gleichung (4.32) die Steigung im Kraftspektrum umgekehrt proportional zu $\Delta x$ ist, spiegelt sich eine Verringerung der effektiven Dissoziationslänge $x^{*}$ in einer höheren Steigung im Kraftspektrum wider. Somit wird der Verlauf des Kraftspektrums von der Position $x^{*}$ des aktivierten Zustands AZ bestimmt, die ihrerseits aus der Steigung der effektiven Energielandschaft links vom jeweiligen aktivierten Zustand resultiert. So werden in unserem Beispiel die jeweils links vom aktivierten Zustand befindlichen Abschnitte (1), (2) und (3) der Energielandschaft auf die entsprechenden Abschnitte im Kraftspektrum abgebildet.

Wie man erkennt, wird also hier - im Unterschied zu einer harten Feder — die Energielandschaft von rechts nach links gleichsam abgetastet, da jeweils der unmittelbar links neben dem aktivierten Zustand befindliche Teil der Energielandschaft für die Steigung im Kraftspektrum bestimmend ist.

Der Vergleich von analytischer und numerischer Berechnung der Kraftspektren (Abbildung 4.3, Punkte und durchgezogene Linien) zeigt in den meisten Fällen eine gute Übereinstimmung. Mit zunehmender Federkonstante wird die Abweichung bei niedrigen Kräften größer, was insbesondere in dem Kraftspektrum mit $k=0.01 \mathrm{~N} / \mathrm{m}$ (links unten) erkennbar ist. Der Grund hierfür ist, dass die kritische Kraft $F_{c}$ [Gleichungen (4.18) und (4.19)], unterhalb derer die Näherungen in Gleichung (4.17) ungenau werden, mit zunehmender Federkonstante ansteigt. Für die im Regime weicher Feder verwendeten Federkonstanten $10^{-4} \mathrm{~N} / \mathrm{m}, 10^{-3} \mathrm{~N} / \mathrm{m}$ und $10^{-2} \mathrm{~N} / \mathrm{m}$ beträgt $F_{c}$ etwa $0.8 \mathrm{pN}, 8 \mathrm{pN}$ bzw. $80 \mathrm{pN}$; für die im Regime harter Feder verwendeten Federkonstanten $0.1 \mathrm{~N} / \mathrm{m}, 0.5 \mathrm{~N} / \mathrm{m}$ und $100 \mathrm{~N} / \mathrm{m}$ ergibt sich für $F_{c} 20 \mathrm{pN}, 46 \mathrm{pN}$ bzw. $64 \mathrm{pN}$.

Der Vergleich von analytischer und numerischer Behandlung zeigt insbesondere, dass die beiden Regimes recht gut aneinander grenzen, d.h., dass die obere Grenze für die Federkonstante im Regime weicher Feder in der Nähe der unteren Grenze für die Federkonstante im Regime harter Feder liegt und die Theorie somit für alle Federkonstanten gut anwendbar ist.

Das eigentliche Ziel unserer Theorie war die Rekonstruktion von Kraftprofilen auf Grund- 

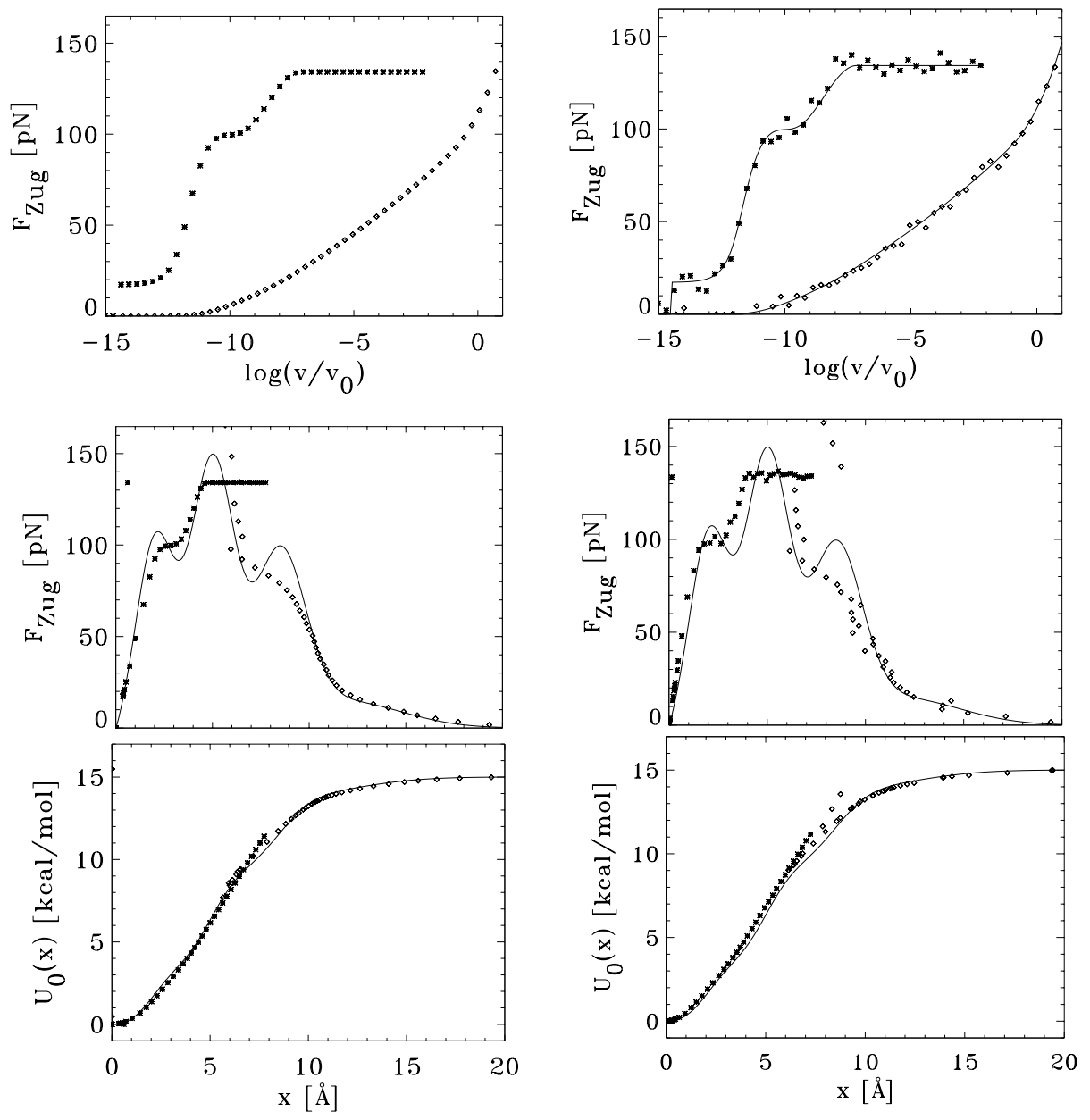

Abbildung 4.5: Rekonstruktion von Kraftprofil und Energielandschaft aus zwei Kraftspektren. Oben: Aus einem vorgegebenen Kraftprofil wurde numerisch ein Spektrum abgeleitet (durchgezogene Linien), zu dem Rauschen addiert wurde [Karos für die weiche Feder $(k=0.001 \mathrm{~N} / \mathrm{m})$ und Sterne für die harte Feder $(k=1 \mathrm{~N} / \mathrm{m})$ ]. Aus den verrauschten Spektren rekonstruiertes Kraftprofil (Mitte) und daraus abgeleitete Energielandschaft (unten).

lage von Kraftspektren vermittels der beiden Gleichungen (4.25) und (4.31). Um zu überprüfen, ob die Theorie dies leisten kann, haben wir zwei der in Abbildung 4.3 gezeigten numerisch bestimmten Kraftspektren als "gemessene“ Kraftspektren aufgefasst und geprüft, wie genau sich daraus ohne zusätzliche Informationen das ursprüngliche Kraftprofil rekonstruieren lässt. Wie in Abbildung 4.5 (links oben) gezeigt, haben wir dazu aus den Kraftspektren mit den Federkonstanten $k=1 \mathrm{~N} / \mathrm{m}$ und $k=0.001 \mathrm{~N} / \mathrm{m}$ jeweils 50 äquidistante Datenpunkte (Sterne bzw. Karos) extrahiert. Um eine typische experimentelle Ungenauigkeit zu modellieren, haben wir zusätzlich zu jedem Datenpunkt der numerisch bestimmten Kraftspektren eine gaußverteilte Zufahlszahl mit einer Halbwertsbreite von $\sigma=12 \mathrm{pN}$ (entsprechend einem Messfehler von $10 \%$ ) addiert (rechts oben in der Abbildung). Die durchgezogenen Linien kennzeichnen hier die unverrauschten numerisch berechneten Kraftspektren (wie in der Abbildung links oben), die Sterne bzw. Karos die entsprechend verrauschten Kraftspektren. Die mittleren Bilder zeigen die aus 
den unverrauschten (links) und verrauschten (rechts) Kraftspektren rekonstruierten Kraftprofile, die unteren die Energielandschaften, die durch Integration der Kraftprofile über die Reaktionskoordinate gewonnen wurden. Die Sterne repräsentieren dabei die Punkte, die von dem Kraftspektrum aus dem Regime harter Feder herrühren, die Karos resultieren aus dem Kraftspektrum aus dem Regime weicher Feder. Die durchgezogenen Linien kennzeichnen hier das vorgegebene, ursprüngliche Kraftprofil bzw. die daraus abgeleitete Energielandschaft.

Zunächst ist erkennbar, dass aus den unverrauschten Kraftspektren (links) wesentliche Merkmale des ursprünglichen Kraftprofils rekonstruiert weden konnten. Analoges gilt für die Energielandschaft, deren Rekonstruktion nur geringe Abweichungen von der originalen Energielandschaft aufweist. Die rechte Seite der Abbildung zeigt, dass auch eine typische Messungenauigkeit die Rekonstruktion von Kraftprofil und Energielandschaft im Vergleich zum unverrauschten Kraftspektrum nicht wesentlich beeinträchtigen sollte. Mit einem Messfehler von $20 \%$ war eine Rekonstruktion nicht mehr möglich.

Darüber hinaus zeigen die Rekonstruktionen, wie weiche und harte Federn in der Tat komplementär zueinander wirken: Mit einer harten Feder konnte der Abschnitt links vom globalen Maximum im Kraftprofil rekonstruiert werden, mit einer weichen Feder der Abschnitt rechts vom globalen Maximum.

Bei Verwendung einer harten Feder werden gerade diejenigen Abschnitte des Kraftprofils gut wiedergegeben, bei denen die Steigung nicht negativ ist. Dagegen können Bereiche, die unmittelbar den Maxima im Kraftprofil folgen und somit eine negative Steigung aufweisen, nicht aufgelöst werden. Dies liegt darin begründet, dass erstens der Verlauf der Kraftspektren (abgesehen vom Rauschen) jeweils monoton wächst und zweitens zwei Datenpunkte an den Stellen $v_{2}>v_{1}$ im Kraftspektrum den Reaktionskoordinaten $x_{2} \geq x_{1}$ zugeordnet werden. Dies hat zur Folge, dass mit einer harten Feder die Struktur des Kraftprofils rechts vom globalen Maximum nicht aufgelöst werden kann.

Mit einer weichen Feder dagegen werden diejenigen Abschnitte der Energielandschaft (unteres Bild) gut wiedergegeben, die mit ihrer konvexen Hülle zusammenfallen. Abweichungen von der konvexen Hülle, wie sie in unserem Beispiel etwa in Form der „Delle" bei der Reaktionskoordinate $x$ zwischen 6.5 und $9 \AA$ vorkommt, können nicht erfasst werden. Für das Kraftprofil (mittleres Bild) bedeutet dies, dass die Umgebung der Maxima nicht exakt rekonstruiert werden kann, wie es im Bereich zwischen 6.5 und $9 \AA$ um das lokale Maximum bei $x \approx 8.5 \AA \mathrm{zu}$ sehen ist.

Dieser Test zeigt, dass es in der Tat möglich sein sollte, aus Kraftspektren, die mit verschiedenen Federkonstanten gemessen werden, viele Details aus Kraftprofilen und Energielandschaften von Rezeptor-Ligand-Bindungen zu rekonstruieren. Die Rekonstruktion wird um so vollständiger, je größer der Bereich der Zuggeschwindigkeiten ist, mit denen die forcierte Dissoziation erfolgt, und um so genauer, je niedriger die Federkonstante der weichen Feder und je höher die der harten Feder ist. Dabei gibt es eine weitgehende Komplementarität zwischen weicher und harter Feder. Da es in den meisten kraftinduzierenden Einzelmolekülexperimenten gegenwärtig nicht möglich ist, sowohl mit einer weichen als auch mit einer harten Feder zu messen, erscheint es sinnvoll, verschiedene Experimente zu kombinieren, etwa BFP-Experimente, in denen sehr weiche Federn verwendet werden, und kraftmikroskopische Experimente, bei denen eher härtere Federn eingesetzt werden. 


\section{Kapitel 5}

\section{Simulation der forcierten Dissoziation des AN02-DNP-Hapten-Komplexes}

In diesem Kapitel untersuchen wir den forcierten Dissoziationsprozess des AN02-DNPHapten-Komplexes. Nach einer kurzen Beschreibung des Aufbaus von Antikörpern und der aus Experimenten bekannten Eigenschaften des hier betrachteten Antikörper-DNPHapten-Komplexes entwickeln wir das Simulationsmodell. Dies beinhaltet die Konstruktion einer geeigneten Lösungsmittelumgebung sowie Minimierung und Equilibrierung des Komplexes. Sodann beschreiben und diskutieren wir die Dissoziationssimulationen. Wir konzentrieren uns dabei auf Dissoziationskräfte, Wechselwirkungsenergien während des Dissoziationsprozesses und den strukturellen Verlauf der Dissoziation. Insbesondere analysieren wir den Dissoziationspfad, auf dem sich das Haptenmolekül in den Simulationen aus der Bindungstasche herausbewegte, die Reaktion der AN02-Bindungstasche auf diese Bewegung sowie die Wechselwirkungen zwischen dem Haptenmolekül und den Aminosäuren der Bindungstasche während des Dissoziationsprozesses. Wir richten dabei besonderes Augenmerk auf die Frage, ob es nur einen ausgezeichneten Dissoziationspfad und damit eine eindeutige Folge von Wechselwirkungen im Verlauf des Dissoziationsprozesses gibt, oder ob eine ganze Reihe unterschiedlicher Pfade und Wechselwirkungsfolgen zu beobachten ist. Schließlich untersuchen wir den Einfluss einzelner Aminosäuren der Bindungstasche auf den Dissoziationsprozess, indem wir Dissoziationssimulationen zu zwei Mutanten von AN02 durchgeführt haben. 


\subsection{Der AN02-DNP-Hapten-Komplex}

Wie in Abbildung 5.1 schematisch gezeigt, bestehen Antikörper (Immunoglobuline) aus zwei identischen schweren Ketten (mit jeweils etwa 440 Aminosäuren) und zwei identischen leichten Ketten (etwa 220 Aminosäuren), die sich Y-förmig zusammenlagern¹. Die schweren Ketten untergliedern sich in eine variable (V) und drei (manchmal auch vier) konstante $(\mathrm{C})$ Domänen, während leichte Ketten je eine variable und eine konstante Domäne aufweisen. Die beiden Antigen bindenden $\mathrm{F}_{\mathrm{ab}}$-Fragmente sind aus den variablen Domänen $\mathrm{V}_{\mathrm{L}}$ und $\mathrm{V}_{\mathrm{H}}$ sowie der konstanten Domäne $\mathrm{C}_{\mathrm{L}}$ der leichten und der ersten konstanten Domänen $\mathrm{C}_{\mathrm{H}_{1}}$ der schweren Kette aufgebaut.

\section{Antikörper-Antigen-Komplex}

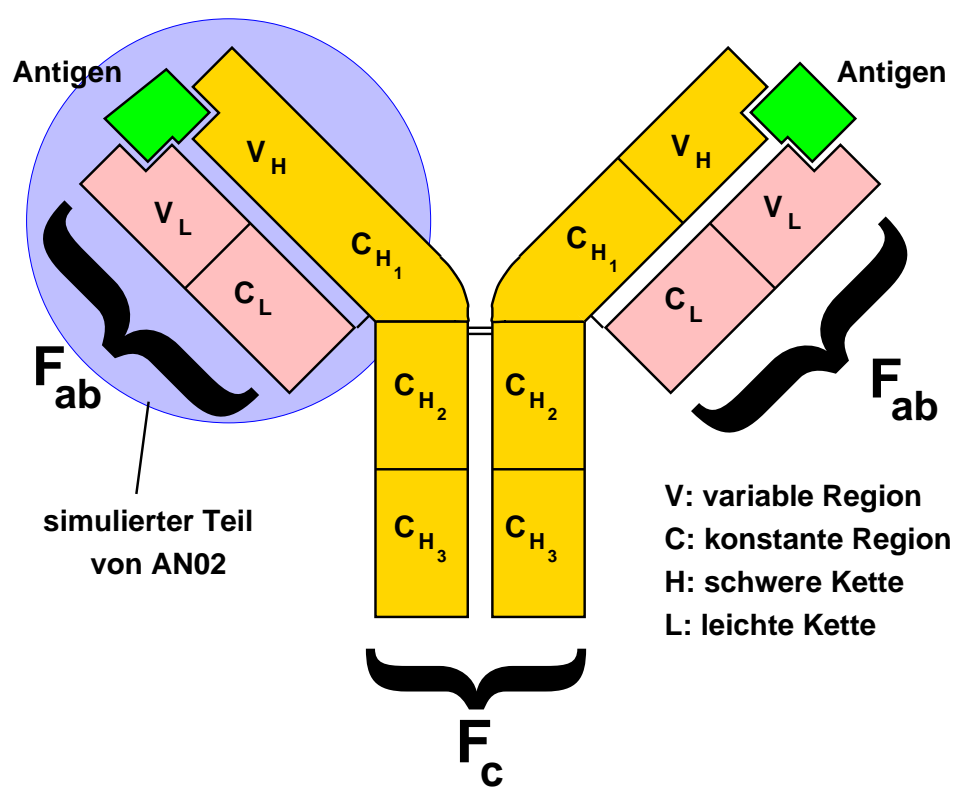

Abbildung 5.1: Schematische Darstellung eines Antikörpers mit konstantem Fragment $\left(\mathrm{F}_{\mathrm{c}}\right)$ und Antigen bindenden Fragmenten $\left(\mathrm{F}_{\mathrm{ab}}\right)$. Die beiden schweren Ketten befinden sich innen (mit $\mathrm{H}$ indiziert), die beiden leichten Ketten außen (mit L indiziert).

Bei der schweren Kette unterscheidet man zwischen den Klassen $\alpha, \gamma, \mu$ und $\epsilon$ (entsprechend unterteilt man in die A-, G-, M- und E-Immunoglobuline), bei der leichten Kette zwischen den Klassen $\kappa$ und $\lambda$ [189]. Die einzelnen Klassen zeichnen sich in erster Linie durch ihre unterschiedlichen charakteristischen Sequenzen, teilweise auch durch geringfügig unterschiedliche Längen aus.

Der in der vorliegenden Arbeit untersuchte monoklonale Antikörper AN02 ist Mitglied einer Familie aus 12 monoklonalen Antikörpern, AN01 - AN12 [79], die alle G-Immunoglobuline sind und gegen ein Spin-markiertes Dinitrophenyl (DNP) - Hapten ${ }^{2}$ gerichtet

\footnotetext{
${ }^{1} \mathrm{Im}$ folgenden wird die Zugehörigkeit von Aminosäuren zur leichten Kette mit (L) und zur schweren Kette mit (H) gekennzeichnet. TYR31(L) etwa bezeichnet Tyrosin 31 der leichten Kette.

${ }^{2}$ Als Haptene werden diejenigen Teile von Antigenen bezeichnet, die deren so genannten Determinanten
} 
sind, wobei ein 2,2,6,6-Tetramethyl-1-piperindinyoxy-(TEMPO)-Ring als Spinmarkierung fungiert [78] (siehe auch weiter unten die Abbildungen 5.2 und 5.4). AN02 ist aus schweren Ketten der Subklasse $\gamma_{1}$ und leichten Ketten der Klasse $\kappa$ aufgebaut, ähnlich dem gegen Lysozym gerichteten Antikörper HyHel-5 der Maus [191].

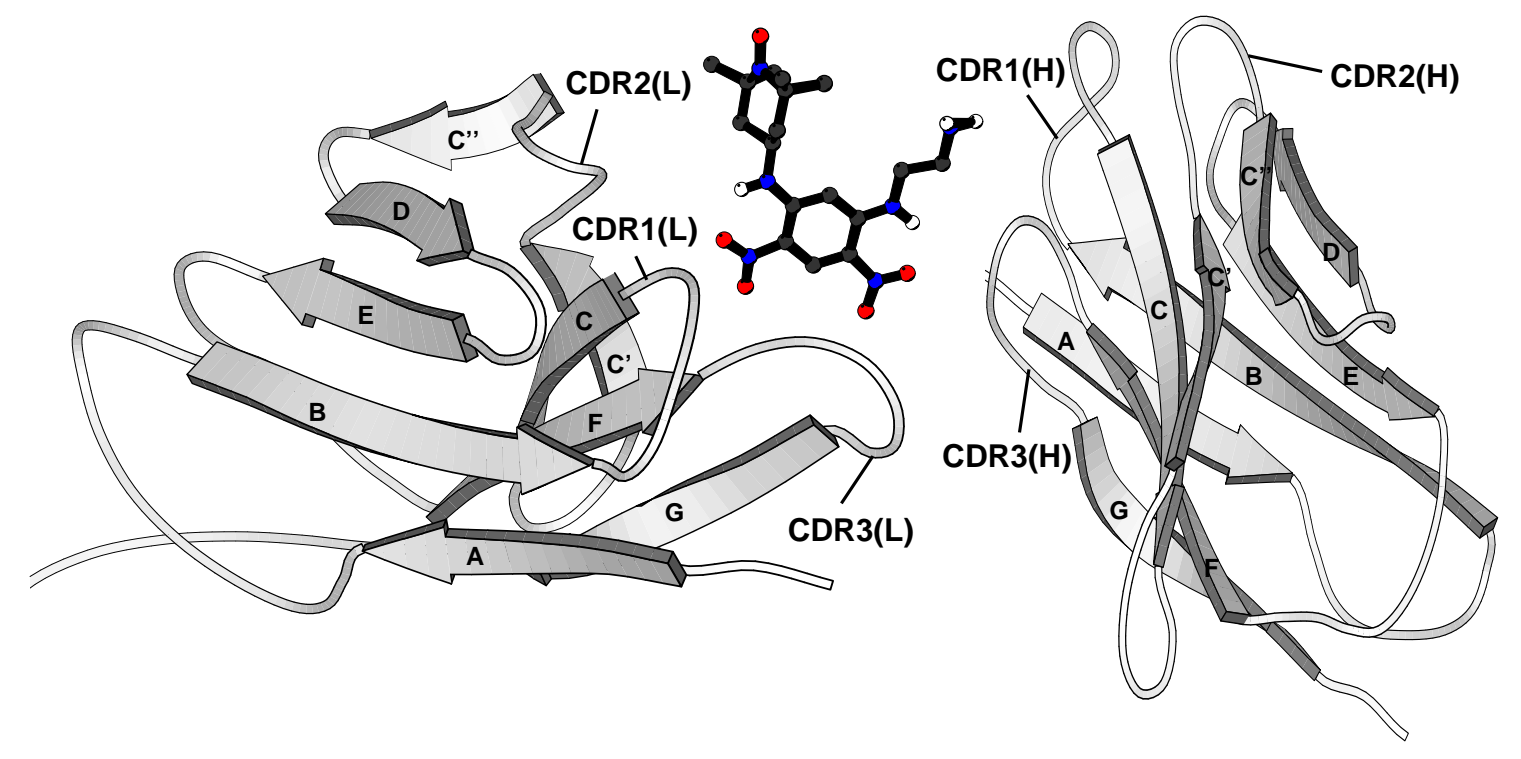

Abbildung 5.2: Bänderdarstellung der variablen Domänen der leichten Kette (links) und der schweren Kette (rechts) von AN02 mit gebundenem DNP-Hapten (Kugel-StrichZeichnung). Markiert sind die „Komplementarität bestimmenden Regionen (CDR's)“, die von besonderer Bedeutung für die Bindung sind.

Wie in Abbildung 5.1 gezeigt, umfasst unser Simulationsmodell ein $\mathrm{F}_{\mathrm{ab}}$-Fragment von AN02 mit gebundenem Hapten. Wie bei allen Antikörpern weisen die variablen und konstanten Domänen das $\mathrm{F}_{\mathrm{ab}}$-Fragments von AN02 eine charakteristische Faltung auf (siehe auch Ref. [192] und dortige Referenzen). Abbildung 5.2 zeigt die Faltung der variablen Regionen in „Bänderdarstellung“: Jede der beiden gezeigten Domänen ist aus zwei antiparallelen $\beta$-Faltblättern aufgebaut, die über eine allen Antikörpern gemeinsame Topologie von Schleifen miteinander verbunden sind [189]. Die konstante Kette besteht aus sieben $\beta$-Strängen $(\mathrm{A}-\mathrm{G}$ ), die variable Kette aus neun $\beta$-Strängen (zusätzlich C' und C"). Die Schleifen zwischen B und C, C' und C" sowie F und G werden wegen ihrer hohen Sequenzvariabilität als hypervariable Schleifen bezeichnet und bilden die so genannten Komplementarität bestimmenden Regionen CDR1, CDR2 und CDR3 (CDR steht für complementarity determinig region), die bei der Bindung des Antigens eine zentrale Rolle spielen. (Für AN02 sind die CDR's zusammen mit der Sequenz des $\mathrm{F}_{\mathrm{ab}}$-Fragments in Anhang A angegeben.) Trotz der hohen Sequenzvariabilität unterscheiden sich die hypervariablen Schleifen der leichten und der schweren Kette in ihren Faltungsmustern in verschiedenen Antikörpern nur geringfügig und sind im wesentlichen immer an derselben Stelle der Oberfläche von Immunoglobulinen lokalisiert.

Die paramagnetischen Eigenschaften des Spin-markierten DNP-Haptens erlaubten es,

bestimmen, an die die passenden Antikörper spezifisch binden. Ein Antigen kann mehrere unterschiedliche Haptene aufweisen [190]. 
die Eigenschaften der Bindungstasche mit Methoden der Kernspinresonanzspektroskopie (NMR) zu untersuchen [193-195]. Insbesondere konnte aufgeklärt werden, wie die einzelnen Residuen zur Bindung des Haptens beitragen und wie sich die vor allem in den hypervariablen Schleifen geringfügig unterschiedlichen Sequenzen der monoklonalen Antikörper AN01 - AN12 auf die Bindung auswirken. NMR-Experimente an selektiv deuteriertem AN02 belegten einen hohen Tyrosingehalt in der Bindungstaschenregion [196], wie es bei Antikörpern oft der Fall ist (Tyrosin ist die in der Bindungstaschenregion von Antikörpern am häufigsten vorkommende Aminosäure in der schweren Kette und nach Serin die zweithäufigste in der leichten Kette [197]). Weiter konnte gezeigt werden, dass das gebundene Hapten in direkten Kontakt mit mindestens zwei Tryptophan-Seitengruppen tritt. Dieser Befund wurde schließlich bestätigt durch die Struktur des kristallisierten AN02- $\mathrm{F}_{\mathrm{ab}}$-Fragments mit gebundenem DNP-Hapten [79], die mittels der Röntgenstrukturanalyse mit einer Auflösung von $2.9 \AA$ aufgeklärt wurde (Eintrag 1BAF in der Brookhaven Protein Data Bank) [191].

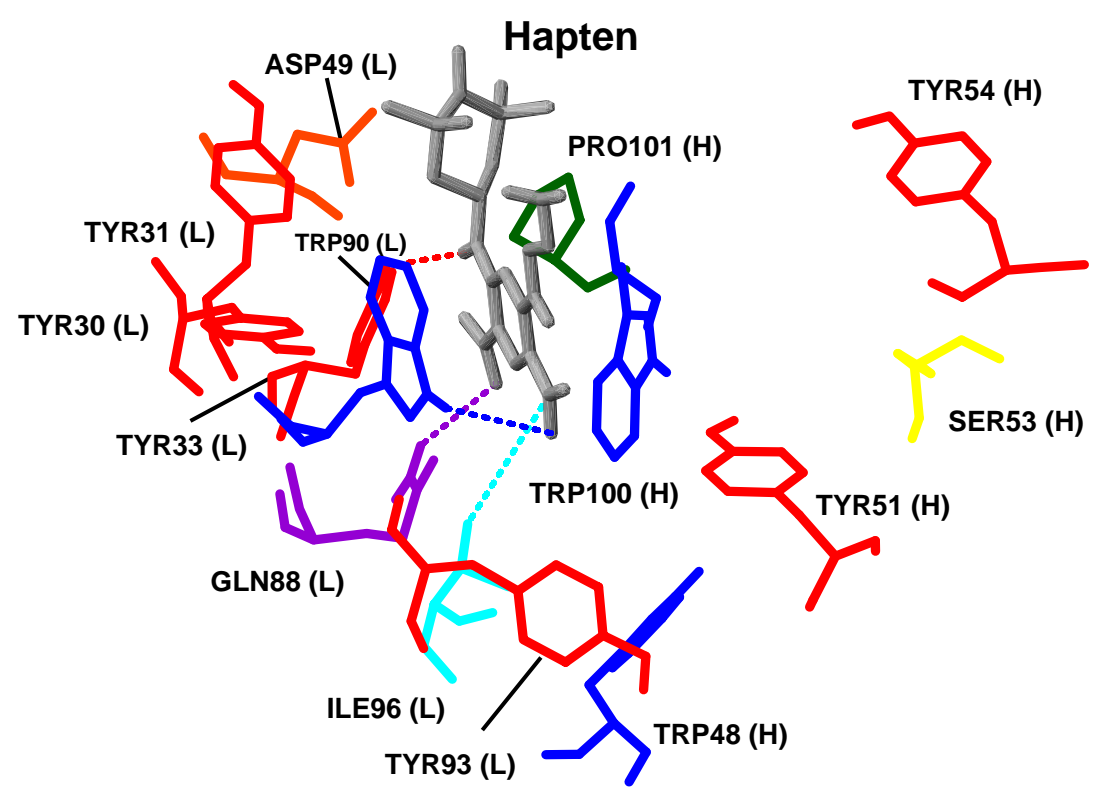

Abbildung 5.3: Aminosäuren der Bindungstasche des AN02-Antikörpers [191] mit gebundenem DNP-Hapten. Kurzreichweitige bindende Wechselwirkungen wie Wasserstoffbrücken und Van der Waals-Kontakte zwischen Aminosäuren der Bindungstasche und Hapten sind gestrichelt eingezeichnet.

Abbildung 5.3 zeigt die Struktur der Bindungtaschenregion von AN02 mit gebundenem Hapten. Die auf Grund der Röntgenstruktur erwarteten Wechselwirkungen (Wasserstoffbrücken und Van der Waals-Kontakte) zwischen Hapten und einzelnen Residuen der Bindungstasche [191] sind gestrichelt eingezeichnet. Deutlich zu erkennen ist, dass das Haptenmolekül wie in einem Sandwich zwischen den Seitenketten von TRP90(L) und TRP100(H) liegt, wobei der DNP-Ring des Haptens in Deckung mit dem 5-Ring von TRP100(H) ist und zwischen dem 5-Ring und dem 6-Ring von TRP90(L) liegt. Die- 
se Konfiguration wird stabilisiert durch Wasserstoffbrücken zwischen dem Sauerstoff in der Seitenkette von TYR33(L) und dem Stickstoff N8 im Hapten-Mittelteil ${ }^{3}$ (oberste gestrichelte Linie), zwischen dem Stickstoff in der Seitenkette von GLN88(L) und dem Sauerstoff O27 der zweiten Nitrogruppe des Haptens sowie zwischen dem Stickstoff im 5-Ring von TRP90(L) und dem Sauerstoff O24 der ersten Nitrogruppe des Hapten-DNPRings. Desweiteren gibt es starke Van der Waals-Kontakte zwischen dem aromatischen Ring von TYR33(L) mit der zweiten Nitrogruppe (N26,O27,O28) des DNP-Rings sowie mit der Seitenkette von ILE96(L) zu der ersten Nitrogruppe (N23,O24,O25) des DNPRings. Weitere auffällige Eigenschaften sind, dass die Seitenketten-Sauerstoffatome von ASP49(L) zur Mitte des TEMPO-Rings von Hapten gerichtet sind und dass der aromatische Ring von TYR30(L) im senkrechtem Kontakt mit dem 5-Ring von TRP90(L) steht. Die Autoren von Ref. [191] weisen allerdings darauf hin, dass im Kristall einige Residuen der Bindungstasche in Kontakt mit Residuen von Molekülen in benachbarten Zellen des Kristallgitters seien, was zu Unterschieden zwischen den Strukturen der Bindungstasche im Kristall und in Lösung führen könne. Dies gelte insbesondere für TYR30(L), dessen aromatischer Ring sich parallel zu dem TYR30(L) des symmetrisch angeordneten Moleküls in der benachbarten Zelle ausrichtet. Dies wird im Lichte der Simulationsergebnisse aus der Minimierung und der Equilibrierung näher diskutiert werden.

\footnotetext{
${ }^{3}$ Zur Notation der Hapten-Atome siehe weiter unten Abbildung 5.4.
} 


\subsection{Das Simulationsmodell}

Ausgangspunkt aller in diesem Kapitel beschriebenen Simulationen des $\mathrm{F}_{\mathrm{ab}}$-Fragments von AN02 mit gebundenem DNP-Hapten ist die soeben beschriebene Röntgenstruktur, die die Positionen aller schweren Atome enthält. Die für die MD-Simulation benötigten, in Kapitel 2 beschriebenen Parameter - etwa Partialladungen oder Van der Waals-Radien - wurden für die Proteinatome der auf CHARMM [93] basierenden Parameterbibliothek von XPLOR [165] entnommen (Dateien param19.pro und toph19.pro). In dieser Parametrisierung werden die polaren Wasserstoffatome explizit behandelt, während alle nicht-polaren Wasserstoffe über Compound-Atome implizit berücksichtigt werden (siehe Abschnitt 2.2). Da die Röntgenstruktur keine Koordinaten für die Wasserstoffatome enthält, mussten die Koordinaten der polaren Wasserstoffatome in das Simulationsmodell eingefügt werden. Dies wurde mit der XPLOR-Routine hbuild bewerkstelligt, die zur Platzierung dieser Wasserstoffatome lokale Energieminimierungen durchführt. Alle Aminosäuren desselben Typs wurden identisch beschrieben.

Für das Haptenmolekül konnte auf keine Parameterbibliothek zurückgegriffen werden; geeignete Parameter mussten vielmehr neu bestimmt werden. Dabei wurde besonderes Augenmerk auf die Partialladungen gerichtet, da diese in hohem Maße bindungsrelevant und zudem in der Regel sehr molekülspezifisch sind, so dass hierfür keine Standardparameter (wie für Proteine) verwendet werden konnten. Ebenfalls wichtig sind die Van der Waals-Parameter; diese sind aber für die verschiedenen Atome gut definiert, so dass hierfür die entsprechenden CHARMM-Parameter übernommen wurden. Kraftkonstanten für chemische Bindungen sind dagegen zwar weniger gut definiert, jedoch ist dies für die interessierenden nicht-kovalenten Bindungseigenschaften unkritisch [89] — daher wurden diese ebenfalls der genannten Parameterbibliothek entnommen.

Die Partialladungen des DNP-Haptens wurden aus semiempirischen quantenchemischen Rechnungen bestimmt, in denen die Schrödinger-Gleichung für das Vielelektronen-System numerisch gelöst, die Geometrie des Moleküls optimiert und die Elektronenverteilung berechnet wurden. Daraus wurden Partialladungen für alle Atome im Molekül abgeleitet (Abbildung 5.4). Die Rechnungen wurden mit dem Quantenchemie-Programm UNICHEM [112] durchgeführt. Um die Resultate aus den UNICHEM-Rechnungen zu überprüfen, wurden darüber hinaus Dichtefunktionalrechnungen mit dem Programmpaket DMOL [111] durchgeführt, wobei die so berechneten Partialladungen nur geringfügig von den mit UNICHEM berechneten abwichen.

Ein geeignetes Modell der nativen Lösungsmittelumgebung des AN02-DNP-Hapten-Komplexes wurde erzeugt wie in Abschnitt 2.3 beschrieben: Hier wurde der Komplex so in ein Wassertröpfchen mit konvexer Geometrie platziert, dass ein Mindestabstand von der Oberfläche des Komplexes zur Tröpfchenoberfläche von 12 A gewährleistet war (siehe dazu auch Abbildung 2.1). Um Oberflächeneffekte zu minimieren, wurde im Bereich der eigentlich interessierenden Bindungstaschenregion der Mindestabstand zur Tröpfchenoberfläche zu $22 \AA$ gewählt, was etwa der Dicke von 6 - 7 Wassermolekülen entspricht. Das resultierende Simulationssystem umfasste insgesamt 44571 Atome, davon 13461 Wassermoleküle, 41 Natrium-Ionen und 34 Chlorid-Ionen. 


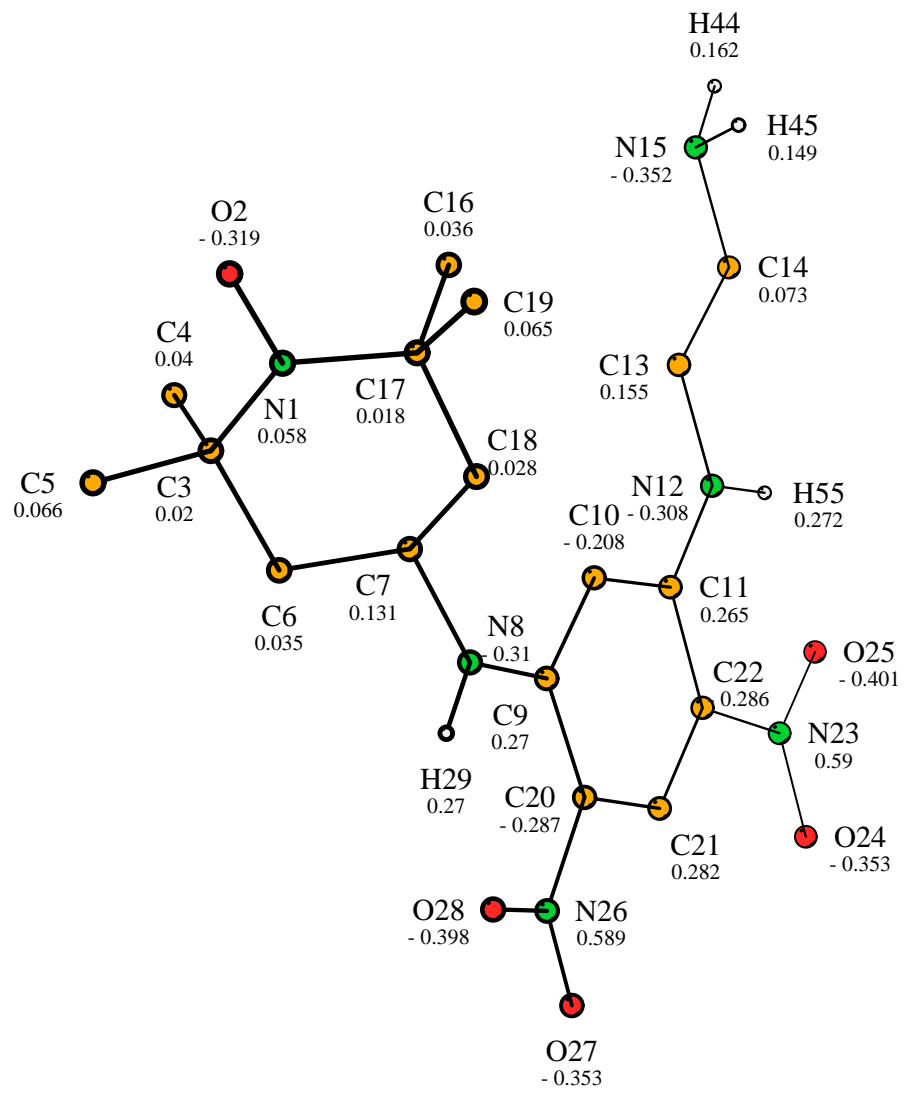

Abbildung 5.4: Struktur von DNP-Hapten mit Atombezeichnungen und Partialladungen, die mit UNICHEM [112] berechnet wurden. 


\subsection{Minimierung und Equilibrierung}

Dieses Simulationssystem wurde zunächst minimiert, um, wie in Abschnitt 2.4 beschrieben, eventuelle Verspannungen der Röntgenstruktur zu lösen, und dann equilibriert mit dem Ziel, das System bei einer Temperatur von $300 \mathrm{~K}$ relaxieren zu lassen.

\subsubsection{Methoden}

In der Minimierung nähert sich das Simulationssystem entlang eines Gradienten in der Potenziallandschaft einem lokalen Minimum. Für den AN02-DNP-Hapten-Komplex erfolgte die Minimierung, indem die Dynamik des Simulationssystems in dem in Abschnitt 2.2 beschriebenen Kraftfeld mit zunächst sehr kleinen Integrationsschrittweiten berechnet wurde, wobei die Bewegung jedes einzelnen Atoms (a) auf $0.08 \AA$ pro Integrationsschritt begrenzt und (b) stark gedämpft wurde. Zusätzlich war das System dabei mit einer Kopplungskonstante von $1 \mathrm{ps}^{-1}$ an ein Wärmebad mit einer Temperatur von $0 \mathrm{~K}$ verbunden [89]. Die Dämpfung wurde durch einen (inversen) Dämpfungskoeffizienten $\eta$ bewerkstelligt, mit dem die durch die wirkenden Kräfte bedingte Verschiebung eines Atoms in jedem Integrationsschritt multipliziert wurde. Entsprechend bedeutet $\eta=0$ keine Bewegung (unendlich starke Dämpfung) und $\eta=1$ keine Dämpfung (freie Dynamik). Tabelle 5.1 zeigt die verwendeten Integrationsschrittweiten $\Delta \mathrm{t}$ und die Dämpfungskoeffizienten $\eta$ der einzelnen Minimierungsphasen. Während der Minimierung ließen wir keine stochastischen Kräfte auf die Wassermoleküle der Oberflächenschicht wirken, weil sie einer Minimierung insofern entgegengerichtet sind, als sie die Moleküle an der Oberfläche in einer beständigen Bewegung halten, so dass deren potenzielle und kinetische Energie nicht minimal werden können. Wir betrachteten das Systems als hinreichend minimiert, sobald sich der durchschnittliche Gradient auf einem Wert unter $1 \mathrm{kcal} /(\mathrm{mol} \cdot \AA)$ stabilisierte.

\begin{tabular}{|c|c|c|}
\hline $\begin{array}{c}\text { Anzahl der } \\
\text { Integrationsschritte }\end{array}$ & $\begin{array}{c}\text { Integrationsschrittweite } \Delta \mathrm{t} \\
{[\mathrm{fs}]}\end{array}$ & $\begin{array}{c}\text { inverser Dämpfungskoeffizientt } \eta \\
100\end{array} 0^{0.2}$ \\
0.3 & 0.01 \\
100 & 0.4 & 0.05 \\
100 & 0.5 & 0.1 \\
100 & 0.8 & 0.2 \\
100 & 1.0 & 0.5 \\
100 & 1.0 & 0.7 \\
100 & 1.0 & 0.9 \\
100 & 1.0 & 0.99 \\
100 & 1.0 & 0.999 \\
\hline
\end{tabular}

Tabelle 5.1: Parameter für die einzelnen Minimerungsphasen. Der Dämpfungskoeffizient $\eta$ gibt an, mit welchem Faktor die Verschiebung der Atome in jedem Integrationsschritt multipliziert wurde. Dementsprechend bewirkte $\eta=0$ totale Dämpfung und $\eta=1$ freie (ungedämpfte) Dynamik. 
In der auf die Minimierung folgenden Equilibrierungsphase wurde das Simulationssystem mit einer Kopplungskonstante von $0.1 \mathrm{ps}^{-1}$ an ein Wärmebad mit einer Temperatur von $300 \mathrm{~K}$ gekoppelt [89]. Die Integrationsschrittweite wurde dabei — wie in allen folgenden Simulationen - auf 1 fs festgesetzt. Zusätzlich haben wir von diesem Zeitpunkt an die (temperaturabhängigen) stochastischen Kräfte für die Wassermoleküle an der Systemoberfläche wirken lassen. Die Kopplungkonstante für die Dämpfung dieser Wassermoleküle (die, wie beschrieben, auch die Stärke der stochastischen Stöße bestimmt) wurde auf $10 \mathrm{ps}^{-1}$ gesetzt. Dieser Wert erwies sich in früher durchgeführten MD-Simulationen [55,56] für die realistische Beschreibung der Oberflächenwassermoleküle als geeignet. Außerdem wurden von diesem Zeitpunkt an die Bindungslängen zwischen schweren Atomen und an sie kovalent gebundenen Wasserstoffatomen mit dem SHAKE-Algorithmus [118] konstant gehalten. Insgesamt wurde das Simulationssystem 1500 ps equilibriert. Zu Analysezwecken wurden die Koordinaten alle 100 fs gespeichert, so dass die Equilibrierungstrajektorie aus insgesamt 15000 Koordinatensätzen bestand.

Zur Bewertung der Equilibrierung wurden die folgenden Observablen herangezogen:

a) Mittlere quadratische Abweichung ( $\mathrm{rmsd}^{4}$ )

Die mittlere quadratische Abweichung einer gegebenen Struktur von einer Referenzstruktur ist definiert als

$$
\operatorname{rmsd}=\min _{\{\mathrm{T}, \mathrm{R}\}} \sqrt{\frac{1}{N} \sum_{i=1}^{N}\left(x_{i}-x_{i}^{0}\right)^{2}+\left(y_{i}-y_{i}^{0}\right)^{2}+\left(z_{i}-z_{i}^{0}\right)^{2}} .
$$

Dabei sind $x_{i}, y_{i}, z_{i}$ bzw. $x_{i}^{0}, y_{i}^{0}, z_{i}^{0}$ die cartesischen Koordinaten der $N$ Atome der gegebenen bzw. der Referenzstruktur, die in die rmsd-Berechnung mit einbezogen wurden, $\{\mathrm{T}, \mathrm{R}\}$ bezeichnet die Menge aller Translationen und Rotationen. Für die Equilibrierungstrajektorie wurden als Referenzstrukturen zum einen die als Ausgangsstruktur verwendete Röntgenstruktur und zum anderen die letzte Struktur der 1500 ps langen Trajektorie herangezogen. Die rmsd-Werte wurden sowohl für den gesamten gelösten Komplex als auch jeweils separat für die konstante Region, die variable Region (vgl. dazu Abbildung 5.1) und die Bindungstaschenregion von AN02 bestimmt, wobei jeweils alle schweren Atome einbezogen wurden. Zur Bindungstasche wurden die in Abbildung 5.3 gezeigten Aminosäuren gerechnet.

\section{b) Wechselwirkungen des Haptenmoleküls mit Aminosäuren der Bindungstasche}

Hier wurde die Summe aus Van der Waals- und elektrostatischen Wechselwirkungen des Haptenmoleküls sowohl mit der Bindungstasche von AN02 insgesamt als auch separat mit einzelnen Aminosäuren im Verlauf der Equilibrierung betrachtet.

Wann wurde das Simulationssystem als hinreichend relaxiert angesehen? Hierzu merken wir zunächst an, dass es in Proteinen Relaxationsprozesse gibt, die weit oberhalb der Nanosekundenzeitskala liegen [198]. Daher müssen wir davon ausgehen, dass man in MDSimulationen auf Grund der begrenzten Simulationszeitspanne keine vollständig relaxierte Struktur eines in Wasser gelösten Proteins erhält. Für die in dieser Arbeit beschriebenen Simulationen betrachteten wir daher das System als hinreichend relaxiert, wenn es

\footnotetext{
${ }^{4}$ rmsd steht für root mean square deviation.
} 
einen Zustand erreichte, in dem es sich auf der Simulationszeitskala als strukturell stabil erwies. Wir bezeichnen einen solchen Zustand als „metastabilen Zustand“. Folgende Kriterien erachteten wir für einen metastabilen Zustand als relevant: (a) die mittlere quadratische Abweichung von der Röntgenstruktur sollte keine signifikante Drift auf Grund von Nichtgleichgewichtseffekten mehr aufweisen und die wesentlichen Strukturmerkmale des AN02- $F_{\mathrm{ab}}$-Fragments, insbesondere die $\beta$-Faltblattstruktur, sollten erhalten geblieben sein . (b) Die wesentlichen, aus Experimenten bekannten Wechselwirkungen des DNPHaptens mit Aminosäuren der Bindungtasche sollten vorhanden sein. Punkt (a) wollen wir eingehender erläutern. Wie in Ref. [199] vorgeschlagen, werden zwei verschiedene Arten von Driften im rmsd-Verlauf unterschieden: Zum einen eine Drift, die daher rührt, dass das System zu Beginn nicht in einem metastabilen Zustand ist und sich während der Equilibrierung einem solchen nähert (Nichtgleichgewichts-Relaxation), zum anderen eine Drift, die dadurch zustande kommt, dass das System seine unmittelbare Umgebung im Konfigurationsraum im Rahmen einer ungerichteten diffusiven Bewegung permanent abtastet. Letzteres findet auch bei Systemen statt, die sich bereits in einem metastabilen Zustand befinden.

Die rmsd-Berechnung, die von einer bereits relaxierten Struktur ausgeht, erlaubt es, diese beiden Driften voneinander zu trennen: Der erste steile Anstieg des rmsd-Verlaufs entlang der nun rückwärts durchlaufenen Trajektorie wird dem Abtasten der unmittelbaren Umgebung zugeschrieben, ein weiterer, nach einem Plateau bzw. einer Phase sehr geringer Drift erfolgender Anstieg, der bis zur Ausgangsstruktur der Simulation reicht, wird als Folge der Nichtgleichgewichts-Relaxation interpretiert ${ }^{5}$. Dieses Vorgehen gibt einem einen Anhaltspunkt an die Hand, ab wann das Simulationssystem als hinreichend relaxiert gelten kann.

\subsubsection{Ergebnisse und Diskussion}

Nach einer Minimierungszeit von 1 ps betrachteten wir den gelösten AN02-Hapten-Komplex als hinreichend minimiert, da der durchschnittliche Gradient, mit dem sich das Simulationssystem einem lokalen Minimum in der Potenziallandschaft näherte, sich bereits nach etwa $700 \mathrm{fs}$ auf etwa $0.8 \mathrm{kcal} /(\mathrm{mol} \cdot \AA)$ stabiliserte und daraufhin keine signifikante Drift mehr aufwies.

a) Mittlere quadratische Abweichung (rmsd)

Der Verlauf des rmsd von der Röntgenstruktur (Abbildung 5.5, fette Linie) zeigt in den ersten 150 ps einen steilen, dann einen erheblich geringeren Anstieg. Ab 1150 ps ist auf der 1500 ps-Zeitskala der Equilibrierung annähernd ein Plateau auf einem Niveau von etwa $3.1 \AA$ erreicht. Der rmsd-Verlauf ausgehend von der letzten Struktur (dünne Linie, gelesen von rechts nach links) zeigt dahingegen bereits nach etwa 200 ps bei rund $1.5 \AA$ einen plateauähnlichen Verlauf, der sich von 1300 bis etwa 550 ps erstreckt. Danach

\footnotetext{
${ }^{5}$ Hierbei wird vorausgesetzt, dass die Trajektorie an der Stelle, von der aus die rückwärtige rmsdBerechnung beginnt, schon länger als die Zeitspanne in einem metastabilen Zustand war, die für das Abtasten der unmittelbaren Umgebung im Konfigurationsraum benötigt wird.
} 


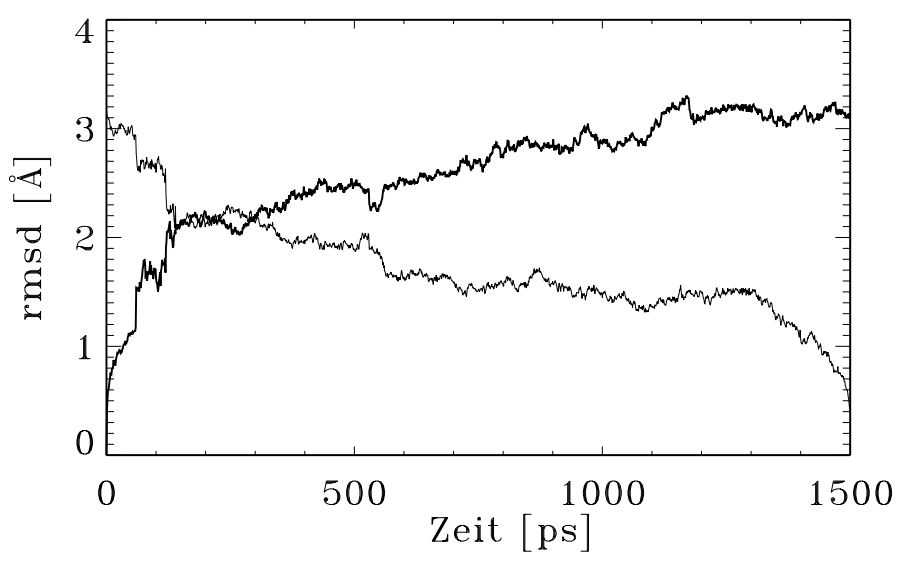

Abbildung 5.5: Verlauf der mittleren quadratischen Abweichung des AN02-DNP-HaptenKomplexes von der Röntgenstruktur (fett) bzw. von der Struktur nach 1500 ps Equilibrierung (dünn). Zur Erklärung siehe Text.
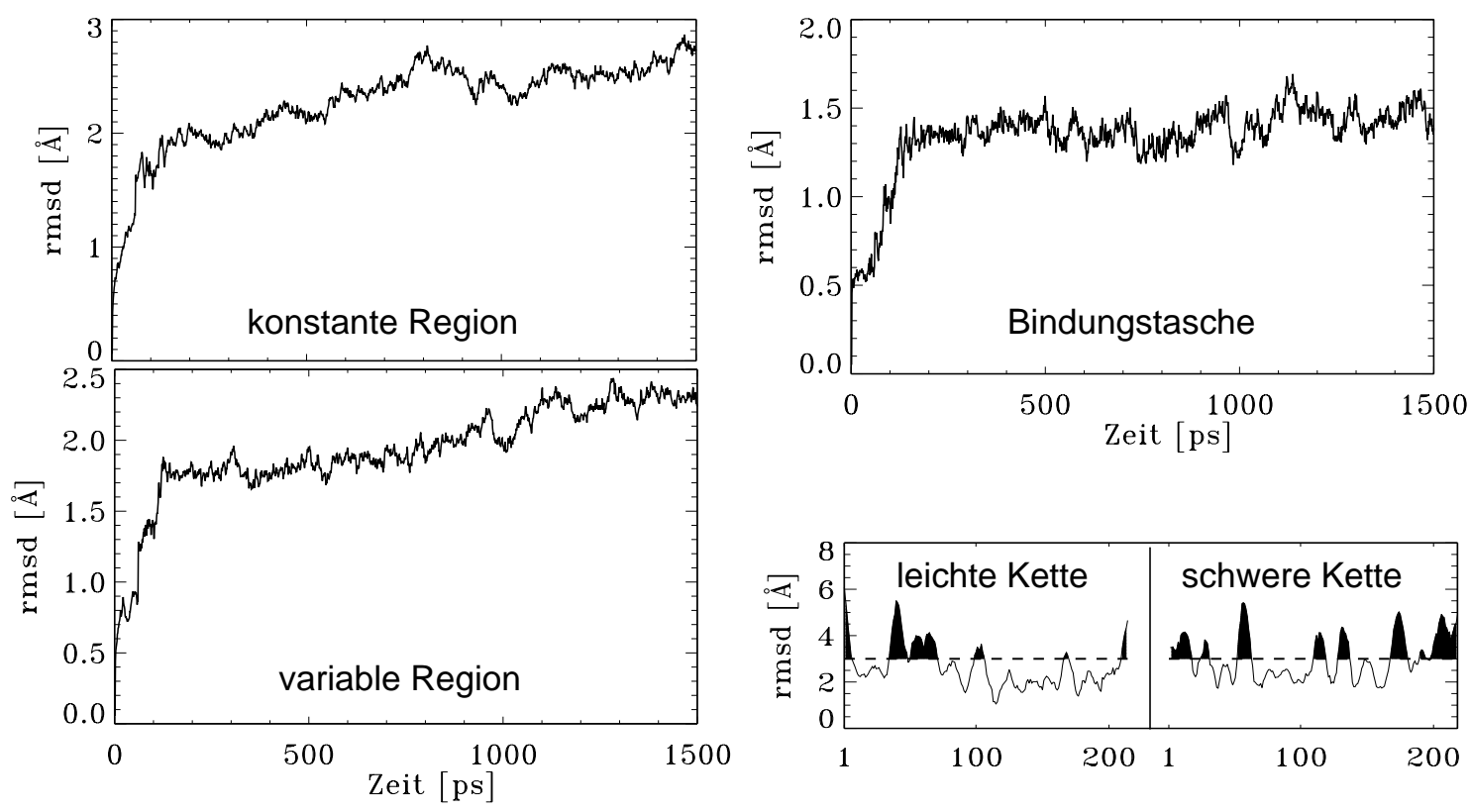

Abbildung 5.6: Verlauf der mittleren quadratischen Abweichungen von der Röntgenstruktur für die konstante Region (oben links), die variable Region (unten links) und die Bindungstasche einschließlich des Haptenmoleküls (oben rechts) während der Equilibrierung. Unten rechts: Mittlere quadratische Abweichung von der Röntgenstruktur aufgeschlüsselt nach dem Beitrag der einzelnen Aminosäuren. Die Daten wurden über die letzten 500 ps der Equilibrierungstrajektorie gemittelt. In den dunkel eingefärbten Bereichen sind diejenigen Regionen hervorgehoben, die mit über $3 \AA$ besonders stark zur mittleren quadratischen Abweichung beitrugen (vgl. dazu Abbildung 5.7). 
erfolgt ein weiterer Anstieg, der sich (mit unterschiedlichen Steigungen) bis zum Zeitpunkt 0 ps (der der Röntgenstruktur entspricht) fortsetzt.

Röntgenstruktur

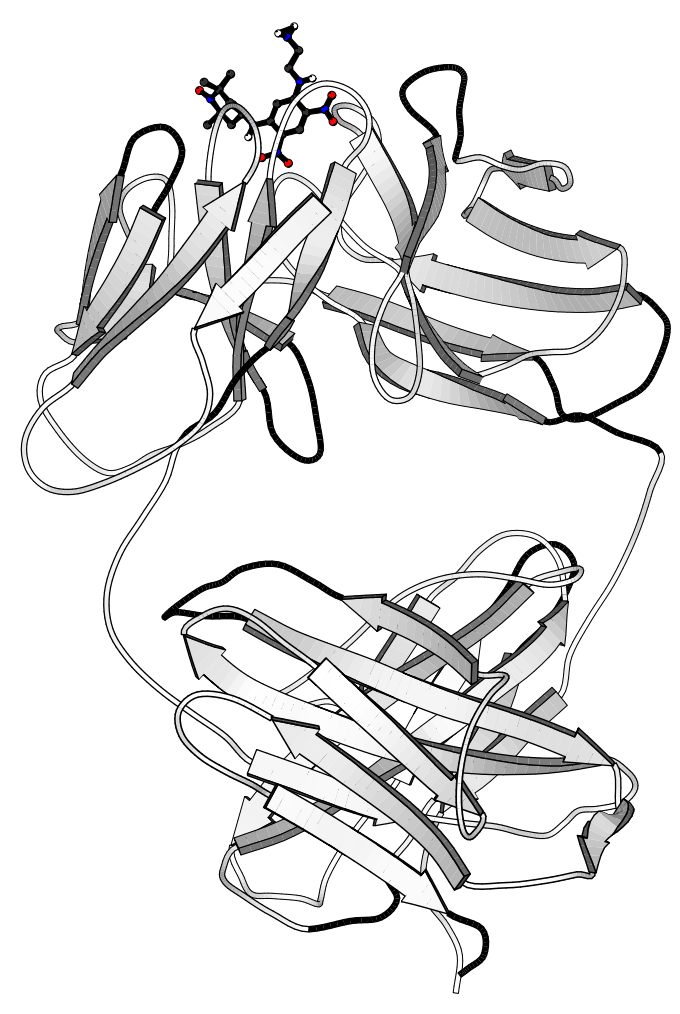

nach 1300 ps

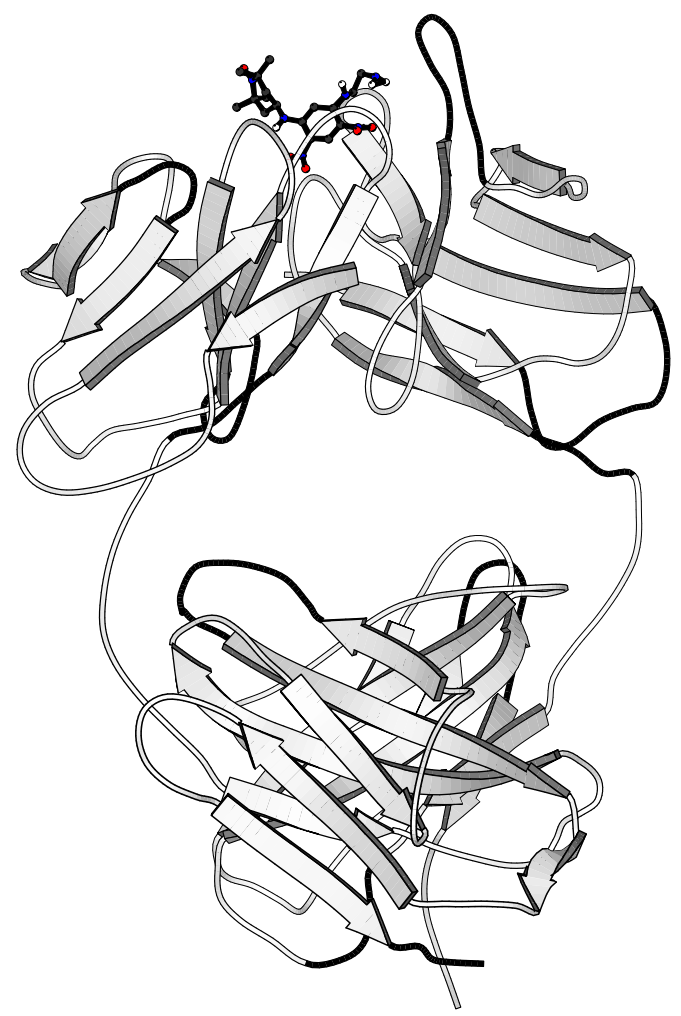

Abbildung 5.7: Vergleich der AN02-DNP-Hapten-Röntgenstruktur mit einer repräsentativen Struktur nach 1300 ps Equilibrierung. Die Regionen, die besonders stark zur mittleren quadratischen Abweichung beitrugen, sind dunkel eingefärbt (vgl. Abbildung 5.6, unten rechts).

Aus Abbildung 5.6 ist ersichtlich, dass die Gesamtdriften für die einzelnen Domänen (konstante und variable Region) mit etwa $2.6 \AA$ bzw. $2.3 \AA$ deutlich kleiner sind als die für den gesamten Komplex. Die unten in der Abbildung aufgetragene Drift für die Bindungstasche stabilisiert sich sogar bereits nach weniger als 200 ps auf einem mittleren Niveau von 1.4 A. Schließlich zeigt Abbildung 5.7, wie sich im Mittel die Gesamtdrift von der Röntgenstruktur auf die einzelnen Aminosäuren verteilt. Es sind diejenigen Bereiche eingefärbt, die eine Abweichung von $3 \AA$ überschreiten. Deutlich erkennbar ist, dass es sowohl für die leichte Kette (links) als auch für die schwere Kette (rechts) einige lokalisierte Ausschläge gibt; diese markieren zusammenhängende Peptidstücke, die kollektiv eine stärkere Abweichung von der Röntgenstruktur aufweisen als die meisten anderen Aminosäuren in den beiden Polypeptidketten. Diese eingefärbten Bereiche sind ebenfalls in Abbildung 5.7 hervorgehoben, in der der Röntgenstruktur des gesamten Komplexes eine als repräsentativ ausgewählte Struktur nach 1300 ps Equilibrierung gegenübergestellt ist. Hier zeigt sich, dass es sich bei den Peptidstücken mit starker Drift im wesentlichen um 
Schleifen handelt, die sich eher an der Oberfläche des Proteins befinden.

Den ersten Anstieg des rmsd-Verlaufs mit der letzten Struktur als Referenzpunkt (Abbildung 5.5, dünne Linie) interpretieren wir als die Phase des Abtastens der unmittelbaren Umgebung im Konfigurationsraum, während wir den zweiten, zum Zeitpunkt 550 ps einsetzenden Anstieg der Nichtgleichgewichts-Relaxation des Komplexes zuschreiben. Wir werten dies als Indiz, dass das Simulationssystem nach dem rmsd-Kriterium bereits nach etwa $550 \mathrm{ps}$ in dem weiter oben definierten Sinne als hinreichend relaxiert gelten kann. Die rmsd-Verläufe der einzelnen Domänen (Abbildung 5.6) zeigen, dass die domäneninternen Abweichungen von der Röntgenstruktur erheblich kleiner sind als die des gesamten $F_{\text {ab }}$-Fragments; sie zeugen davon, dass sich die konstante und variable Domäne wie starre Körper kollektiv gegeneinander bewegen, was angesichts der „losen“ Verbindung der Domänen (vgl. weiter unten Abbildung 5.7) nicht überrascht; geringe Verdrehungen gegeneinander haben bereits einen erhebliche Anstieg des rmsd-Werts der gesamten Struktur zur Folge, was darauf verweist, dass es nicht wesentliche Änderungen in der Sekundärstruktur des Proteins sind, die die Gesamtdrift bedingen. Wie Abbildungen 5.6 (unten rechts) und 5.7 verdeutlichen, sind es vor allem die besonders beweglichn Schleifen an der Oberfläche der Polypeptidkette, die überproportional stark zur Gesamtdrift beitragen. Desweiteren wies die eigentlich interessierende Region um die Bindungstasche eine ausgesprochen geringe Drift von $1.5 \AA$ auf. Wir halten somit fest, dass, nach dem rmsd-Kriterium zu urteilen, die wesentlichen Strukturmerkmale, insbesondere die $\beta$-Faltblattstruktur des Komplexes, während der Equilibrierungsphase erhalten blieben.

\section{b) Wechselwirkungen des Haptenmoleküls mit Aminosäuren der Bindungstasche}

Abbildung 5.8 zeigt die Wechselwirkungsenergie zwischen dem Haptenmolekül und der gesamten Bindungstasche während der Equilibrierungsphase. In der Gesamtenergie (oben) und der elektrostatischen Energie (Mitte) ist bis 150 ps eine deutliche Drift erkennbar, die sehr genau mit der in dem Verlauf der rmsd-Werte für die Bindungstasche (Abbildung 5.6, unten) zusammenfällt. Der weitere Verlauf weist keine signifikante Drift mehr auf, zeigt jedoch relativ starke Fluktuationen. Mit durchschnittlich $-45 \mathrm{kcal} / \mathrm{mol}$ trugen Van der Waals-Wechselwirkungen etwa dreimal so stark wie elektrostatische Wechselwirkungen zur Bindung bei.

Abbildung 5.9 schlüsselt auf, wie sich die nicht-bindenden Wechselwirkungen, d.h. die Summe aus Van der Waals- und elektrostatischen Wechselwirkungen mit dem Haptenmolekül auf die einzelnen Bindungstaschenresiduen aufteilten. In der oberen Hälfte sind die Wechselwirkungen zu den Aminosäuren der leichten Kette, in der unteren Hälfte die zu den Aminosäuren der schweren Kette aufgetragen. Die Dicke der Balken ist proportional zur Stärke der Wechselwirkung. Die wichtigsten dieser Wechselwirkungen sind in den Schnappschüssen von der Bindungstasche in Abbildung 5.10 gestrichelt eingezeichnet. 


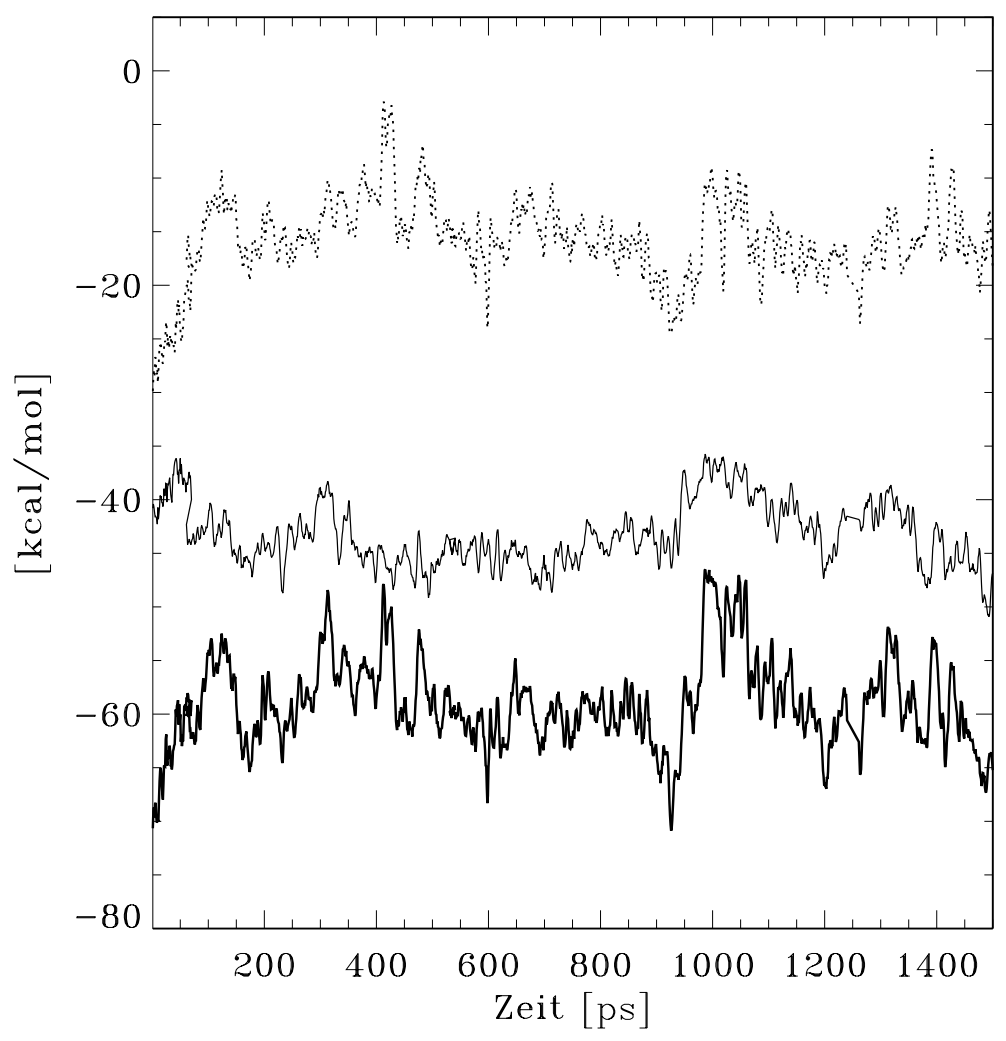

Abbildung 5.8: Potenzielle (fett), Van der Waals- (dünn) und elektrostatische Energie (gepunktet) zwischen Hapten und den Aminosäuren der Bindungstasche während der Equilibrierung.

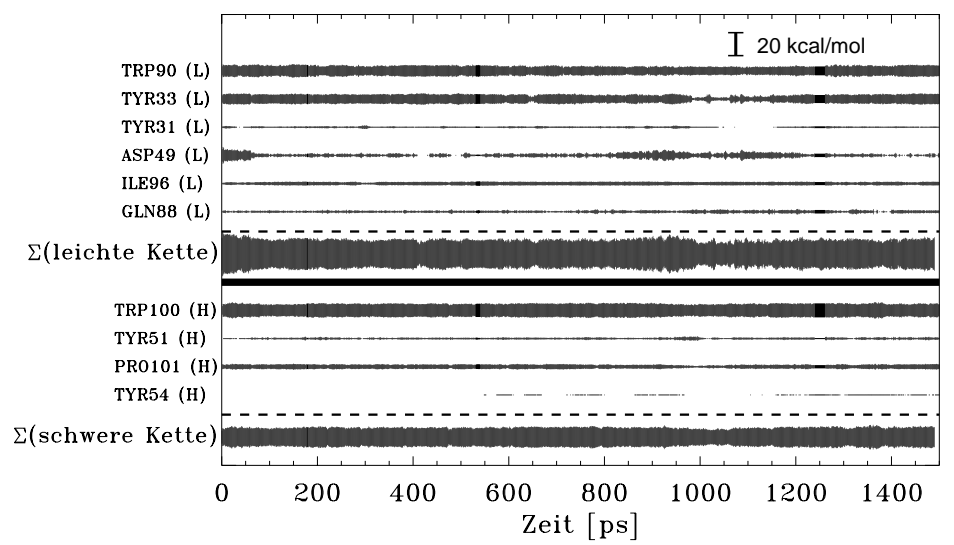

Abbildung 5.9: Summe aus elektrostatischen und Van der Waals-Wechselwirkungen zwischen Hapten und einzelnen Aminosäuren der leichten Kette (obere Hälfte) und der schweren Kette (untere Hälfte) während der Equilibrierung. Die Dicke der Linien ist proportional zur Stärke der Wechselwirkungen (siehe Maßstab rechts oben). 


\section{Röntgenstruktur}

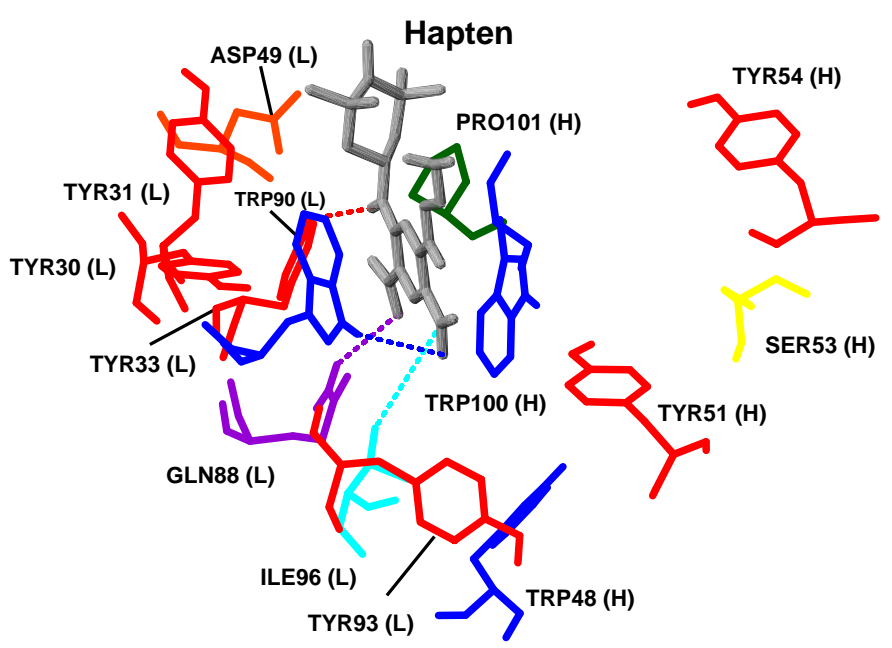

nach 1300 ps

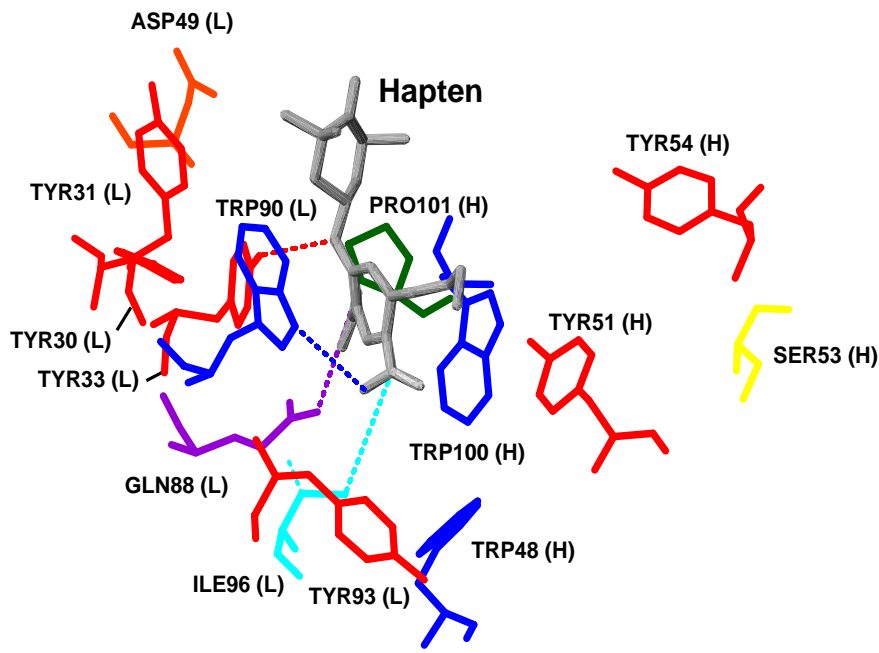

Abbildung 5.10: AN02-Bindungstasche mit gebundenem Hapten (grau) in der Röntgenstruktur (oben) und nach 1300 ps Equilibrierung (unten). Wasserstoffbrücken und Van der Waals-Kontakte zwischen Hapten und Aminosäuren der Bindungstasche sind mit gepunkteten Linien gekennzeichnet. 
Zunächst ist in Abbildung 5.9 und in den Schnappschüssen deutlich zu sehen, dass starke Wechselwirkungen von Hapten mit TRP90(L) und TRP100(H) und die aus ihnen gebildete Sandwich-Konfiguration während der Equilibrierung erhalten blieben. Gleiches gilt, abgesehen von leichten Schwankungen, für die Wasserstoffbrücke von TYR33(L) zum Hapten sowie die Van der Waals-Kontakte von ILE96(L), GLN88(L) und PRO101(H).

Ein signifikanter Unterschied zwischen der Röntgenstruktur und der relaxierten Struktur liegt darin, dass sich der aromatische Ring von TYR30(L) etwas von der Seitenkette von TRP90(L) entfernt hat und nicht mehr exakt senkrecht zur Letzteren orientiert ist (siehe Abbildung 5.10). Der aromatische Ring von TYR30(L) erwies sich in allen Simulationen als recht beweglich. Wie bereits erwähnt, gilt die Position gerade dieses aromatischen Rings in der Röntgenstruktur als unsicher, da sie durch Wechselwirkungen zu Molekülen in benachbarten Zellen des Kristalls bedingt sein kann [191]. So erscheint es möglich, dass TYR30(L), wie in unseren Simulationen beobachtet, in Lösung beweglicher ist als im Kristall. Wir gehen davon aus, dass die veränderte Konformation von TYR30(L) der Grund dafür ist, dass sich TRP90(L) während der Equilibrierung geringfügig in Richtung Ausgang der Bindungstasche bewegte und somit etwas anders zum Haptenmolekül orientiert war, ohne dass sich dadurch die Sandwich-Konfiguration signifikant verändert hätte. Weitere Unterschiede bestehen darin, dass die Seitenkette des am Ausgang der Bindungstasche an der Proteinoberfläche befindlichen ASP49(L) während der Equilibrierung aus der Bindungstasche herausbewegte, während sich umgekehrt die Amino-Ethyl-AminoKette des Haptens etwas in die Bindungstasche hineinbewegte. Dadurch änderten sich die Wechselwirkungen des Haptenmoleküls mit der Bindungstasche jedoch nicht signifikant.

Zusammenfassend stellen wir fest, dass der AN02-DNP-Hapten-Komplex nach einer Equilibrierungszeit von rund $550 \mathrm{ps}$ in einen auf der Simulationszeitskala metastabilen Zustand relaxierte, in dem sich insbesondere die Bindungstaschenregion nicht wesentlich von der Röntgenstruktur unterscheidet. Entsprechend wurden alle Strukturen der Equilibrierungstrajektorie nach dem Zeitpunkt von $550 \mathrm{ps}$ als geeignet angesehen, um als Ausgangsstruktur für die im folgenden beschriebenen Dissoziationssimulationen zu dienen. 


\subsection{Dissoziationssimulationen}

Dieser Abschnitt beschreibt die Dissoziationssimulationen von AN02-DNP-Hapten. Er gliedert sich in vier Teile. Im ersten Teil fassen wir die Vorgehensweise zusammen und benennen die für die AN02-DNP-Hapten-Dissoziationssimulationen spezifischen Parameter; die methodischen Details, die allen Simulationen kraftmikroskopischer Experimente gemeinsam sind, wurden bereits in Kapitel 3 erörtert. Im zweiten Teilabschnitt analysieren wir die Kräfte, die in den Simulationen aufgewendet werden mussten, um das Hapten aus der AN02-Bindungstasche zu ziehen. Auf Grundlage des in Abschnitt 4.1 abgeleiteten Modells werden wir die auf der Nanosekundenzeitskala berechneten Dissoziationskräfte auf die Millisekundenzeitskala interpolieren und so zu einer Vorhersage für eine experimentell bestimmte Dissoziationskraft kommen. Der dritte Teilabschnitt hat eine eingehende strukturelle Analyse des forcierten Dissoziationsprozesses zum Inhalt, in der die Dissoziationspfade des Haptens aus der Bindungstasche sowie die während des Dissoziationsprozesses beobachteten Wechselwirkungen zu einzelnen Aminosäuren der Bindungstasche betrachtet und diskutiert werden. Im vierten und letzten Teilabschnitt werden die Ergebnisse aus Dissoziationssimulationen von zwei Mutanten des AN02-DNPHapten-Komplexes erörtert. Die jeweiligen Auswertungsmethoden werden zu Beginn eines jedenTeilabschnitts beschrieben. 


\subsubsection{Das Simulationsverfahren}

In Kapitel 3 wurde die allgemeine Simulationsmethode zur forcierten Dissoziation von Rezeptor-Ligand-Komplexen beschrieben. Hier sollen nur diejenigen Details erörtert werden, die spezifisch für AN02-DNP-Hapten sind.

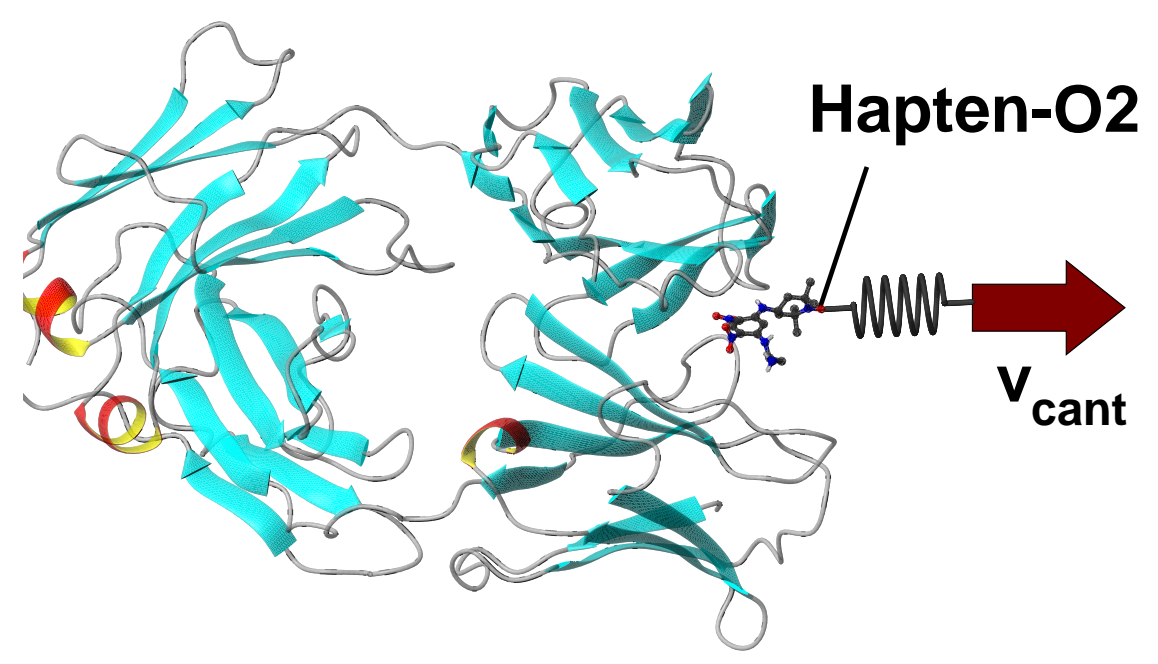

Abbildung 5.11: Vorgehensweise in den Dissoziationssimulationen zum AN02-DNPHapten-Komplex. Das Sauerstoffatom O2 der Spin-markierenden Nitrogruppe des Haptens ist an ein harmonisches Potenzial gekoppelt (durch eine Feder symbolisiert), welches den Cantilever eines Kraftmikroskops modelliert und im Verlauf der Dissoziationssimulation mit konstanter Zuggeschwindigkeit $v_{\text {cant }}$ nach rechts (Pfeil) bewegt wird. Das Lösungsmittelmodell ist nicht gezeigt (vgl. Abbildung 2.1).

Wie in Abbildung 5.11 gezeigt, wurde das Sauerstoffatom „O2“ der Spin-markierenden Nitrogruppe an das in Abschnitt 3.2 eingeführte harmonische Zugpotenzial (Feder) gekoppelt, da im kraftmikroskopischen Experiment gerade dieses Atom mit der Spitze des Cantilevers verbunden ist. Entsprechend der in Abschnitt 3.2.2 diskutierten Abwägung zwischen erwünschter Ortsauflösung des Kraftprofils und möglichst geringer atomarer Fluktuationen durch das Federpotenzial entschieden wir uns für eine Kraftkonstante des harmonischen Potenzials von $2.8 \mathrm{~N} / \mathrm{m}$, was etwa der 40-fache Wert der Federkonstante des im Experiment verwendeten Cantilevers ist. Diese Wahl ermöglichte eine hochaufgelöste Abtastung des Kraftprofils: Eine Auslenkung des O2-Atoms um $1 \AA$ A bewirkte eine Änderung der Zugkraft von $280 \mathrm{pN}$, so dass auch kleine Positionsänderungen im Kraftprofil detektiert werden konnten, die durch das Brechen oder Bilden der kurzreichweitigsten Wasserstoffbrücken bedingt waren. Dazu sei auf eine eingehendere Diskussion weiter unten verwiesen. Mit einem solchen Zugpotenzial blieben Auslenkungen des O2-Atoms in Zugrichtung von $\Delta z=\sqrt{\frac{k_{\mathrm{B}} T}{k_{0}}} \approx 0.4 \AA$ möglich. Dies entsprach etwa der Amplitude der Fluktuationen, die das ungestörte O2-Atom während der Equilibrierung auf einer Zeitskala von 100 ps aufwies. Da wir damit die durch das Zugpotenzial bedingte Störung 
des Systems als hinreichend klein erachteten, erschien es uns hier als gerechtfertigt, vom Experiment abzuweichen und eine höhere Federkonstante zu wählen.

Es sei an dieser Stelle hervorgehoben, dass das gewählte steile Zugpotenzial nur in Zugrichtung wirkte. In den Richtungen senkrecht zur Zugrichtung wurde ein sehr viel flacheres harmonisches Potenzial mit einer Federkonstante von $0.07 \mathrm{~N} / \mathrm{m}$ angelegt, um der Tatsache Rechnung zu tragen, dass auch im kraftmikroskopischen Experiment bei von Null verschiedenen Zugkräften, bei denen der Polymerlinker zwischen Cantilever und dem Haptenmolekül gespannt ist, die seitliche Bewegungsfreiheit des Haptenmoleküls eingeschränkt ist.

Die Kraftkonstante des Schwerpunktpotenzials, das eine Drift des Schwerpunkts des Antikörpers verhindern sollte (siehe Abschnitt 3.2), war so festzulegen, dass einerseits nur sehr geringe Auslenkungen des Schwerpunkts von seiner Gleichgewichtsposition möglich waren und zum anderen auch hier die Störung des Systems möglichst gering blieben. Wir wählten eine Kraftkonstante von $k_{1}=28 \mathrm{~N} / \mathrm{m}$, was Fluktuationen des Schwerpunkts innerhalb der Grenzen von $0.3 \AA$ um seine Ruhelage zuließ und jedes Atom einer maximalen Rückstellkraft von weniger als $1 \mathrm{pN}$ aussetzte und somit einer vernachlässigbaren Störung unterwarf.

Die Zuggeschwindigkeit $v_{\text {cant }}$ war einerseits so groß zu wählen, dass der Komplex in der zur Verfügung stehenden Simulationszeitspanne getrennt wurde. Andererseits sollte sie so klein wie möglich sein, um dem kraftmikrokopischen Experiment, das auf einer um mehrere Größenordnungen längeren Zeitskala und entsprechend unter Verwendung sehr viel kleinerer Zuggeschwindigkeiten stattfindet, möglichst nahezukommen. Um eine maximale Rechenzeit von 4 Monaten für eine Dissoziationssimulation auf dem in Abschnitt 2.2 beschriebenen Hochleistungsparallelrechne nicht zu überschreiten, stand uns bei einer Rechengeschwindigkeit von etwa $60 \mathrm{ps}$ am Tag für die längste Dissoziationssimulation eine Simulationszeitspanne von $7 \mathrm{~ns}$ zur Verfügung. Daraus ergab sich als kleinst mögliche Zuggeschwindigkeit etwa $0.1 \mathrm{~m} / \mathrm{s}$. Um die Abhängigkeit der Dissoziationskraft von der Zuggeschwindigkeit zu untersuchen, wurden insgesamt 39 Dissoziationssimulationen mit Zuggeschwindigkeiten zwischen 0.1 und $100 \mathrm{~m} / \mathrm{s}$ mit entsprechenden Simulationszeitspannen zwischen $7 \mathrm{~ns}$ und $15 \mathrm{ps}$ durchgeführt. Diese starteten alle von derselben Ausgangsstruktur, die der Equilibrierungstrajektorie nach eine Zeitspanne von 1300 ps entnommen wurde. Um zusätzlich zu studieren, wie die Dissoziationspfade in den einzlenen Dissoziationssimulationen unter weitgehend gleichen Simulationsbedingungen variierten, führten wir weitere 20 Dissoziationssimultionen mit identischen Zuggeschwindigkeiten von $v_{\text {cant }}=5 \mathrm{~m} / \mathrm{s}$ durch; diese Simulationen unterschieden sich lediglich in ihren Ausgangsstrukturen, die der Equilibrierungstrajektorie in der Zeitspanne zwischen 680 und 1500 ps entnommen wurden. 
Abschließend sind in Tabelle 5.2 die in den Dissoziationssimulationen verwendeten Parameter aufgeführt.

Anzahl der Atome im Simulationssystem:

davon AN02:

4081

Hapten:

32

Wasser:

40383

$\mathrm{Na}^{+}$-Ionen:

34

$\mathrm{Cl}^{-}$-Ionen:

41

Schichtdicke für stochastische Randbedingungen:

$7.0 \AA$

maximaler Reibungskoeffizient für die Wassermoleküle

an der Oberfläche des Simulationsvolumens:

$10 \mathrm{ps}^{-1}$

Temperatur:

$300 \mathrm{~K}$

Zeitkonstante für die Wärmebadkopplung:

$1 \mathrm{ps}^{-1}$

Kraftkonstante für das Zugpotenzial in Zugrichtung:

$2.8 \mathrm{~N} / \mathrm{m}$

Kraftkonstante in den dazu senkrechten Richtungen:

$0.07 \mathrm{~N} / \mathrm{m}$

Kraftkonstante für das Schwerpunktpotenzial:

$28 \mathrm{~N} / \mathrm{m}$

Bereich der Zuggeschwindigkeiten $v_{\text {cant }}$ :

$0.1 \mathrm{~m} / \mathrm{s} \ldots 100 \mathrm{~m} / \mathrm{s}$

Simulationszeitspannen:

$7000 \mathrm{ps} \ldots 15 \mathrm{ps}$

Anzahl der Dissoziationssimulationen insgesamt:

58

mit unterschiedlichen Zuggeschwindigkeiten:

39

mit $v_{\text {cant }}=5 \mathrm{~m} / \mathrm{s}$ :

20

Tabelle 5.2: Parameter für die Dissoziationssimulationen zu AN02-Hapten. 


\subsubsection{Kraftprofile und Dissoziationskräfte}

\section{Methoden}

Für jede Dissoziationssimulation wurde die Zugkraft als Funktion der Cantileverposition $z_{\text {cant }}$ („Kraftprofil“) aufgezeichnet. Abbildung 5.12 (oben) zeigt exemplarisch ein solches Kraftprofil, gewonnen aus einer Dissoziationssimulation des AN02-DNP-HaptenKomplexes mit einer Zuggeschwindigkeit von $v_{\text {cant }}=1 \mathrm{~m} / \mathrm{s}$. Es weist hochfrequente Fluktuationen mit Amplituden von bis zu $300 \mathrm{pN}$ auf. Diese Fluktuationen rühren vor allem von den thermischen Bewegungen des Atoms Hapten-O2 innerhalb des Zugpotenzials her. Da wir in den Simulationen zugunsten einer besseren Ortsauflösung des Kraftprofils eine sehr viel härtere Feder als im Experiment verwendet haben, sind hier die Fluktuationen in der Zugkraft erheblich größer; insbesondere wird das Maximum des Kraftprofils, aus dem wir die Dissoziationskraft ableiten (siehe Abschnitt 3.2.1), maßgeblich durch die thermischen Bewegungen bestimmt. In den kraftmikroskopischen Experimenten ist der Cantilever dagegen vergeleichsweise weich, so dass hier thermische Bewegungen des O2Atoms nur zu vernachlässigbaren Fluktuationen in der Kraft führen und die gemessenen Dissoziationskraft somit maßgeblich durch die Wechselwirkungen des Haptenmoleküls mit den Aminosäuren der Bindungstasche bestimmt ist. Um auch in den Simulationen eine Dissoziationskraft zu erhalten, die von den Wechselwirkungen zwischen AN02 und Hapten herrührt, wollen wir den durch die thermischen Bewegungen bedingten Kraftfluktuationen durch geeignete Glättung des Kraftprofils „herausfiltern“. Denn würde man diese Kraftfluktuationen miteinbeziehen, würde man die Dissoziationskraft deutlich zu hoch abschätzen. Die Glättung eines aus einer Dissoziationssimulation erhaltenen Kraftprofils (Abbildung 5.12, oben) erfolgte durch Faltung mit einer Gauß-Funktion der Breite $\sigma$ (Abbildung 5.12 unten). Die Breite $\sigma$ der Gauß-Funktion sollte dabei so gewählt werden, dass der Einfluss thermischer Bewegungen auf das Kraftprofil weitgehend eliminiert wurde, Fluktuationen auf Grund von kurzreichweitigen Wechselwirkungen des Haptenmoleküls mit Aminosäuren der Bindungstasche sich aber weiterhin widerspiegelten.

Um eine geeignete Glättungsbreite festzulegen, wurde die Verteilung der Längen von den Wechselwirkungen mit kürzester Reichweite, den Wasserstoffbrücken, herangezogen. Aus früheren Dissoziationssimulationen wissen wir bereits, dass Wasserstoffbrücken in Rezeptor-Ligand-Bindungen von erheblicher Bedeutung sind [55]. Für den Fall, dass sich solche Verteilungen für alle Wasserstoffbrücken gut mit Gauß-Funktionen identischer oder sehr ähnlicher Schwankungsbreite approximieren lassen, ist diese Schwankungsbreite die obere Grenze für die Glättungsbreite, da andernfalls die von Wasserstoffbrücken herrührenden Fluktuationen herausgefiltert werden würden. Abbildung 5.13 (durchgezogene Linie) zeigt exemplarisch für eine einzelne stabile Wasserstoffbrücke ihre Längenverteilung, die aus der Equilibrierungstrajektorie über eine Zeitspanne von 100 ps extrahiert und mit einer Gauß-Funktion (gestrichelte Linie) approximiert wurde. Ihr Schwerpunkt liegt bei $3.0 \AA$ und ihre Schwankungsbreite beträgt $0.15 \AA$. ndere Wasserstoffbrücken wiesen nahezu identische Längenverteilungen auf. Auf Grundlage dieser Daten wurde die mittlere Glättungsbreite für das Kraftprofil auf $0.15 \AA$ festgelegt (durchgezogene Linie in Abbildung 5.12, unten). Die Dissoziationskraft wurde nun als die Maximalkraft in einem auf diese Weise geglätten Kraftprofil definiert. Da dieses Vorgehen nicht frei von Willkür 

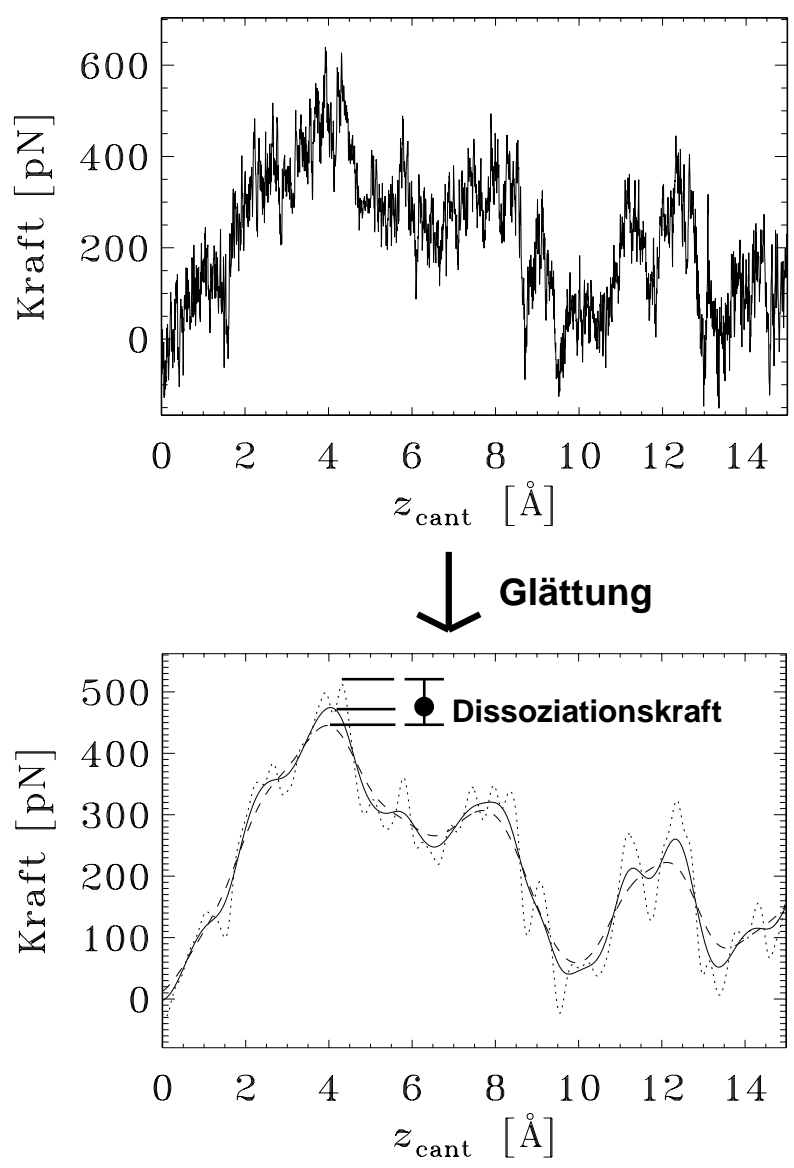

Abbildung 5.12: Oben: Kraftprofil, gewonnen aus einer Dissoziationssimulation mit einer Zuggeschwindigkeit von $v_{\text {cant }}=1 \mathrm{~m} / \mathrm{s}$. Unten: Geglättetes Kraftprofil mit Glättungsbreiten von $0.15 \AA$ (durchgezogene Linie), $0.075 \AA$ (gepunktete Linie) und $0.3 \AA$ (gestrichelte Linie). Die Dissoziationskraft wurde als das Maximum des Kraftprofils mit mittlerer Glättungsbreite definiert. Der Einfluss der Willkür in der Wahl der Glättungsbreite auf die berechnete Dissoziationskraft wurde durch Betrachten der Maxima der Kraftprofile mit kleinerer bzw. größerer Glättungsbreite abgeschätzt.

ist, wurde eine obere Grenze für die Dissoziationskraft durch Glättung mit einer Breite von $0.075 \AA$ (gepunktete Linie) und eine untere Grenze durch Glättung mit einer Breite von $0.3 \AA$ (gestrichelte Linie) ermittelt.

\section{Ergebnisse und Diskussion}

Die so aus den 39 Simulationen erhaltenen Dissoziationskräfte sind in Abbildung 5.14 als Funktion der Zuggeschwindigkeit logarithmisch aufgetragen. Links oben sind dieselben Daten in einer linearen Auftragung gezeigt. Zunächst ist deutlich zu erkennen, dass die Dissoziationskraft mit wachsender Zuggeschwindigkeit $v_{\text {cant }}$ zunimmt. Dabei können zwei Regimes voneinander unterschieden werden: ein lineares Regime für Zuggeschwindigkeiten $v_{\text {cant }}>3 \mathrm{~m} / \mathrm{s}$, das insbesondere in der linearen Auftragung erkennbar ist (siehe lineare Approximation in Form der gestrichelt-gepunkteten Linien) und das mit Stokesscher Reibung erklärt werden kann [55,58]; ein zweites Regime für Zuggeschwindigkeiten 


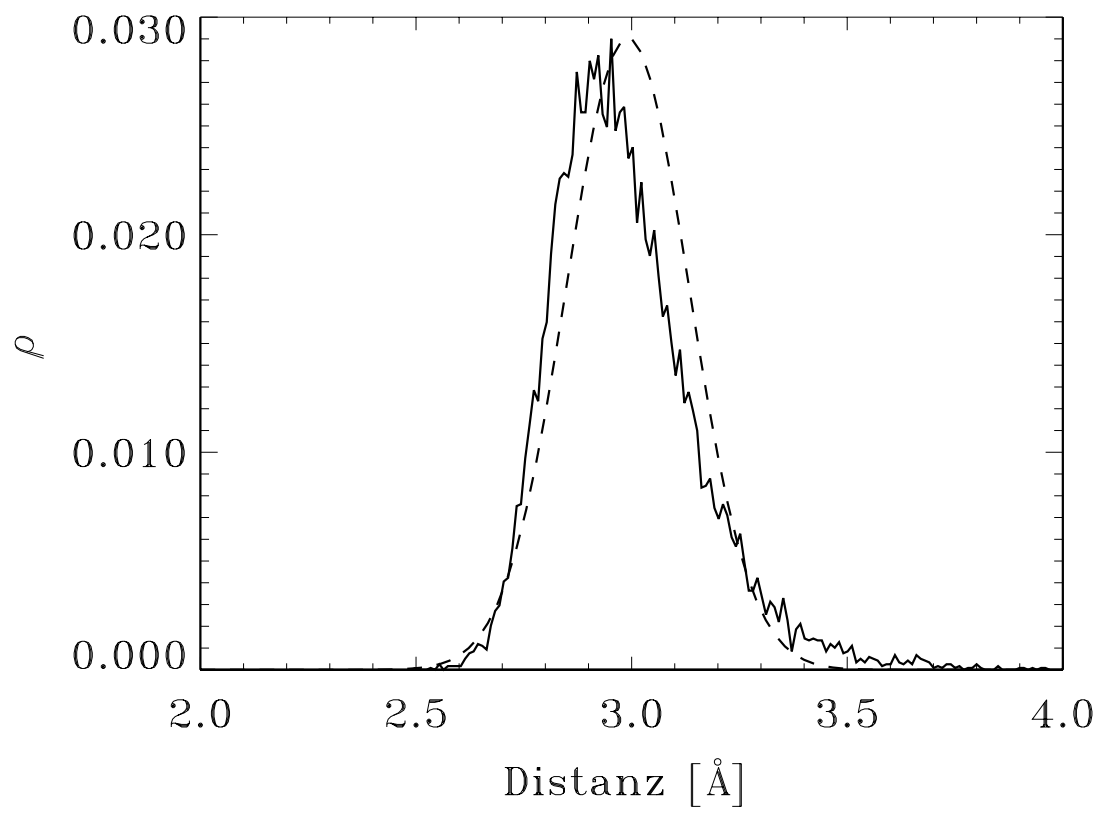

Abbildung 5.13: Verteilung der Längen von Wasserstoffbrückenbindungen, abgeleitet aus den Simulationen (durchgezogene Linie) und approximiert durch eine Gauß-Verteilung (gestrichelte Linie).

$v_{\text {cant }}<3 \mathrm{~m} / \mathrm{s}$, bei dem die Dissoziationskräfte signifikant niedrigere Werte annehmen als die lineare Approximation (deutlich zu erkennen in der logarithmischen Auftragung), für das wir aktivierte Prozesse verantwortlich machen, die durch thermische Fluktuationen getrieben wurden [68]. Das lineare Regime ist schon mehrfach in Simulationen beobachtet worden [55, 62], während das Regime der aktivierten Prozesse zwar erwartet [55, 58, 88], bisher allerdings wegen zu kurzer Simulationszeitspannen noch nicht erkennbar war.

Um ausgehend von diesen berechneten Kräften abzuschätzen, welche Dissoziationskraft auf der experimentellen Zeitskala erwartet werden kann, haben wir Gleichung (4.8) aus dem in Kapitel 4 beschriebenen Modell an die berechneten Dissoziationskräfte angepasst. Die hierfür benötigte spontane Dissoziationskonstante $k_{\text {off }}$ wurde für das vorliegende AN02-DNP-Hapten-System noch nicht gemessen, jedoch diejenigen der sehr ähnlichen Komplexe AN02-DNP-Glycin $\left(k_{\text {off }} \approx 100 \mathrm{~s}^{-1}\right)$ und AN02-DNP-Diglycin $\left(k_{\text {off }} \approx\right.$ $130 \mathrm{~s}^{-1}$ ) [200]. Wir konnten daher annehmen, dass die spontane Dissoziationskonstante für den hier untersuchten AN02-DNP-Hapten-Komplex im Bereich $k_{\text {off }}=110 \pm 70 \mathrm{~s}^{-1}$ liegt $^{6}$. Das Ergebnis dieser Anpassung ist in Abbildung 5.14 anhand der durchgezogenen Linien gezeigt. Die gestrichelten Linien zeigen die Anpassung auf Grundlage der oberern bzw. unteren Grenzen für die Dissoziationskräfte und der spontanen Dissoziationskonstante. Wir erwarten für das kraftmikroskopische Dissoziationsexperiment zum AN02-DNP-Hapten-Komplex eine Dissoziationskraft von $65 \pm 25$ pN (weiße Raute). Für den Reibungskoeffizienten $\gamma$ ergab sich aus der Anpassung ein Wert von $18.6 \mathrm{Ns} / \mathrm{m}$, für

\footnotetext{
${ }^{6}$ Die entspricht einer Aktivierungbarriere $\Delta G=-k_{\mathrm{B}} T \ln \frac{k_{\text {off }}}{\omega} \approx 11 \mathrm{kcal} / \mathrm{mol}$, wenn man den KramersVorfaktor $\omega=10^{10} \mathrm{~s}^{-1}$ wählt.
} 


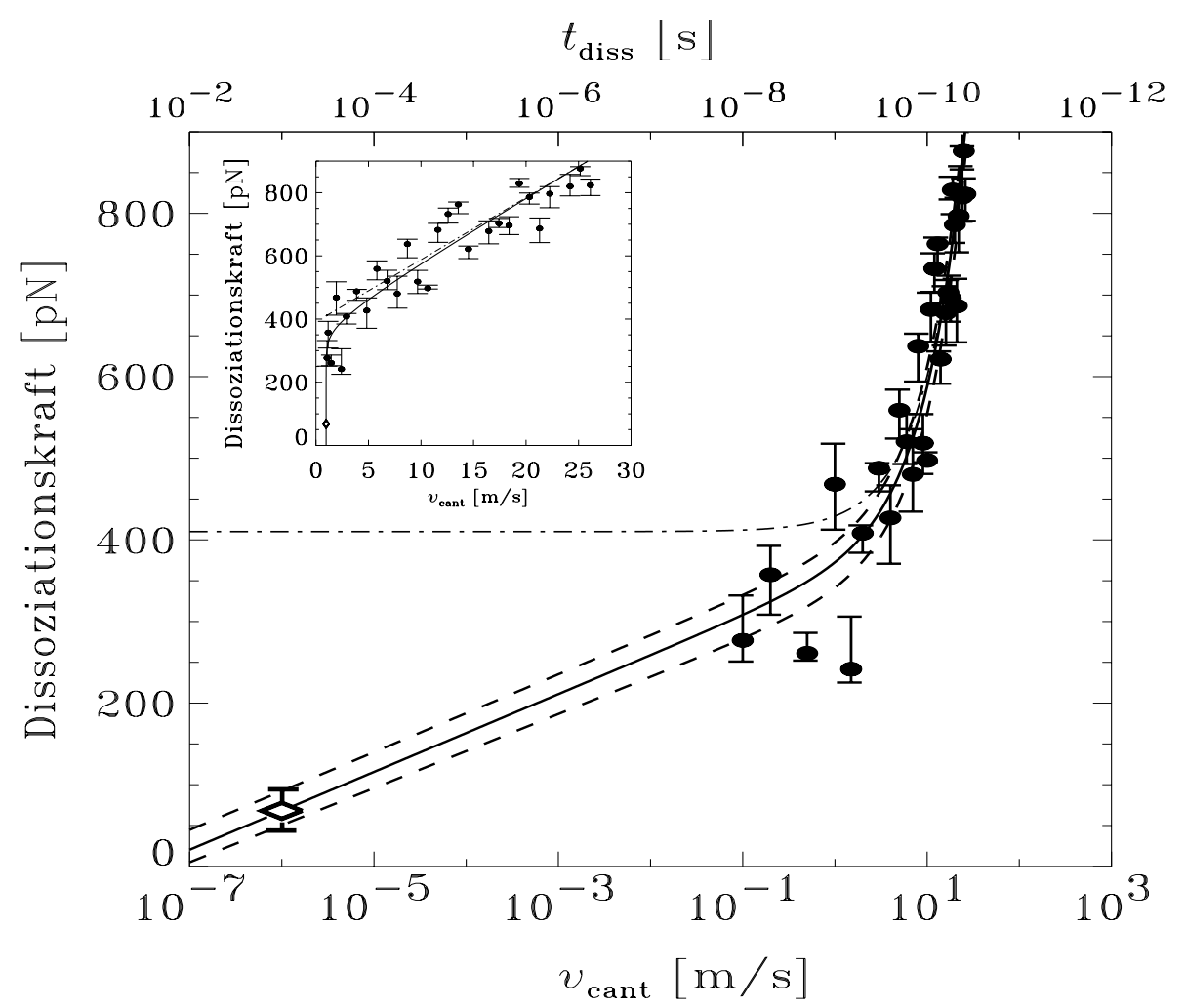

Abbildung 5.14: Aus den Dissoziationssimulationen abgeleitete Dissoziationskräfte (schwarze Punkte) in Abhängigkeit von der Zuggeschwindigkeit in logarithmischer Auftragung und in linearer Auftragung (Diagramm oben links). Die Interpolation der berechneten Dissoziationskräfte (durchgezogene Linie) anhand des in Abschnitt 4.1 beschriebenen Modells, das Stokessche Reibung, aktivierte Prozesse und die spontane Dissoziationsrate berücksichtigt, führt zu einer für die experimentelle Millisekunden-Zeitskala erwarteten Dissoziationskraft von $65 \pm 25 \mathrm{pN}$ (weiße Raute). Die gestrichelten Linien zeigen die Interpolation auf Grundlage der oberen bzw. der unteren Grenzen der berechneten Dissoziationskräfte. Die gepunktet-gestrichelte Linie zeigt eine lineare Extrapolation, die lediglich den Beitrag Stokesscher Reibung berücksichtigt.

die Dissoziationslänge $L \approx 3.0 \AA$ und für deren Schwankungsbreite $\Delta L \approx 3.6 \AA$. Die letzten beiden Werte sind in guter Übereinstimmung mit den Werten, die direkt aus den einzelnen Dissoziationssimulationen abgeleitet wurden (Abbildung 5.15), wobei wir die Dissoziationslänge mit der Position des Maximums im Kraftprofil abgeschätzt haben.

Die hier beschriebenen Dissoziationssimulationen sind unseres Wissens nach die ersten überhaupt, die über eine hinreichend lange Simulationszeitspanne bzw. mit hinreichend kleinen Zuggeschwindigkeiten durchgeführt wurden, um in das Regime vorzudringen, in dem durch thermische Fluktuationen getriebene aktivierte Prozesse dominieren. So trugen Reibungskräfte bei der Dissoziationssimulation mit der Zuggeschwindigkeit von $v_{\text {cant }}=$ $0.1 \mathrm{~m} / \mathrm{s}$ nur noch mit rund $3 \mathrm{pN}$ zur Dissoziationskraft bei, wohingegen aktivierte Prozesse die Dissoziationskraft bereits um etwa $100 \mathrm{pN}$ erniedrigten. Bei einer Zuggeschwindigkeit von $25 \mathrm{~m} / \mathrm{s}$ betrug die Reibungskraft dahingegen rund $500 \mathrm{pN}$, während aktivierte Prozesse hier einen vergleichsweise kleinen Einfluss auf die Dissoziationskraft hatten. 


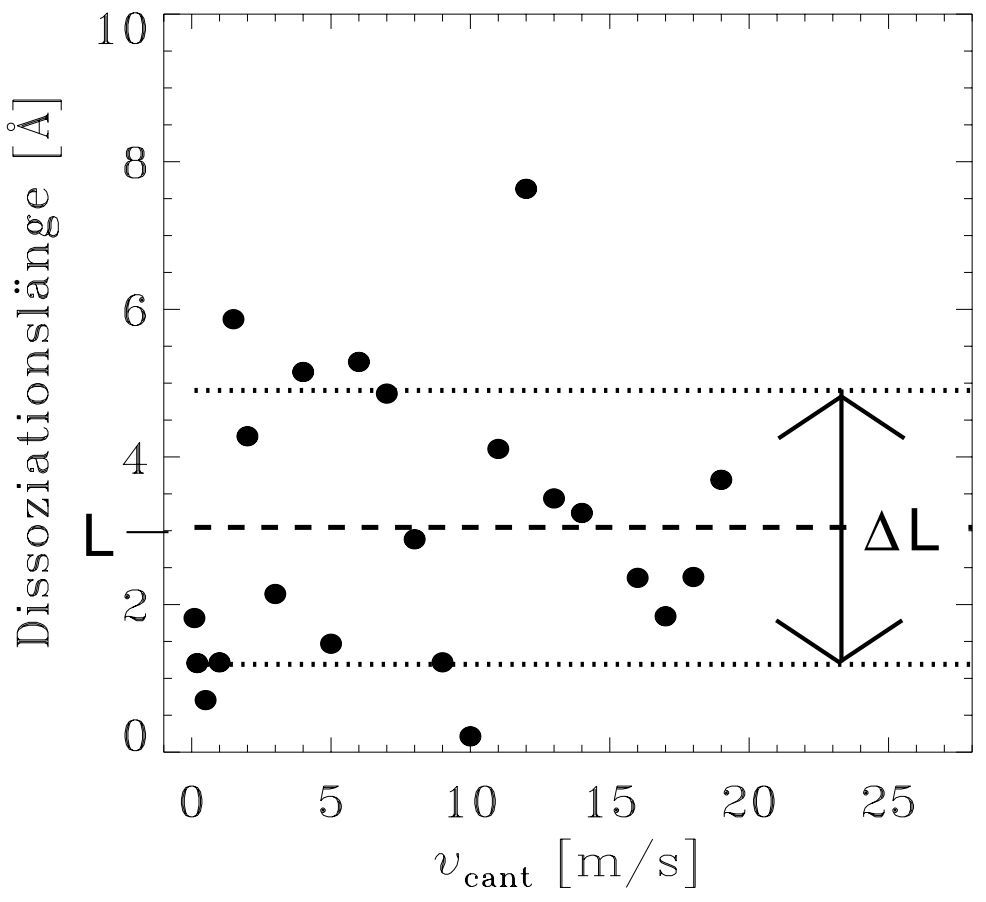

Abbildung 5.15: Dissoziationslängen aus den Dissoziationssimulationen als Funktion der Zuggeschwindigkeit. $L$ bezeichnet die mittlere Dissoziationslänge, $\Delta L$ die Standardabweichung.

Experimentelle Werte für die AN02-DNP-Hapten-Dissoziationskraft liegen noch nicht vor, doch sind kraftmikropische Experimente zu diesem Komplex am Lehrstuhl Gaub an der Universität München in Arbeit; so ist zu erwarten, dass unsere Vorhersage demnächst überprüft werden kann. 


\subsubsection{Dissoziationspfade und Wechselwirkungen}

In diesem Abschnitt soll aus den durchgeführten Simulationen ein Modell des Dissoziationsprozesses extrahiert werden, das die relevanten Bewegungen und Wechselwirkungen zusammenfasst. Insbesondere wollen wir die folgenden Fragen beantworten: Mit welchen Aminosäuren tritt das Haptenmolekül während des Dissoziationsvorgangs in Wechselwirkungen und welche dieser Wechselwirkungen dominieren? Auf welchen Pfaden im Konfigurationsraum bewegt sich das Haptenmoleküls aus der Bindungstasche, wie viele solcher Pfade gibt es und worin unterscheiden sie sich gegebenenfalls? Welche Konformationsänderungen ereigneten sich innerhalb der Bindungstasche, als wie flexibel erwies sich die Bindungstasche? Insbesondere die Fragen nach den Dissoziationspfaden und nach der Konformationsflexibiltät zielen darauf ab zu klären, welchen Einfluss entropische Beiträge auf die Bindungs- bzw. Dissoziationskinetik nehmen.

\section{Methoden}

\section{(a) Wechselwirkungen:}

Zur Charakterisierung der während des Dissoziationsprozesses getrennten oder transient auftretenden Wechselwirkungen wurden die folgenden Observablen herangezogen und berechnet:

- Summe der Wechselwirkungsenergien zwischen DNP-Hapten und der Bindungstasche als Funktion der Cantileverposition $z_{\text {cant }}$, aufgeschlüsselt in elektrostatische und Van der Waals-Anteile.

- Summe aus elektrostatischen und Van der Waals-Wechselwirkungsenergien zwischen DNP-Hapten und einzelnen Aminosäuren der Bindungstasche sowie zwischen DNPHapten und der gesamten leichten Kette bzw. der gesamten schweren Kette als Funktion der Cantileverposition $z_{\text {cant }}$, deren gemeinsame Auftragung für jede Dissoziationssimulation ein Wechselwirkungsmuster ergibt.

- Stärke der Wasserstoffbrücken zwischen DNP-Hapten und Aminosäuren der Bindungstasche. Dabei wurden Wasserstoffbrücken wie in Ref. [148] mit Hilfe eines kombinierten Abstands- und Energiekriteriums definiert: Danach wurde ein Wasserstoffbrückenkontakt angenommen, sobald der Abstand zwischen Donor- und Akzeptoratom weniger als $4 \AA$ betrug und die Summe aus elektrostatischen und Van der Waals-Wechselwirkungen zwischen den beteiligten polaren Gruppen kleiner als $-1 \mathrm{kcal} / \mathrm{mol}$ war. Die Stärke der Wasserstoffbrücke wurde über die Wechselwirkungsenergie quantifiziert.

- Wasserbrücken zwischen DNP-Hapten und Aminosäuren der Bindungstasche. Dabei wurde eine Wasserbrücke definiert als ein Wassermolekül, das gleichzeitig Wasserstoffbrücken zu DNP-Hapten und zu einer Aminosäure der Bindungstasche ausbildete und dadurch eine Wechselwirkung zwischen DNP-Hapten und Aminosäure vermittelte. 


\section{(b) Strukturelle Analyse}

In der strukturellen Analyse interessieren wir uns zunächst für die Dissoziationspfade, d.h. die Positionen des Haptenmoleküls im Verlauf des Dissoziationsprozesses relativ zu den Aminosäuren der Bindungstasche. Dafür wurden vornehmlich die Simulationen mit kleinen Zuggeschwindigkeiten $\left(v_{\text {cant }} \leq 2 \mathrm{~m} / \mathrm{s}\right)$ herangezogen.

Anschließend wird, und das ist das Hauptziel der strukturellen Analyse, der Reaktionsweg im Konfigurationsraum von Protein und Ligand charakterisiert werden. Dies erfordert insbesondere, die für die kollektive Bewegung aller Atome der Bindungstasche essentiellen Freiheitsgrade zu identifizieren. Dabei stützen wir uns wesentlich auf die vor kurzem in das Gebiet der MD-Simulation eingeführte [201-206] Methode der Hauptkomponentenanalyse [207], welche es gestattet, in linearer Näherung diejenigen (kollektiven) Freiheitsgrade zu konstruieren, die den größten Teil der Bewegung einer gegebenen MD-Simulation beschreiben. Darüber hinaus wollen wir die Hauptkomponentenanalyse dazu benutzen, den Beitrag der Entropie zur freien Energie der AN02-DNP-Hapten-Bindung abzuschätzen.

Zur Hauptkomponentenanalyse fassen wir, wie in Abbildung 5.16 veranschaulicht, die instantane Konfiguration $\mathbf{x}(t)$ eines betrachteten Moleküls (oder Molekül-Komplexes) zum Zeitpunkt $t$ als einen Punkt im $3 N$-dimensionalen Konfigurationsraum auf. Entsprechend werden die $M$ Konfigurationen der in einer MD-Simulation berechneten Trajektorie, die ein Ensemble approximiert, durch eine „Punktwolke“ $\left\{\mathbf{x}\left(t_{1}\right), \mathbf{x}\left(t_{2}\right), \ldots, \mathbf{x}\left(t_{M}\right)\right\}$ im Konfigurationsraum dargestellt (Abbildung 5.16, Mitte). Diese Punktwolke wird nun durch ihren Mittelwert $\overline{\mathbf{x}}=\langle\mathbf{x}\rangle$ und ihre Kovarianzmatrix $\mathbf{K}_{\mathbf{x}}=\left\langle(\mathbf{x}-\overline{\mathbf{x}}) \cdot(\mathbf{x}-\overline{\mathbf{x}})^{\mathrm{T}}\right\rangle$ beschrieben; ihre Dichte kann dann durch die multivariate Gauß-Verteilung

$$
\rho(\mathbf{x}) \propto \exp \left[-\frac{1}{2}(\mathbf{x}-\overline{\mathbf{x}}) \mathbf{K}_{\mathbf{x}}^{-1}(\mathbf{x}-\overline{\mathbf{x}})\right]
$$

approximiert werden. Durch Diagonalisierung der Kovarianzmatrix

$$
\mathbf{C}=\mathbf{Q}^{\mathrm{T}} \mathbf{K}_{\mathbf{x}} \mathbf{Q}
$$

erhält man die Eigenvektoren $\mathbf{Q}=\left(\mathbf{v}_{1}, \mathbf{v}_{2}, \ldots, \mathbf{v}_{3 N}\right)$ der Verteilung mit den zugehörigen Eigenwerten $c_{i}(i=1, \ldots, 3 N)$; die Varianz der Punktwolke in der Richtung des $i$-ten Eigenvektors ist durch $\sqrt{c_{i}}$ gegeben. Sortiert man also die Eigenvektoren nach der Größe ihrer Eigenwerte, so beschreibt der erste Eigenvektor, $v_{1}$, die (kollektiven) Bewegungen des betrachteten Moleküls mit der größten Amplitude, entsprechend der zweite Eigenvektor, $v_{2}$ die mit der zweitgrößten Amplitude usw. Die Eigenvektoren $v_{i}$ bezeichnen wir auch als die essentiellen Freiheitsgrade des betrachteten Systems. Ein in diesem Sinne optimiertes Bild der Konformationsdynamik (Abbildung 5.16) erhält man damit durch Projektion der Trajektorie auf den durch die beiden ersten Eigenvektoren aufgespannten Unterraum, $\left(q_{1}, q_{2}\right)=\left(\mathbf{v}_{1} \cdot \mathbf{x}, \mathbf{v}_{2} \cdot \mathbf{x}\right)$, wobei die Eigenvektoren als normiert angenommen werden.

Die Hauptkomponentenanalysen, die wir zur Identifikation der essentiellen Freiheitsgrade im Dissoziationsprozess des AN02-DNP-Hapten-Komplexes durchgeführt haben, basieren auf den Trajektorien aus 20 Dissoziationssimulationen mit einer Zeitspanne von jeweils $300 \mathrm{ps}$ (da die Atompositionen alle $100 \mathrm{fs}$ abgespeichert wurden, entspricht dies $3000 \mathrm{Ko}-$ ordinatensätzen pro Simulation), die alle dieselbe Zuggeschwindigkeit von $v_{\text {cant }}=5 \mathrm{~m} / \mathrm{s}$ 


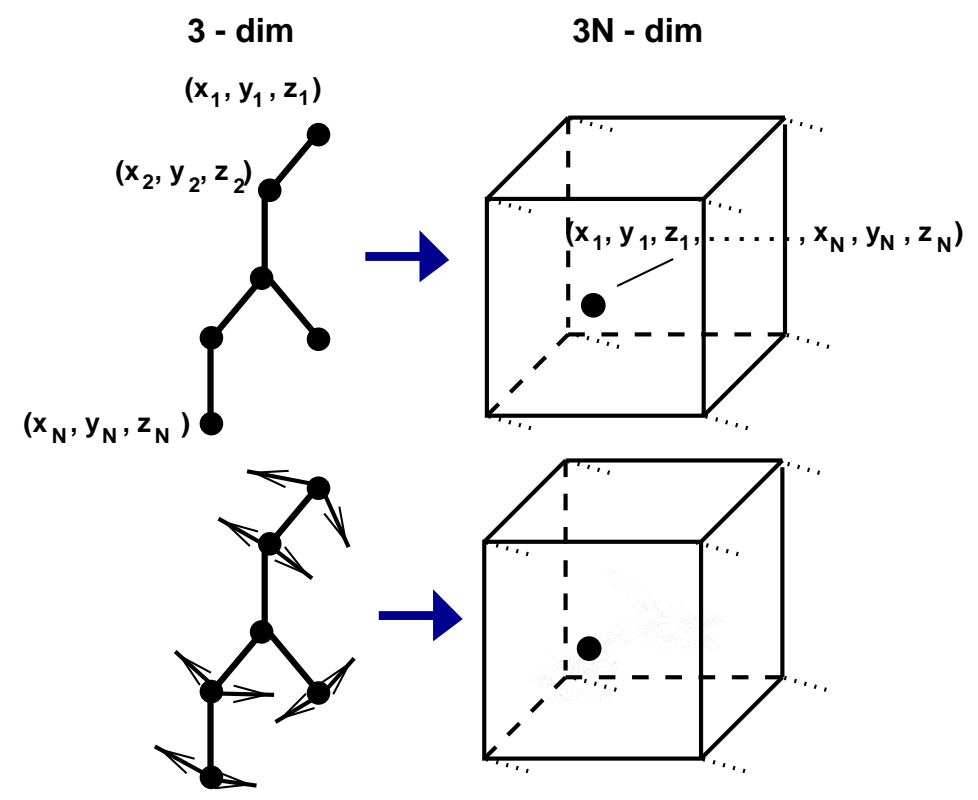

Projektion

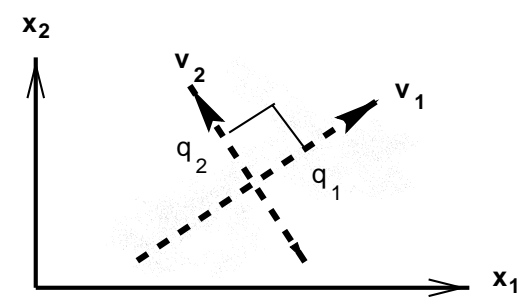

Abbildung 5.16: Prinzip der Hauptkomponentenanalyse: Eine Konfiguration eines betrachteten $N$-atomigen Moleküls (oben links) wird durch einen Punkt im $3 N$-dimensionalen Konfigurationsraum (oben rechts) repräsentiert, und entsprechend ein Ensemble von Konfigurationen (Mitte, links) durch eine „Punktwolke“ (Mitte, rechts). Die ersten beiden von den aus der Hauptkomponentenanalyse gewonnenen Eigenvektoren $\left(v_{1}\right.$ und $\left.v_{2}\right)$ weisen in die Richtung mit den beiden größten Ausdehnungen der Punktwolke (Projektion im Bild unten).

aufweisen und sich lediglich in ihren Ausgangsstrukturen unterscheiden. In die Hauptkomponentenanalyse wurde nur die Bindungstasche des Komplexes (einschließlich des Haptens) mit insgesamt 475 Atomen einbezogen, so dass sich daraus ein 1425-dimensionaler Konfigurationsraum ergibt. Eine der Hauptkomponentenanalysen basierte auf allen 20 Trajektorien zusammen, d.h. auf einem Ensemble von 60000 Koordinatensätzen. Um sich ein Bild davon zu machen, welche kollektiven Bewegungen die ersten Eigenvektoren beschreiben, haben wir deren Richtungen in Schnappschüssen der Bindungstasche anhand von Pfeilen an den einzelnen Aminosäuren angedeutet.

Zum Vergleich der Dissoziationssimulationen untereinander betrachten wir zum einen die Projektionen aller Trajektorien auf jeden der ersten sechs wichtigsten Eigenvektoren als Funktion der Cantileverposition, zum anderen die Projektionen auf den Unterraum, der von dem zweiten und den dritten Eigenvektor aufgespannt wird. In diesen Projektionen 
zeigt sich, welchen Weg im Konfigurationsraum die einzelnen Simulationen entang dieser Eigenvektoren während des Dissoziationsvorgangs nahmen; insbesondere das Ausmaß der strukturellen Heterogenität in den Dissoziationspfaden wird hier erkennbar. Diese strukturelle Heterogenität sollte sich auch in einem entropischen Beitrag zur freien Energie des AN02-DNP-Hapten-Komplexes entlang des Reaktionswegs zeigen.

Im Folgenden wollen wir erläutern, wie wir mit Hilfe der Hauptkomponentenanalyse die Entropie zur AN02-DNP-Hapten-Bindung abgeschätzt haben. Die Entropie lässt sich schreiben als [43]

$$
S=-k_{B} \int \rho(\mathbf{x}) \ln \rho(\mathbf{x}) d^{3 N} \mathbf{x},
$$

wobei $k_{B}$ die Boltzmannkonstante ist und sich das Integral über den Konfigurationsraum erstreckt (da wir keine geschwindigkeitsabhängigen Kräfte einbeziehen, ist der Beitrag der Impulse zur freien Energie des Systems konstant und wird daher hier nicht betrachtet).

Nach den Referenzen [208,209] lässt sich Gleichung (5.4) mit Hilfe der Gaußschen Approximation $\rho(\mathbf{x})$ der Konfigurationsdichte [Gleichung (5.2)] umformen zu [210]

$$
S=S_{0}+\frac{3}{2} N k_{B}+\frac{1}{2} k_{B} \ln \left[(2 \pi)^{3 N} \operatorname{det}\left(\mathbf{K}_{\mathbf{x}}\right)\right],
$$

wobei $S_{0}$ eine Konstante ist. Für die Entropiedifferenz zwischen zwei unterschiedlichen Konformationen 1 und 2 ergibt sich [208]

$$
\Delta S_{12}=\frac{1}{2} k_{B} \ln \frac{\operatorname{det}\left(\mathbf{K}_{\mathbf{x}}^{1}\right)}{\operatorname{det}\left(\mathbf{K}_{\mathbf{x}}^{2}\right)} .
$$

Die Determinante von $\mathbf{K}_{\mathbf{x}}^{i}(i=1,2)$ ist gleich dem Produkt der Eigenwerte; dieses Produkt kann damit sehr anschaulich als Abschätzung des Volumens $V_{i}$ aufgefasst werden, das die Trajektorie im Konfigurationsraum einnimmt.

Wir wollen den soeben beschriebenen Ansatz, der die Entropie eines Ensembles von Konfigurationen abzuschätzen erlaubt, verallgemeinern, indem wir in dem Konfigurationsraum nun Reaktionswege betrachten, und aus ihnen den Verlauf der Entropie des AN02DNP-Hapten-Komplexes während des Dissoziationsprozesses, d.h. als Funktion der Cantileverposition $z_{\text {cant }}$ (der Reaktionskoordinate) abschätzen. Dieser Verlauf dient uns als Maß für die strukturelle Heterogenität der Dissoziationspfade. Dazu betrachten wir die zeitabhängige Entropie

$$
\begin{aligned}
S(t) & =\int \rho(\mathbf{x}, t) \ln \rho(\mathbf{x}, t) d^{3 N} \mathbf{x} \\
& =\int d t^{\prime} \int \rho(\mathbf{x}, t) \ln \rho(\mathbf{x}, t) \delta\left(t^{\prime}-t\right) d^{3 N} \mathbf{x}
\end{aligned}
$$

zu jeder Zeit $t$ während des Dissoziationsprozesses; $\delta(t)$ ist dabei die Delta-Funktion. In $Z(t)$ sind hier alle Konfigurationen berücksichtigt, die man in allen Reaktionswegen zum Zeitpunkt $t$ bzw. bei der Cantileverposition $z_{\text {cant }}(t)$ vorfindet. Unter der Annahme, dass alle diese Konfigurationen zu jedem Zeitpunkt $t$ ein Ensemble approximieren, kann die Entropiedifferenz $\Delta S(t)$ nach Gleichung (5.6) berechnet werden. Um für jeden Zeitpunkt $t$ hinreichend viele, aus den Simulationen extrahierte Konfigurationen zur Verfügung zu 
haben, betrachten wir zur Berechnung der Entropiedifferenz $\Delta S(t)$ alle Konfigurationen aus dem Intervall $[t, t+\Delta t]$ mit $\Delta t>0$, d.h. wir ersetzen $\delta(t)$ in Gleichung (5.7) durch

$$
\chi=\frac{1}{\Delta t}[\Theta(t)-\Theta(t+\Delta t)]
$$

mit der Theta-Funktion $\Theta(t)$. Da unsere Reaktionskoordinate die Cantileverposition $z_{\text {cant }}(t)$ ist, ersetzen wir nun $t$ durch $z_{\text {cant }}(t)$, was keine qualitative Änderung bedeutet, da $z_{\text {cant }}(t)$ linear in $t$ ist.

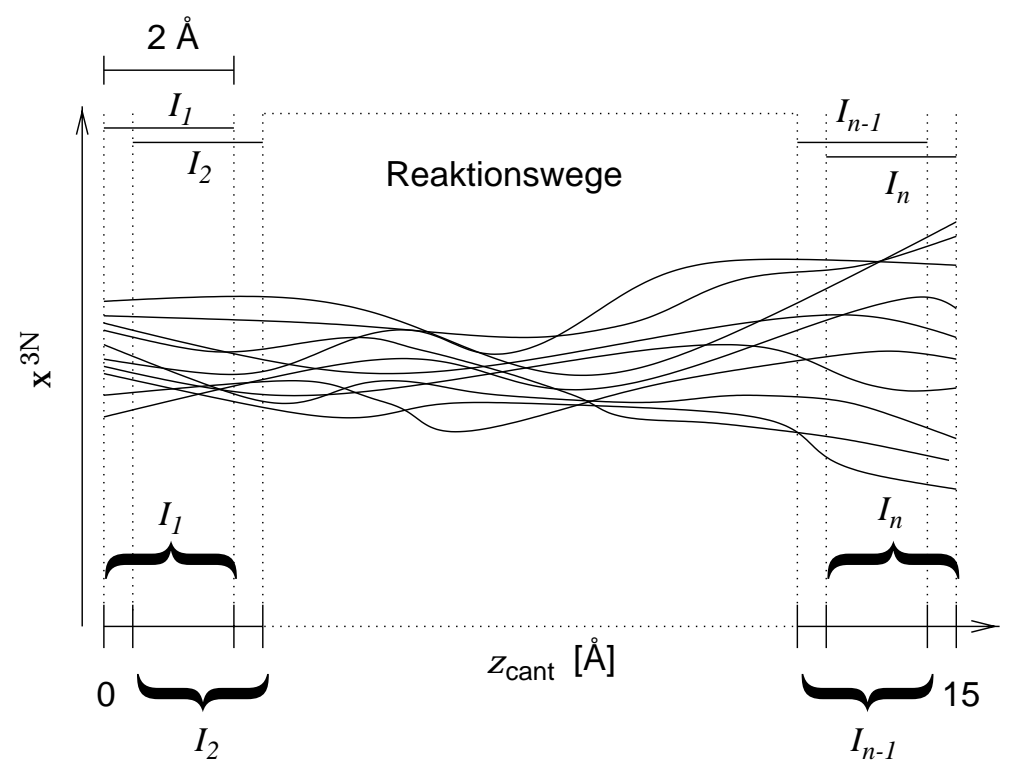

Abbildung 5.17: Skizze zur Berechnung des Entropieverlaufs. Durchgezogene Linien markieren hypothetische Reaktionswege des Dissoziationsprozesses als Funktion der Reaktionskoordinate $z_{\text {cant }}$. Die vertikale Achse fasst alle Freiheitsgrade $x^{3 N}$ zusammen. Zur Abschätzung des Entropie als Funktion von $z_{\text {cant }}$ definieren wir die Intervalle $I_{1}, I_{2}, \ldots, I_{n}$. Für jedes Intervall $I_{i}(i=1, \ldots, n)$ wurde nach Gleichung (5.6) die Entropie des Ensembles aus allen denjenigen Konfigurationen bestimmt, die auf den Reaktionswegen innerhalb des Intervalls $I_{i}$ lokalisiert sind.

Wie in Abbildung 5.17 gezeigt, teilen wir die Reaktionskoordinate $z_{\text {cant }}$ in dem Bereich von $0-15 \AA$ in $2 \AA$-Intervalle $I_{i}(i=1, \ldots, n)$ ein, die jeweils um $0.1 \AA$ zueinander versetzt sind. Für jedes Intervall $I_{i}$ berechnen wir nach Gleichung (5.6) die Konfigurationsentropie. Dabei setzen wir für $\operatorname{det}\left(\mathbf{K}_{\mathbf{x}}^{1}\right)$ das mittlere Konfigurationsvolumen jedes einzelnen Reaktionswegs und für $\operatorname{det}\left(\mathbf{K}_{\mathbf{x}}^{2}\right)$ das Konfigurationsvolumen aller Reaktionswege zusammen innerhalb des Intervalls $I_{i}$. Da die einzelnen Trajektorien in jedem Intervall mit 400 Koordinatensätzen weniger Konfigurationen beinhalten als der Konfigurationsraum Dimensionen hat und somit bei der Diagonalisierung der Kovarianzmatrizen $\mathbf{K}_{\mathbf{x}}^{1}$ und $\mathbf{K}_{\mathbf{x}}^{2}$ einige Eigenwerte verschwinden, schätzen wir die Konfigurationsvolumina mit dem Produkt lediglich der größten Eigenwerte ab. Dies ist gerechtfertigt, weil, wie sich zeigen wird, die Änderung in der Entropie maßgeblich durch die langsamen Freiheitsgrade, die durch die ersten Eigenvektoren mit den größten Eigenwerten beschrieben werden, bestimmt ist und sich der entropische Beitrag von den schnellen Freiheitsgraden im Verlauf des Prozesses 
kaum ändert. Verschiedene Studien haben ergeben, dass in Proteinen bereits etwa $90 \%$ aller Fluktuationen durch die ersten 10 - 20 Eigenvektoren beschrieben werden [201-203], so dass die weiteren Eigenvektoren nur noch entsprechend wenig zur gesamten Bewegung im Protein beitragen und im wesentlichen hochfrequente Fluktuationen mit kleiner Amplitude beschreiben. Um den Einfluss der Anzahl der Eigenwerte, die zur Berechnung der Entropie herangezogen wurden, abzuschätzen, wurden in 11 separaten Berechnungen die größten 50, 55, 60, ..., 100 Eigenwerte zugrunde gelegt.

\section{Ergebnisse}

Zunächst beschreiben wir die Ergebnisse aus den ersten Schritten des Dissoziationsprozesses. Diese erwiesen sich in nahezu allen durchgeführten Dissoziationssimulationen als einander sehr ähnlich, d.h. als strukturell homogen. Anschließend gehen wir auf den weiteren Verlauf des Dissoziationsprozesses ein, der im Gegensatz zu den ersten Schritten eine überraschend große strukturelle Heterogenität aufwies. Zum Abschluss betrachten wir die kollektiven Bewegungen, durch die sich die Dissoziationssimulationen auszeichneten.

\section{Erste Schritte des Dissoziationsprozesses: Strukturelle Homogenität}

Die Schnappschüsse in Abbildung 5.18 zeigen die Ereignisse, die während der ersten Phase des Dissoziationsprozesses im Bereich der Bindungstasche bei allen Simulationen gleichermaßen beobachtet wurden, wobei der Dissoziationsprozess von oben $\left(z_{\text {cant }}=0 \AA\right.$, gebundener Zustand) nach unten $\left(z_{\text {cant }} \approx 4 \AA\right)$ fortschreitet. Wasserstoffbrücken und Van der Waals-Kontakt zwischen Hapten und Aminosäuren der Bindungstasche sind dabei mit gepunkteten Linien gekennzeichnet. Der zweite Schnappschuss in der Abbildung $\left(z_{\text {cant }} \approx 2 \AA\right)$ illustriert das erste signifikante Ereignis des Dissoziationsprozesses: die (relativ schwache) Wasserstoffbrücke (Pfeil) zwischen dem Seitenketten-Stickstoff von GLN88(L) und der zweiten Nitrogruppe von Hapten $(\mathrm{N} 26, \mathrm{O} 27, \mathrm{O} 28)$ brach, was eine leichte Verdrehung sowohl des DNP-Rings um die Ring-Achse im Uhrzeigersinn als auch eine Umorientierung der Nitrogruppe „nach oben“, d.h. in Richtung Ausgang der Bindungstasche zur Folge hatte. Gleichzeitig verschwand auch die Wasserbrücke, die zwischen GLN88(L) und der zweiten Nitrogruppe bestand (nicht gezeigt). Daraufhin ereigneten sich weitere Änderungen in den Wechselwirkungen zwischen Hapten und Bindungstaschen- 


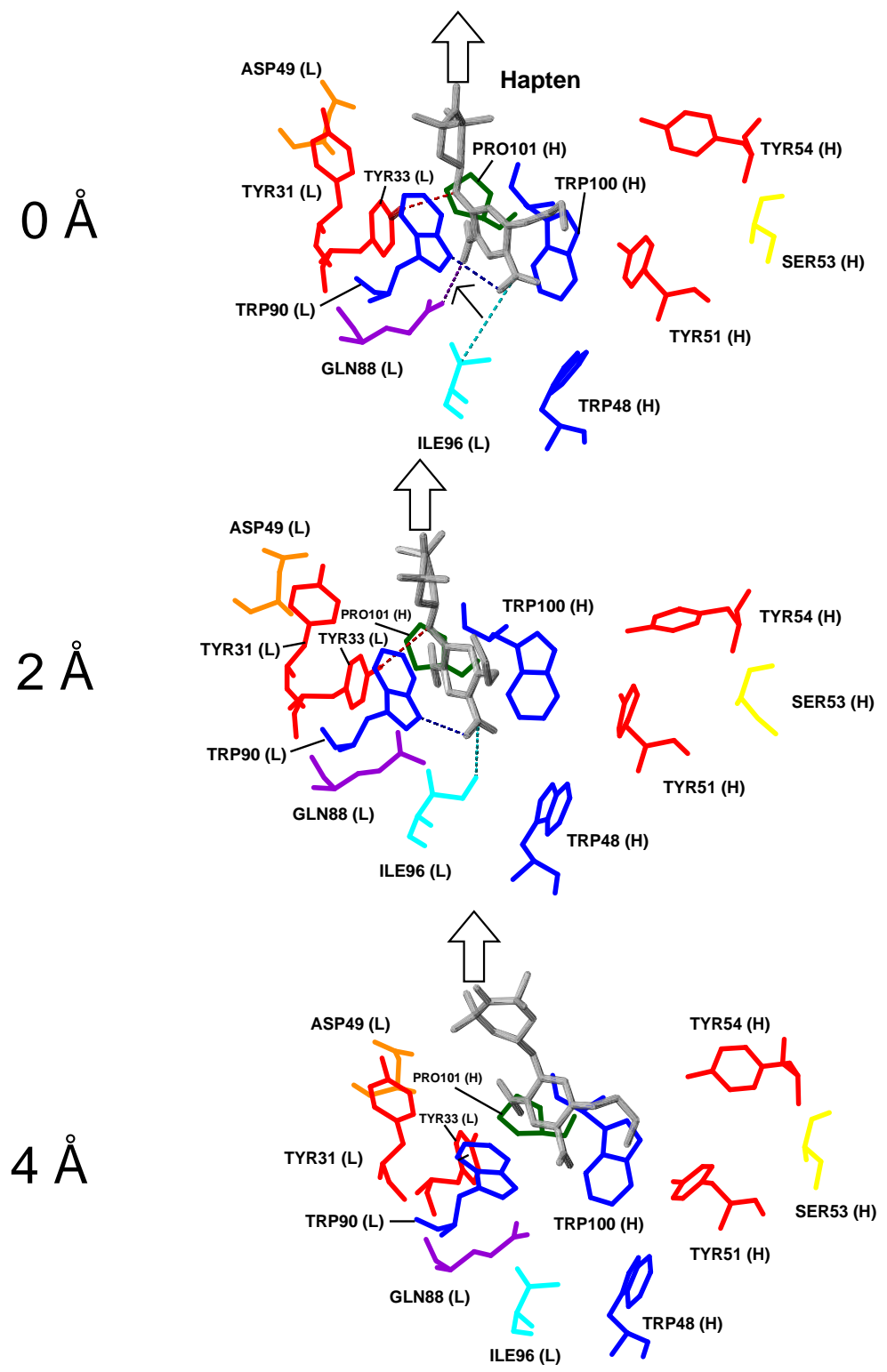

Abbildung 5.18: Schnappschüsse der Bindungstasche von AN02 mit Hapten. Links ist jeweils die Cantileverposition $z_{\text {cant }}$ angegeben. Wasserstoffbrücken und Van der WaalsKontakte zwischen Hapten und Aminosäuren der Bindungstasche sind durch gepunktete Linien gekennzeichnet. Die großen Pfeile weisen in die Zugrichtung. 
aminosäuren (dritter Schnappschuss in der Abbidlung), deren chronologische Reihenfolge jedoch in den einzelnen Dissoziationssimulation variierte: Es lösten sich die Van der Waals-Kontakte der Seitenkette von ILE96(L) zu der ersen Nitrogruppe des DNP-Rings und es brachen die Wasserstoffbrücken zwischen dem Stickstoff im 5-Ring von TRP90(L) und dem Sauerstoff O24 der ersten Nitrogruppe sowie zwischen der Hydroxylgruppe des TYR33(L) und der Aminogruppe N8,H29 im Mittelteil von Hapten. Letzteres führte zu einer Konformationsänderung des Haptenmoleküls, dessen Mittelteil sich abrupt von der leichten Kette weg in Richtung der schweren Kette bewegte. Zudem öffnete sich die Sandwich-Konfiguration leicht, indem sich die Seitenketten TRP90(L) und TRP100(H) etwas von dem DNP-Ring wegdrehten. Außerdem bewegte sich die Seitenkette von TRP100(H), die in allen Simulationen eine vegleichsweise große Flexibilität in der Zugrichtung aufwies, etwas tiefer in die Bindungstasche hinein ${ }^{7}$. Die veränderte Lage der Seitenkette von TRP100(H) ermöglichte eine erhöhte Flexibilität der Amino-EthylAmino-Kette des Haptenmoleküls, die in einigen Simulationen Wasserstoffbrücken zu den Hydroxylgruppen von TYR51(H) und TYR54(H) ausbildete (hier nicht gezeigt). Im Zuge dieser Ereignisse führte das Haptenmolekül die erste signifikante Dissoziationsbewegung aus, indem sich der DNP-Ring ein Stück weit in Richtung Ausgang der Bindungstasche bewegte.

In den meisten Dissoziationssimulationen war das Maximum im Kraftprofil bereits nach den soeben beschriebenen ersten Dissoziationsschritten überwunden. Allerdings war es nicht möglich, das Überschreiten dieser maximalen Kraftbarriere einer einzelnen Wechselwirkung (bzw. das Brechen dieser Wechselwirkung) zwischen dem Haptenmolekül und einer Aminosäure der Bindungstasche zuzuordnen. In einigen Simulationen fiel das Absinken der Zugkraft mit dem Reißen der Wasserstoffbrücke zwischen GLN88(L) und dem Haptenmolekül zusammmen, in anderen mit der starken Bewegung des TRP100(H), in wieder anderen mit dem Abschwächen der Van der Waals-Kontakte zwischen ILE96(L) und PRO101(H) mit dem Haptenmolekül. Es gab auch Simulationen, in denen sich keine zeitliche Abfolge dieser Ereignisse ausmachen ließ, weil sie sich innerhalb derselben Zeitspanne im Dissoziationsprozess ereigneten. Dies legt die Vermutung nahe, dass die berechnete Dissoziationskraft nicht ausschließlich die Folge einer lokalisierten, spezifischen Wechselwirkung zwischen dem Haptenmolekül und einer Aminosäure ist, sondern dass sie durch das Zusammenwirken von mehreren Aminosäuren in der Umgebung des Haptens mitbedingt ist.

\section{Der weitere Verlauf des Dissoziationsprozesses: Strukturelle Heterogenität}

Die Reihenfolge, in der sich die einzelnen Wechselwirkungen zwischen dem Haptenmolekül und den Aminosäuren der Bindungstasche in der soeben beschriebenen ersten Dissoziationsphase abschwächten bzw. ganz verschwanden, erwies sich als entscheidend für die nachfolgenden Dissoziationsschritte. Von besonderer Bedeutung für den Dissoziationspfad war, ob zuerst die Wasserstoffbrücke zwischen TYR33(L) und dem Haptenmolekül verschwand oder ob zuerst die stabile Sandwich-Konfiguration aufgebrochen wurde. Abbildung 5.19 illustriert die unterschiedlichen Szenarien. Die drei Schnappschüsse auf der linken Seite

\footnotetext{
${ }^{7}$ Die Flexibilität der TRP100(H)-Seitenkette entlang der zum Ausgang der Bindungstasche gerichteten Achse deutete sich auch schon in der Equilibrierungssimulation an.
} 
zeigen den Fall, dass zuerst die Sandwich-Konfiguration aufbrach, indem TRP100(H) sich in die Bindungstasche hineinbewegte, wobei die Wasserstoffbrücke zwischen TYR33(L) und Hapten intakt blieb. Dieses hatte zur Folge, dass sich das Haptenmolekül zur leichten Kette hinbewegte und im weiteren Verlauf des Dissoziationsprozesses in starke Wechselwirkungen mit TYR31(L) und dem am Ausgang der Bindungstasche gelegenen ASP49(L) trat, sowohl über direkte Wasserstoffbrücken und Van der Waals-Kontakte als auch über indirekte Wasserbrücken. Diesen Dissoziationspfad bezeichnen wir als Route entlang der leichten Kette.

Das andere Szenario ist in den drei Schnappschüssen auf der rechten Seite gezeigt. Hier brach zuerst die Wasserstoffbrücke von TYR33(L) zu Hapten, was zu einer abrupten Bewegung der Aminogruppe des Hapten-Mittelteils hin zur schweren Kette führte, während das Hapten zunächst noch in einer sandwichartigen Konfigution verblieb. In diesem Szenario kam es zu starken Wechselwirkungen zwischen der Amino-Ethyl-Amino-Kette des Haptenmoleküls und TYR51(H) und TYR54(H) sowie zwischen der ersten Nitrogruppe des DNP-Rings (N23,O24,O25) mit der Hydroxylgruppe von TYR54(H) (dritter Schnappschuss auf der rechten Seite). Der hier beobachtete Dissoziationspfad wurde als Route entlang der schweren Kette bezeichnet.

Abbildung 5.20 macht deutlich, dass es nicht nur die beiden extremen Routen entlang der leichten Kette bzw. schweren Kette gab, sondern dass ein ganzer „Fächer“ von Dissoziationspfaden zu beobachten war. Jede der durchgezogenen Linien kennzeichnet den Dissoziationspfad einer der 20 Simulationen, die alle mit derselben Zuggeschwindigkeit von $v_{\text {cant }}=5 \mathrm{~m} / \mathrm{s}$ durchgeführt wurden. Für die beiden extremen Routen ist das Haptenmolekül in seinem ungebundenen Zustand explizit gezeigt. Deutlich zu sehen ist, dass sich die Routen auffächern, nachdem das Haptenmolekül die Sandwich-Konfiguration verlassen hat. In dieser Vielfalt an Dissoziationspfaden, die gleichbedeutend damit ist, dass dem AN02-Komplex während des Dissoziationsprozesses ein weiter Bereich im Konfigurationsraum zugänglich ist, zeigt sich die bereits angesprochene strukturelle Heterogenität.

Diese Heterogenität spiegelt sich auch in den Wechselwirkungsmustern der einzelnen Dissoziationssimulationen wider. Solche Muster sind gezeigt für eine Simulation, die repräsentativ für die Route entlang der leichten Kette ist (Abbildung 5.21, links) und eine, die repräsentativ für die Route entlang der schweren Kette ist (rechts) ${ }^{8}$. Unter den Wechselwirkungsmustern ist jeweils das zugehörige Kraftprofil gezeigt.

Zunächst ist leicht zu erkennen, dass sich die beiden Wechselwirkungsmuster deutlich voneinander unterscheiden. Für die Route entlang der leichten Kette blieben die Wechselwirkungen zur leichten Kette länger erhalten als diejenigen zur schweren Kette; die Wechselwirkungen zu TYR31(L) und ASP49(L), die sich in allen Simulationen als vergleichsweise bewegliche Aminosäuren herausstellten, verstärkten sich sogar zunächst. Für den umgekehrten Fall, der Route entlang der schweren Kette, gilt das Gegenteil: Hier blieben die Wechselwirkungen zur schweren Kette länger intakt bzw. es bildeten sich neue, insbesondere zu TYR54(H). Unterschiedliche Dissoziationspfade führten auch zu Varia-

\footnotetext{
${ }^{8}$ Beide Simulationen wurden mit derselben Zuggeschwindigkeit $v_{\text {cant }}=1 \mathrm{~m} / \mathrm{s}$ durchgeführt; sie unterschieden sich lediglich in den Ausgangsstrukturen, die der Equilibrierungstrajektorie zu den Zeitpunkten 800 bzw. 1300 ps entnommen wurden.
} 


\section{Route entlang}

\section{leichter Kette}

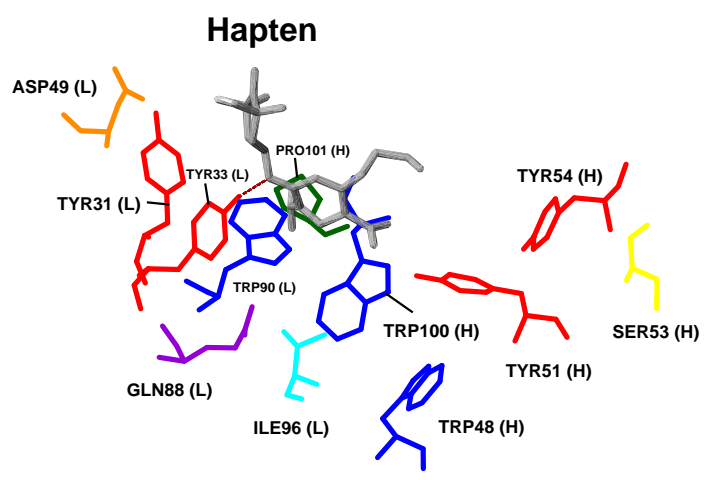

schwerer Kette

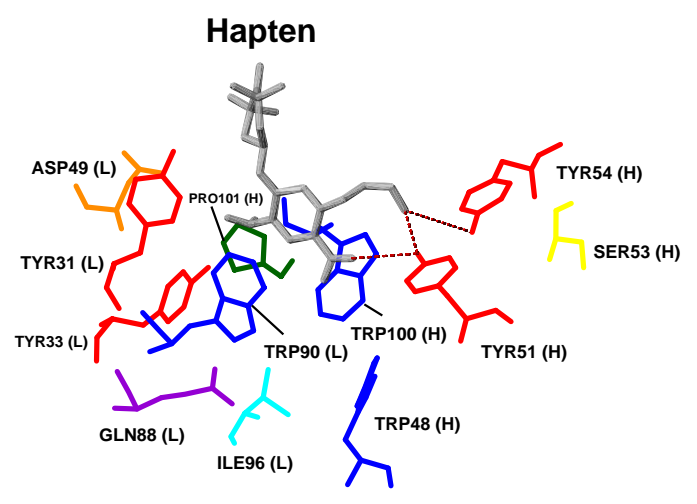

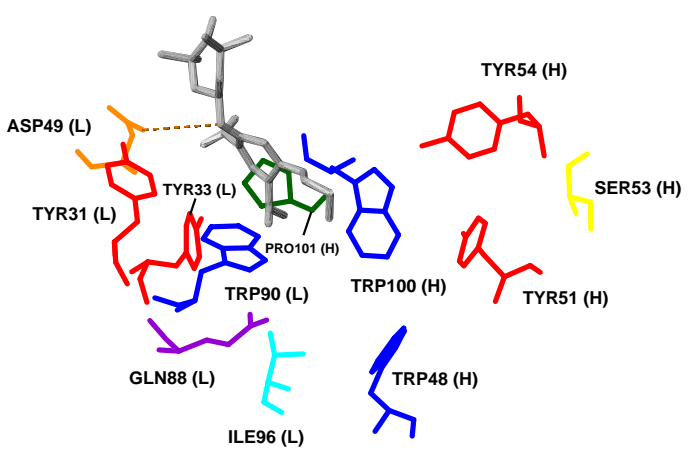
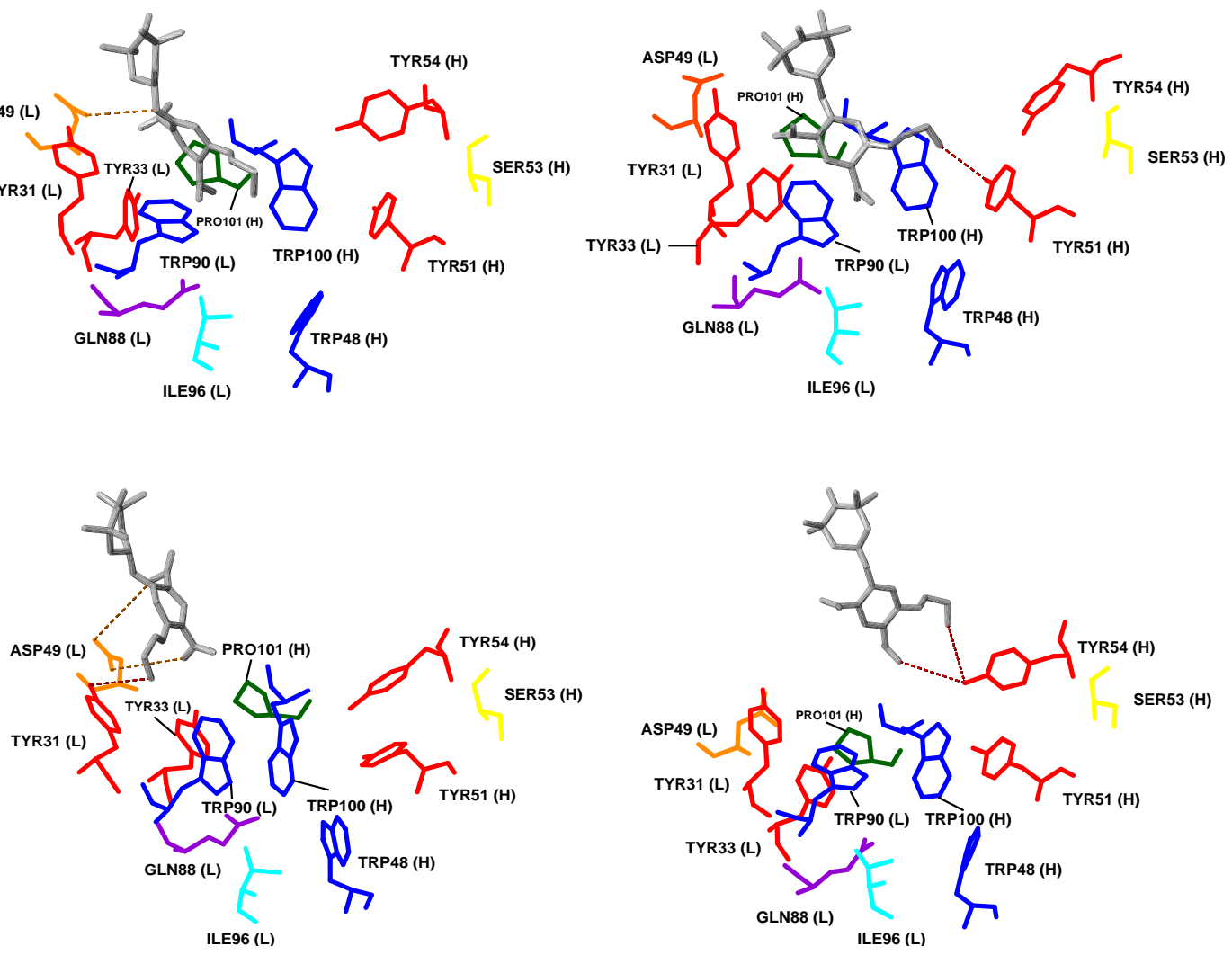

Abbildung 5.19: Schnappschüsse von Dissoziationssimulationen, die verschiedene Dissoziationspfade (Routen) aufweisen. Die drei Schnappschüsse auf der linken Seite zeigen einen Dissoziationspfad entlang der leichten Kette, die drei auf der rechten Seite einen entlang der schweren Kette. Die Cantileverpositionen in den Schnappschüssen sind $z_{\text {cant }} \approx 5 \AA$ (oben), $z_{\text {cant }} \approx 8 \AA$ (Mitte) und $z_{\text {cant }} \approx 10 \AA$ (unten). Wasserstoffbrücken und Van der Waals-Kontalte des Haptens mit Amnisosäuren sind mit gepunkteten Linien gekennzeichnet. 


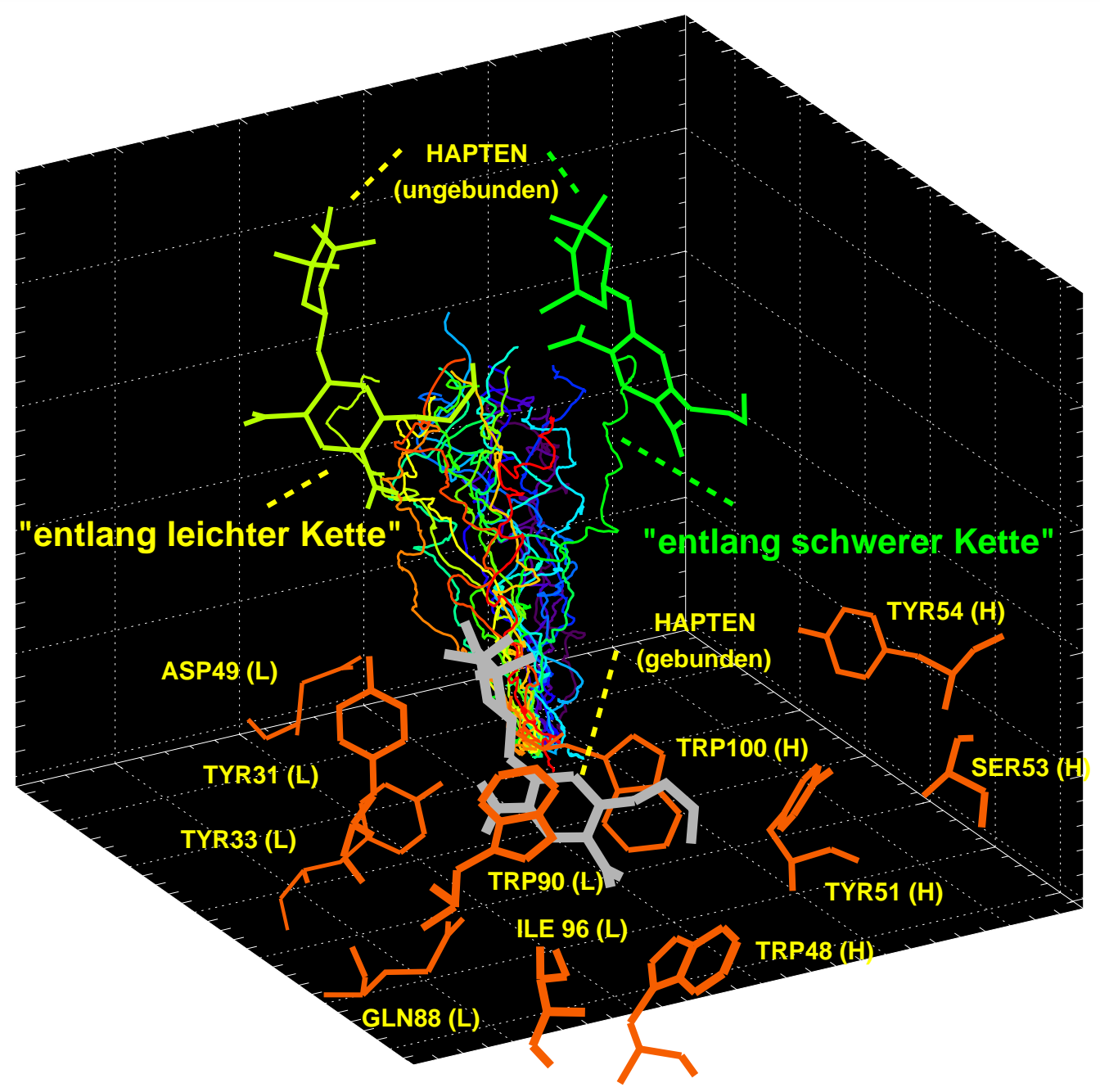

Abbildung 5.20: Beobachtete Dissoziationspfade (durchgezogene Linien) des Haptenmoleküls (grau im gebundenen Zustand und gelb bzw. grün im ungebundenen Zustand für die Routen entlang der leichten bzw. schweren Kette) für ein Ensemble aus 20 Dissoziationssimulationen.

tionen in den Kraftprofilen, insbesondere in den Dissoziationskräften. Tendenziell waren die Dissoziationskräfte für Simulationen mit Dissoziationspfaden entlang der schweren Kette höher als für die Dissoziationspfade entlang der leichten Kette.

Ein signifikanter Unterschied zwischen den verschiedenen, insbesondere den beiden extremen Routen besteht auch in dem unteschiedlichen Verlauf der Gesamtwechselwirkungen des Haptenmoleküls mit den Aminosäuren der Bindungstaschen während des Dissoziationsprozesses, wie aus Abbildung 5.22 ersichtlich ist. Gezeigt sind die gesamten nichtbindenden (oben), die elektrostatischen (Mitte) und die Van der Waals-Wechselwirkungen für zwei Simulationen, bei denen die Dissoziationspfade entlang der schweren Kette verliefen (durchgezogene Linien) sowie für zwei Simulationen mit Dissoziationspfaden entlang der leichten Kette (gepunktete Linien). Für die Route entlang der leichten Kette schwächten sich die elektrostatischen Wechselwirkungen erst sehr viel später ab als es bei der Route entlang der schweren Kette der Fall war. Bei den Van der Waals- 

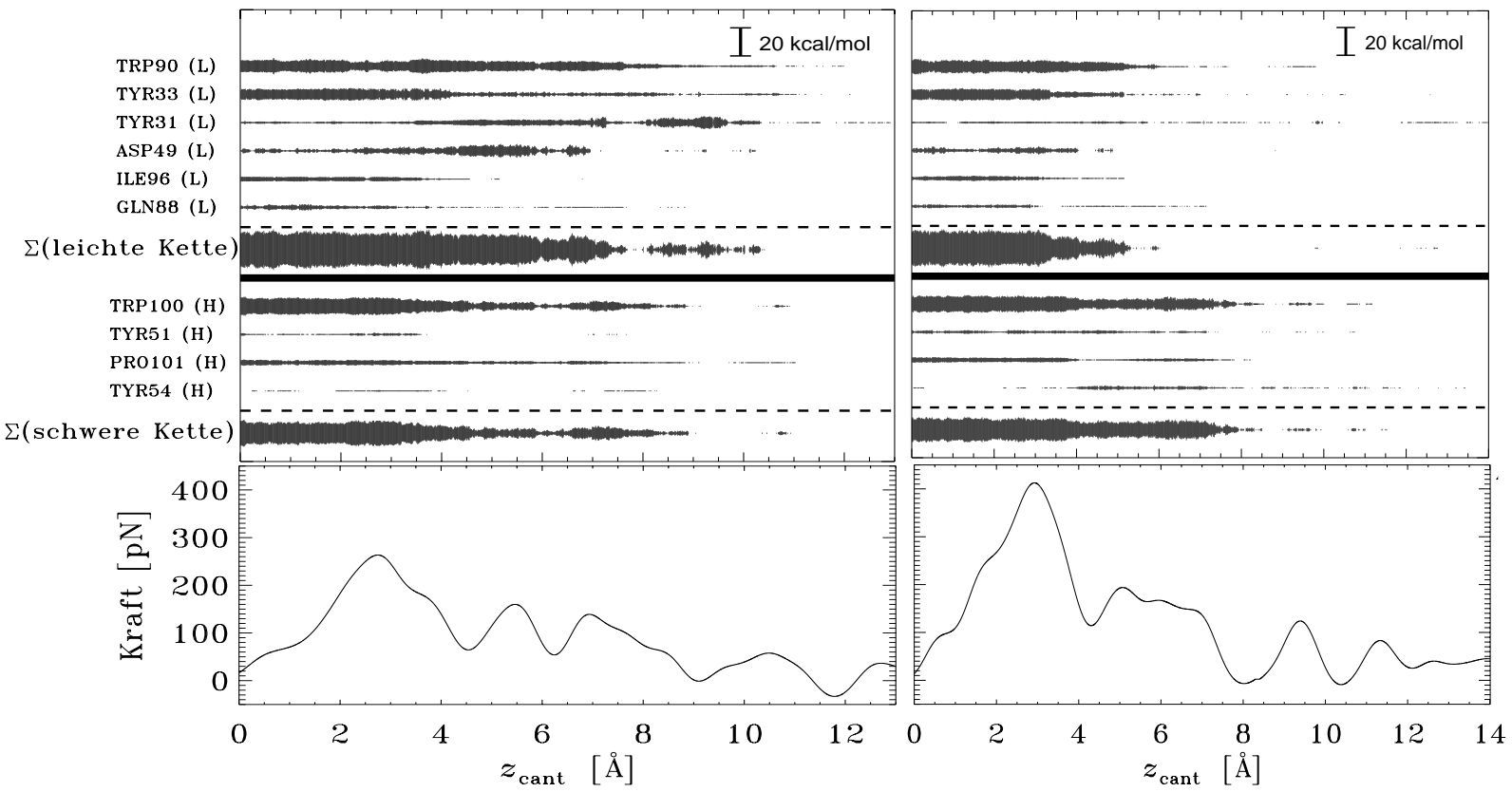

Abbildung 5.21: Oben: Wechselwirkungsmuster (oben) und Kraftprofile (unten) während des Dissoziationsprozesses für zwei repräsentative Simulationen mit Dissoziationspfaden entlang der leichten Kette (links) bzw. entlang der schweren Kette (rechts). Die Dicke der Balken in den Wechselwirkungsmustern ist ein Maß für die Stärke der Wechselwirkungen.

Wechselwirkungen verhielt es sich tendenziell ähnlich: Insbesondere im späteren Verlauf des Dissoziationsprozesses für Cantileverpositionen zwischen 6 und $10 \AA$ wiesen die Simulationen mit Dissoziationspfaden entlang der leichten Kette stärkere Van der WaalsWechselwirkungen auf.

Abbildung 5.23 zeigt, wodurch der Unterschied in den elektrostatischen Wechselwirkungen hauptsächlich bedingt ist: Für Routen entlang der leichten Kette trug im späteren Verlauf des Dissoziationsprozesses (für $z_{\text {cant }} \geq 4 \AA$ ) die Aminosäure ASP49(L) deutlich zu den elektrostatischen, teilweise auch zu den Van der Waals-Wechselwirkungen bei, was bei den Routen entlang der schweren Kette nicht der Fall war. Die Stärke dieses Beitrags variierte jedoch stark von Simulation zu Simulation, zumal ASP49(L) zusammen mit der hypervariablen Schleife, in der es sich befindet, kollektive Bewegungen mit vergleichsweise großer Amplitude bis zu $5 \AA$ ausführte.

\section{Essentielle kollektive Bewegungen während des Dissoziationsprozesses}

Welches sind die wesentlichen, kollektiven Freiheitsgrade in der Bindungstasche während des Dissoziationsprozesses? Um diese Frage zu beantworten, wurde, wie in Abschnitt 5.4.3 beschrieben, eine Hauptkomponentenanalyse für 20 Trajektorien durchgeführt, die den Dissoziationssimulationen mit einer Zuggeschwindigkeit von jeweils $5 \mathrm{~m} / \mathrm{s}$ entstammen.

In den Schnappschüssen in Abbildung 5.24 sind die jeweiligen Eigenvektoren durch dünne schwarze Linien an den Atomen angedeutet. Die Pfeile zeigen die mittleren Richtungen 

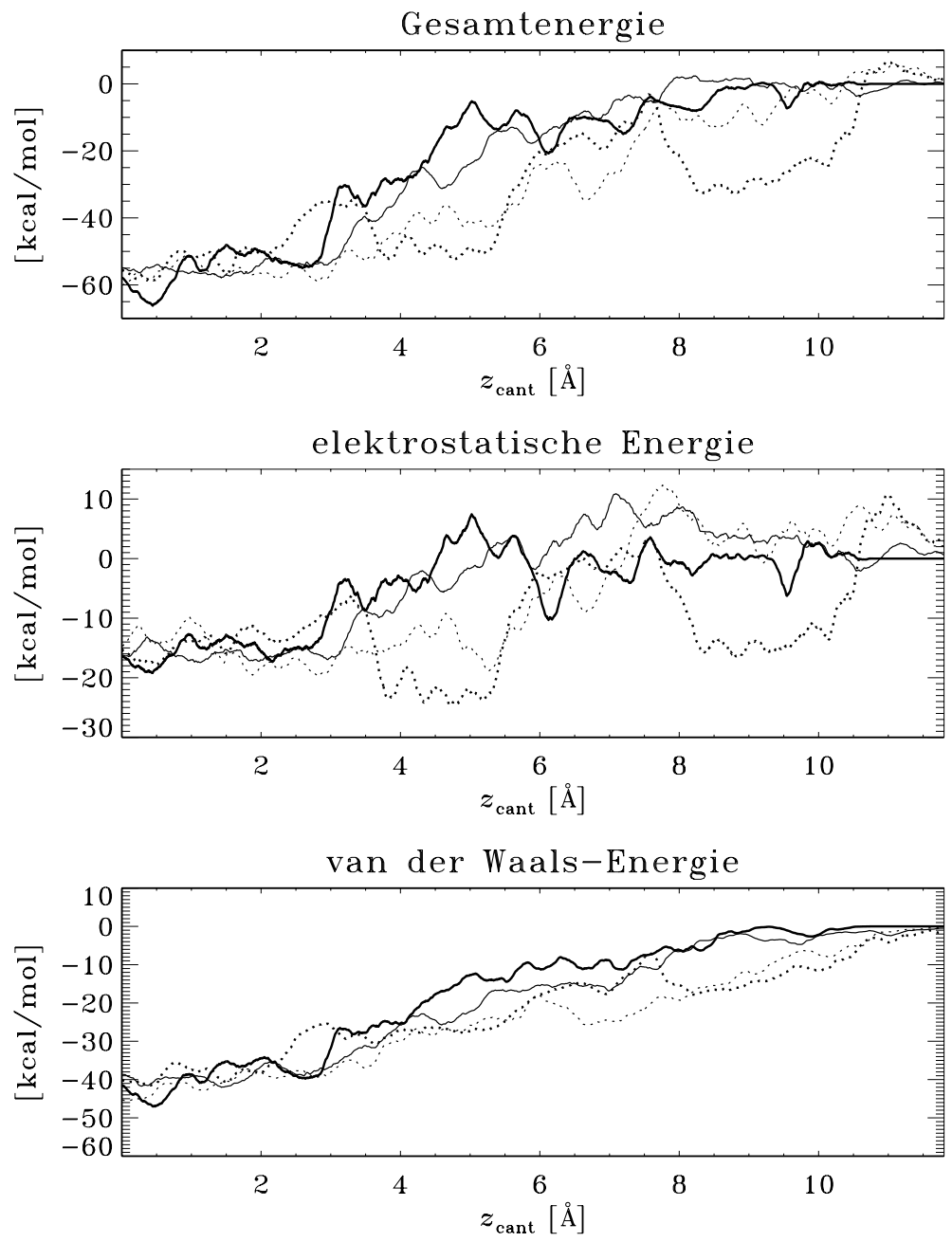

Abbildung 5.22: Wechselwirkungen des Haptenmoleküls mit der gesamten Bindungstasche als Funktion der Cantileverposition für zwei Dissoziationsimulationen mit einem Dissoziationspfad entlang der schweren Kette (durchgezogene Linien) und zwei Dissoziationssimulationen mit Dissoziationspfaden entlang der leichten Kette (gepunktete Linien).

für die einzelnen Residuen oder Teile von Residuen entlang des jeweiligen Eigenvektors. Es sei angemerkt, dass die schwarzen Linien und die Pfeile nur darüber etwas aussagen, entlang welcher Achsen die dominanten Bewegungen stattfanden, nichts aber darüber, ob sie in positiver oder negativer Richtung verliefen. Welche Bewegung entlang der Eigenvektoren wirklich realisiert wurde, zeigt Abbildung 5.25. Hier ist für jede Simulation (farbige Linien) die Projektion der Bindungstasche auf die ersten sechs Eigenvektoren als Funktion der Cantileverposition aufgetragen (die Zahlen ganz rechts geben an, zu welchen Zeitpunkten in der Equilibrierungstrajektorie die Ausgangsstrukturen der einzelnen Simulationen entnommen wurden).

Aus dem ersten Schnappschuss in Abbildung 5.24, der die Bewegung entlang des ersten Eigenvektors visualisiert, geht hervor, dass in den Dissoziationssimulationen Bewegungen in Zugrichtung dominierten. Die Projektion auf den ersten Eigenvektor (in Abbildung 5.25 links oben) zeigt, dass diese Bewegung bei allen Simulationen in dieselbe Richtung verlief. 

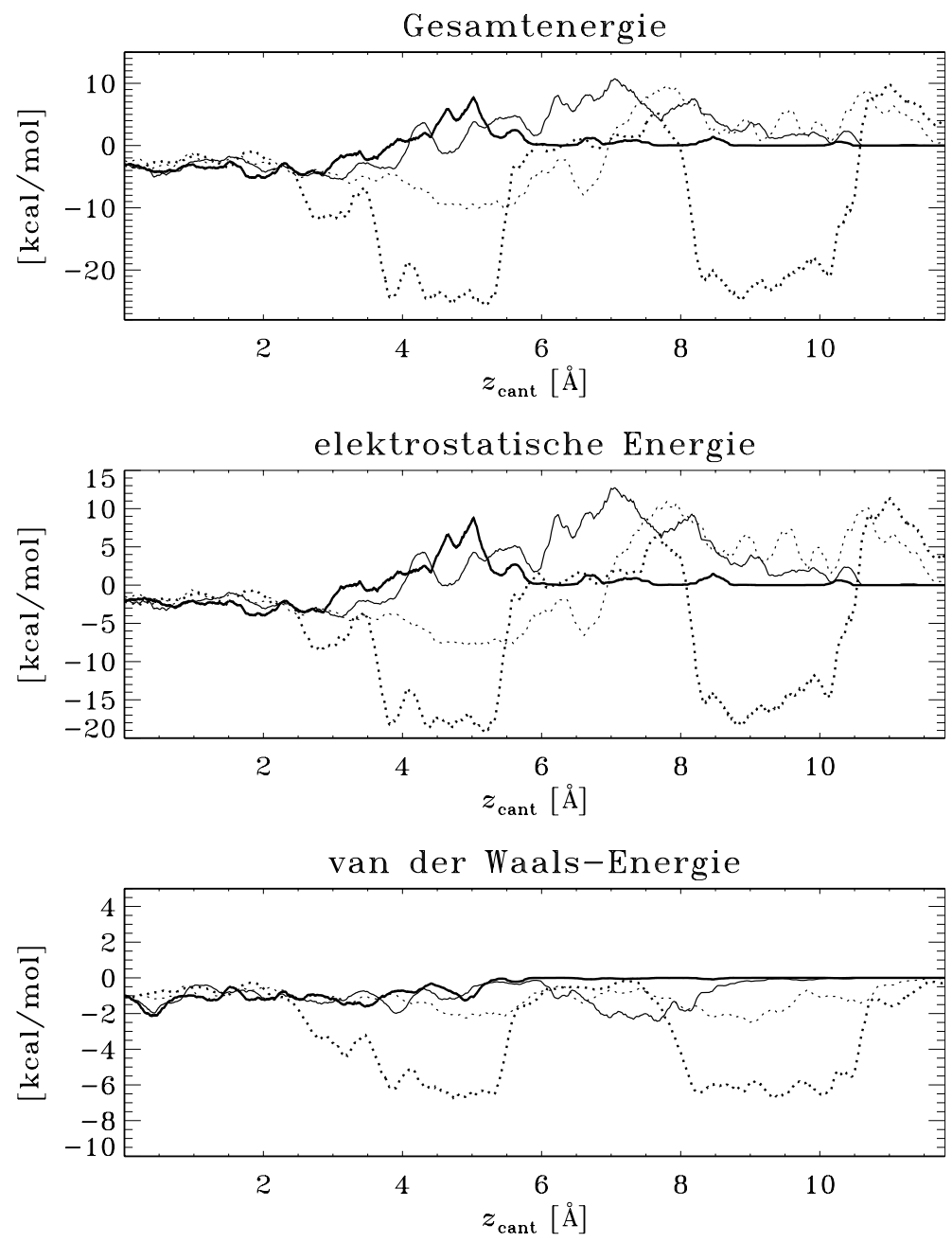

Abbildung 5.23: Wechselwirkungen des Haptenmoleküls mit ASP49(L). Die Art der Auftragung ist wie in Abbildung 5.22.

Der erste Eigenvektor ist fast ausschließlich mit der Bewegung des Haptenmoleküls aus der Bindungstasche verbunden. Dies zeigt, dass die Dissoziationsbewegungen über alle anderen Bewegungen in der Bindungstasche dominierten. Dies ist nicht verwunderlich, da das Zugpotenzial bei dem Haptenmolekül eine lange, gerichtete Bewegung aus der Bindungstasche heraus induziert hat. So beinhaltet der erste Eigenvektor keine wesentliche neue Information, er spiegelt vielmehr unsere Vorgehensweise in den Dissoziationssimulationen wider.

Ganz anders der zweite Eigenvektor (Schnappschuss rechts oben in Abbildung 5.24): Hier beschreibt der Eigenvektor eine deutliche seitwärtige Bewegung des Haptenmoleküls (entweder hin zur leichten Kette oder zur schweren Kette). Aus der Projektion auf den zweiten Eigenvektor (Bild rechts oben in Abbildung 5.25) geht hervor, dass in den verschiedenen Simulationen beide Richtungen realisiert wurden. Nach der ersten Dissoziationsphase, die bis $z_{\text {cant }} \approx 4 \AA$ andauert und in der die Projektionen in etwa parallel verlaufen, fächern sich die Projektionen auf. Genau hier zeigt sich die strukturelle Heterogenität: Es wurden in den Simulationen unterschiedliche Dissoziationspfade realisiert, die entweder entlang 


\section{Eigenvektor}

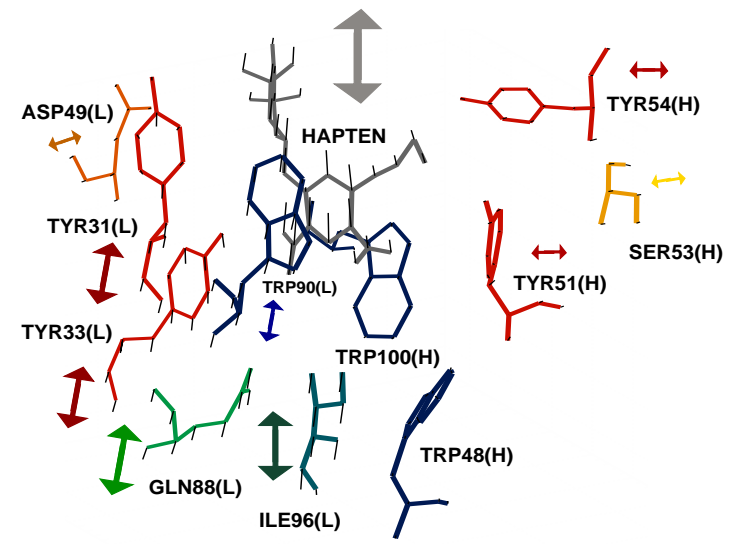

3. Eigenvektor

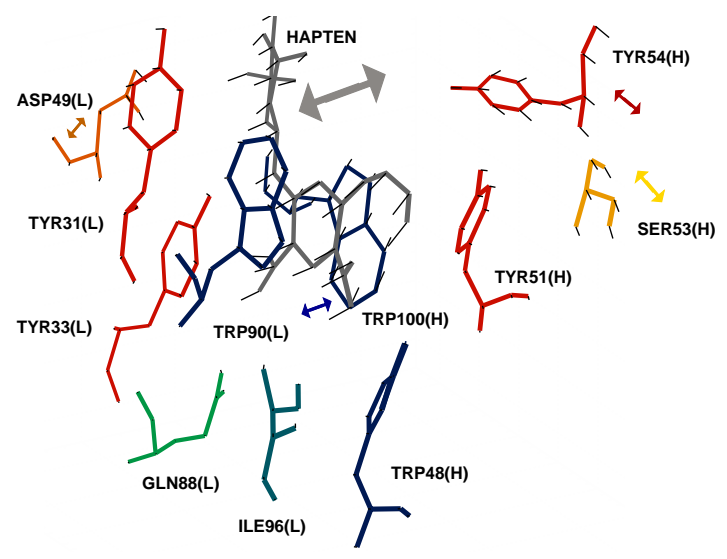

2. Eigenvektor

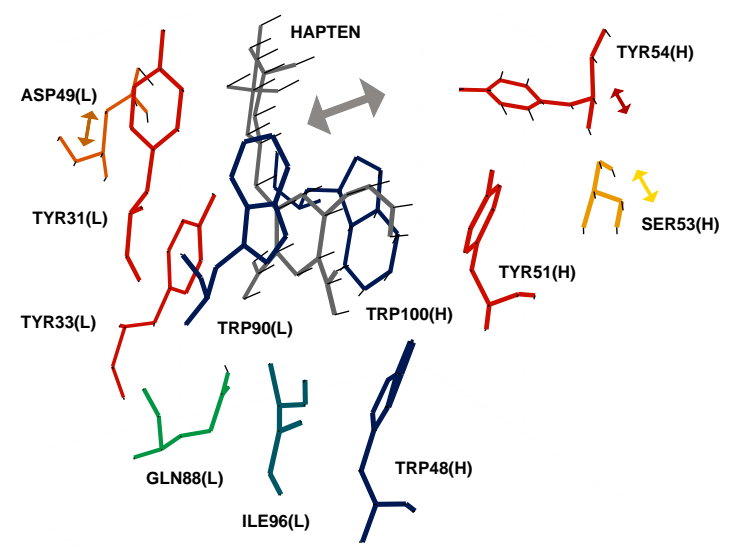

4. Eigenvektor

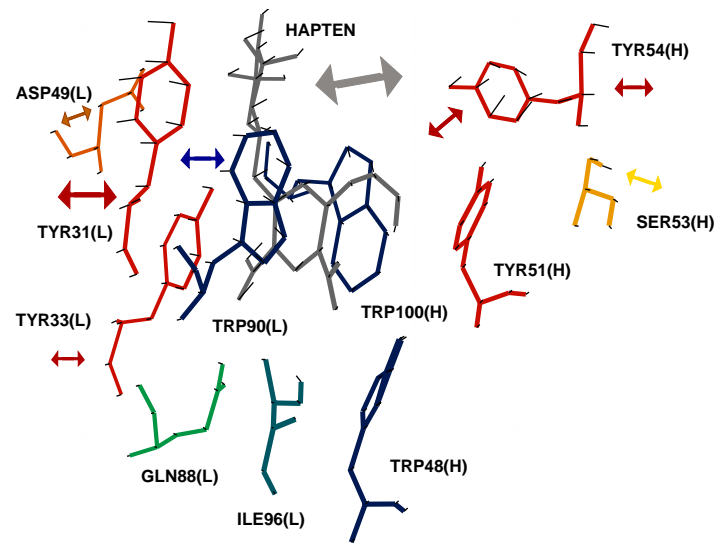

Abbildung 5.24: Andeutung der vier wichtigsten Eigenvektoren durch dünne schwarze Linien an den Atomen sowie durch Pfeile für gesamte Residuen oder Teile von Residuen. Die Länge der schwarzen Linien sowie die Größe der Pfeile deuten die Amplituden der jeweiligen Bewegungen an.

der leichten oder entlang der schweren Kette oder aber auch zwischen diesen extremen Routen verliefen. Auch der dritte Eigenvektor (in Abbildung 5.25, linkes Bild in der Mitte) beschreibt eine seitwärtige Bewegung des Haptenmoleküls, entsprechend fächern sich die Projektionen der einzelnen Simulationen leicht auf. Darüber hinaus beinhaltet der dritte Eigenvektor eine signifikante Bewegung der Seitenkette von TRP100(H). Dies stimmt mit der Beobachtung überein, dass sich diese Seitenkette tiefer in die Bindungstasche hineinbewegte, als sich das Hapten aus dem Tryptophan-Sandwich löste. Der vierte Eigenvektor hingegen repräsentiert eher kollektive Bewegungen der leichten Kette bzw. der schweren Kette, die gegeneinander gerichtet sind. Sehr anschaulich zeigt sich die strukturelle Heterogenität in den in Abbildung 5.26 gezeigten Projektionen der neun ausgewählten Trajektorien auf den Unterraum, der von dem zweiten und dem dritten Eigenvektor aufgespannt wird. Dabei kennzeichnet das Karo die Ausgangsstruktur für die jeweilige Dissoziationssimulation (die dem gebundenen Zustand entspricht) und das 


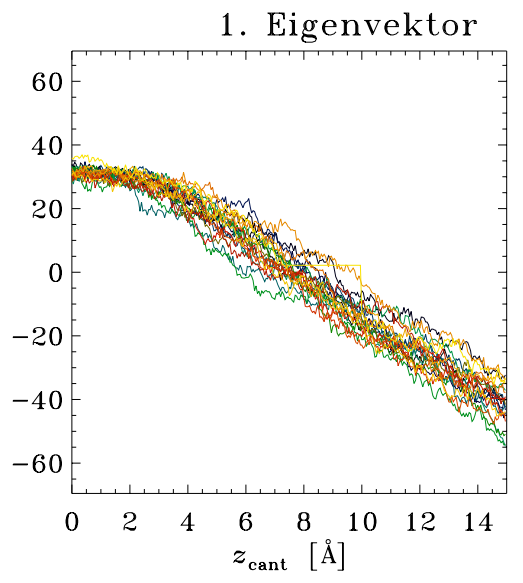

3. Eigenvektor

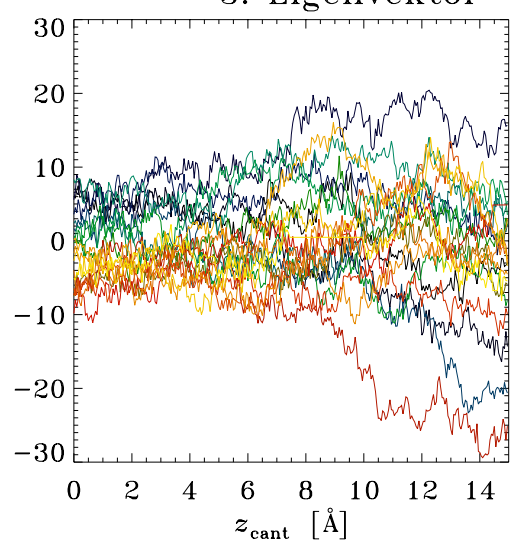

5. Eigenvektor

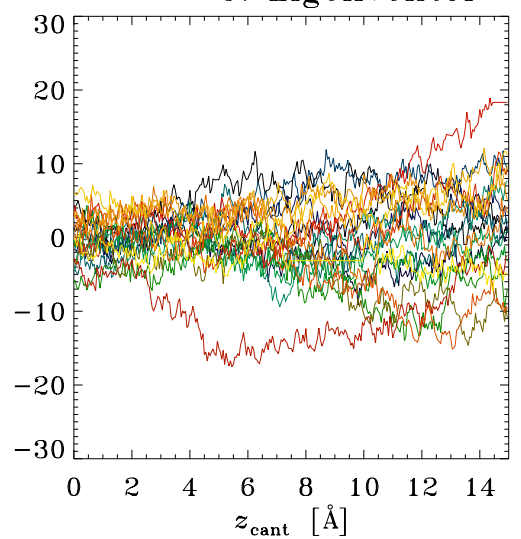

2. Eigenvektor

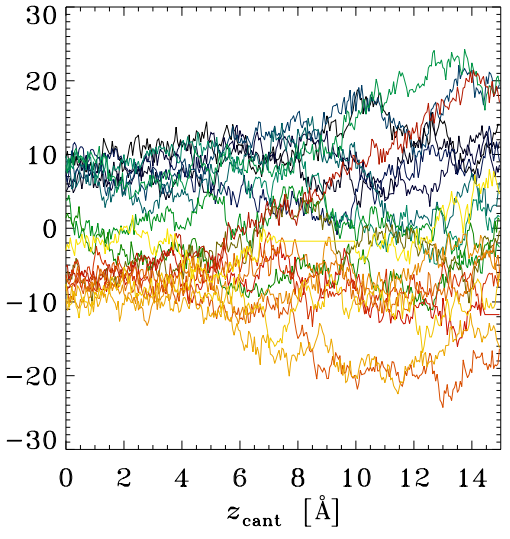

4. Eigenvektor

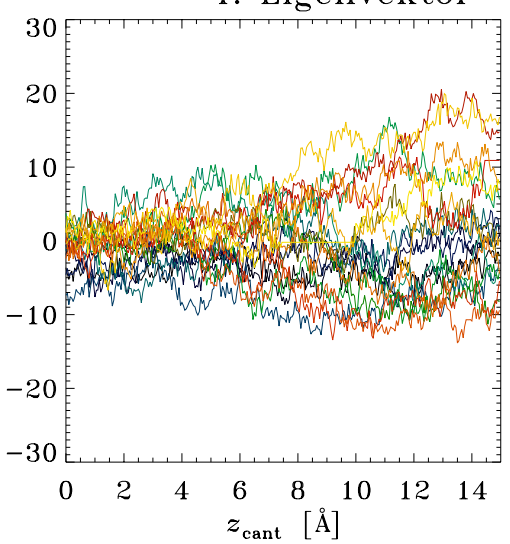

6. Eigenvektor

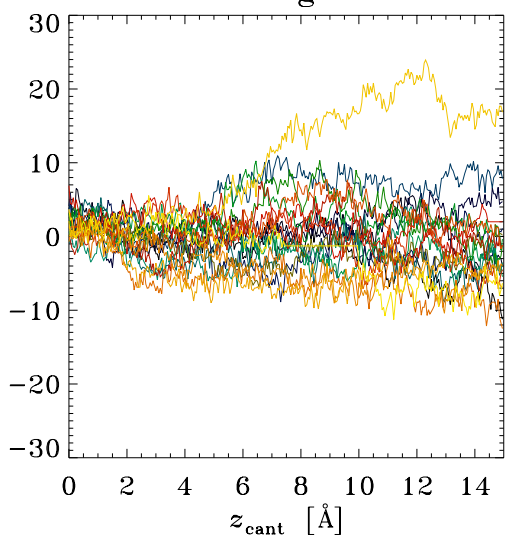

680

705

720

750

790

1000

1020

1040

1060

1240

1270

1280

1300

1320

1350

1400

1420

1430

1440

1500

Abbildung 5.25: Projektion der 20 Trajektorien auf die sechs wichtigsten Eigenvektoren als Funktion der Cantileverposition. Die Farbcodierung gibt an, zu welchem Zeitpunkt (in ps) die Ausgangsstruktur der jeweiligen Dissoziationssimulation der Equilibrierungstrajektorie entnommen wurde.

Dreieck die Endstruktur (ungebundener Zustand). Offensichtlich unterscheiden sich die 

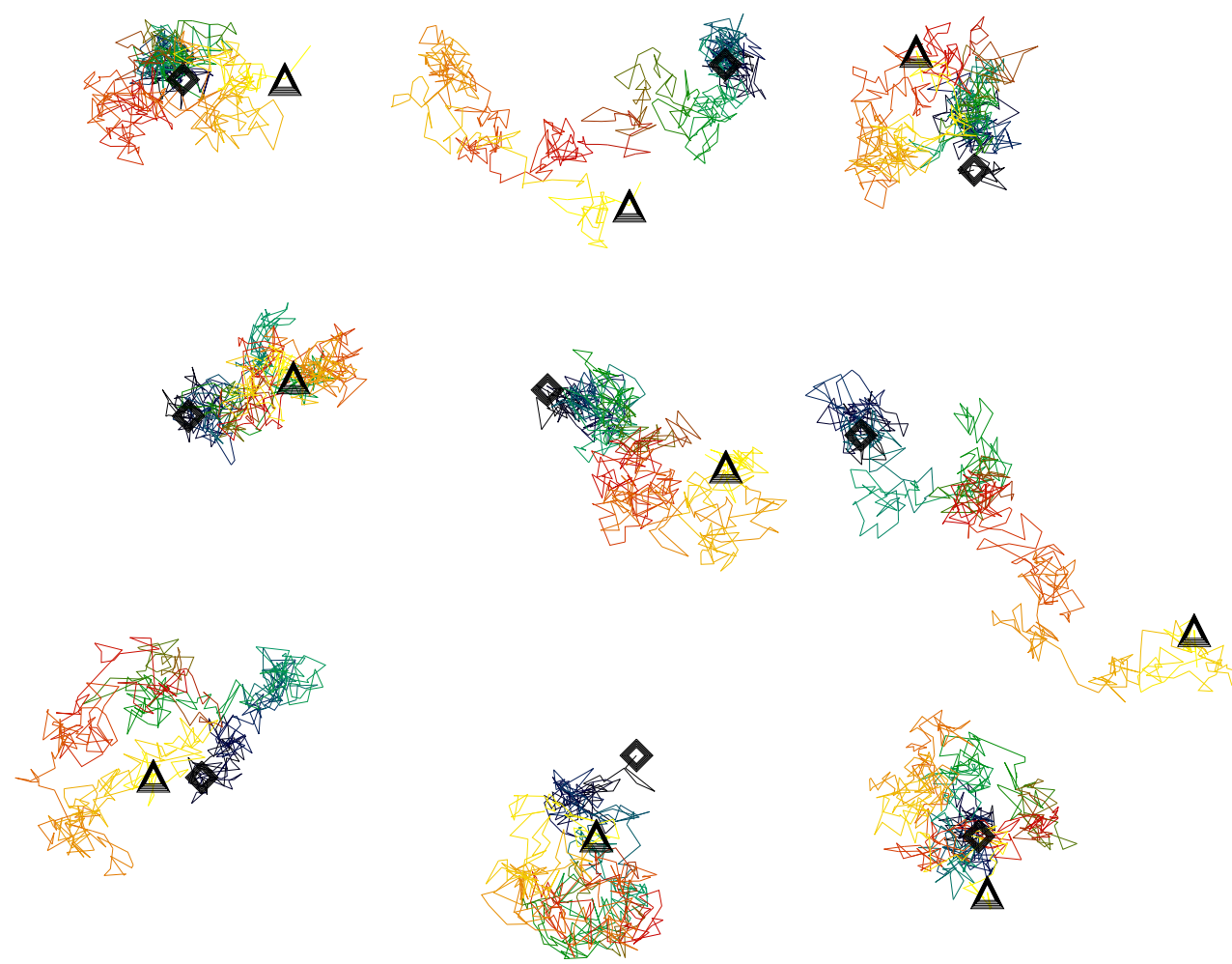

Abbildung 5.26: Projektion von neun ausgewählten Trajektorien auf den Unterraum, der vom zweiten und dritten Eigenvektor aufgespannt wird. Das Karo markiert den Anfang der Trajektorie, das Dreieck ihr Ende.

Projektionen stark voneinander, was bedeutet, dass die einzelnen Trajektorien im Konfigurationsraum sehr unterschiedlich verlaufen. Dies weist darauf hin, dass das von allen Trajektorien zusammen eingenommene Volumen im Konfigurationsraum größer ist als das einer einzelnen Trajektorie, was einem ein quantitatives Maß für strukturelle Heterogenität an die Hand gibt.

Wir haben das Verhältnis dieser Volumina nach Gleichung (5.6) ausgenutzt, um den entropischen Beitrag zur Bindung entlang des Dissoziationspfades (d.h. als Funktion der Cantileverposition) grob abzuschätzen. Die Abschätzung des energetischen Beitrags der Entropie zur freien Bindungsenergie bei einer Temperatur von $300 \mathrm{~K}$ zeigt Abbildung 5.27. Die verschiedenen Kurven entsprechen den unterschiedlichen Anzahlen von Eigenwerten (zwischen 50 und 100), die zur Abschätzung des im Konfigurationsraum eingenommenen Volumens herangezogen wurden. Mit zunehmender Anzahl von Eigenwerten ist eine sehr gute Konvergenz der Kurven erkennbar. Die Verwendung von deutlich mehr als 100 Eigenwerten führte wieder zu einer stärkeren Streuung (Daten nicht gezeigt).

Aus Abbildung 5.27 lässt sich ablesen, dass die Entropie bei einer Cantileverposition zwischen 4 und $8 \AA$ stark zunimmt und mit etwa $4 \mathrm{kcal} / \mathrm{mol}$ deutlich zur Aktivierungsbarriere von $\Delta G \approx 11 \mathrm{kcal} / \mathrm{mol}$ beiträgt. Durch den signifikanten Entropiebeitrag wird die Aktivierungsbarriere $\Delta G=\Delta U+P \Delta V-T \Delta S^{9}$ deutlich abgesenkt.

\footnotetext{
${ }^{9}$ Da der Druck unter physiologischen Bedingungen konstant ist, fällt hier die Gibbssche freie Energie praktisch mit der Helmholtzschen freien Energie $\Delta F=\Delta U-T \Delta S$ zusammen.
} 


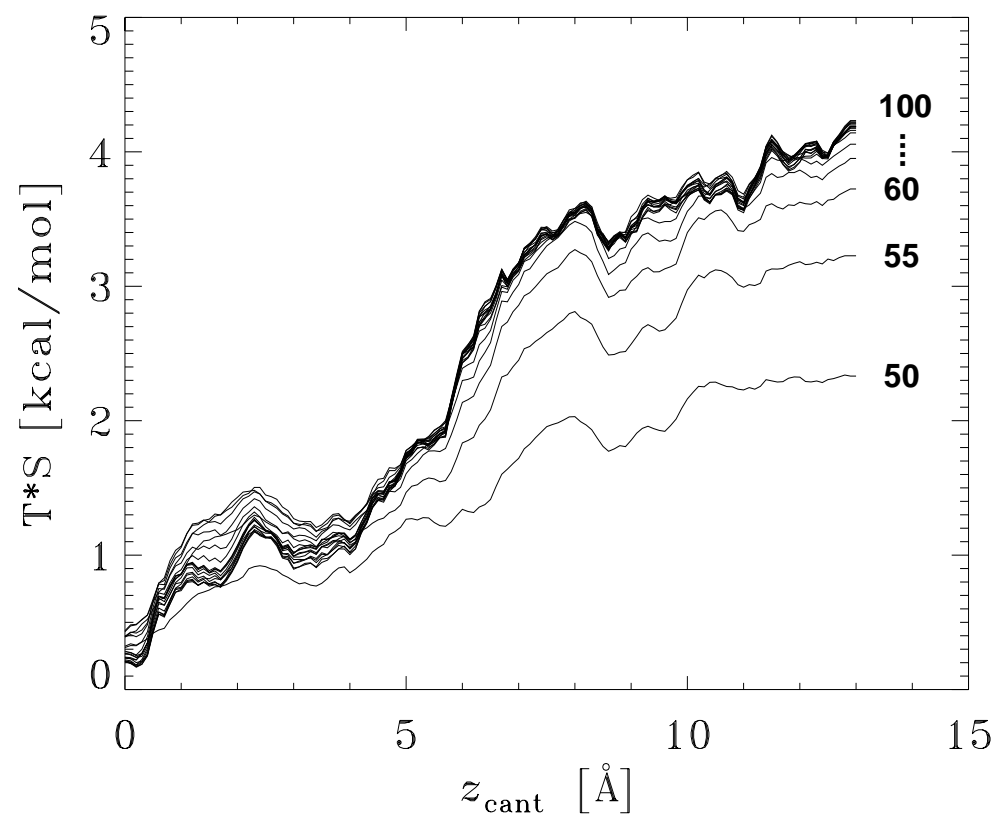

Abbildung 5.27: Verlauf des aus den Dissoziationssimulationen abgeschätzten energetischen Beitrags der Entropie als Funktion der Cantileverposition. Die Unterschiede in den Kurven rühren von den unterschiedlichen, rechts angegebenen Anzahlen der Eigenwerte, die zur Abschätzung der Entropie miteinbezogen wurden. Zur weiteren Erklärung siehe Text.

Der Verlauf der Entropie steht im Einklang mit den in Abbildung 5.20 gezeigten Dissoziationspfaden, die sich erst, nachdem das Haptenmolekül das Tryptophan-Sandwich bei $z_{\text {cant }} \approx 4 \AA$ verlassen hat, stark auffächern und ein deutlich vergrößertes, im Konfigurationsraum zugängliches Volumen vermuten ließen. 


\subsubsection{Zusammenfassung und Diskussion}

Die aus den Dissoziationssimulationen des AN02-DNP-Hapten-Komplexes abgeleiteten Dissoziationskräfte wiesen eine Abhängigkeit von der Zuggeschwindigkeit auf, die sich für hohe Zuggeschwindigkeiten gut mit Stokesscher Reibung und für niedrige Zuggeschwindigkeiten mit aktivierten Prozessen, getrieben durch thermische Fluktuationen, beschreiben lässt. Unseres Wissens konnte somit zum ersten Mal mit Hilfe von LangzeitDissoziationssimulationen mit Zeitspannen von bis zu 7 ns der Einfluss aktivierter Prozesse beobachtet werden. Ein einfaches Modell, das Stokessche Reibung und aktivierte Prozesse berücksichtigt und in das die spontane Dissoziationsrate des AN02-DNP-HaptenKomplexes eingeht, erlaubte die Interpolation der berechneten Dissoziationskräfte auf die Millisekunden-Zeitskala kraftmikroskopischer Dissoziationsexperimente. Auf dieser Grundlage erwarten wir für solche Experimente eine Dissoziationskraft von $65 \pm 25 \mathrm{pN}$.

Im Vergleich mit dem Dissoziationssprozess zu Streptavidin-Biotin [55,56] ergab die strukturelle Analyse der Dissoziationssimulationen zu AN02-DNP-Hapten eine bemerkenswert große strukturelle Heterogenität der Dissoziationspfade und der Wechselwirkungen des DNP-Haptens mit den Aminosäuren der Bindungstasche im Verlauf des Dissoziationsprozesses. Nachdem das Haptenmolekül das durch mehrere Wasserstoffbrücken, Wasserbrücken und Van der Waals-Kontakte stabilisierte Tryptophan-Sandwich verlassen hatte, standen ihm eine Vielzahl von Routen offen, auf denen es aus der Bindungstasche gelangen konnte. Die beiden extremen Routen verliefen entlang der leichten Kette bzw. entlang der schweren Kette. Die Vielzahl der möglichen Dissoziationspfade ist gleichbedeutend mit einem großen Volumen, das dem AN02-DNP-Hapten-Komplex im hochdimensionalen Konfigurationsraum während des Dissoziationsprozesses zugänglich ist, was wiederum einen signifikanten entropischen Beitrag zur Bindung impliziert. Der entropische Beitrag zur freien Aktivierungsenergie von $\Delta G \approx 11 \mathrm{kcal} / \mathrm{mol}$ wurde anhand der Simulationen mit $4 \mathrm{kcal} / \mathrm{mol}$ abgeschätzt. Dieser hohe entropische Beitrag senkt die freie Aktivierungsbarriere entsprechend ab, so dass die Reaktionskinetik wesentlich von der Entropie abhängt. Dies begründet die Vermutung, dass der entropische Beitrag dazu geeignet ist, Antikörper über die Justierung der Aktivierungsbarriere auf unterschiedliche Antigene abzustimmen und somit die Reaktionskinetik zu optimieren. Dies ist in Übereinstimmung mit der kürzlich gemachten Entdeckung, dass die Geometrie der Bindungstasche durch Punktmutationen an Stellen in bis zu $15 \AA$ Entfernung nachhaltig verändert werden kann [80], was ein Indiz für die große Konformationsflexibilität der Bindungstaschenregion von Antikörpern ist. Desweiteren begünstigt ein hoher entropischer Beitrag eine effiziente Abtastung von Antigenen, da die mit der Entropie verbundene Vielzahl von Konfigurationsmöglichkeiten, unter denen die Bindung zwischen Antikörper und Antigen zustande kommen kann, bedingt, dass es nicht auf eine exakte Orientierung der Bindungspartner zueinander ankommt, sondern gleichsam der erste Annäherungsversuch von Antikörper und Antigen darüber entscheidet, ob eine spezifische Bindung zustande kommt oder nicht. Auf diese Weise können potenzielle Antigene schnell und effizient abgetastet werden. 


\subsubsection{Dissoziationsprozesse von zwei Mutanten}

In Abschnitt 5.4.3 haben wir gesehen, dass einige Aminosäuren in starke Wechselwirkungen zum Hapten treten. Hier wollen wir der Frage nachgehen, ob diese auch stark zur Dissoziationskraft beitragen. Dazu wurden, wie Abbildung 5.28 illustriert, in dem Simulationsmodell von AN02 unabhängig voneinander zwei Punktmutationen vorgenommen: Durch die eine wurde eine starke Wasserstoffbrücke einer Bindungstaschenaminosäure zum Hapten entfernt, durch die andere eine zusätzliche Wasserstoffbrücke geschaffen, wodurch wir in den analog zum Wildtyp (WT) durchgeführten Dissoziationssimulationen jeweils eine signifikante Änderung in den Dissoziationslkraft erwarteten.

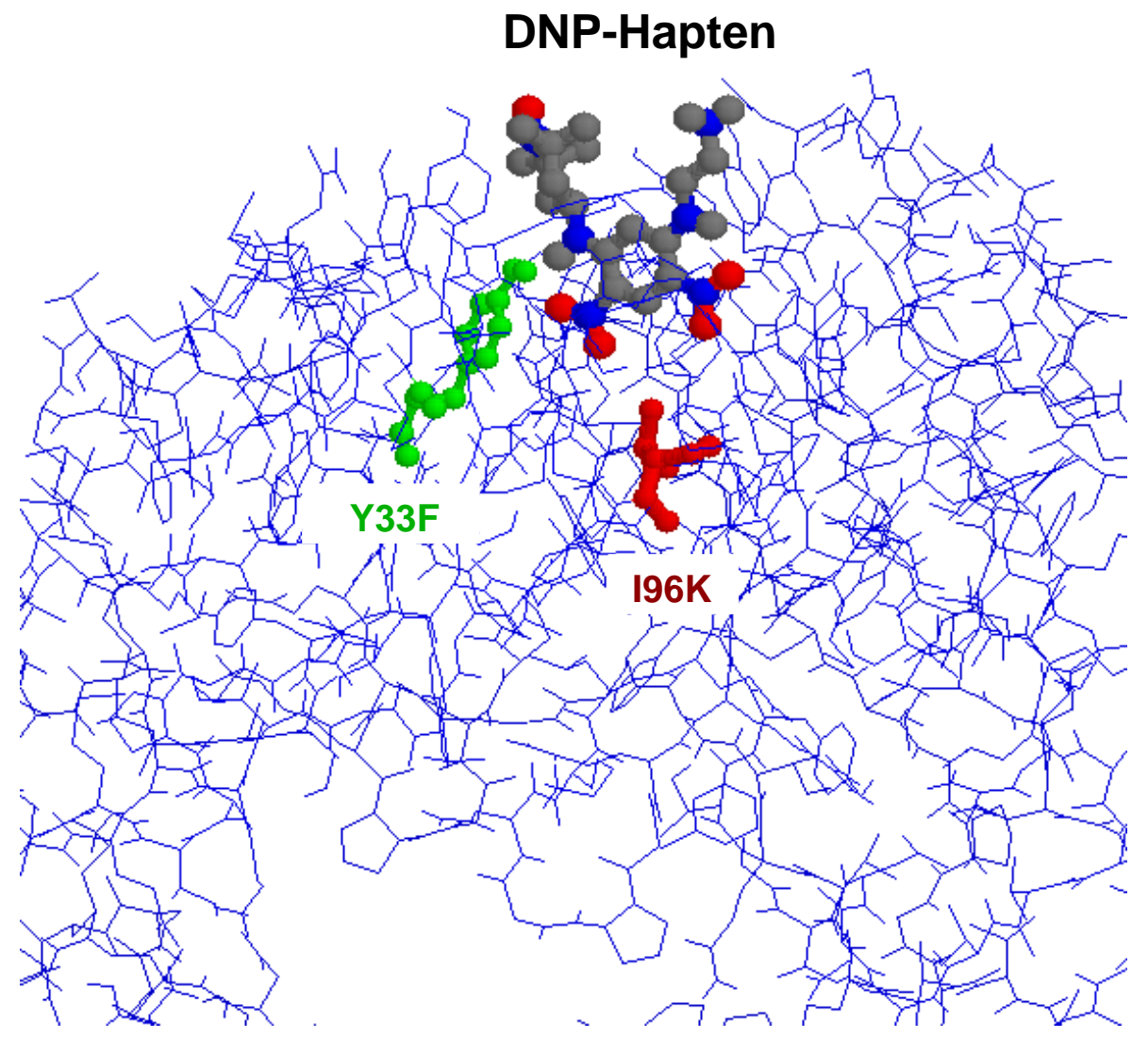

Abbildung 5.28: Punktmutationen des AN02-DNP-Hapten-Komplexes. In der einen Mutante wurde TYR33(L) durch PHE (Y33F) ersetzt, in der anderen ILE96(L) durch LYS (I96K).

Bei der ersten Punktmutation wurde das Tyrosin-33 der leichten Kette durch ein Phenylanalin ersetzt (Y33F), bei der zweiten das Isoleucin-96 der leichten Kette durch ein Lysin (I96K) (siehe Abbildung 5.28). Die Y33F-Mutante unterschied sich vom WildtypAN02 (WT) lediglich darin, dass bei Phenylanalin im Gegensatz zum Tyrosin an dem aromatischen Ring der Seitenkette keine (polare) Hydroxylgruppe gebunden ist. Dadurch wurde erreicht, dass die starke Wasserstoffbrücke von TYR33(L) zum Mittelteil des Haptens im gebundenen Zustand wegfiel (siehe dazu weiter unten Abbildung 5.31). Deswegen 
erwarteten wir hier, dass die Dissoziationskraft signifikant niedriger sein würde als beim Wildtyp. Die I96K-Mutante wurde so konstruiert, dass das LYS96 im Gegensatz zu ILE96(L) im Wildtyp in signifikante elektrostatische Wechselwirkungen mit dem DNPRing des Haptenmoleküls trat und eine starke Wasserstoffbrücke $(<-5 \mathrm{kcal} / \mathrm{mol}) \mathrm{zu} \mathrm{dem}$ Sauerstoff O25 der ersten Nitrogruppe des DNP-Rings ausbildete (siehe dazu weiter unten Abbildung 5.33). Hierfür erwarteten wir eine höhere Dissoziationskraft als beim Wildtyp.

\section{Methoden}

Als Ausgangsstruktur für beide Mutanten diente eine Wildtyp-Struktur des AN02-DNPHapten-Komplexes, die der Equilibrierungstrajektorie zum Zeitpunkt von 1300 ps entnommen wurde. Für die Y33F-Mutante wurde die Hydroxylgruppe der aromatischen Seitenkette von TYR33(L) entfernt und dem so „mutierten“ Residuum die aus der Parameterbibliothek von XPLOR stammenden Parameter für Phenylanalin zugeordnet. Die auf diese Weise veränderte Struktur wurde für weitere 50 ps equilibriert, um einen weitgehend relaxierten Zustand der Y33F-Mutante zu generieren.

Die I96K-Punktmutation bedeutete im Vergleich zur Y33F-Punktmutation einen deutlich stärkeren Eingriff, da zum einen die Seitenkette von Lysin länger ist als die von Isoleucin (sie enthält eine zusätzliche polare $\mathrm{NH}_{3}$-Gruppe) und zum anderen die Seitenkette von Lysin im Gegensatz zum Isoleucin einfach positiv geladen ist. So wurde Lysin so platziert, dass keine energetisch ungünstige Überlappung mit benachbarten Aminosäuren auftrat. Dies wurde mit dem Molekül-Editor von Quanta [110] bewerkstelligt. Um die zusätzliche positive Ladung auszugleichen, wurde das nächst gelegene positiv geladenene Natrium-Ion entfernt. Die so erhaltene Struktur der I96K-Mutante wurde für weitere 100 ps equilibriert.

Ausgehend von den equilibrierten Strukturen der beiden Mutanten wurden jeweils 22 Dissoziationssimulationen mit Zuggeschwindigkeiten zwischen $50 \mathrm{~m} / \mathrm{s}$ und $0.2 \mathrm{~m} / \mathrm{s}$ durchgeführt. Dissoziationskräfte sowie Wechselwirkungen zwischen dem Haptenmolekül und den Aminosäuren der Bindungstasche wurden wie in Abschnitt 5.4.3 beschrieben berechnet.

\section{Ergebnisse und Diskussion}

Sowohl die mittlere quadratische Abweichung des AN02-DNP-Hapten-Komplexes und ausgewählter Regionen (vgl. Abbildungen 5.5 - 5.6 in Abschnitt 5.3.2) als auch die Wechselwirkungen des Haptenmoleküls mit den einzelnen Aminosäuren der Bindungstasche wurden durch die Punktmutationen kaum beeinflusst. Die einzigen signifikanten (und beabsichtigten) Unterschiede bestanden darin, dass bei der Y33F-Mutante eine Wasserstoffbrücke wegfiel [TYR33(L) - Hapten-N8] und bei der I96K-Mutante eine starke Wasserstoffbrücke hinzukam [LYS96(L) - Hapten-O25]. Die Lage der mutierten Residuen blieb während der Equilibrierung unverändert.

Abbildung 5.29 zeigt einen Vergleich der Dissoziationskräfte als Funktion der Zuggeschwindigkeit für den Wildtyp (gefüllte Kreise), die Y33F-Mutante (Dreiecke) und die I96K-Mutante (Karos). Entgegen des beabsichtigten Effekte ist das überraschende Ergebnis, dass sich die Dissoziationskräfte der beiden Mutanten und des Wildtyps nicht 


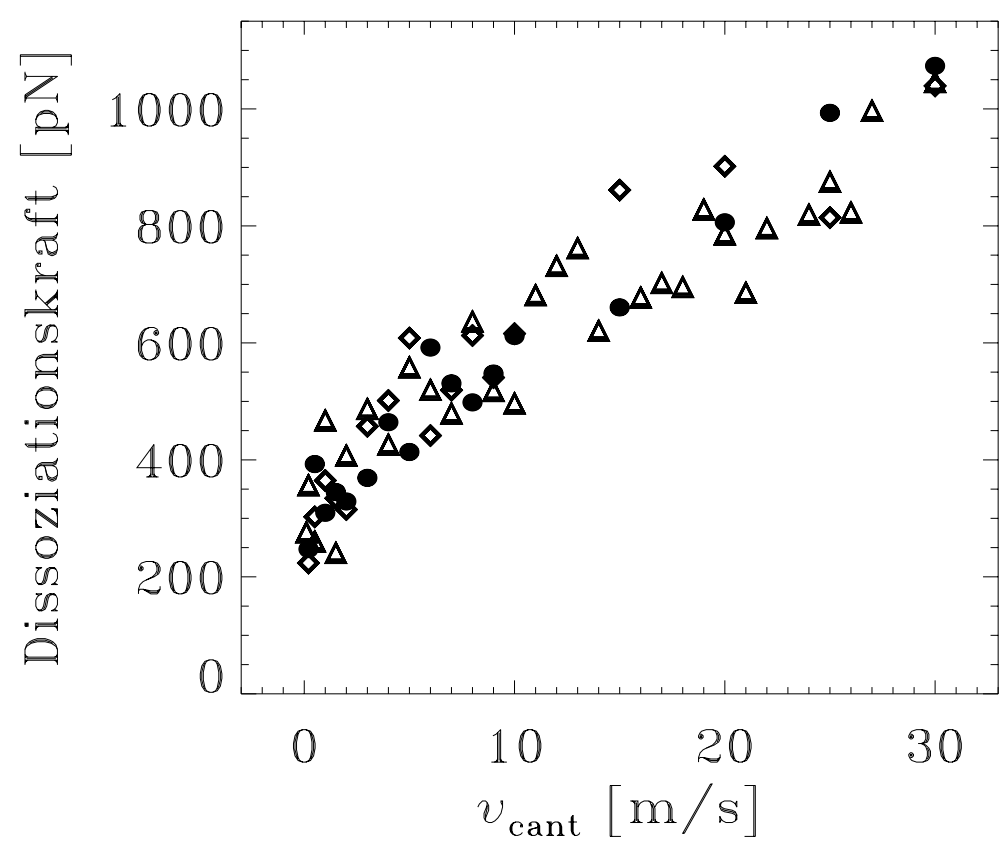

Abbildung 5.29: Dissoziationskräfte als Funktion der Zuggeschwindigkeit für den Wildtyp (Kreise), die Y33F-Mutante (Dreiecke) und die I96K-Mutante (Karos) des AN02-DNPHapten-Komplexes.

signifikant voneinander unterscheiden. Das in Abschnitt 4.1 beschriebene Modell zur Interpolation der berechneten Dissoziationskräfte auf die experimentelle Zeitskala ergibt für die Y33F-Mutante $68 \pm 25 \mathrm{pN}$ und für die I96K-Mutante $73 \pm 20 \mathrm{pN}$ (gegenüber $65 \pm 25 \mathrm{pN}$ für den Wildtyp). Dabei wurde für die Mutanten dieselbe Dissoziationskonstante angenommen wie beim Wildtyp.

Aus den in Abbildung 5.30 gezeigten Wechselwirkungsmustern für zwei Dissoziationssimulationen der Y33F-Mutante mit $v_{\text {cant }}=1 \mathrm{~m} / \mathrm{s}$ (links) bzw. $v_{\text {cant }}=0.5 \mathrm{~m} / \mathrm{s}$ (rechts) geht hervor, dass das Haptenmolekül in dem späteren Verlauf des Dissoziationsprozesses $\left(\mathrm{ab} z_{\text {cant }} \approx 4 \AA\right.$ ) über einen längeren Zeitraum in starke Wechselwirkungen zu TYR31(L) trat, was bei dem Wildtyp in dieser Weise nicht der Fall war (vgl. dazu die Wechselwirkungsmuster in Abbildung 5.21). Diese neue „späte“ Wechselwirkung war in den meisten Simulationen (wie in den beiden hier als repräsentativ gezeigten) an einer zweiten, hohen Kraftbarriere im Kraftprofil bei $z_{\text {cant }} \approx 6-8 \AA$ beteiligt. In einigen Simulationen (siehe Abbildung 5.30, rechts) bildete diese zweite Barriere sogar das globale Maximum im Kraftprofil und war somit bestimmend für die Dissoziationskraft.

Die nähere Untersuchung der Dissoziationsprozesse zeigte, warum die „entfernte“ starke Wechselwirkung bei der Y33F-Mutante und die „zusätzliche“ starke Wechselwirkung bei der I96K-Mutante nicht zu niedrigeren bzw. höheren Dissoziationskräften führte.

Warum es in der Y33F-Mutante im Verlauf des Dissoziationsprozesses zu einer deutlich stärkeren Wechselwirkung mit TYR31(L) kam als beim Wildtyp, machen die beiden Schnappschüsse in Abbildung 5.31 deutlich. Oben ist der gebundene Zustand des mutierten AN02-DNP-Hapten-Komplexes mit dem PHE33(L) gezeigt, das keine Wasserstoffbrücke mehr zum Mittelteil des Haptenmoleküls ausbilden kann (angedeutet durch die ge- 


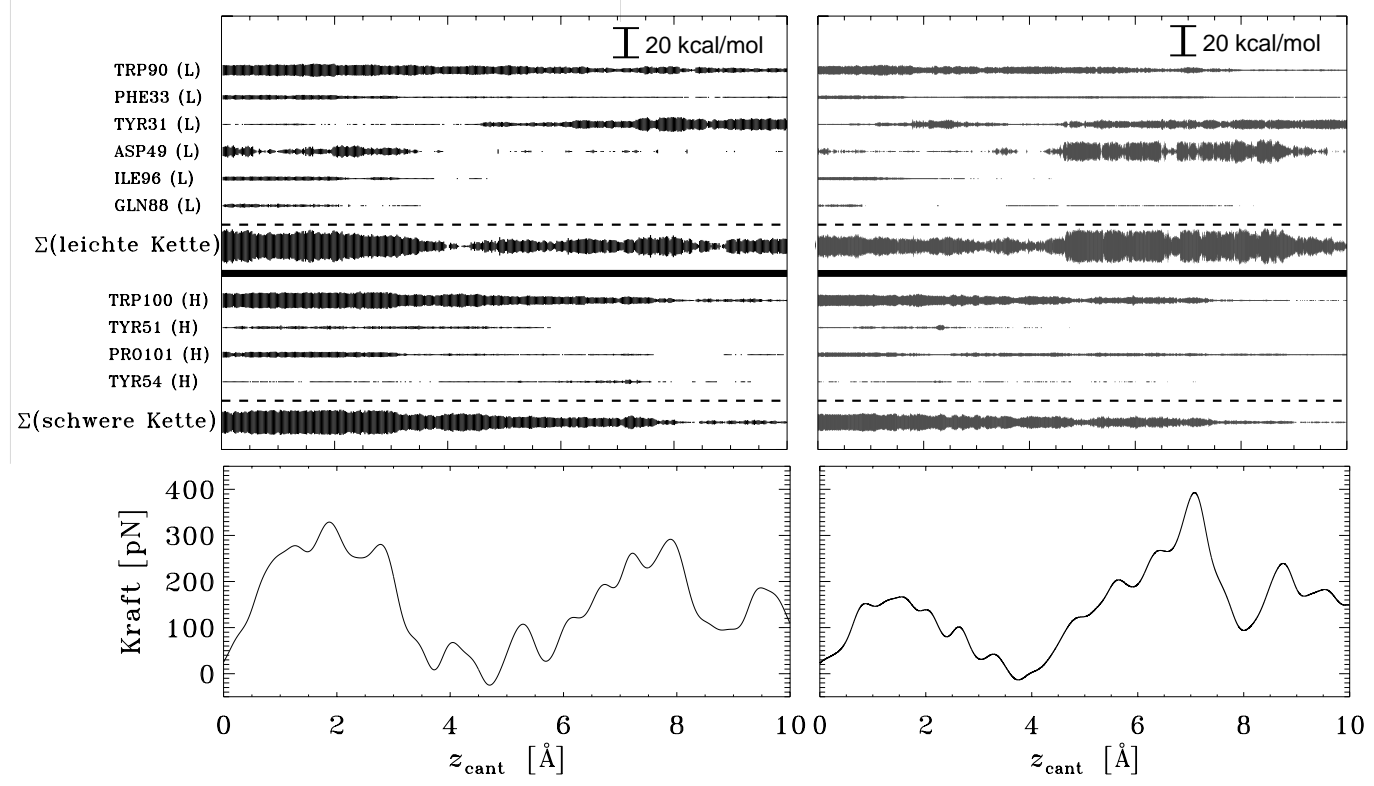

Abbildung 5.30: Wechselwirkungsmuster (oben) und Kraftprofile (unten) für zwei Dissoziationssimulationen der Y33F-Mutante mit $v_{\text {cant }}=1 \mathrm{~m} / \mathrm{s}\left(\right.$ links) und $v_{\text {cant }}=0.5 \mathrm{~m} / \mathrm{s}$ (rechts).

kreuzte gepunktete Linie). Anhand des unteren Schnappschusses (bei $z_{\text {cant }} \approx 4 \AA$ ) ist nun erkennbar, dass sich die Seitenkette von TYR31(L) im Verlauf des Dissoziationsprozesses deutlich auf das Haptenmolekül zubewegt und gleichsam die Rolle des WT-TYR33(L) 

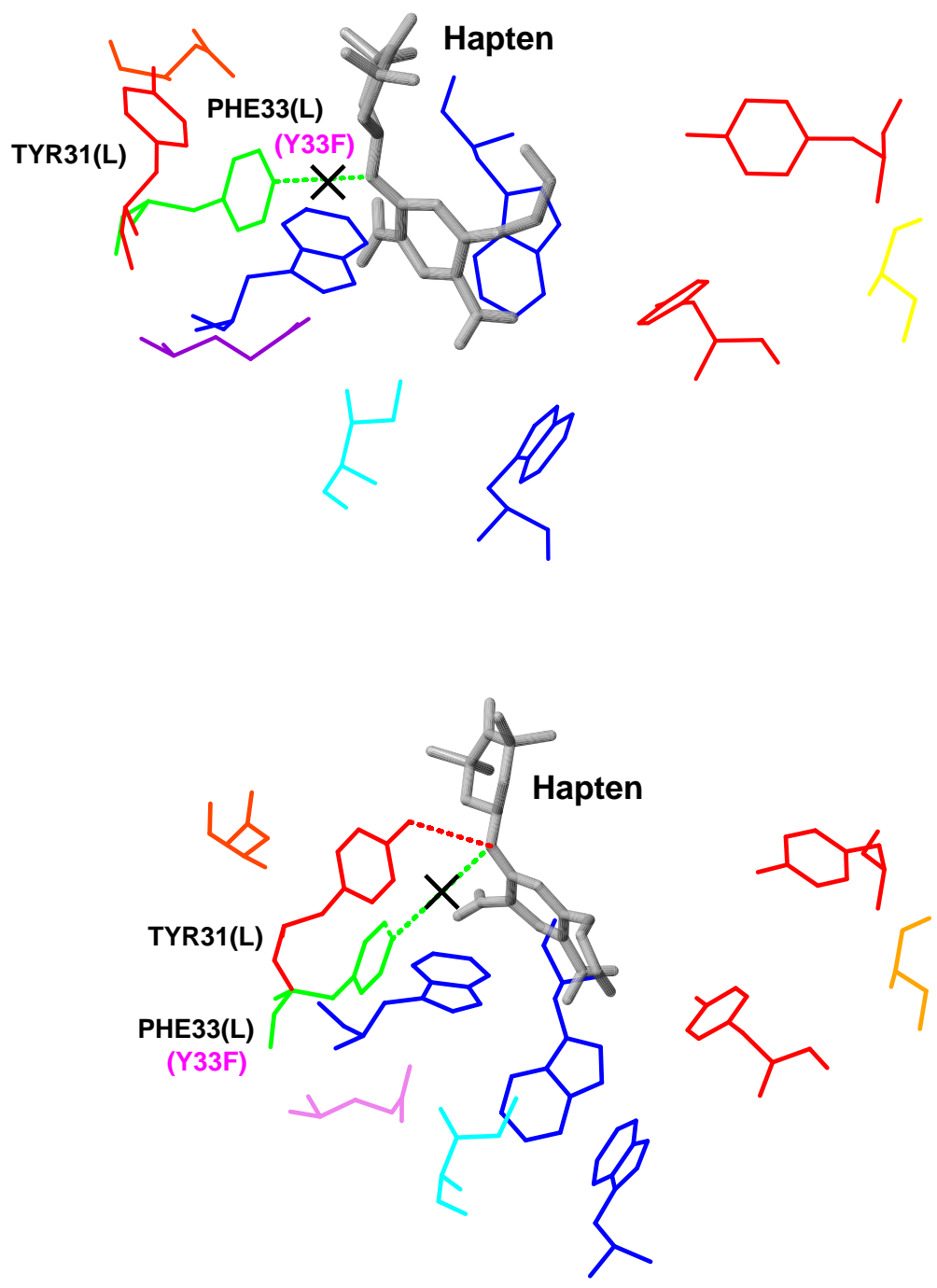

Abbildung 5.31: Schnappschüsse der Bindungstasche zum Dissoziationsprozess der Y33FMutante. Oben: gebundener Zustand $\left(z_{\text {cant }}=0 \AA\right)$. Unten: Zustand bei $z_{\text {cant }} \approx 4 \AA$. Gepunktete Linien kennzeichnen Wasserstoffbrücken zwischen Hapten und Aminosäuren der Bindungstasche. Die gekreuzten gepunkteten Linien deuten an, dass PHE33(L) im Gegensatz zu TYR33(L) im Wildtyp keine Wasserstoffbrücke zum Haptenmolekül ausbilden kann. Zur Bezeichnung der Aminosäuren siehe Abbildung 5.10. 
übernommen hat. Insbesondere bildete TYR31(L) eine starke Wasserstoffbrücke von der Hydroxylgruppe des aromatischen Seitenrings zur Aminogruppe von Hapten aus.

Die nahezu unveränderten Dissoziationskräfte erklären sich somit dadurch, dass sich bei der Y33F-Mutante die Gesamtwechselwirkungen des Haptenmoleküls mit der Bindungstasche im Verlauf des Dissoziationsprozesses im Vergleich zum Wildtyp kaum änderten. Dennoch haben wir es mit einem modifizierten Bindungsmechanismus zu tun. Zum einen hat sich die Bindung im Tryptophan-Sandwich etwas abgeschwächt, was sich an der im Mittel leicht erniedrigten ersten Barriere im Kraftprofil (bei $z_{\text {cant }}=1-3 \AA$ ) zeigte. Zum anderen musste jedoch im weiteren Verlauf des Dissoziationsprozesses eine leicht erhöhte Barriere überwunden werden, die durch eine signifikante Konformationsänderung in der Bindungstasche während des Dissoziationsprozesses — nämlich die Annäherung des Seitenkette von TYR31(L) an das Haptenmolekül — bedingt ist. Etwas vereinfacht lässt sich sagen, dass man sich bei der Y33F-Mutante die Erniedrigung der einen (frühen) Barriere im Kraftprofil durch die Erhöhung der anderen (späten) Barriere erkauft hat.

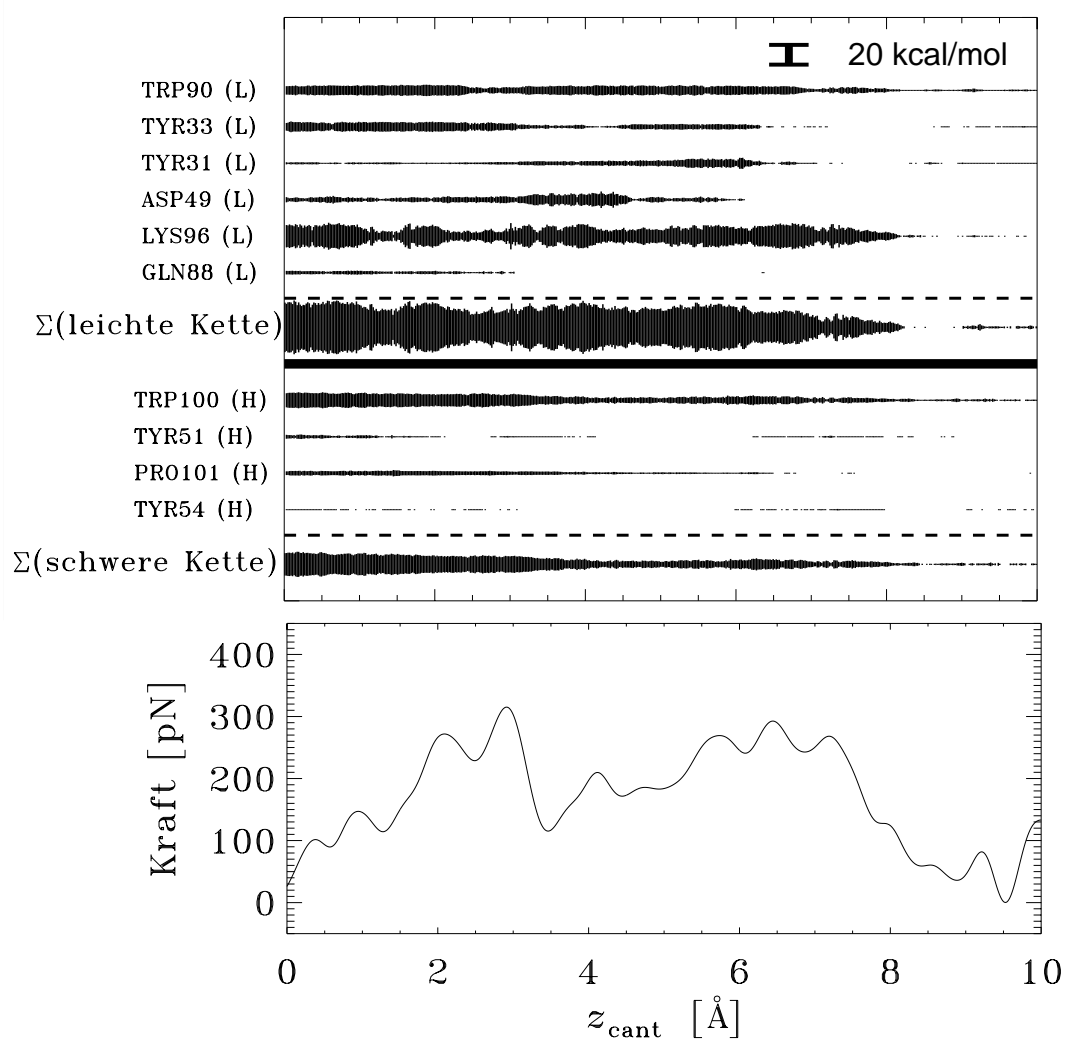

Abbildung 5.32: Oben: Wechselwirkungsmuster der I96K-Mutante für eine Dissoziationssimulation mit $v_{\text {cant }}=1 \mathrm{~m} / \mathrm{s}$. Unten: Kraftprofil für dieselbe Dissoziationssimulation.

Die Analyse der Dissoziationsprozesse der I96K-Mutante ergab, dass die Wechselwirkungen des Haptenmoleküls mit LYS96(L) die Dissoziationskraft kaum beeinflussten. Es zeigte sich nämlich, dass, wie ein repräsentatives Wechselwirkungsmuster in Abbildung 5.32 illustriert, diese Wechselwirkung in der Regel länger intakt blieb als die anderen in der 

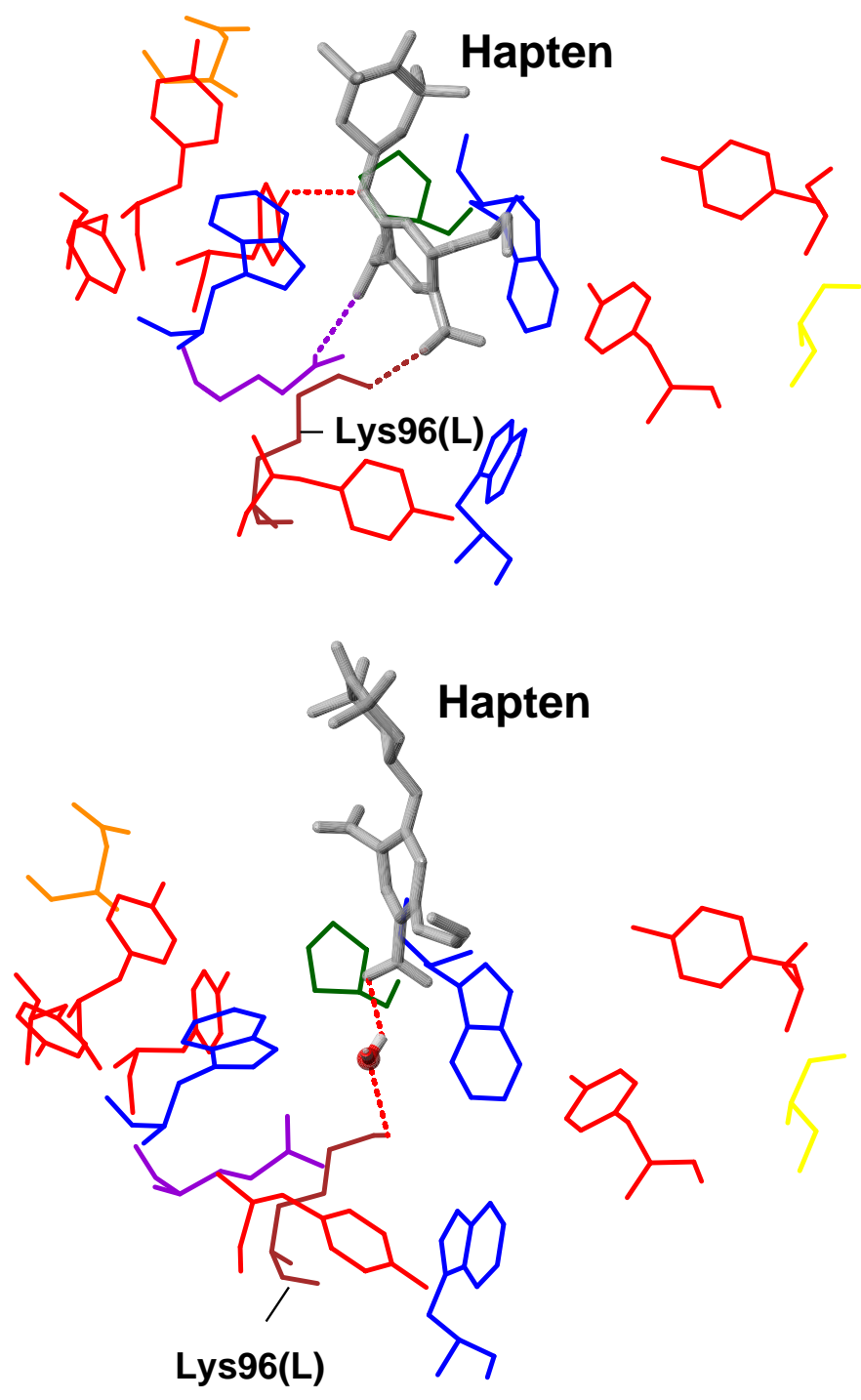

Abbildung 5.33: Schnappschüsse der Bindungstasche zum Dissoziationsprozess der I96KMutante. Oben: gebundener Zustand $\left(z_{\text {cant }}=0 \AA\right)$. Unten: Zustand bei $z_{\text {cant }} \approx 8 \AA$. Auch gezeigt ist ein Wassermolekül, das eine Wasserbrücke zwischen LYS96(L) und der ersten Nitrogruppe der DNP-Gruppe des Haptens ausbildet (gepunktete Linie).

Sandwich-Konfiguration beobachteten Wechselwirkungen. So schwächten sich nach Überquerung des globalen Maximums im Kraftprofil bei $z_{\text {cant }} \approx 3 \AA$ (siehe Krtaftprofil in Abbildung 5.32) die Wechselwirkungen zu TYR33(L), GLN88(L) und TRP90(L) ab oder brachen ganz. Die Seitenkette von LYS96(L) erwies sich dahingegen zum einen als recht beweglich, so dass sie den Dissoziationsbewegungen des Haptenmoleküls ein Stück weit folgen konnte, zum anderen bildete sich im weiteren Varlauf eine starke Wasserbrücke zwischen der ersten Nitrogruppe des DNP-Rings und der Lysin-Seitenkette (siehe den zweiten Schnappschuss in Abbildung 5.32). Das Brechen dieser Wasserbrücke verursachte in den meisten Dissoziationssimulationen der I96K-Mutante eine weitere Kraftbarriere bei 
$z_{\text {cant }}=6-8 \AA$; da diese aber fast immer niedriger war als die erste, beim Verlassen der Sandwich-Konfiguration beobachtete Barriere, spielte sie für die Dissoziationskraft keine Rolle.

Die I96K-Mutante ist ein instruktives Beispiel für ein recht allgemeines Prinzip, das unsere Mutanten-Simulationen aufzeigen: Im Gegensatz zur Bindungsenergie setzen sich Dissoziationskräfte nicht einfach additiv aus einzelnen Wechselwirkungsbeiträgen zusammen. Vielmehr kommt es, wie in Abbildung 5.34 verdeutlicht, entscheidend darauf an, an welcher Stelle des Reaktionswegs die einzelnen Wechselwirkungen Kräfte hervorrufen. In diesem stark vereinfachten Bild gibt es prinzipiell zwei verschiedene Möglichkeiten, die Dissoziationskraft zu erhöhen: entweder die Punktmutation trägt dazu bei, dass eine
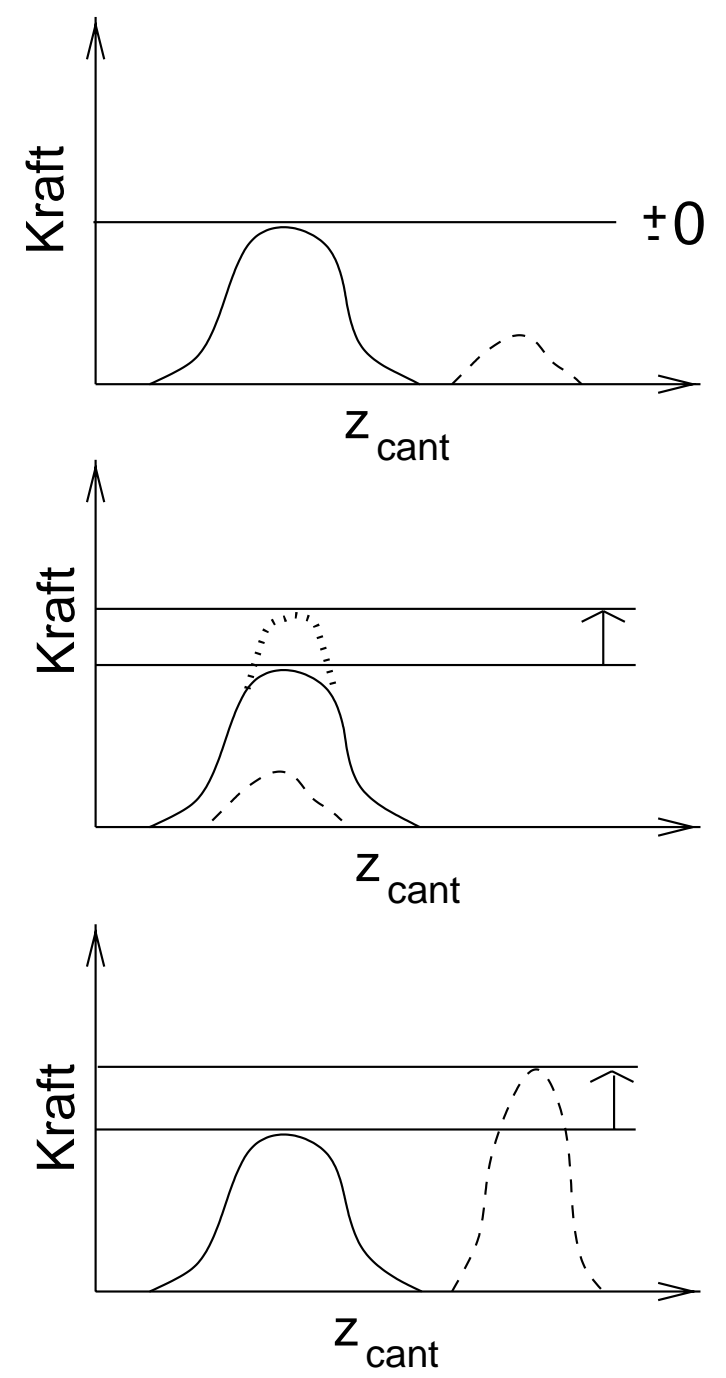

Abbildung 5.34: Einfluss individueller Wechselwirkungen auf die GesamtDissoziationskraft. Oben: Der durch eine Punktmutation zusätzlich eingeführte Kraftbeitrag (gestrichelt) wirkt an einer andereren Stelle des Reaktionswegs (gemessen über $\left.z_{\text {cant }}\right)$ als das Maximum im ursprünglichen Kraftprofil (durchgezogene Linie). Deswegen ist die Dissoziationskraft im Vergleich zum Wildtyp unverändert. Mitte: Der Kraftbeitrag durch die Punktmutation fällt mit dem bereits vorhandenen Kraftmaximum zusammen, wodurch die Dissoziationskraft erhöht wird (gepunktete Linie). Unten: Die Kraftbeiträge wirken zwar, wie oben, an verschiedenen Stellen des Reaktionswegs, doch der durch die Punktmutation neu hinzugekommene Beitrag übersteigt das Maximum des ursprünglichen Kraftprofils, so dass sich hier die Dissoziationskraft erhöht.

im Wildtyp vorhandene Barriere im Kraftprofil signifikant erhöht wird (Abbildung 5.34, Mitte) oder sie bedingt eine zusätzliche Barriere (unten), die allerdings nur dann in Erscheinung tritt, wenn sie höher ist als die ursprüngliche Barriere. Bei der I96K-Mutante 
war beides nicht der Fall: Weder wirkte LYS96(L) gleichzeitig mit den anderen Aminosäuren der Bindungstasche (Möglichkeit 1), noch bewirkte sie eine weitere, höhere Barriere (Möglichkeit 2).

Auch wenn das ursprüngliche Ziel, die Dissoziationskraft durch Punktmutationen gezielt zu erniedrigen bzw. zu erhöhen, nicht erreicht wurde, förderten die Dissoziationssimulationen der beiden Mutanten neue Aspeke des Bindungsmechanismus zutage: die Y33FMutante zeigte, dass eine wichtige, durch Mutation eliminierte Aminosäure mit Hilfe einer Konformationsänderung während des Dissoziationsprozesses durch eine andere ersetzt werden konnte. Die I96K-Mutante zeigte zwar, wie beabsichtigt, eine weitere Barriere im Kraftprofil; sie reichte jedoch nicht aus, die Gesamt-Dissoziationskraft zu erhöhen. Beide Mutanten zeigen, dass die mutierten Aminosäuren nicht separat, sondern in ihrem Zusammenwirken mit den anderen Aminosäuren der Bindungstasche zu betrachten sind. 


\section{Kapitel 6}

\section{Dehnungssimulationen von Polymermolekülen}

Dieses Kapitel ist den mechanischen und elastischen Eigenschaften einzelner Polymermoleküle gewidmet. Neben den intermolekularen Wechselwirkungen sind es gerade diese Einzelmoleküleigenschaften, welche die makroskopischen Eigenschaften von Materialien oder Werkstoffen bestimmen. Ihre vertiefte Kenntnis auf atomarer Ebene ist daher Voraussetzung für die Entwicklung und Optimierung von Werkstoffen mit maßgeschneiderten Eigenschaften.

Wie bereits einleitend erwähnt, wurden seit Beginn der neunziger Jahre die elastischen Eigenschaften einer Vielzahl von Polymeren mit Hilfe von mechanischen Kraftmessungen untersucht, darunter auch zahlreichen kraftmikroskopischen Experimenten [17-19,21-24]. Schon in Kapitel 3 wurde beschrieben, dass in diesen Experimenten einzelne Polymere zwischen Cantilever und einer Unterlage eingespannt und anschließend gedehnt werden (vgl. dazu Abbildung 3.1 in Kapitel 3), wobei die Dehnung des Polymermoleküls in Folge der wirkenden Zugkraft in so genannten Kraft-Ausdehnungs-Kurven aufgetragen wird. Eine solche Kraft-Ausdehnungs-Kurve charakterisiert das elastische Verhalten des untersuchten Polymermoleküls; ihre Steigung ist ein Maß für die Elastizität des Moleküls. In unseren ganz analog zu den kraftmikroskopischen Experimenten durchgeführten MD-Simulationen, in denen ebenfalls einzelne Polymermoleküle gedehnt wurden, konnten solche Kraft-Ausdehnungs-Kurven berechnet werden [17,68,70]. Darüber hinaus verschafften die Simulationen detaillierten Einblick in die atomaren Prozesse, die während des Dehnungsprozesses stattfanden; sie dienten somit insbesondere der Interpretation der gemessenen und berechneten Elastizitäten auf atomarer Ebene.

Hier konzentrieren wir uns auf die mechanischen Eigenschaften der drei Polysaccharide Dextran, Cellulose und Amylose, die die Natur vielseitig einsetzt, sowie des wasserlöslichen Polymers Polyethylenglykol (PEG), das in vielen industriellen, biotechnischen oder klinischen Anwendungen zum Einsatz kommt. 


\subsection{Dehnungssimulationen von Polysacchariden}

Polysaccharide spielen eine bedeutende Rolle in zahlreichen biologischen Prozessen. Sie dienen nicht nur als Energiespeicher und Brennstoffe, sondern auch der Stabilisierung von Strukturen, etwa in pflanzlichen oder bakteriellen Zellwänden, im Bindegewebe oder in den Außenskeletten von Arthropoden [211]. Polysaccharidfragmente in Glykoproteinen sind darüber hinaus von großer Bedeutung bei der molekularen Erkennung [212].

Dextrane sind Speicherpolysaccharide in Bakterien und in Hefen. Amylose ist Hauptbestandteil der pflanzlichen Stärke und kommt zu einem geringeren Teil auch in Glykogen vor, dem Glucosespeicher in tierischen Zellen. Cellulose dient vor allem der Strukturbildung in Pflanzen- und Holzfasern. Es ist die am häufigsten auftretende organische Verbindung in der Biosphäre. (In ihr werden jährlich etwa $10^{15} \mathrm{~kg}$ Cellulose synthetisiert und abgebaut [211].) Wie die meisten biologisch wichtigen Polysaccharide sind Dextran, Amylose und Cellulose aus Pyranoseringen aufgebaut, die aus 5 Kohlenstoffatomen und einem Sauerstoffatom bestehen (Abbildung 6.1). Sie kommen in einer Vielzahl von Zellstrukturen vor, wo sie vielfach erheblichen mechanischen Kräften ausgesetzt sind [213-218]. Es wurde bislang angenommen, dass die Pyranoseringe auf mechanische Kräfte mit einer elastischen Deformation reagieren, jedoch war über die atomaren Details solcher kraftinduzierter Deformationen nur wenig bekannt.

Der Aufbau und die Verknüpfung der untersuchten Polysaccharide ist in Abbildung 6.1 gezeigt. Pyranoseringe können grundsätzlich eine Sessel- oder eine Wannenkonformation einnehmen, wobei man bei der Sesselkonformation zwischen der ${ }^{4} \mathrm{C}_{1}$ - und $\operatorname{der}{ }^{1} \mathrm{C}_{4}$ Konformation unterscheidet (siehe oben links bzw. oben Mitte in der Abbildung). Die Sesselkonformation ist deutlich stabiler als die Wannenkonformation [219,220], und bei den hier untersuchten Polysacchariden trifft man fast ausschließlich die ${ }^{4} \mathrm{C}_{1}$-Konformation an [221-226]. Nach der Orientierung der Hydroxylgruppe am Kohlenstoffatom C1 unterscheidet man zwischen $\alpha$ - und $\beta$-Glucopyranose: Bei $\alpha$-Glucopyranose (zweite Reihe, links) befindet sich diese Gruppe unterhalb der Ringebene, während sie in der $\beta$ Konfiguration (zweite Reihe, rechts) oberhalb steht.

Wie unten rechts in Abbildung 6.1 gezeigt, handelt es sich bei Dextran um $\alpha$ - $(1,6)$ Glucopyranose, d.h. die einzelnen Pyranoseringe sind über die Kohlenstoffatome $\mathrm{C} 1$ und C6 miteinander verbrückt. Bei Amylose und Cellulose handelt es sich jeweils um $\alpha-(1,4)-$ bzw. $\beta$-(1,4)-Glucopyranose, da hier die Verbrückung über die Kohlenstoffatome C1 und $\mathrm{C} 4$ erfolgt (unten links in der Abbildung). 


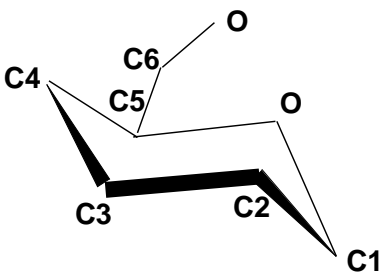

${ }^{4}$ C1-Sessel

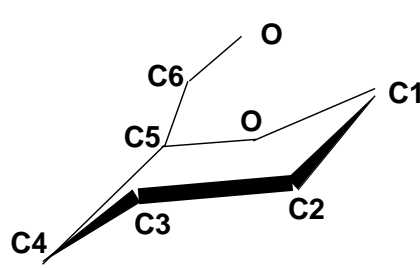

${ }^{1}$ C4-Sessel

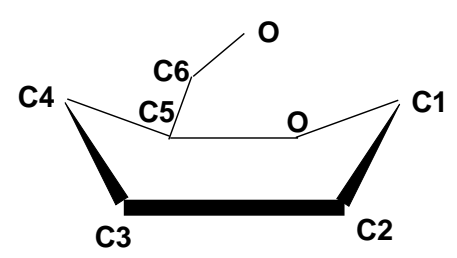

Wanne

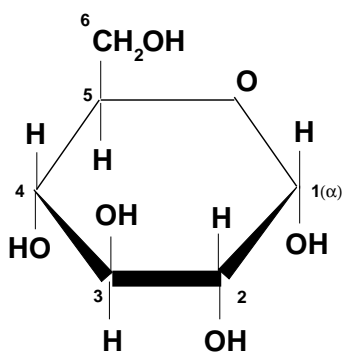

$\alpha$-Glucopyranose
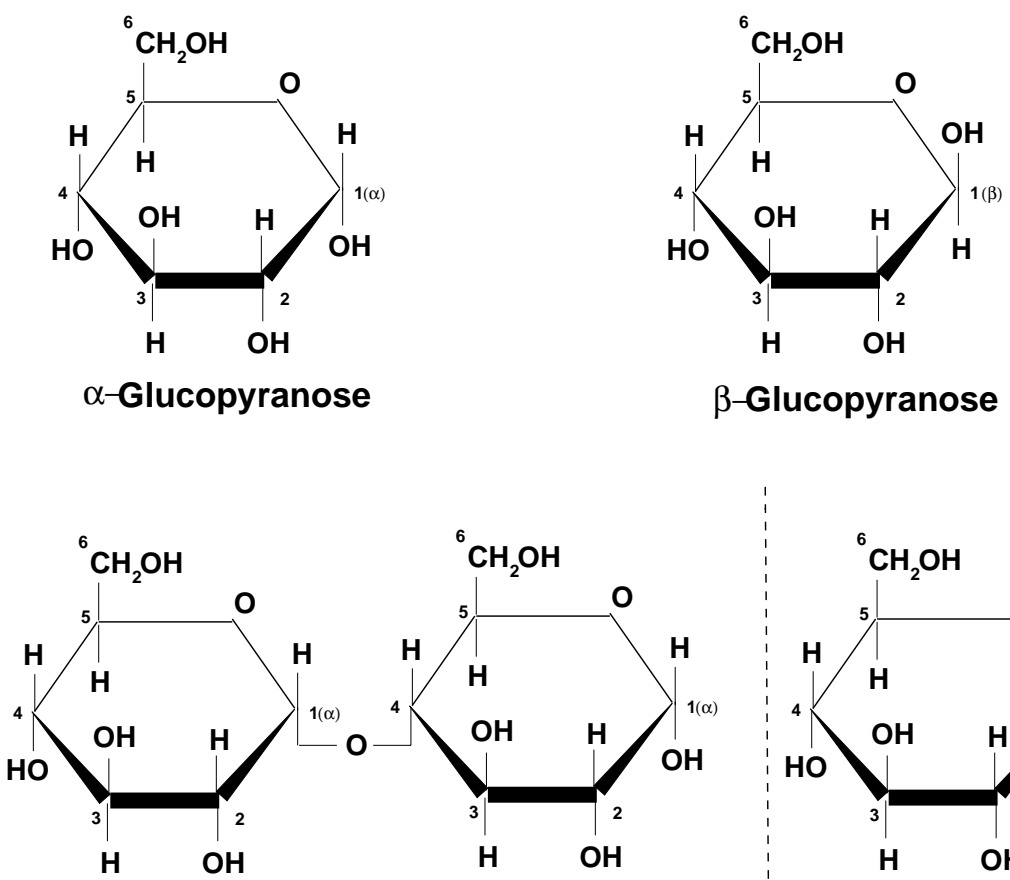

$\alpha-(1,4)$-Glucopyranose (Amylose)

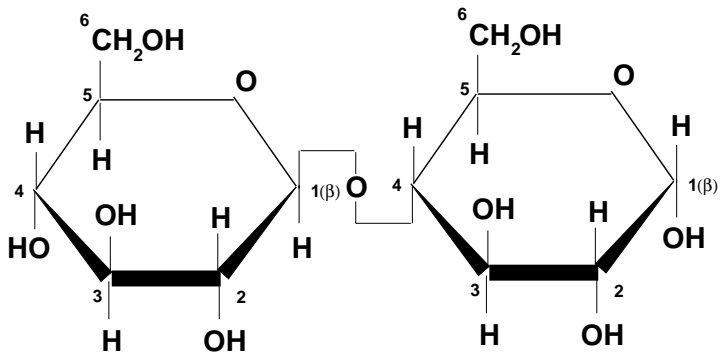

$\beta-(1,4)-$ Glucopyranose (Cellulose)

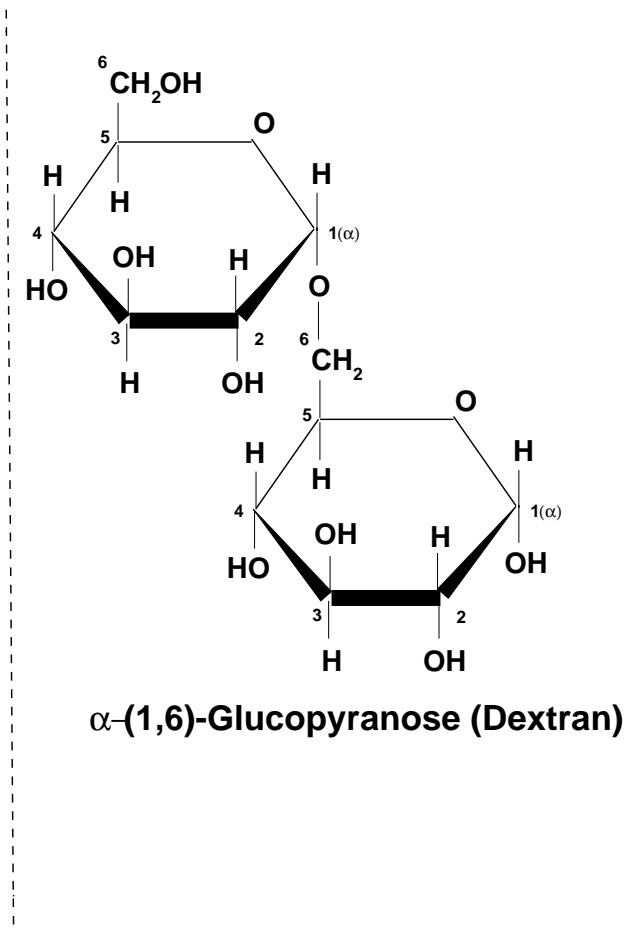

Abbildung 6.1: Oben: Mögliche Konformationen von Pyranoseringen. Zweite Reihe: Bei $\alpha$-Glucopyranose befindet sich die Hydroxylgruppe am Kohlenstoffatom C1 unterhalb der Ringebene, bei $\beta$-Glucopyranose oberhalb. Unten: Amylose und Cellulose bestehen aus $(1,4)$-verbrückten, Dextran aus (1,6)-verbrückten Pyranoseringen. 


\subsubsection{Dextran}

Noch bevor wir die ersten MD-Simulationen des Dehnungsprozesses von Dextran durchgeführt haben, waren in Hermann Gaubs Gruppe (Lehrstuhl für Angewandte Physik der Universität München) bereits kraftmikroskopische Experimente durchgeführt worden, in denen Dextran mit Zugkräften bis zu 250 pN gedehnt wurde. Im Bereich sehr niedriger Zugkräfte von weniger als $100 \mathrm{pN}$ ließ sich die Elastizität des Polymers als ein rein entropischer Effekt erklären, wie etwa die gute Übereinstimmung der aus AFM-Experimenten gewonnenen Kraft-Ausdehnungs-Kurven mit dem „wormlike chain“-Modell [227] zeigte $[6,12,17,228,229]$. Bei höheren Kräften traten jedoch deutliche Abweichungen auf, so dass neben dem entropischen Beitrag noch weitere Kraftbeiträge angenommen werden mussten. Man vermutete, dass diese durch die Dehnung von Bindungs- und Torsionswinkeln hervorgerufen werden. Diese Hypothese wollten wir mit den im Folgenden beschriebenen MD-Simulationen überprüfen.

\section{Methoden}

Für die MD-Simulationen wurden Dextranpolymere verschiedener Länge (2 bis 10 Monomere) mit dem Molekül-Editor von Quanta [110] modelliert. Alle Strukturen wurden so lange minimiert, bis der Gradient der potenziellen Energie jeweils kleiner als $0.1 \mathrm{kcal} /(\mathrm{mol}$ $\AA)$ war. Wie auch für alle folgenden Simulationen, wurden die Parameter für das Kraftfeld und die Partialladungen der in Quanta verfügbaren CHARMM-basierten Parameterbibliothek für Polymermoleküle entnommen. Für ein Dextranpentamer wurde eine explizite zylinderförmige Lösungsmittelumgebung aus TIP3-Wassermolekülen [164] mit Solvate [174] erstellt. Für dieses Simulationssystem, das 663 Wassermoleküle enthielt, wurde das in Abschnitt 2.3 beschriebene Sbound-Potenzial verwendet. Alle übrigen Simulationen wurden in vacuo mit einer Dielektrizitätskonstante von $\epsilon=1$ durchgeführt, da wir nur geringe Lösungsmitteleffekte erwarteten. Die Integrationsschrittweite betrug jeweils 1 fs. Die Länge der chemischen Bindungen zu Wasserstoffatomen wurde mit dem SHAKE-Algorithmus konstant gehalten. Alle Dextranpolymere wurden jeweils über eine Zeitspanne von 60 ps equilibriert, wobei die Atome an ein $300 \mathrm{~K}$-Wärmebad mit einer Kopplungskonstanten von $10 \mathrm{ps}^{-1}$ gekoppelt wurden. Die aus der Equilibrierungsphase resultierenden Strukturen dienten als Ausgangspunkt für die nachfolgenden Dehnungssimulationen.

Die Dehnungssimulationen zu Dextran wurden wie in Abbildung 6.2 skizziert durchgeführt (zur besseren Übersichtlichkeit ist hier nur ein Dextrandimer gezeigt): Das an dem Kohlenstoffatom C6 gebundene Sauerstoffatom des linken Monomers wurde mit einem relativ steifen harmonischen Potenzial mit einer Kraftkonstante von $28 \mathrm{~N} / \mathrm{m}$ fixiert. Dagegen wurde das am weitesten rechts befindliche Sauerstoffatom, das an dem Kohlenstoffatom C1 gebunden ist, einem weichen harmonischen Zugpotenzial unterworfen. Die Kraftkonstante hierfür betrug $70 \mathrm{mN} / \mathrm{m}$, ein typischer Wert für Cantilever, die in kraftmikroskopischen Einzelmolekülexperimenten verwendet werden. Das Zugpotenzial wurde im Verlauf einer Dehnungssimulation mit konstanter Zuggeschwindigkeit in Zugrichtung (in der Abbildung nach rechts) bewegt. Auf diese Weise wurde das Dextranpolymer einer kontinuierlich wachsenden Zugkraft unterworfen und das Molekül entsprechend gedehnt. 


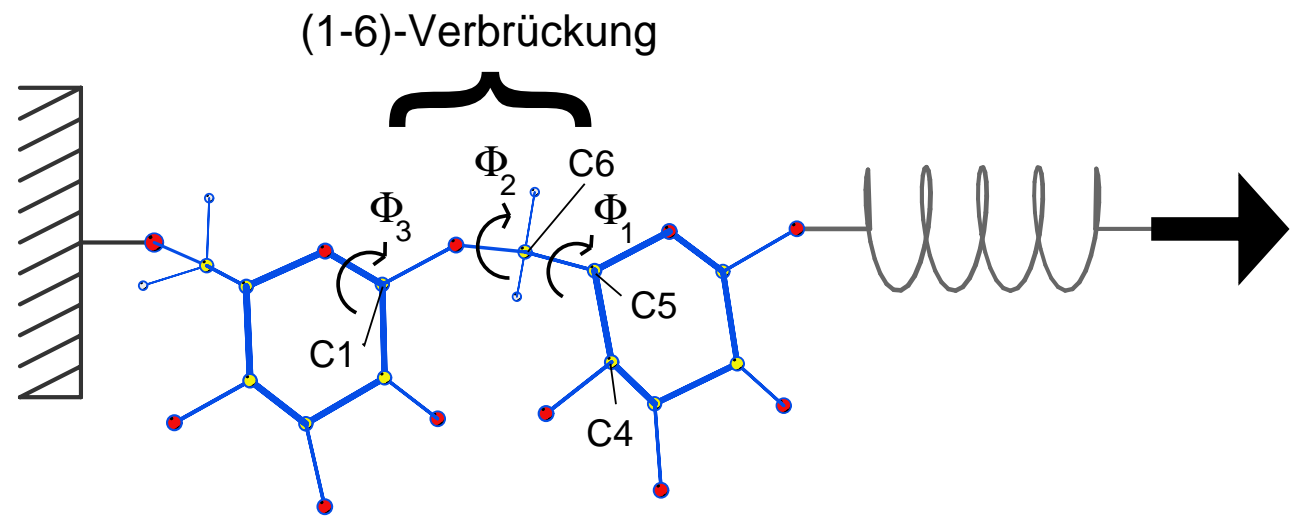

Abbildung 6.2: Vorgehensweise in den Dehnungssimulationen am Beispiel eines Dextrandimers. Die Dihedralwinkel $\Phi_{1}, \Phi_{2}$ und $\Phi_{3}$ dienten der Charakterisierung der Konformation der Verbrückung $\left(\Phi_{1}\right.$ und $\left.\Phi_{2}\right)$ und der Pyranoseringe $\left(\Phi_{3}\right)$.

In allen Dehnungssimulationen wurden die Atompositionen und die aktuelle Zugkraft alle 100 fs abgespeichert. Um eine Kraft-Ausdehnungs-Kurve zu gewinnen, wurde die Zugkraft in Abhängigkeit von der Ausdehnung des Polymers aufgetragen, wobei die Ausdehnung durch den Abstand der beiden terminalen Sauerstoffe definiert wurde. Als weitere Observablen dienten die zeitlichen Verläufe der in Abbildung 6.2 gekennzeichneten Dihedralwinkel $\Phi_{1}, \Phi_{2}$ und $\Phi_{3}$, welche Torsionen um die Bindungen C5-C6 und C6-O der Verbrückung bzw. um die Bindung C1-C2 innerhalb des Pyranoserings beschreiben. Während die ersten beiden Winkel beschreiben, wie benachbarte Ringe zueinander orientiert sind, charakterisiert $\Phi_{3}$ die Konformation eines Pyranoserings (Sessel- oder Wannenkonformation). Jeder dieser Dihedralwinkel besitzt drei Gleichgewichtslagen, $\Phi_{i}^{1}=60^{\circ}, \Phi_{i}^{2}=180^{\circ}$ und $\Phi_{i}^{3}=300^{\circ}(i=1,2,3)$. In der Simulation wurden diese durch ein Kosinuspotenzial

$$
E_{\text {Dihe }}^{\Phi_{i}}=k_{\Phi_{i}}\left[1+\cos \left(n \Phi_{i}\right)\right] \quad(i=1,2,3)
$$

mit der Barrierenhöhe $k_{\Phi_{i}}$ und der Periodizität von $n=3$ beschrieben.

Da wir schon in den Dissoziationssimulationen zu AN02-Hapten eine Abhängigkeit der Dissoziationskraft von der Zuggeschwindigkeit $v_{\text {cant }}$ beobachtet hatten, zogen wir auch hier eine Abhängigkeit in Betracht. Um einen möglichen Einfluss der Zuggeschwindigkeit auf den Dehnungsprozess zu studieren, wurde eine Reihe von Dehnungssimulationen mit Zuggeschwindigkeiten von $0.5-100 \mathrm{~m} / \mathrm{s}$ durchgeführt. Die längste Simulation mit $v_{\text {cant }}=$ $0.5 \mathrm{~m} / \mathrm{s}$ deckte eine Zeitspanne von $50 \mathrm{~ns}$ ab.

\section{Ergebnisse}

Während der Equilibrierungsphase stabilisierten sich die einzelnen Energiebeiträge (potenzielle, elektrostatische, Van der Waals-, Dihedral-, Bindungswinkel- und kovalente Bindungsenergie) nach wenigen Pikosekunden bei den Simulationen von Dextran in vacuo und nach etwa 50 ps bei der Simulation von Dextran in Wasser (Daten nicht gezeigt). Die anfängliche Verbrückungskonformation wie auch die Sesselkonformation blieben unverändert, wie Abbildung 6.3 anhand des Verlaufs der Dihedralwinkel $\Phi_{1}$, $\Phi_{2}$ (Verbrückung) und $\Phi_{3}$ (Ringkonformation) zeigt. Allerdings unterschieden sich die in vacuo 
equilibrierten Strukturen von der in Wasser insofern, als sich der Verbrückungsdihedralwinkel $\Phi_{2}$ auf unterschiedlichen Werten stabilisierte $\left(170^{\circ}\right.$ bzw. $\left.100^{\circ}\right)$, wobei er bei den in vacuo-Simulationen vergleichsweise stark fluktuierte. Darin zeigt sich, dass die Monomere in Wasser und in vacuo geringfügig unterschiedlich zueinander orientiert waren, was allerdings die Ausdehnung der Dextranpolymere kaum veränderte.

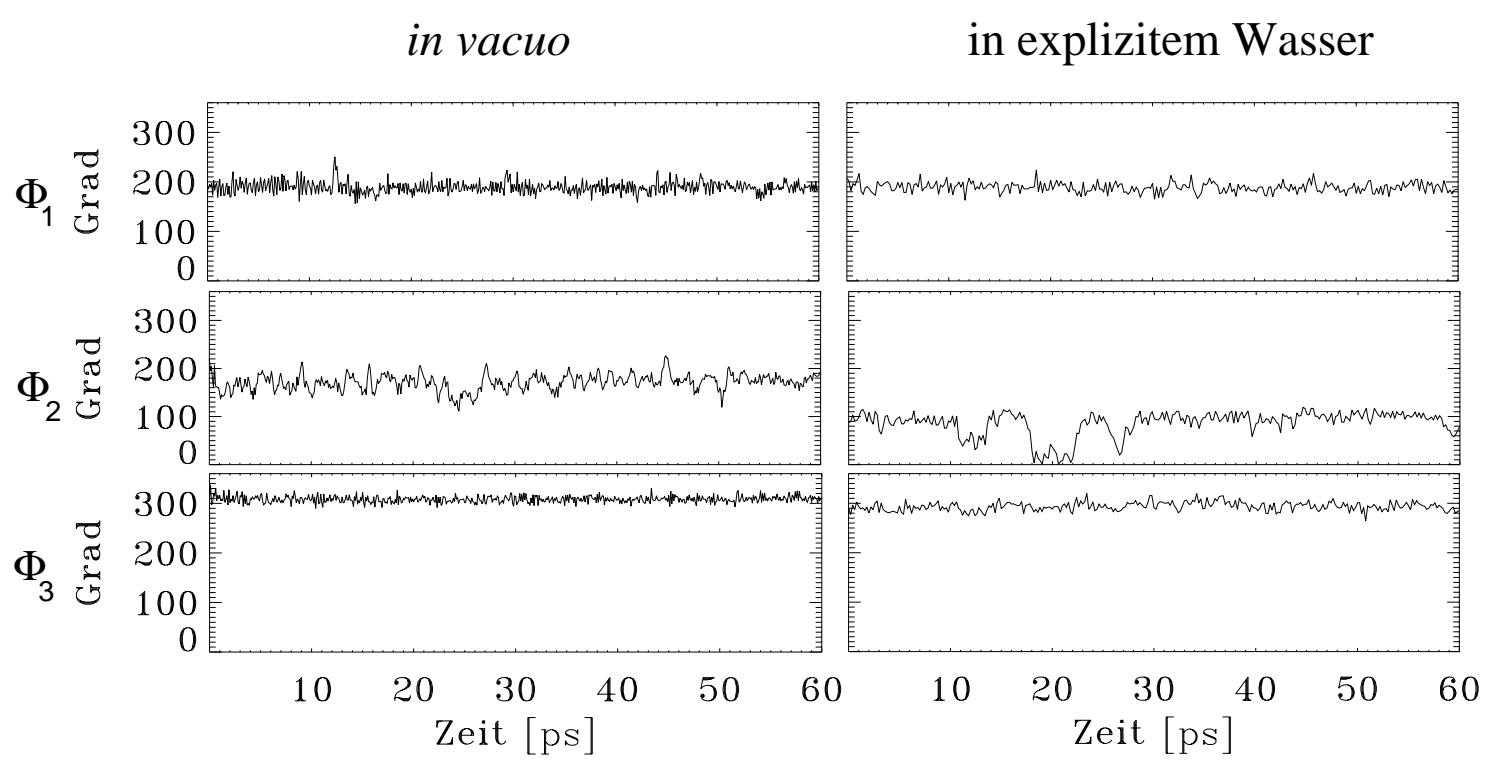

Abbildung 6.3: Verlauf der Dihedralwinkel $\Phi_{1}, \Phi_{2}$ und $\Phi_{3}$ während der Equilibrierung für eine als repräsentativ ausgewählte Simulation. Zur Definition der Dihedralwinkel siehe Abbildung 6.2.

Abbildung 6.4 zeigt die aus vier Dehnungssimulationen extrahierten Kraft-AusdehnungsKurven: zwei zu Dextrandekameren mit unterschiedlichen Zuggeschwindigkeiten $\left[v_{\text {cant }}=\right.$ $0.5 \mathrm{~m} / \mathrm{s}$ (dünne durchgezogene Linie) und $v_{\text {cant }}=100 \mathrm{~m} / \mathrm{s}$ (gepunktete Linie)] und zwei zu Dextranpentameren in vacuo (fette Linie) und in Wasser (gestrichelte Linie) mit $v_{\text {cant }}=$ $10 \mathrm{~m} / \mathrm{s}$. Bei allen Kurven lassen sich drei Elastizitätsregimes unterscheiden, wie anhand der waagerecht gestrichelten Linien in der Abbildung angedeutet ist. Die Regimes 1 und 3 weisen konstante Steigungen von 1000 bzw. 5000 pN/A (d.h. Elastizitäten von 10 bzw. $50 \mathrm{~N} / \mathrm{m}$ ) auf, das zweite Regime beinhaltet den Übergangsbereich zwischen Regime 1 und 3 in Form einer ausgeprägten „Schulter“, wo das Dextranpolymer im Mittel eine sehr hohe Elastizität (geringe Steigung der Kurve) besitzt.

In Regime 2 traten leichte Unterschiede zwischen den Dehnungssimulationen auf. Zum einen ergab sich für hohe Zuggeschwindigkeiten $v_{\text {cant }}>10 \mathrm{~m} / \mathrm{s}$ eine leichte Verschiebung der Schulter zu höheren Zugkräften. Zum anderen fiel bei der Dehnungssimulation des in Wasser gelösten Dextranpentamers der Übergang von dem ersten zum dritten Regime weniger abrupt aus als in den in vacuo-Simulationen. Die Länge der Dextranpolymere (zwischen 2 und 10 Monomere) zeigte keinen signifikanten Einfluss auf die Kraft-AusdehnungsKurve.

Abbildung 6.5 zeigt für ein ausgewähltes Monomer den Verlauf der Dihedralwinkel $\Phi_{1}$, $\Phi_{2}$ und $\Phi_{3}$ während des Dehnungsprozesses für ein Dextranpentamer in vacuo (links) und für ein in Wasser gelöstes Dextranpentamer (rechts). Der Verbrückungs-Dihedralwinkel 


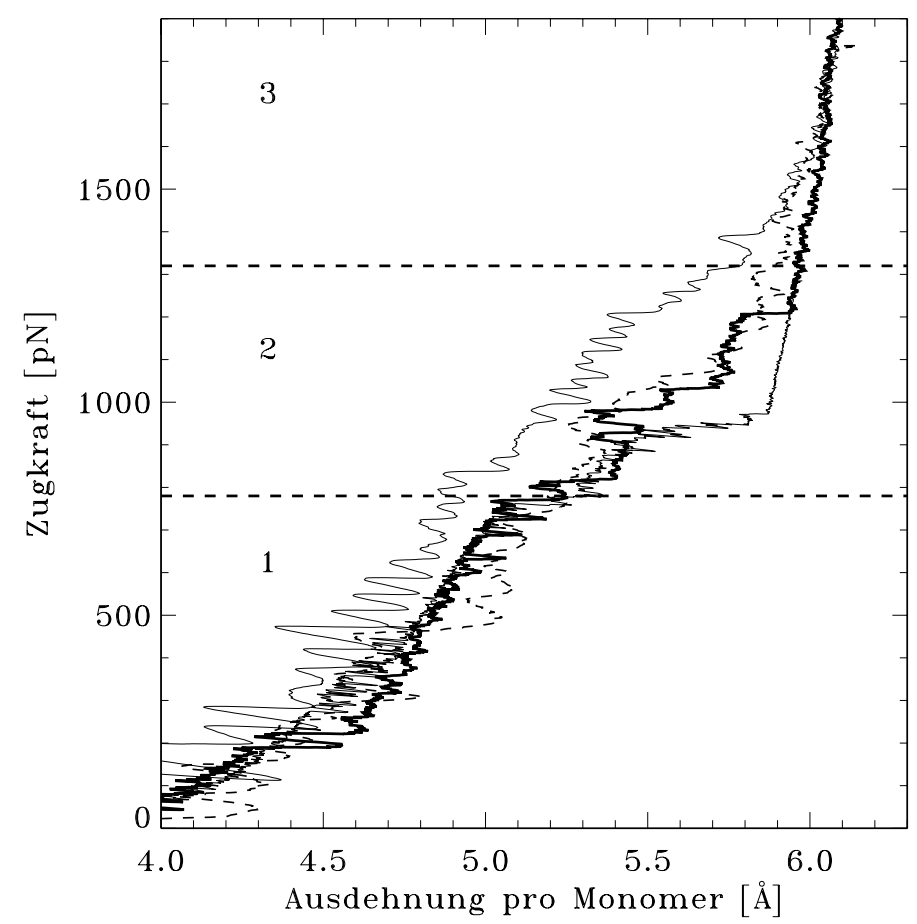

Abbildung 6.4: Kraft-Ausdehnungs-Kurven von Dextranpolymeren verschiedener Länge mit unterschiedlichen Zuggeschwindigkeiten. Fette, durchgezogene Kurve: 5 Monomere, $v_{\text {cant }}=10 \mathrm{~m} / \mathrm{s}$. Dünne, durchgezogene Kurve (links): 10 Monomere, $v_{\text {cant }}=100 \mathrm{~m} / \mathrm{s}$. Dünne, durchgezogene Kurve (rechts): 10 Monomere, $v_{\text {cant }}=0.5 \mathrm{~m} / \mathrm{s}$. Gestrichelte Kurve: 5 Monomere, $v_{\text {cant }}=10 \mathrm{~m} / \mathrm{s}$, explizite Wasserumgebung (die übrigen Simulationen fanden in vacuostatt).

$\Phi_{1}$ änderte sich im Verlauf der Dehnungssimulationen signifikant von $200^{\circ} \mathrm{zu}$ Beginn (als sich das Polymer noch im ungestreckten Zustand befand) auf etwa $50^{\circ}$ am Ende der Simulationen. In den in vacuo-Simulationen war ein Sprung zu beobachten, während bei der Simulation mit explizitem Wasser der Übergang zwischen dem anfänglichen und dem Endwert des Dihedralwinkels $\Phi_{1}$ offensichtlich gedämpft war. Die Sprünge von $\Phi_{1}$ erfolgten in allen anderen Monomeren in ähnlicher Weise (nicht gezeigt); sie fanden unter den einzelnen Monomeren allerdings nicht korreliert statt, sondern verteilten sich über ein Zeitfenster, das sich bei der hier gezeigten Simulation von 500 bis 800 ps erstreckte, mit entsprechenden Zugkräften zwischen 800 auf 1200 pN. Bei einigen Monomeren traten in dieser Zeitspanne mehrere Sprünge von der einen in die andere Stellung auf, bevor sich $\Phi_{1}$ endgültig auf $50^{\circ}$ stabilisierte. Der andere Dihedralwinkel in der Verbrückung, $\Phi_{2}$, wuchs in den in vacuo-Simulationen von im Mittel $150^{\circ}$ auf $180^{\circ}$ leicht an, wobei er sich in den meisten Monomeren gerade zu dem Zeitpunkt auf dem Endwert stabilisierte, als sich $\Phi_{1}$ in den einzelnen Monomeren schlagartig zu ändern begann. In der Simulation mit explizitem Wasser zeigte $\Phi_{2}$ keine wesentlichen Veränderungen.

Der als Indikator für die Ringkonformation ausgewählte Dihedralwinkel $\Phi_{3}$ blieb während aller Dehnungssimulationen nahezu unverändert. 


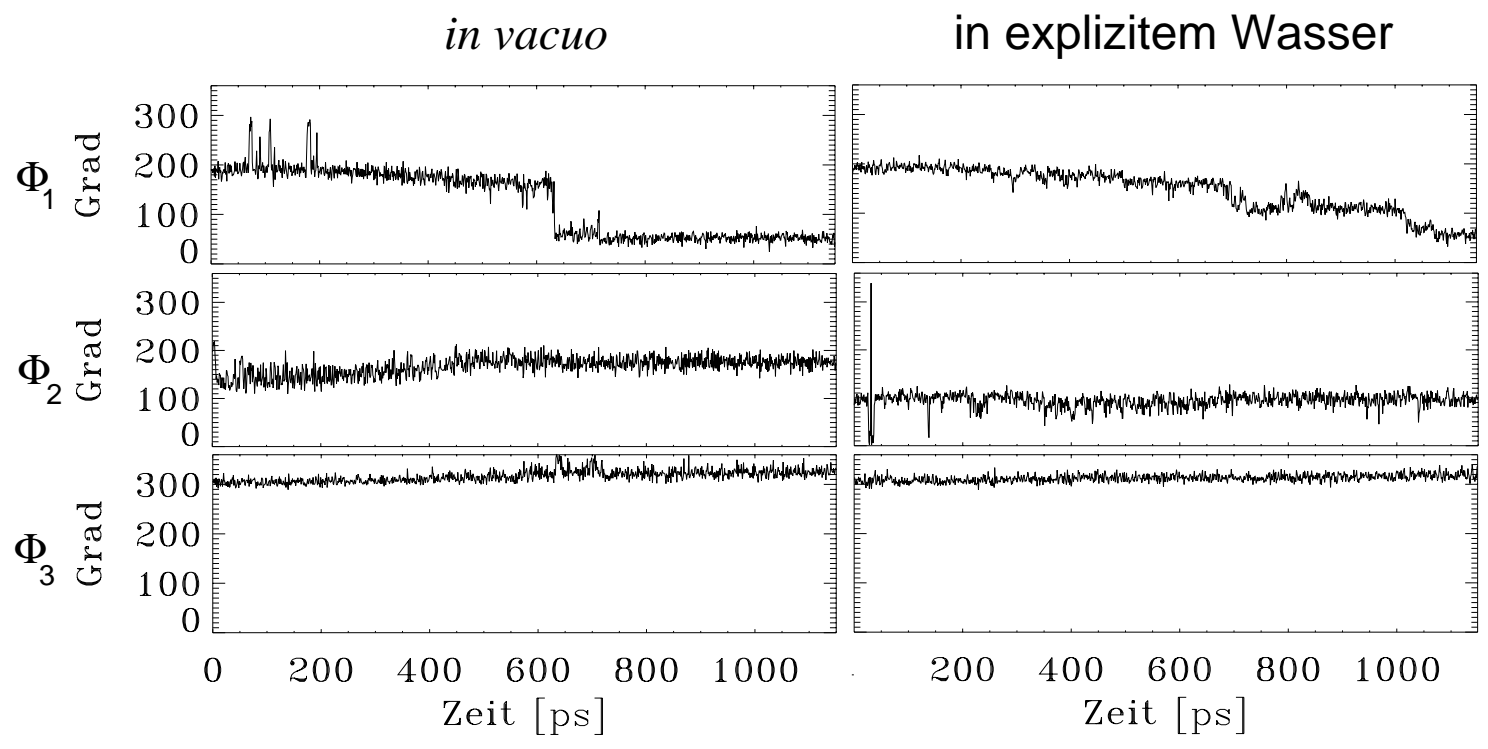

Abbildung 6.5: Verlauf der Dihedralwinkel $\Phi_{1}, \Phi_{2}$ und $\Phi_{3}$ während der Dehnungssimulation eines Dextranpentamers in vacuo (links) und in expliziter Wasserumgebung (rechts).

\section{Diskussion}

Die Dehnungssimulationen zeigten, dass die Monomere eines Dextranpolymers bereits bei einer Zugkraft von etwa $100 \mathrm{pN}$ in nahezu gestreckter Form angeordnet waren (siehe dazu den Schnappschuss in Abbildung 6.6). So können entropische Kräfte, die eine an Konfigurationsmöglichkeiten reichere, weniger gestreckte Konformation der Dextranpolymere begünstigen, bei höheren Kräften keine große Rolle mehr spielen. Die im ersten Regime der Kraft-Ausdehnungs-Kurve beobachtete mittlere Elastizität von etwa $10 \mathrm{~N} / \mathrm{m}$ konnte auf die kontinuierliche Dehnung sowohl von Dihedralwinkeln (siehe Abbildung 6.5) als auch von Bindungswinkeln (nicht gezeigt) zurückgeführt werden. Damit konnte die aus den experimentellen Kraft-Ausdehnungs-Kurven abgeleitete Hypothese, dass bei Zugkräften bis $250 \mathrm{pN}$ bereits Winkel verformt werden, aus Sicht der MD-Simulationen bestätigt werden.

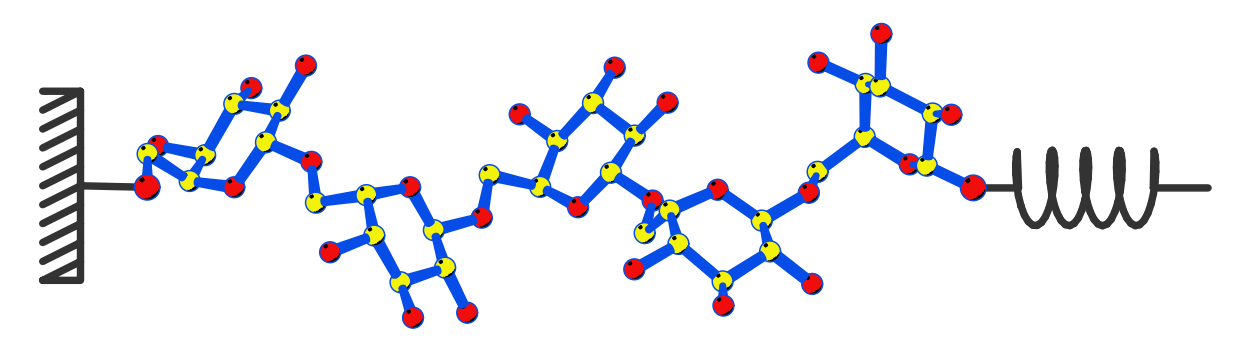

Abbildung 6.6: Schnappschuss der Struktur eines Dextranpentamers bei einer anliegenden Zugkraft von $100 \mathrm{pN}$, bei der die Monomere bereits in annähernd gestreckter Form angeordnet sind.

Die in den Simulationen beobachtete ausgeprägte Schulter in den Kraft-AusdehnungsKurven stellte jedoch etwas qualitativ völlig Neues und Unerwartetes dar. Diese Schulter 
zeugt davon, dass in einem Regime von Zugkräften, das etwa zwischen 700 und $1300 \mathrm{pN}$ liegt, die Elastizität der Dextranpolymere drastisch zunahm, da hier die mittlere Länge der einzelnen Monomere ohne erhebliche weitere Steigerung der Zugspannung signifikant anwuchs. Dies weist darauf hin, dass sich in der Konformation von Dextran in diesem Regime eine deutliche Änderung vollziehen musste. Der Verlauf des Dihedralwinkels $\Phi_{1}$ zeigt, dass diese Änderung in der Verbrückung der Monomere zu suchen ist, da dieser sich gerade zu dem Zeitpunkt sprunghaft änderte als die Schulter in der Kraft-AusdehnungsKurve auftrat. Eine genauere Betrachtung der Struktur ergab, dass der Sprung von $\Phi_{1}$ von $200^{\circ}$ auf $50^{\circ} \mathrm{zu}$ einer Verlängerung von etwa $0.8 \AA$ pro Monomer in Zugrichtung führte.

Es zeigte sich, dass die sprunghafte Änderung des Dihedralwinkels $\Phi_{1}$ einen ebenso sprunghaften Verlauf der Kraft-Ausdehnungs-Kurve zur Folge hatte, wie in den in vacuoSimulationen deutlich zu sehen ist (siehe die durchgezogenen Kurven Abbildung 6.4 und die linke Seite von Abbildung 6.5). Der gleichmäßigere Übergang des Dihedralwinkels $\Phi_{1}$ von seinem Anfangs- auf den Endwert bei der Simulation mit explizitem Wasser führte dagegen zu einer leicht ,verschmierten“ Schulter in der Kraft-Ausdehnungs-Kurve (siehe gestrichelte Kurve in Abbildung 6.4). Den Grund für den kontinuierlicheren Übergang von Dextran in Wasser sehen wir in der Reibung, die die Wassermoleküle dem Dextran entgegensetzen und es somit in seiner Bewegung dämpfen. Diese Dämpfung zeigt sich auch in einer meist etwas geringeren Amplitude und einer niedrigeren Frequenz der Fluktuationen in den Dihedralwinkeln.

Abbildung 6.7 zeigt die beobachteten kraftinduzierten Konformationsänderungen eines Dextrandimers anhand von vier Schnappschüssen. Die Zugspannung nimmt dabei von oben nach unten fortschreitend zu. Im zweiten und dritten Schnappschuss ist deutlich zu sehen, wie der Bindungswinkel in der Verbrückung, der durch die Atome O, C6 und C5 gebildet wird (in der Abbildung durch einen Kreis hervorgehoben), zunächst am fixierten Ende des Dimers, dann zwischen den beiden Monomeren umklappt, was eine Verlängerung des Moleküls mit sich bringt.

Die von uns vorhergesagten Elastizitätsregimes ließen weitere kraftmikroskopische Experimente in der Gruppe von Hermann Gaub folgen, in denen Dextran vermittels einer neuen Technik, die eine sehr viel festere Kopplung des Polymers an den Cantilever und an die Unterlage ermöglicht, bis zu sehr viel höheren Kräften (etwa 1000 pN) gedehnt wurde als in den vorausgehenden Experimenten. In diesen Experimenten konnten die aus den Simulationen abgeleiteten Kraft-Ausdehnungs-Kurven sehr gut reproduziert werden [17]. Insbesondere war auch eine ausgeprägte Schulter zu beobachten. Die Zugkräfte, bei denen die Schulter auftrat und somit der Übergang von dem Regime hoher und zu dem geringer Elastizität stattfand, waren im Experiment mit rund 700-800 pN [17,21] nur geringfügig niedriger als in der Simulation. 


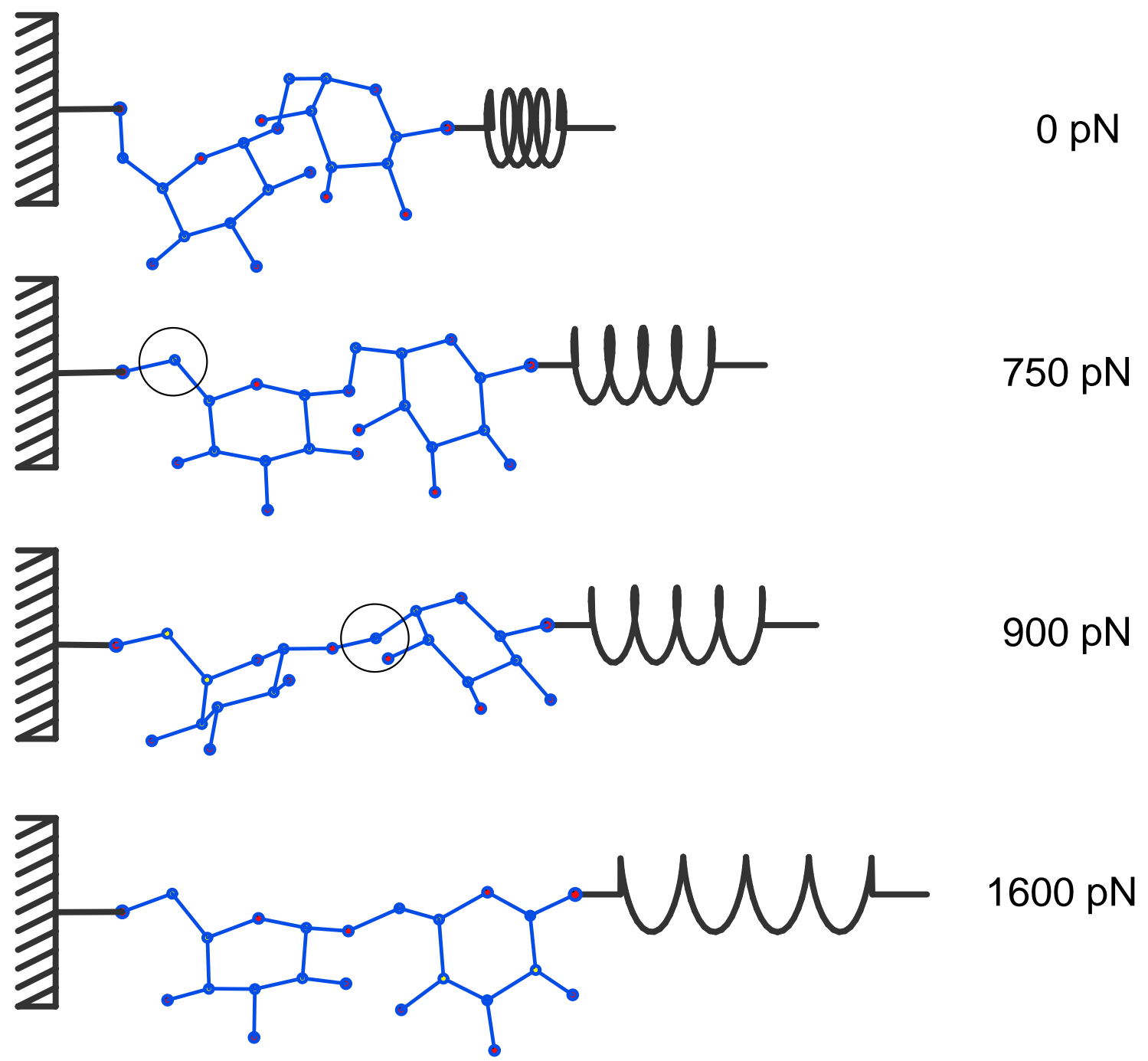

Abbildung 6.7: Schnappschüsse eines Dextrandimers während des simulierten Dehnungsprozesses. Rechts sind die aktuell wirkenden Zugkräfte angegeben. Die Kreise markieren jeweils die Stelle in der Verbrückung, an der sich ein Konformationsübergang ereignet. 


\subsubsection{Cellulose und Amylose}

Die unerwarteten Ergebnisse zur Elastizitätscharakteristik von Dextran motivierten weitere kraftmikroskopische Experimente an anderen Polysacchariden, insbesondere an Cellulose und Amylose [22]. Im Gegensatz zum $(1,6)$-verbrückten Dextran weisen diese eine (1,4)-Verbrückung auf. Auch zu diesen beiden Polysacchariden haben wir Dehnungssimulationen durchgeführt, die in diesem Abschnitt dargestellt werden.

\section{Methoden}

Die Vorgehensweise bei den Dehnungssimulationen zu Cellulose und Amylose (Abbildung 6.8) war analog zu der bei Dextran. Im Folgenden werden deswegen nur diejenigen methodischen Details erwähnt, die sich von denen in den Dextransimulationen unterscheiden. $\beta$-(1,4)-Glucopyranose (Cellulose) und $\alpha$-(1,4)-Glucopyranose (Amylose) wurden in verschiedenen Längen (2 bis 16 Monomere) mit Hilfe des Molekül-Editors in Quanta [110] modelliert und anschließend minimiert und equilibriert. Die beiden Strukturen, die sich lediglich in der Verbrückung voneinander unterscheiden (siehe dazu auch Abbildung 6.1), sind in Abbildung 6.8 als Dimer gezeigt. Da die explizite Berücksichtigung einer Wasser-

\section{$\beta(1,4)$-Glucopyranose (Cellulose)}

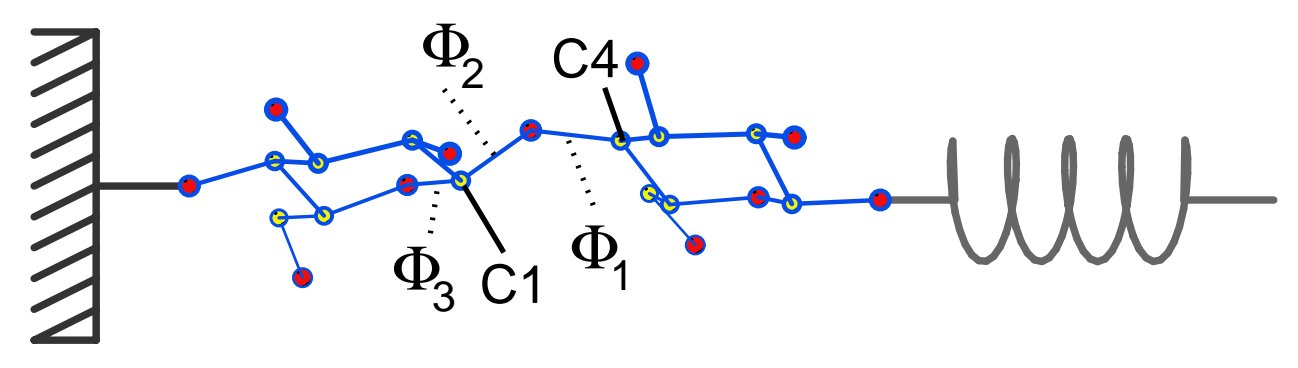

\section{$\alpha(1,4)$-Glucopyranose (Amylose)}

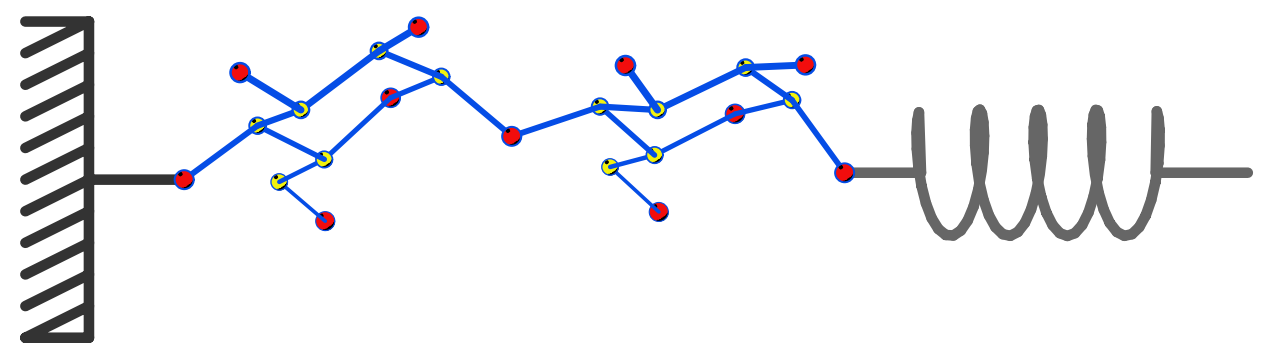

Abbildung 6.8: Vorgehensweise bei den Dehnungssimulationen zu Cellulose und Amylose. Mit den angedeuteten Dihedralwinkeln $\Phi_{1}, \Phi_{2}$ und $\Phi_{3}$ wurden die Konformationen der Verbrückung bzw. der Pyranoseringe charakterisiert.

umgebung bei Dextran nur zu marginalen Unterschieden im Vergleich zu den in vacuo- 
Simulationen führte, wurden auch Cellulose und Amylose in vacuo simuliert. Lediglich ein Amylosepentamer wurde analog zu dem weiter oben beschriebenen Dextranpentamer in einer expliziten Wasserumgebung simuliert, um die Gültigkeit dieses Vorgehens zu überprüfen.

Wie Abbildung 6.8 zeigt, wurde hier am linken Ende des Polymers das an dem Kohlenstoffatom C4 gebundene Sauerstoffatom fixiert, während das Zugpotenzial (Feder) auf das Sauerstoffatom wirkte, das am Kohlenstoffatom C1 des am rechten Ende befindlichen Monomers gebunden war.

Zusätzlich wurde für ein $\alpha$-(1,4)-Glucopyranose-Dimer (Maltose) das in den MD-Simulationen verwendete CHARMM-Kraftfeld mit Hilfe von Dichtefunktionalrechnungen überprüft. Dazu wurden „quasistatische“ Dehnungssimulationen (d.h. Temperatur $T=0 \mathrm{~K}$ ) durchgeführt, d.h. die Struktur des Dimers wurde für ausgewählte gestreckte Zustände zwischen 4.2 und $6.3 \AA$ in separaten Simulationen sowohl ,klassisch“ mit dem CHARMMKraftfeld als auch in quantenmechanischen Rechnungen minimiert. Letztere wurden mit dem Dichtefunktionalprogramm CPMD [230] durchgeführt, das über ein geeignetes Interface an das verwendete MD-Simulationsprogramm EGO gekoppelt wurde [231]. Für das Austauschwechselwirkungsfunktional wurden dabei Vanderbilt-Pseudopotenziale [232] verwendet. Für die Entwicklung der Wellenfunktion der Elektronendichte in ebene Wellen wurde ein cutoff von 25 Rydberg angesetzt. Als Kriterium für den Vergleich der Kraftfeldrechnungen mit den quantenmechanischen Rechnungen dienten die potenzielle Energie bzw. die Grundzustandsenergie des Dimers sowie die Ringgeometrie, beschrieben durch den Dihedralwinkel $\Phi_{3}$.

Bei einer Reihe von Amylose-Simulationen wurde untersucht, welchen Einfluss die Rotationsflexibilität zwischen benachbarten Monomeren auf den Dehnungsprozess hat. In diesen Simulationen wurde der Dihedralwinkel $\Phi_{3}$ in der Verbrückung fixiert, so dass die Ringebenen der benachbarten Monomere in antiparalleler Orientierung zueinander standen. Dazu wurde in das Kraftfeld ein zusätzliches Zwangspotenzial der Form

$$
U_{\text {fix }}:=U_{0} \cos \left(\Phi_{1}+\Delta \Phi\right)
$$

eingefügt, das mit $\Delta \Phi=233^{\circ}$ so gewählt wurde, dass die antiparallele Orientierung $\Phi_{1}=-53^{\circ}$ energetisch favorisiert wurde. Für den Maximalwert $U_{0}$ des Zwangspotenzials wurden Werte zwischen 2.5 und $10 \mathrm{kcal} / \mathrm{mol}$ gewählt.

Für Cellulose und Amylose wurden Dehnungssimulationen mit Zuggeschwindigkeiten zwischen 50 und $1 \mathrm{~m} / \mathrm{s}$ durchgeführt. Für die Analyse der Strukturen während des Dehnungsprozesses wurden die längsten Simulationen herangezogen, die mit $v_{\text {cant }}=1 \mathrm{~m} / \mathrm{s}$ eine Zeitspanne von jeweils 40 ns umfassten.

\section{Ergebnisse und Diskussion}

Die Cellulose- und Amylosepolymere zeigten während der Equilibrierungsphase nach etwa 50 ps keine Drift in der Energie mehr, und die anfänglichen Konformationen (insbesondere die Sesselkonformation der Pyranoseringe) blieben erhalten. 


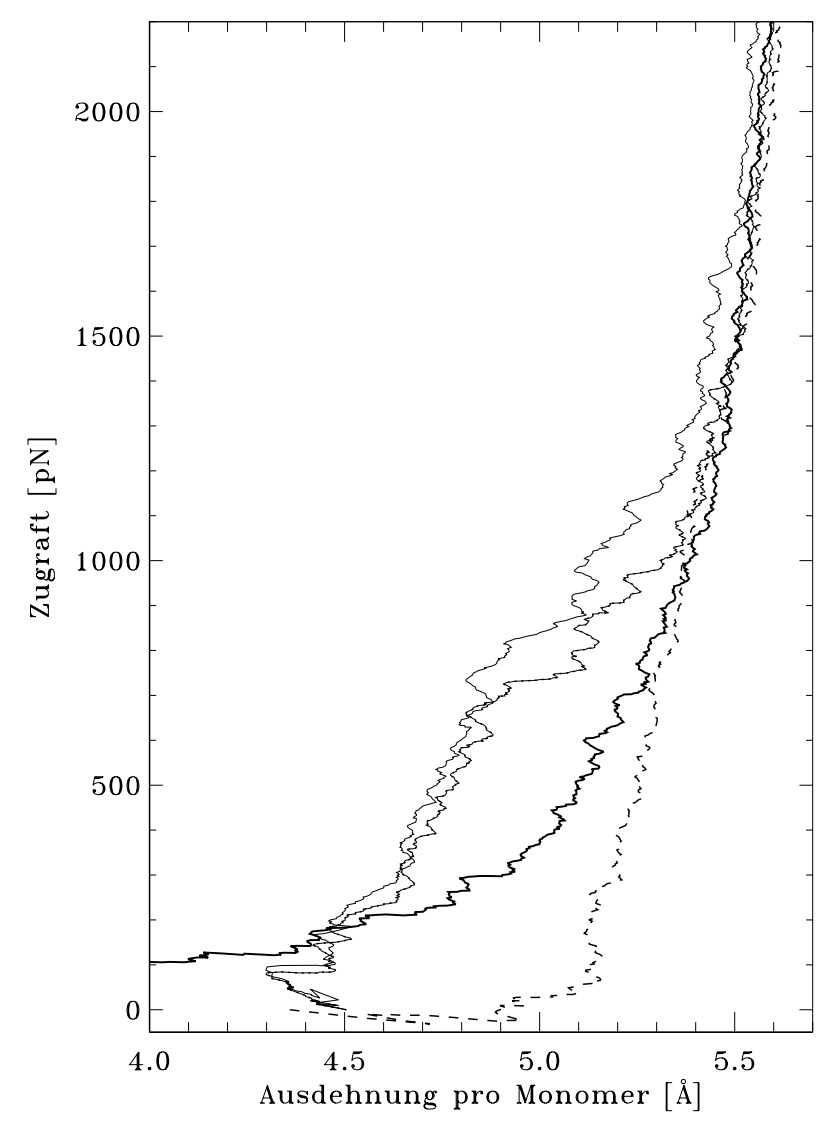

Abbildung 6.9: Kraft-Ausdehnungs-Kurven von Cellulose (gestrichelte Kurve) und Amylose (durchgezogene Kurven) abgeleitet aus Dehnungssimulationen mit einer Zuggeschwindigkeit $v_{\text {cant }}=1 \mathrm{~m} / \mathrm{s}$. Die Simulationen von Amylose wurden mit (dünne Linien) und ohne (dicke Linie) Zwangspotenzial, das die antiparallele Orientierung der Monomere zueinander begünstigt, durchgeführt.

Abbildung 6.9 zeigt Kraft-Ausdehnungs-Kurven für 16-mere von Cellulose (gestrichelte Kurve) und Amylose (durchgezogene Kurven). Für Cellulose können zwei Regimes unterschieden werden: ein Regime hoher Elastizität für Zugkräfte unter $100 \mathrm{pN}$ und ein Regime hoher Steifigkeit (d.h. geringer Elastizität) für Zugkräfte über 100 pN. In dem Regime hoher Elastizität wurde das 16-mer aus einer teilweise gefalteten Konformation in eine im wesentlichen linear verlaufende Polymerkette mit einer durchschnittlichen Monomerausdehnung von knapp über $5 \AA$ überführt. Da in dieser Phase der dem Polymer zugängliche Konfigurationsraum zunehmend reduziert wird, nehmen wir an, dass dieses Elastizitätsregime entropisch dominiert ist. Dies bestätigten in der Tat die experimentell ermittelten Kraft-Ausdehnungs-Kurven, in denen der Bereich bis $100 \mathrm{pN}$ sehr gut mit dem ,worm like chain model" [12] beschrieben werden konnte $[17,19]$ und daher hier nicht untersucht wurde.

Im Gegensatz zum Regime hoher Elastizität ist das Regime hoher Steifigkeit durch die Deformation von Bindungs- und Torsionswinkeln bestimmt. Die nähere Betrachtung ergab, dass die Kraft-Ausdehnungs-Kurve von Cellulose eine ganz leichte (in der Abbildung kaum sichtbare) Schulter bei einer Zugkraft von etwa $1600 \mathrm{pN}$ aufweist. Die Elastizität des 
Polymers beträgt unterhalb dieser Schulter etwa 3300 - 3600 pN/Å, oberhalb der Schulter etwa $5100 \mathrm{pN} / \AA$.
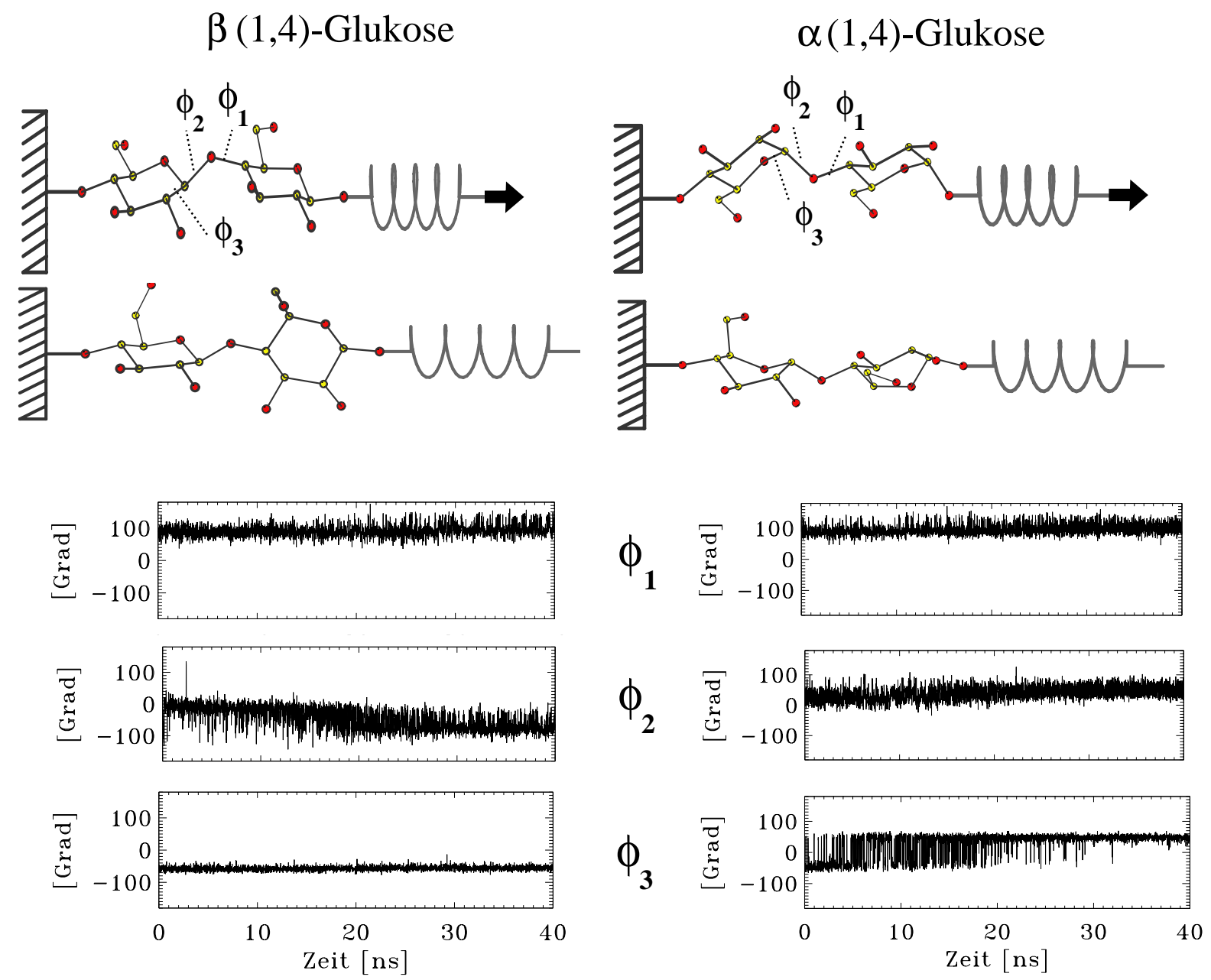

Abbildung 6.10: Konformationsänderungen von Cellulose (links) und Amylose (rechts) während der Dehnungssimulationen. Die oberen Strukturen zeigen die anfänglichen Konformationen (nur zwei von 16 Monomeren sind gezeigt), die unteren zeigen repräsentative Schnappschüsse nach einer Simulationszeit von 30 ns bei einer Zugkraft von etwa 1700 pN. Unten sind die Verläufe der Dihedralwinkel $\Phi_{1}, \Phi_{2}$ und $\Phi_{3}$ im Verlauf der Simulation aufgetragen.

Die Versteifung von Cellulose bei einer Zugkraft von etwa 1600 pN rührt von einer Drehung der Monomere um die in der Verbrückung befindliche C1-O-Achse her, die durch den Winkel $\Phi_{2}$ beschrieben wird. Dieser Effekt ist in der linken Hälfte von Abbildung 6.10 gezeigt: In dem unteren Schnappschuss, der bei einer Zugkraft von $1700 \mathrm{pN}$ als ein repräsentativer ausgewählt wurde, hat sich der rechte Monomer bezüglich des linken Monomers um die mit $\Phi_{2}$ bezeichnete Achse gedreht. Die gezeigte Struktur suggeriert zwar eine Drehung eher um $\Phi_{1}$, jedoch identifizieren die Verläufe von $\Phi_{2}$ und $\Phi_{1}$ im unteren Teil der Abbildung den Dihedralwinkel $\Phi_{2}$ als denjenigen, bei dem sich im Dehnungsprozess signifikante Veränderungen ergaben. Entsprechend wurde die intermonomere Rotation mit Hilfe des Dihedralwinkels $\Phi_{2}$ quantifiziert, der einen Übergang von anfänglich $0^{\circ}$ auf einen mittleren 
Wert von $-60^{\circ}$ im gedehnten Zustand zeigt. Diese Übergänge ereigneten sich überwiegend im Zeitfenster zwischen 15 und $22 \mathrm{~ns}$ (mit entsprechenden Zugkräften zwischen 1300 und $1600 \mathrm{pN}$ ). Da damit nur ein sehr geringer Zuwachs in der Ausdehnung von weniger als $0.1 \AA$ pro Monomer einherging, ist dieser Übergang in der Kraft-Ausdehnungs-Kurve kaum zu erkennen.

Im Gegensatz zu Cellulose zeigt Amylose bei Zugkräften zwischen 250 und $1000 \mathrm{pN}$ eine sehr viele höhere Elastizität (Abbildung 6.9 durchgezogene, fette Kurve). (Die beiden dünnen durchgezogenen Kurven werden weiter unten diskutiert.) Bei höheren Zugkräften haben Amylose und Cellulose in etwa dieselbe Elastizität.

Worin liegt der signifikante Unterschied in den Elastizitäten von Amylose und Cellulose bei Zugkräften unterhalb von $1000 \mathrm{pN}$ begründet? Die Schnappschüsse auf der rechten Seite in Abbildung 6.10 geben hier Aufschluss: Jedes Monomer in Amylose machte eine Konformationsänderung von einer Sessel- in eine Wannenkonformation durch. Dies zeigt auch der Verlauf von Dihedralwinkel $\Phi_{3}$ (unterste Kurve in der Abbildung), den wir als geeignete Observable für den Sessel-Wannen-Übergang ausgewählt haben: $\Phi_{3} \approx-50^{\circ}$ entspricht dabei einer Sesselkonformation, $\Phi_{3} \approx+50^{\circ}$ einer Wannenkonformation. Dieser intramonomere Übergang bewirkt eine erhebliche Verlängerung von etwa $0.5 \AA$ pro Monomer; das ist wesentlich mehr, als es bei dem intermonomeren Übergang von Cellulose der Fall ist. Im Gegensatz zu Cellulose änderte sich bei Amylose die Orientierung der Monomere nur ganz geringfügig (siehe die $\Phi_{2}$-Verläufe unten in der Abbildung).

Somit ereignete sich bei Amylose ähnlich wie bei den im Abschnitt 6.1.1 beschriebenen Dextransimulationen ein Konformationsübergang, der zu einer signifikanten Verlängerung des Polymers führte. Im Gegensatz zu Dextran führte der Konformationsübergang von Amylose jedoch zu keiner Schulter in der Kraft-Ausdehnungs-Kurve. Dies steht allerdings in krassem Gegensatz zu den experimentell ermittelten Kraft-Ausdehnungs-Kurven, da diese ebenso für Amylose eine ausgeprägte Schulter aufwiesen [22]. Warum also zeigt die aus unseren Simulationen zu Amylose abgeleitete Kraft-Ausdehnungs-Kurve keine Schulter?

Eine Schulter in der Kraft-Ausdehnungs-Kurve tritt dann auf, wenn sich die zu einer Verlängerung und Versteifung des Polymers führenden Übergänge in allen Monomeren kollektiv, d.h. in einem mehr oder weniger schmalen Zeitfenster bzw. einem kleinen Bereich um eine kritische Zugkraft ereignen, bei der das Polymer relativ abrupt länger und steifer wird. Dem Verlauf von $\Phi_{3}$ ist jedoch zu entnehmen, dass während einer Dehnungssimulation in dem Amylosepolymer zahlreiche Übergänge von der Sessel- in die Wannenkonformation (und zurück) stattfanden, die über eine lange Zeitspanne (entsprechend über ein breites Intervall von Zugkräften) verteilt waren. Bereits bei niedrigen Kräften von wenig mehr als $100 \mathrm{pN}$ kam es zu vereinzelten Übergängen in den Monomeren, die dann im weiteren Verlauf in ihrer Häufigkeit zunahmen; erst nach etwa 25 ns bei einer Zugkraft von weit über $1000 \mathrm{pN}$ hatten alle Monomere eine beständige Wannenkonformation eingenommen. Wenn man die mittlere Konformation aller Monomere betrachtet, bedeutet dies, dass sich der Sessel-Wannen-Übergang aus Sicht des gesamten Polymers nicht abrupt (wie der Konformationsübergang beim Dextran, siehe Abbildung 6.5), sondern nur ganz allmählich vollzog. Entsprechend versteifte und verlängerte sich das Polymer ebenfalls nur ganz allmählich, so dass die Kraft-Ausdehnungs-Kurve keinen Sprung zu 
einer größeren Ausdehnung pro Monomer und damit keine Schulter aufweist.

Offensichtlich fanden bei Amylose die Sessel-Wannen-Übergänge nicht kollektiv statt. Da man für statistisch unabhängige Übergänge ein kollektives Verhalten erwarten würde, haben wir überprüft, ob benachbarte Monomere tatsächlich statistisch unabhängig (also unkorreliert) flippen. Die quantitativen Ergebnisse einer solchen Korrelationsanalyse werden wir in dem Exkurs im nächsten Abschnitt ausführlich beschreiben; den wesentlichen Befund wollen wir zur weiteren Diskussion der elastischen Eigenschaften von Amylose bereits hier vorwegnehmen: Die Korrelationsanalyse ergab eine signifikante Antikorrelation in den Übergängen benachbarter Monomere. Während die ersten isolierten Übergänge einzelner Monomere in die Wannenkonformation schon bei relativ niedrigen Zugkräften stattfanden, waren offensichtlich erheblich höhere Zugkräfte erforderlich, wenn einer oder beide der Nachbarn bereits zuvor die Wannenkonformation eingenommen hatten. Die Behinderung weiterer benachbarter Konformationsübergänge erklärt die höheren Zugkräfte, die erforderlich waren, um auch diese späteren Übergänge zu induzieren. Diese „Antikooperativität" unterdrückte demzufolge die Kollektivität der Übergänge, was erklärt, dass in der Kraft-Ausdehnungs-Kurve keine Schulter zu beobachten war.

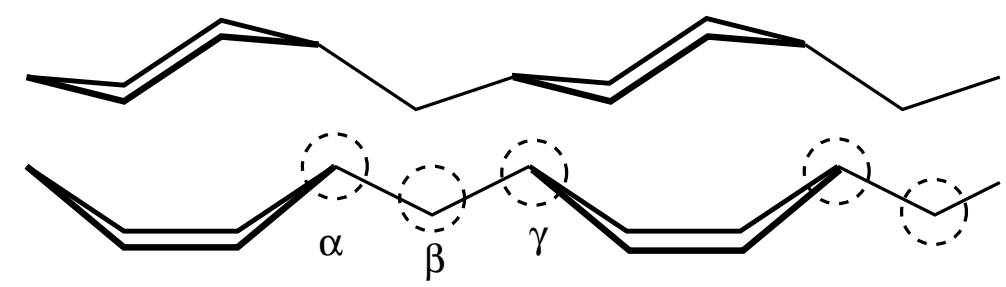

Abbildung 6.11: Skizze von zwei benachbarten Monomeren in Sessel- (oben) bzw. Wannenkonformation (unten). Zur Erklärung der Antikooperativität der Sessel-WannenÜbergänge wurde die Hypothese aufgestellt, dass die Wannenkonformation von benachbarten, parallel zueinander ausgerichteten Monomeren die Bindungswinkel $\alpha, \beta$ und $\gamma$ in der Verbrückung bei weiterer Dehnung stärker pro Längeneinheit deformiert, als es bei der Sesselkonformation der Fall ist.

Warum sind also die Konformationsübergänge von Amylose in den Dehnungssimulationen im Gegensatz zum experimentellen Befund signifikant antikorreliert? Die Analyse der Simulationsdaten ergab, dass sich die Monomere, bevor die ersten Sessel-WannenÜbergänge auftraten, parallel zueinander orientiert waren, selbst dann, wenn benachbarte Monomere der ungestreckten Ausgangsstruktur in zufälliger oder sogar strikt antiparalleler Orientierung zueinander standen. An diese Beobachtung anknüpfend führte eine nähere Betrachtung der Geometrie von Amylose (siehe Abbildung 6.11) zu der Hypothese, dass bei paralleler Orientierung die in der Abbildung mit $\alpha, \beta$ und $\gamma$ bezeichneten Bindungswinkel in der Verbrückung zwischen zwei Monomeren bei weiterer Dehnung stärker pro Längenheit deformiert werden, sobald beide Monomere in der Wannenkonformation sind. Diese stärkere Deformation der Bindungswinkel würde die hohen Zugkräfte erklären, die erforderlich sind, um in benachbarten Monomeren eine Wannenkonformation zu bewirken.

Zur detaillierten Überprüfung dieser Hypothese sei auf den nächsten Abschnitt verwiesen. Da die in den Simulationen beobachtete Antikooperativität strikt mit der parallelen Ausrichtung der Monomere zueinander einherging und unsere Hypothese einen ursächlichen 


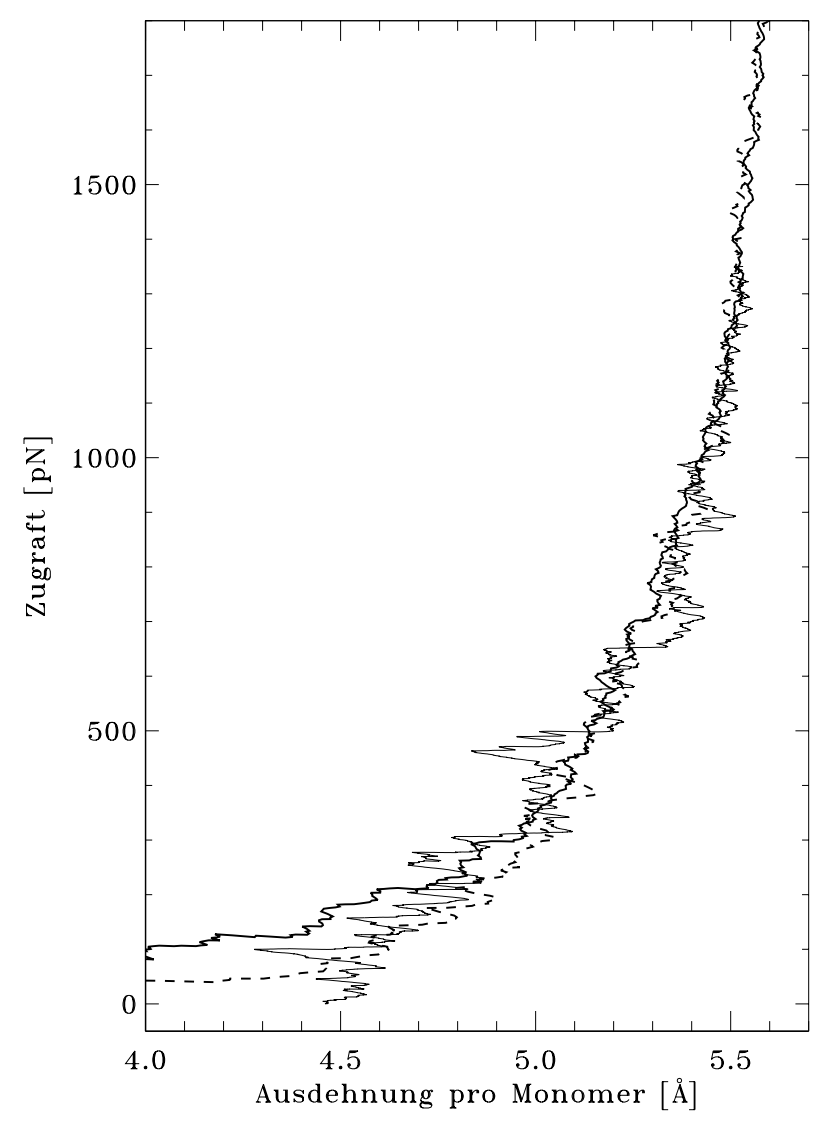

Abbildung 6.12: Kraft-Ausdehnungs-Kurven für einen Amylose-16-mer in vacuo (fette durchgezogene Kurve), für einen Amylosepentamer in Wasser (dünne durchgezogene Kurve) und für einen Amylosepentamer in vacuo (gestrichelte Kurve). Die Zuggeschwindigkeiten bei den ersten beiden Simulationen betrug $10 \mathrm{~m} / \mathrm{s}$, bei der letzten $1 \mathrm{~m} / \mathrm{s}$.

Zusammenhang zwischen beidem aufstellt, wollen wir hier zunächst der Frage nachgehen, ob die Diskrepanz zwischen Experiment und Simulation darauf hinweist, dass die parallele Ausrichtung der Monomere ein Artefakt der MD-Simulationen war.

Um Anhaltspunkte zu bekommen, wo die in den Dehnungssimulationen beobachtete parallele Orientierung der Monomere und die damit einhergehende Antikooperativität in den Sessel-Wannen-Übergängen herrührt, wurden weitere Dehnungssimulationen durchgeführt. Diese sollten Aufschluss darüber geben, welchen Einfluss die Länge der Polymerkette, die Zuggeschwindigkeit sowie die Einbeziehung einer Wasserumgebung auf die Kraft-Ausdehnungs-Kurve von Amylose hat. Zusätzlich wurde das in den MD-Simulationen verwendete CHARMM-Kraftfeld überprüft, indem Dichtefunktionalrechnungen zu einem Amylosedimer durchgeführt und mit klassischen CHARMM-Kraftfeldrechnungen verglichen wurden, wie es weiter oben im Methodenteil beschrieben ist.

Abbildung 6.12 zeigt die aus den zusätzlichen Dehnungssimulationen erhaltenen KraftAusdehnungs-Kurven. Die Elastizität des Amylosepentamers in vacuo (gestrichelt) zeigt nur minimale Abweichungen zu der bereits weiter oben diskutierten Kraft-AusdehnungsKurve des Amylose-16-mers in vacuo (dicke, durchgezogene Kurve). Dieses gilt auch für weitere, in der Abbildung nicht gezeigte Dehnungssimulationen mit Polymerlängen 


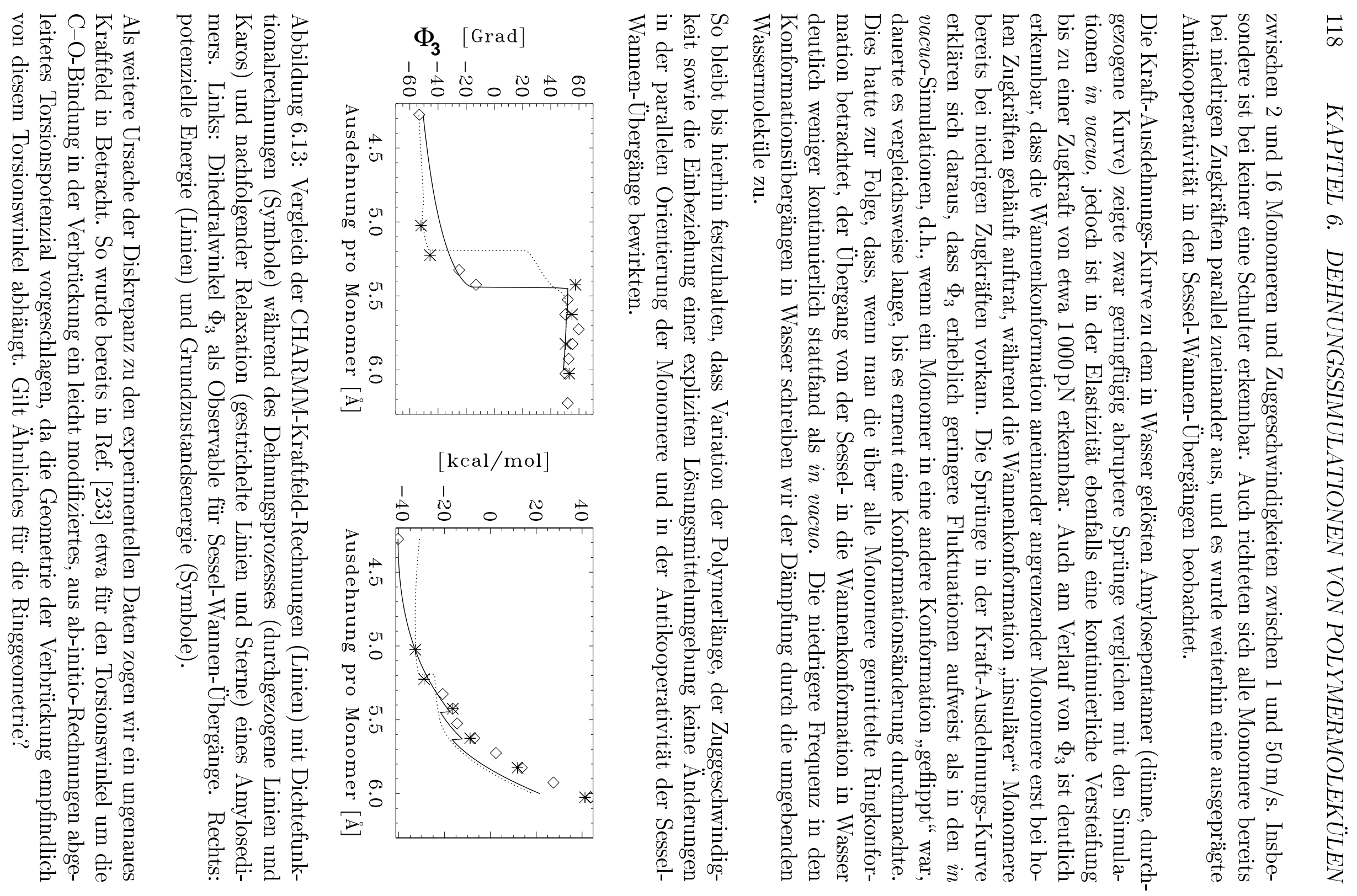


Wie aus Abbildung 6.13 jedoch ersichtlich, zeigen die zur Überprüfung des Kraftfeldes mit Hilfe des Dichtefunktionalprogramms CPMD durchgeführten quantenmechanischen Rechnungen (Symbole) eine gute Übereinstimmung mit den klassischen CHARMM-KraftfeldRechnungen (Linien). An Hand des Dihedralwinkels $\Phi_{3}$ (links) ist erkennbar, dass der Sessel-Wannen-Übergang bei nahezu identischen Polymerausdehnungen auftrat, und dass die (minimierte) potenzielle Energie in Abhängigkeit von der Polymerausdehnung für das CHARMM-Kraftfeld (rechts, Linien) gut mit den Dichtefunktionalwerten übereinstimmte (Symbole) - lediglich bei großen Ausdehnungen von über $5.5 \AA$ pro Monomer gab es geringfügige Abweichungen. Letzteres überrascht allerdings nicht, weil wir uns hier bereits in einem Bereich befinden, in dem wir weit von dem Gleichgewichtszustand des Moleküls entfernt sind, so dass die harmonischen Näherungen im klassischen Kraftfeld keine sehr genaue Beschreibung mehr liefern können. Entscheidend ist, dass der SesselWannen-Übergang durch das CHARMM-Kraftfeld offensichtlich zutreffend beschrieben wird.

Alle diese zum Teil recht aufwendigen Tests belegen, dass die ausgeprägte Antikooperativität der Sessel-Wannen-Übergänge kein Simulationsartefakt ist. Auch alle anderen den Simulationen zugrunde liegenden Näherungen und Annahmen - etwa die klassische Näherung der Kernbewegung oder die Multipolentwicklung der Coulomb-Wechselwirkung - konnten die beobachtete Diskrepanz nicht verursachen. Dies zwang uns zu dem Schluss, dass die Experimente nicht an den in Abbildung 6.8 gezeigten Polymeren durchgeführt wurden, sondern etwa an chemisch modifizierten Polymeren. Wir vermuteten, dass große Seitengruppen eine parallele Anordnung der Monomere aus sterischen oder elektrostatischen Gründen unterdrücken und damit die Antikooperativität der Konformationsübergänge reduzieren oder verhindern. Tatsächlich werden, wie eine Recherche zeigte, oft Schutzgruppen verwendet, um Polysaccharide zu neutralisieren oder wasserlöslich zu machen [234].

Um diese Hypothese zu überprüfen, wurde nun der vermutete Einfluss großer Seitengruppen im Simulationsmodell berücksichtigt, indem die Anordnung der Ringebenen einem schwachen Zwangspotenzial [Gleichung (6.2)] unterworfen wurde, das eine antiparallele Orientierung der Monomere begünstigt. Tatsächlich zeigten diese modifizierten Simulationen eine ausgeprägte Schulter in der Kraft-Ausdehnungs-Kurve (dünne, durchgezogene Kurven in Abbildung 6.9). Dabei variierte die Zugkraft, bei der die Schulter auftrat, mit der Stärke $U_{0}$ des Zwangspotenzials. Die obere und untere Kurve resultieren aus Dehnungssimulationen mit $U_{0}=5$ bzw. $U_{0}=3.75 \mathrm{kcal} / \mathrm{mol}$.

Eine Überprüfung der in den Dehnungsexperimenten verwendeten Proben hat ergeben, dass Amylose in der Tat über Seitengruppen verfügte. Dabei handelte es sich nach Angaben unserer Kollegen vom Lehrstuhl Gaub in München entweder um Ether-Aceto- oder um Ether-Aceto-N-Succinimid-Seitengruppen [235]. 


\subsubsection{Exkurs: Antikooperativität bei Amyloseübergängen}

In diesem Abschnitt wollen wir die in den MD-Dehnungssimulationen zu Amylose beobachtete Antikooperativität in den Konformationsänderungen benachbarter Monomere näher untersuchen. Zum einen soll in einer analytischen Behandlung der Grad der Antikooperativität quantifiziert werden. Dabei wollen wir aus den Simulationen die freie Energie, die für den Übergang eines gegebenen Monomers von der Sessel- in die Wannenkonformation erforderlich ist, in Abhängigkeit davon abschätzen, ob benachbarte Monomere sich noch in der Sessel- oder bereits in der Wannenkonformation befinden. Zum anderen wollen wir eine physikalische Interpretation für die Antikooperativität finden, also die Frage beantworten, welche Mechanismen für diesen Effekt verantwortlich sind.

Für die analytische Behandlung von Konformationsübergängen innerhalb von Polysacchariden, die unabhängig voneinander auftreten, wurde bereits ein Zwei-Zustands-Modell vorgeschlagen [236]. In diesem Modell, das in Abbildung 6.14 skizziert ist, wird der Zustand eines jeden Monomers durch eine Freie-Energie-Landschaft $G(z)$ beschrieben, in der zwei Minima [in unserem Fall die Sesselkonformation (links) und die Wannenkonformation (rechts)] durch eine Barriere voneinander getrennt sind (fette Linie in der Abbildung). Die Reaktionskoordinate ist dabei die Monomerausdehnung z. Die angelegte Zugkraft wird wieder durch ein harmonisches Federpotenzial $V_{\text {Feder }}$ beschrieben, für das wir hier den Grenzfall eines weichen Cantilevers annehmen, so dass es in dem interessierenden Bereich eine konstante Steigung aufweist (dünne gestrichelte Linie). Ganz analog zu der Abhandlung in Kapitel 4 modifiziert auch hier das Zugpotenzial die Energielandschaft (fette gestrichelte Linie), so dass die Barrierenhöhe $\Delta G^{\uparrow}$ erniedrigt und daher schneller überquert wird.

Um nun auch korrelierte (oder antikorrelierte) Übergänge beschreiben zu können, erweitern wir das Zwei-Zustands-Modell zu einem Vier-Zustands-Modell, das uns in die Lage versetzt, Konformationen und Konformationsübergänge von Paaren benachbarter Monomere zu betrachten. Indem wir den vier Zuständen und den zugehörigen Übergängen freie Energien zuordnen, sollte dieses Modell Aufschluss darüber geben, inwieweit der Konformationszustand eines Monomers die Übergangskinetik eines benachbarten Monomers beeinflusst.

\section{Methoden}

\section{Simulation und Auswertung}

Alle Untersuchungen zur Antikooperativität stützen sich auf die weiter oben in Abschnitt 6.1.2 beschriebene Dehnungssimulation des Amylose-16-mers, wobei diejenige mit der kleinsten Zuggeschwindigkeit, $v_{\text {cant }}=1 \mathrm{~m} / \mathrm{s}$, und entsprechend der längsten Simulationszeitspanne, $T_{0}=40 \mathrm{~ns}$, ausgewählt wurde. Diese eignet sich deswegen sehr gut zu einer Korrelationsanalyse, da in ihr auf Grund der langen Simulationszeitspanne in jedem einzelnen Monomer sehr viele Übergänge von der Sessel- in die Wannenkonformation und zurück auftraten und somit der statistische Fehler klein ist. Da während der Dehnungssimulation die Koordinaten des Polymers alle 100 fs abgespeichert wurden, umfasst 


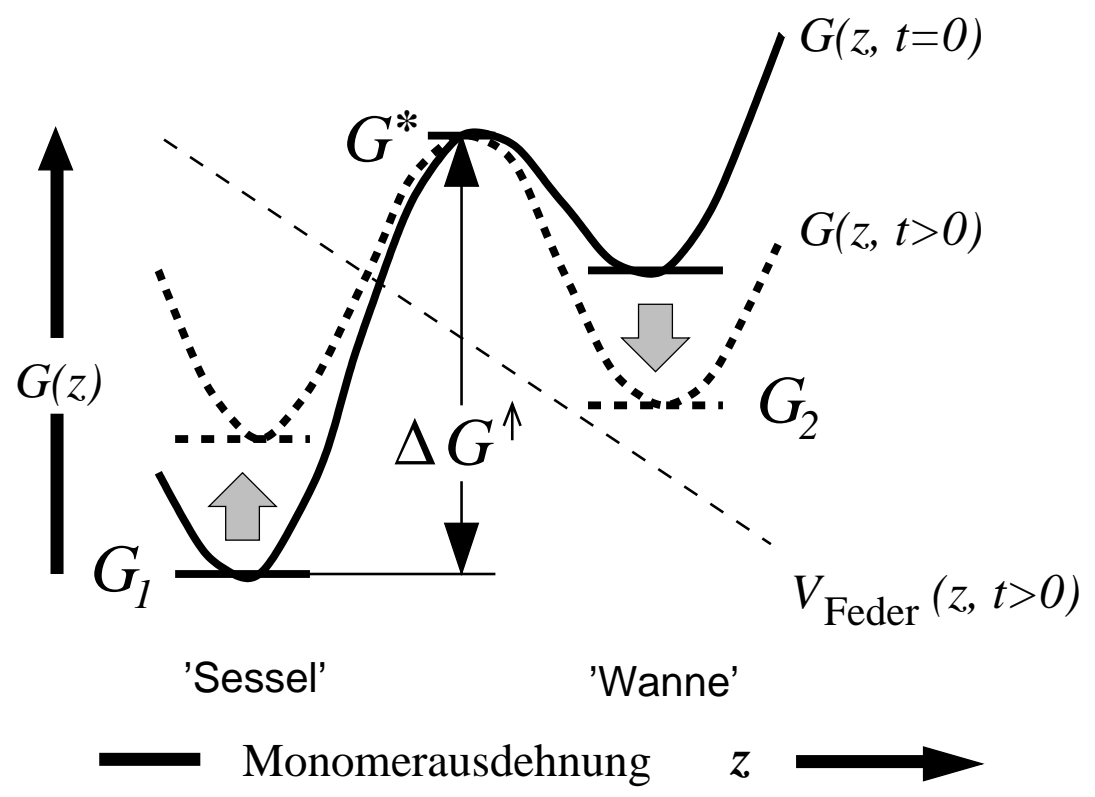

Abbildung 6.14: Zwei-Zustands-Modell für Konformationsübergänge innerhalb einzelner Monomere. Die Freie-Energie-Landschaft $G(z)$ des ungestörten Monomers (fette Linie) als Funktion seiner Ausdehnung $z$ mit der stabilen Konformation 'Sessel' (Edukt) und der metastabilen Konformation 'Wanne' ist modifiziert durch das Federpotenzial $V_{\text {Feder }}$ (dünne gestrichelte Linie), das als Modell für den (weichen) Cantilever dient. Dadurch werden die Barrierenhöhe $\Delta G^{\uparrow}$ erniedrigt (fette gestrichelte Linie) und Konformationsübergänge in Richtung der räumlich ausgedehnteren Wannenkonformation induziert.

diese Trajektorie insgesamt 400000 Koordinatensätze. Für die methodischen Details der Durchführung dieser Simulation sei auf den Methodenteil in Abschnitt 6.1.2 verwiesen.

Aus der Simulation wurden zunächst die Häufigkeiten der Sessel- und Wannenkonformationen ermittelt, um die Wahrscheinlichkeit des Auftretens der einzelnen Konformationen für die Simulationszeitspanne abzuschätzen. Darüber hinaus wurden mittlere Übergangsraten bestimmt, indem für jedes einzelne Monomer Sessel-Wannen- Übergänge abgezählt und zeitlich gemittelt wurden. Für die Statistik der Konformationsübergänge wurde der intramonomere Dihedralwinkel $\Phi_{3}$ (siehe Abbildung 6.8 in Abschnitt 6.1.2) herangezogen, der in der Sesselkonformation um $-50^{\circ}$ und in der Wannenkonformation um $+50^{\circ}$ fluktuierte. Da die Amplitude dieser Fluktuationen wesentlich geringer als $50^{\circ}$ war, konnte die Zuordnung Sessel-/Wannenkonformation mit hinreichender Genauigkeit erfolgen. Desweiteren wurden die Häufigkeiten von Sessel- und Wannenkonformationen in Abhängigkeit von der Konformation des benachbarten Monomers und die über die Zeit gemittelten Häufigkeiten für die Konstellationen 'Sessel'-'Sessel', 'Sessel'-'Wanne', 'Wanne'-'Sessel' und 'Wanne'-'Wanne' bestimmt. Die mittleren Häufigkeiten und Übergangsraten wurden jeweils über Zeitfenster von $100 \mathrm{ps}$ Länge bestimmt, d.h. eine zu einem festen Zeitpunkt gegebene Wahrscheinlichkeit stützt sich auf 1000 Koordinatensätze.

Um einen Einblick zu bekommen, welche atomaren Mechanismen und gegebenenfalls geometrischen Aspekte eine Rolle bei der beobachteten Antikooperativität spielen, haben wir in Analogie zu der in Abschnitt 6.1.2 beschriebenen Minimierung eines Amylosedimers ein 
Amylosepentamer für alle Ausdehnungen zwischen 5 und $6 \AA$ pro Monomer in Schritten von $0.01 \AA$ im CHARMM-Kraftfeld minimiert und dabei den Verlauf der Bindungswinkel $\alpha, \beta$ und $\gamma$, die in Abbildung 6.11 angedeutet sind, als Funktion der Ausdehnung verfolgt. Das Augenmerk lag dabei darauf, wie sich diese Bindungswinkel bei fortschreitender Dehnung des Polymers in Abhängigkeit von den Konformationen der angrenzenden Monomere verändern.

Theorie des zeitabhängigen Vier-Zustands-Modells

Das Vier-Zustands-Modell ist in Abbildung 6.15 gezeigt. In ihm werden die vier möglichen

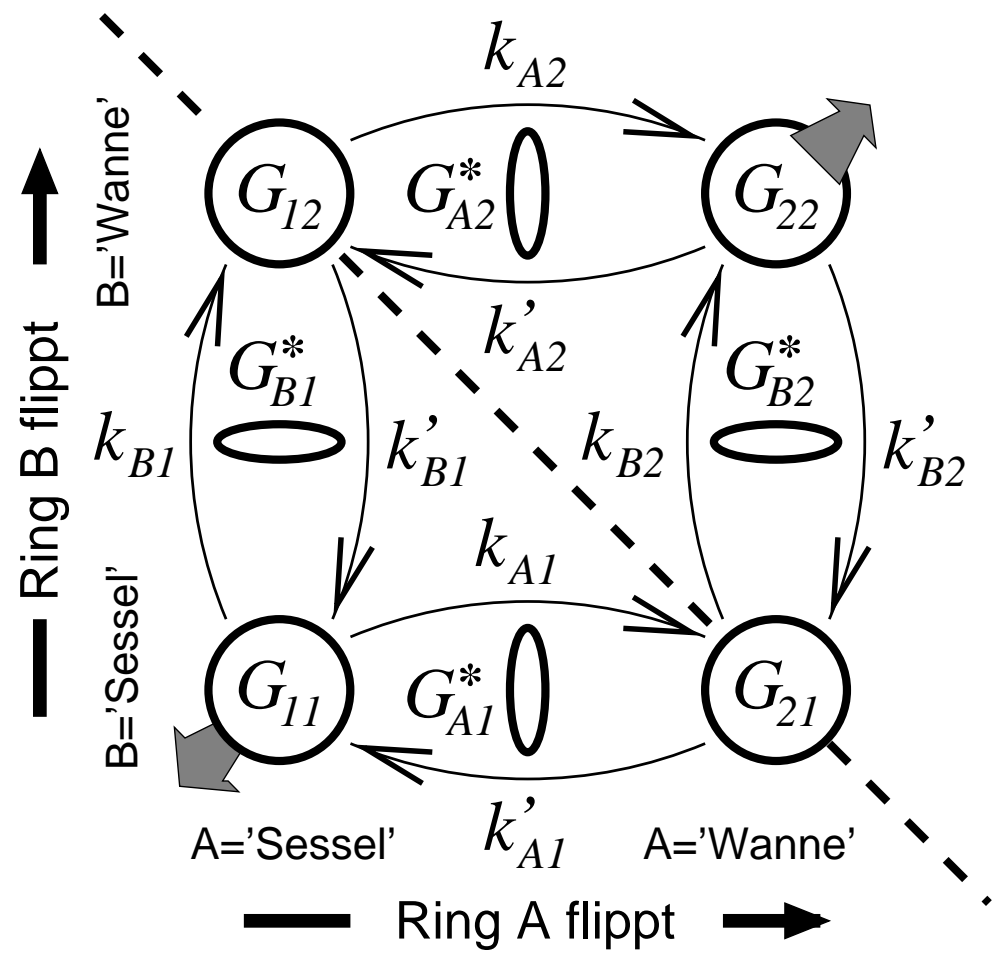

Abbildung 6.15: Vier-Zustands-Modell zur Beschreibung von potenziell (anti)kooperativen Konformationsübergängen in zwei benachbarten Monomeren der Polymerkette. Zur Erklärung siehe Text.

Konformationen mit vier Zuständen beschrieben, nämlich '11' (Ring A und Ring B in Sesselkonformation), '21' (A: Wanne, B: Sessel), '12' (A: Sessel, B: Wanne) und '22' (A: Wanne, B: Wanne). Diese vier Zustände sollen durch die freien Energien $G_{11}, G_{21}, G_{12}$ bzw. $G_{22}$ charakterisiert werden. Wir betrachten die Übergänge („Flips“, durch Pfeile symbolisiert) 'A1' (Ring A flippt, Ring B ist in Sesselkonformation), 'A2' (A: flippt, B: Wanne), 'B1' (A: Sessel, B: flippt) und 'B2' (A: Wanne, B: flippt). Wir nehmen an, dass jeder Übergang von zeitlich vorangegangenen Übergängen statistisch unabhängig ist und beschreiben sie mit den Ratenkonstanten $k_{A 1}, k_{A 2}, k_{B 1}$ und $k_{B 2}$ für die Vorwärtsreaktion (Sessel $\rightarrow$ Wanne); die entsprechenden Ratenkonstanten für die Rückreaktion (Wanne $\rightarrow$ Sessel) sind jeweils gestrichen gekennzeichnet.

Als Maß für die (Anti-)Kooperativität soll der Unterschied der Differenzen $\Delta G_{A 1}:=$ $G_{21}-G_{11}$ und $\Delta G_{A 2}:=G_{22}-G_{12}$ dienen: Ohne jegliche Kooperativität sollten die 
Übergänge von Ring A unabhängig von der Konformation von Ring B sein, die FreieEnergie-Differenzen $\Delta G_{A 1}$ und $\Delta G_{A 2}$ also identisch sein. Analoges gilt für die Übergänge und die Aktivierungsenergien von Ring B.

Das Zugpotenzial der Form

$$
V_{\text {Feder }}:=\frac{k}{2}\left(z-v_{\text {cant }} t\right)^{2} \quad \text { mit } \quad k \Delta z \ll\left|F_{\text {Feder }}\right|
$$

ist anhand der gestrichelten Linie in Abbildung 6.15 dargestellt; $k$ ist hier die Federkonstante, $v_{\text {cant }}$ die Zuggeschwindigkeit, $z$ die Position des Atoms, auf das das Zugpotenzial wirkt, $\Delta z$ die durch den Sessel-Wannen-Übergangs erfolgte Verlängerung eines Monomers und $F_{\text {Feder }}$ eine typische Zugkraft. In dem von uns betrachteten Grenzfall der weichen Feder können wir $V_{\text {Feder }}$ linearisieren: $V_{\text {Feder }}=k z v t+O\left(z^{2}\right)$. Dann ist die Zugkraft $F_{\text {Feder }}=-k v t[+O(z)]$ unabhängig von $z$ und wächst linear mit $t$.

\section{Freie-Energie-Zustände}

Auch hier werden, wie in Abbildung 6.15 durch graue Pfeile angedeutet, alle Zustände, die sich unterhalb der gestrichelten Geraden befinden (entlang derer $V_{\text {Feder }}=0$ ), durch das Zugpotenzial energetisch angehoben, wohingegen alle Zustände, die oberhalb dieser Geraden liegen, energetisch abgesenkt werden. Setzt man voraus, dass sich die Übergangszustände entlang der Reaktionskoordinate genau in der Mitte zwischen benachbarten Gleichgewichtszuständen befinden, so können die durch das Zugpotenzial modifizierten Zustände beschrieben werden durch

$$
\begin{aligned}
& G_{11}(t)=G_{11}+u t \\
& G_{12}(t)=G_{12}=\text { const. } \\
& G_{21}(t)=G_{21}=\text { const. } \\
& G_{22}(t)=G_{22}-u t \\
& G_{A 1}^{*}(t)=G_{A 1}^{*}+u t / 2 \\
& G_{A 2}^{*}(t)=G_{A 2}^{*}-u t / 2 \\
& G_{B 1}^{*}(t)=G_{B 1}^{*}+u t / 2 \\
& G_{B 2}^{*}(t)=G_{B 2}^{*}-u t / 2
\end{aligned}
$$

wobei $u:=k v \Delta z$.

Wenn wir annehmen, dass sich das System zu allen Zeiten nahe des Gleichgewichts befindet (was hier zutrifft, da $u / k_{B} T$ sehr viel kleiner ist als die beobachteten Übergangsraten), dann sind die quasi-stationären Wahrscheinlichkeiten $p_{i j}(t)$ für die vier Zustände $(i j)$ gegeben durch den Boltzmann-Faktor

$$
p_{i j}(t)=\frac{\exp \left[-\beta G_{i j}(t)\right]}{Z(t)}
$$

mit $\beta=1 / k_{B} T$ und der Zustandssumme

$$
Z(t):=\sum_{i^{\prime}, j^{\prime}=1}^{2} \exp \left[-\beta G_{i^{\prime} j^{\prime}}(t)\right]
$$

Verwendet man die Gleichungen (6.4) und (6.5), dann erhält man für die über die gesamte Simulationszeitspanne $T_{0}$ gemittelte Wahrscheinlichkeit, dass beide Ringe etwa im 
Zustand 11 sind,

$$
\begin{aligned}
\left\langle p_{11}\right\rangle_{t} & =\frac{1}{T_{0}} \int_{0}^{T_{0}} p_{11}(t) d t \\
& =\frac{1}{T_{0}} \int_{0}^{T_{0}}\left[1+e^{-\beta\left(\Delta G_{A 1}-u t\right)}+e^{-\beta\left(\Delta G_{B 1}-u t\right)}+e^{-\beta\left(\Delta G_{A 2}+\Delta G_{B 1}-2 u t\right)}\right]^{-1} \\
& =\beta u T_{0}-\frac{1}{2} \ln \left[\frac{1+k_{1} e^{\beta u T_{0}}+k_{2} e^{2 \beta u T_{0}}}{1+k_{1}+k_{2}}\right]+k_{1} D^{-1 / 2} \operatorname{atanh} \frac{y_{1}-y_{2}}{1-y_{1} y_{2}}
\end{aligned}
$$

mit $k_{1}:=e^{-\beta \Delta G_{A 1}}+e^{-\beta \Delta G_{B 1}}, k_{2}:=e^{-\beta\left(\Delta G_{A 2}+\Delta G_{B 1}\right)}, y_{1}:=\left(k_{1}+2 k_{2} e^{\beta u T_{0}}\right) D^{-1 / 2}, y_{2}:=$ $\left(k_{1}+2 k_{2}\right) D^{-1 / 2}$ und $D:=k_{1}^{2}-4 k_{2}$. Auch für den Fall, dass in Gleichung (6.7) $D<0$, erhalten wir eine reelle Zahl als Resultat, da atanh $(i \varphi)=i \operatorname{atan}(\varphi)$. Analoge Rechnungen ergeben entsprechende Resultate für die drei anderen Zustände 12, 21 und 22.

Um eine Vorstellung zu bekommen, wie die so berechneten $\left\langle p_{i j}\right\rangle_{t}(i j=11,12,21,22)$ aussehen, ist deren Verlauf in Abbildung 6.16 als Funktion der Zuggeschwindigkeit für eine konstant gewählte Simulationszeitspanne $T_{0}$ gezeigt. Dazu wurden die Freie-EnergieDifferenzen $\Delta G_{i k}$ herangezogen, die weiter unten in Tabelle 6.1 angegeben sind (diese wurden aus unseren Simulationen abgeschätzt und werden später diskutiert). Die gestrichelte Linie gibt die Zuggeschwindigkeit an, die in den Simulationen verwendet wurde. Wie man erkennt, ist für kleine Zuggeschwindigkeiten die Konstellation 'Sessel'-'Sessel' bevorzugt $\left(\left\langle p_{11}\right\rangle_{t}\right.$ nahe bei Eins), während für große Zuggeschwindigkeiten die Konstellation 'Wanne'-'Wanne' favorisiert ist $\left(\left\langle p_{22}\right\rangle_{t}\right.$ nahe bei Eins). Dies ist leicht zu verstehen, da bei kleiner Zuggeschwindigkeit das Polymer für die gegebene Simulationszeitspanne $T_{0}$ insgesamt nur wenig gedehnt wird, so dass die Wannenkonformation energetisch vergleichsweise ungünstig ist. Bei großer Zuggeschwindigkeit befindet sich das Polymer dagegen über einen langen Abschnitt der Simulationszeitspanne in einem stark gedehnten Zustand, in dem die Wannenkonformation die energetisch günstigere ist.

Zieht man in Betracht, dass $\left\langle p_{11}\right\rangle_{t}+\left\langle p_{12}\right\rangle_{t}+\left\langle p_{21}\right\rangle_{t}+\left\langle p_{22}\right\rangle_{t}=1$ und $\Delta G_{A 1}+\Delta G_{B 2}=$ $\Delta G_{B 1}+\Delta G_{A 2}$, dann erhalten wir drei unabhängige Gleichungen für drei unabhängige, unbekannte Freie-Energie-Differenzen. Diese können berechnet werden, indem man die mittleren Wahrscheinlichkeiten $\left\langle p_{i j}\right\rangle$ aus den Simulationen abschätzt und die drei unabhängigen Gleichungen (numerisch) löst.

\section{Barrierenhöhen}

Um die Barrierenhöhen in unserem Vier-Zustands-Modell zu bestimmen, benötigen wir die Übergangsraten. Nach der Kramers-Theorie in der harmonischen Langevin-Näherung für mittlere bis starke Reibung [183] sind diese Raten auf folgende Weise mit den Barrierenhöhen, etwa $\Delta G_{A 1}^{\uparrow}:=G_{A 1}^{*}-G_{11}$, verknüpft:

$$
k_{A 1}=\kappa e^{-\Delta G_{\mathrm{A} 1}^{\uparrow} / k_{B} T} \quad \text { mit } \quad \kappa:=\frac{\sqrt{\gamma^{2} / 4+\omega_{b}^{2}}-\gamma / 2}{\omega_{b}} \frac{\omega_{0}}{2 \pi} .
$$

Dabei ist der Vorfaktor $\kappa$ durch die Krümmung $\omega_{0}$ der Energielandschaft in der Nähe der Sessel- und Wannenzustände, die Krümmung $\omega_{b}$ an der Stelle des Übergangszustands und den effektiven Reibungskoeffizienten $\gamma$ bestimmt. 


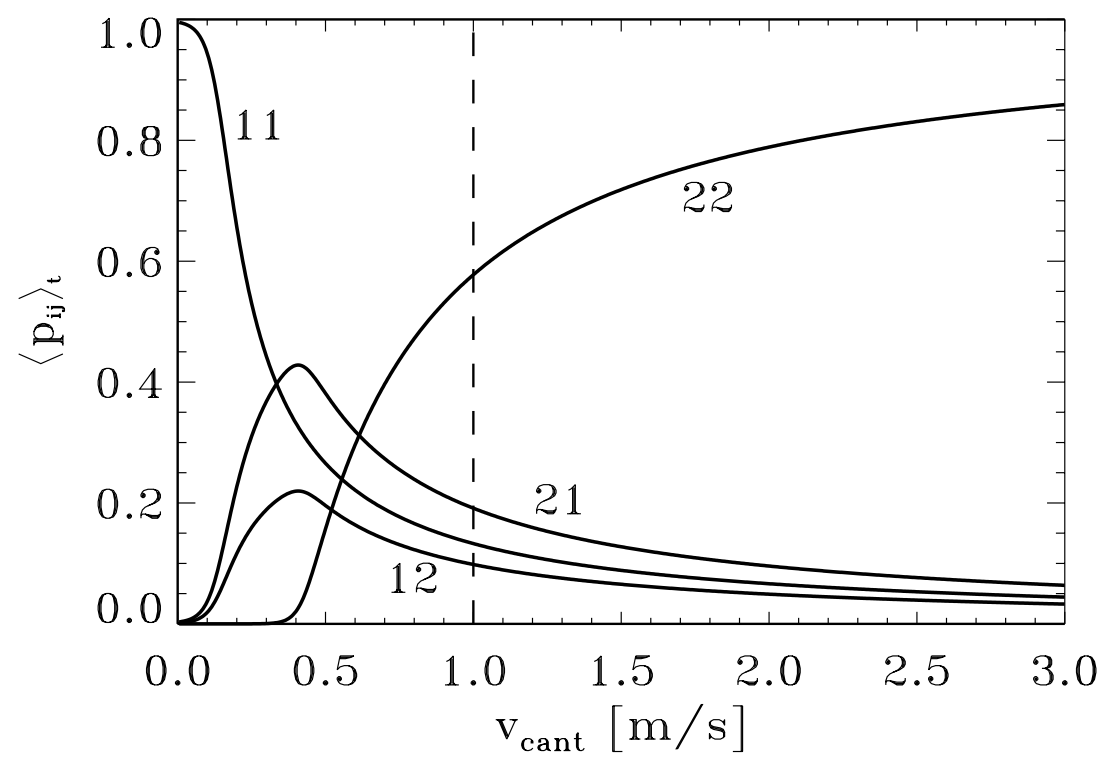

Abbildung 6.16: Mittlere Wahrscheinlichkeiten $\left\langle p_{i j}\right\rangle$ als Funktion der Zuggeschwindigkeit $v_{\text {cant }}$ für alle vier Zustände $i j=11,12,21,22$. Die gestrichelte Linie markiert die in den Simulationen verwendete Zuggeschwindigkeit.

Zur späteren Verwendung definieren wir Barrierenhöhen für die Vorwärtsreaktionen

$$
\Delta G_{A 1}^{\uparrow}:=G_{A 1}^{*}-G_{11}
$$

Barrierenhöhen für die Rückreaktionen

$$
\Delta G_{A 1}^{\downarrow}:=G_{A 1}^{*}-G_{12},
$$

sowie mittlere Barrierenhöhen

$$
\Delta G_{A 1}^{*}:=\frac{1}{2}\left(\Delta G_{A 1}^{\uparrow}+\Delta G_{A 1}^{\downarrow}\right)=G_{A 1}^{*}-\frac{1}{2}\left(G_{11}+G_{21}\right)
$$

Die Barrierenhöhen zwischen den anderen Zuständen sind analog definiert.

Um die Vorfaktoren $\kappa$ der Ratenkonstanten $k$ [Gleichung (6.8)] zu bestimmen, wurde zunächst, wie in Ref [237] vorgeschlagen, das Leistungsspektrum $\hat{C}(\omega)$ der GeschwindigkeitsAutokorrelationsfunktion $C(t)$ des Dihedralwinkels $\Phi_{3}$ aus einer Simulation berechnet, in der keine Zugkräfte angelegt wurden und in der beide Ringe über eine Simulationszeitspanne von $100 \mathrm{ps}$ in der Sesselkonformation verblieben. Da in der harmonischen Langevin-Näherung dieses Spektrum durch

$$
\hat{C}(\omega) \propto \frac{\gamma \omega^{2}}{\left(\omega_{0}^{2}-\omega^{2}\right)^{2}+\gamma^{2} \omega^{2}}
$$

gegeben ist [238], wurden die Resonanzfrequenz $\omega_{0}$ und der Reibungskoeffizient $\gamma$ abgeschätzt, indem dieser Ausdruck an den (geglätteten) Niederfrequenzanteil des Leistungsspektrums angepasst wurde. Die Beiträge mit hohen Frequenzen und kleinen Amplituden 
wurden dabei vernachlässigt. Die Frequenz $\omega_{b}$ an der Stelle des Übergangszustands erhielten wir durch einen Vergleich der Krümmungen der jeweiligen Enthalpieprofile für Sessel-Wannen-Übergänge in der Nähe des Minimums (Sesselkonformation), für die die Resonanzfrequenz nun bekannt ist, und in der Nähe des Maximums (Übergangszustand). Der Vergleich der Enthalpieprofile untereinander rechtfertigte die Annahme, dass sich die Resonanzfrequenzen in den Zuständen 11, 12, 21 und 22 nur marginal voneinander unterscheiden; dasselbe gilt für die Frequenzen $\omega_{b}$.

Die Barrierenhöhen $\Delta G^{*}$ für das ungestörte System wurden nun aus den in den Simulationen beobachteten Übergängen (d.h. aus den mittleren Übergangsraten $\left\langle r_{A 1}\right\rangle_{t},\left\langle r_{A 2}\right\rangle_{t}$, $\left\langle r_{B 1}\right\rangle_{t}$ und $\left.\left\langle r_{B 2}\right\rangle_{t}\right)$ berechnet. In unserem einfachen Modell werden diese mittleren Übergangsraten durch Integration der instantanen Übergangsraten

$$
r_{A 1}(t)=p_{11}(t) k_{A 1}(t)=p_{21}(t) k_{A 1}^{\prime}(t)
$$

bestimmt, wobei die Vorwärtsratenkonstante $k_{A 1}(t)$ und die Rückratenkonstante $k_{A 1}^{\prime}(t)$ in Abbildung 6.15 definiert sind. Die zweite Gleichsetzung in Gleichung (6.13) gilt auf Grund des detaillierten Gleichgewichts. Die Integrale für die zeitlichen Mittelwerte der Übergangsraten können ebenfalls analytisch gelöst werden, indem man Gleichung (6.8) zusammen mit den instantanen Wahrscheinlichkeiten in den Gleichungen (6.5) und (6.6) verwendet:

$$
\begin{aligned}
\left\langle r_{A 1}\right\rangle_{t}= & \kappa e^{-\beta\left(\Delta G_{A 1}^{*}+\Delta G_{A 1} / 2\right)} \frac{1}{T_{0}} \int_{0}^{T_{0}} \frac{e^{-\beta G_{11}(t)}}{Z(t)} e^{\beta u t / 2} d t \\
= & \kappa e^{-\beta\left(\Delta G_{A 1}^{*}+\Delta G_{A 1} / 2\right)} \cdot \\
& \frac{\sqrt{2} k_{2}}{T_{0} u \sqrt{D}}\left[D_{1}^{-1 / 2} \operatorname{atan} \frac{y_{1}-y_{2}}{1+y_{1} y_{2}}-D_{2}^{-1 / 2} \operatorname{atan} \frac{y_{3}-y_{4}}{1+y_{3} y_{4}}\right],
\end{aligned}
$$

wobei $k_{1}, k_{2}$ und $D$ wie oben definiert sind, und $D_{1}:=k_{2}\left(k_{1}-D^{1 / 2}\right), D_{2}:=k_{2}\left(k_{1}+D^{1 / 2}\right)$, $y_{1}:=k_{2} \sqrt{2} / \sqrt{D_{1}} e^{\beta u T_{0}}, y_{2}:=k_{2} \sqrt{2} / \sqrt{D_{1}}, y_{3}:=k_{2} \sqrt{2} / \sqrt{D_{2}} e^{\beta u T_{0}}$ und $y_{4}:=k_{2} \sqrt{2} / \sqrt{D_{2}}$. Man beachte, dass $\kappa$ eine Funktion des Reibungskoeffizienten $\gamma$ und der Frequenzen $\omega_{0}$ und $\omega_{b}$ ist, die weiter oben bereits bestimmt wurden. Gleichung (6.15) und die analogen Ausdrücke für die drei übrigen mittleren Übergangsraten können dann nach den Barrierenhöhen aufgelöst werden, die dann als Funktion der Freie-Energie-Differenzen $\Delta G_{i j}$ erscheinen, die bereits bestimmt wurden.

\section{Ergebnisse und Diskussion}

Für den Verlauf des intramonomeren Dihedralwinkels $\Phi_{3}$, der uns als Indikator für die Ringkonformation dient, sei auf Abbildung 6.10 verwiesen. Die daraus berechneten Besetzungshäufigkeiten $\rho_{i}(i=1,2, \ldots, 16)$ für die Wannenkonfiguration sind in Abbildung 6.17 exemplarisch für den siebten, achten und neunten Monomer [(a)-(c)] als Funktion der Zeit angegeben. Ein Wert von 0 entspricht dabei einer reinen Sesselkonformation, ein Wert von 1 einer reinen Wannenkonformation. Betrachtet man hier die ersten 20 ns etwas genauer, dann stellt man fest, dass die Verläufe von jeweils benachbarten Monomeren [7 und 8 in (a) und (b) bzw. 8 und 9 in (b) und (c)] eine deutliche Komplementarität 
aufweisen. Z.B. zeigt sich bei der durch den Kreis markierten Zunahme in $\rho_{7}$ zugleich eine entsprechende Abnahme in $\rho_{8}$. Entsprechendes gilt für $\rho_{8}$ und $\rho_{9}$ (gestrichelte Kreise). Die Produkte der Besetzungswahrscheinlichkeiten vom siebten und achten bzw. dem achten und neunten Monomer sind in (d) und (e) als Funktion der Simulationszeit aufgetragen - diese Produktwahrscheinlichkeiten nehmen nur für die Konstellation 'Wanne'-'Wanne' den Wert 1 an, ansonsten sind sie Null. Aus ihrem Verlauf geht hervor, dass vereinzelte Sessel-Wannen-Übergänge in allen Monomeren bereits fast zu Beginn des Dehnungsprozesses einsetzen - bis benachbarte Monomere gleichzeitig eine stabile Wannenkonformation einnehmen, vergehen jedoch gut $20 \mathrm{~ns}$, als schon Zugkräfte von über $1000 \mathrm{pN}$ auf das Amylose-16-mer einwirken.
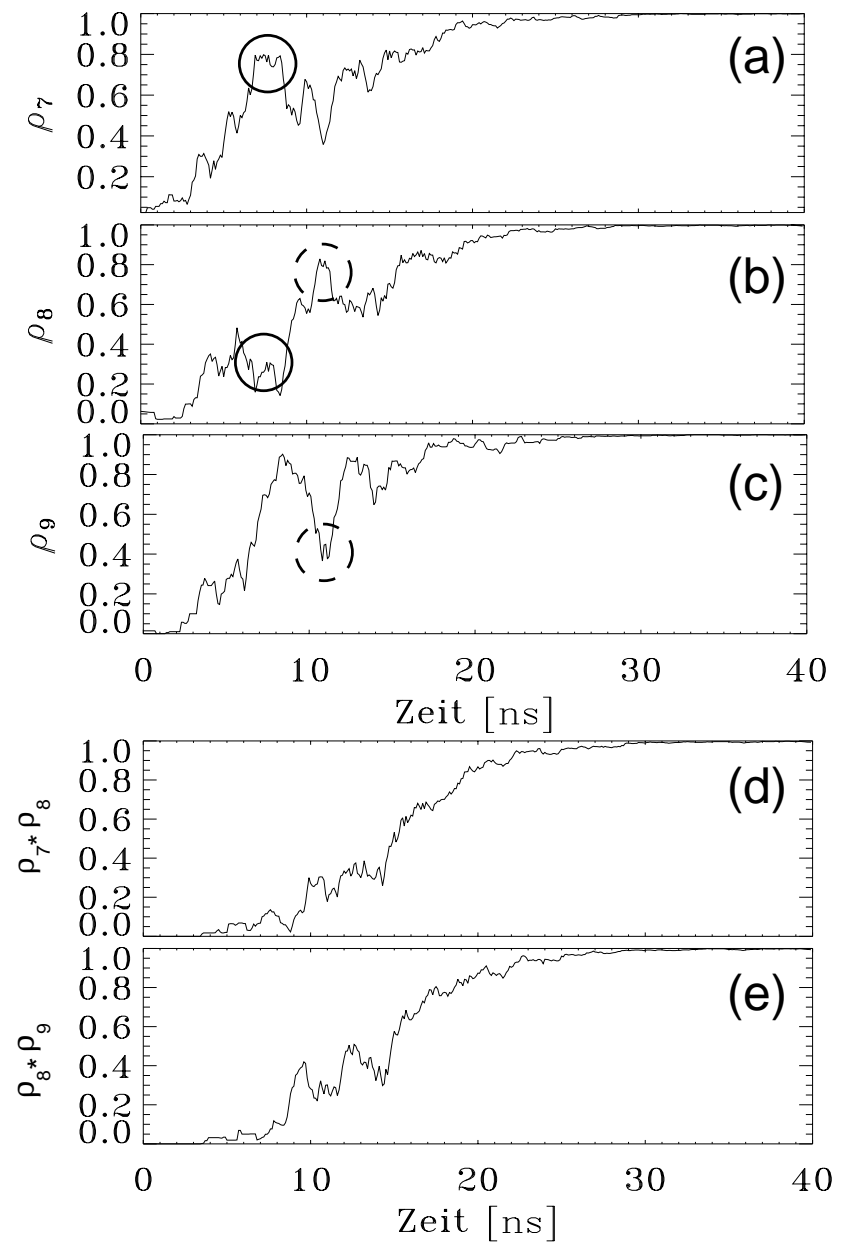

Abbildung 6.17: (a-c): Mittlere, jeweils über 100 ps-Zeitfenster berechnete Besetzungswahrscheinlichkeiten $\rho_{i}$ für die Wannenkonfornation der Monomere $i(i=7,8,9)$. Die Kreise markieren die Stellen, an denen sich die Komplementarität der Besetzungswahrscheinlichkeiten benachbarter Monomere besonders deutlich zeigt. (d) und (e): Die Produktwahrscheinlichkeiten für den siebten und achten sowie den achten und neunten Monomer.

Die zwei Freie-Energie-Differenzen $\Delta G$ und $\Delta G^{*}$ aus unserem einfachen Zwei-ZustandsModell (siehe Abbildung 6.15) wurden aus der $\Phi$-Verteilung $p(\Phi, t)=\exp [-\beta G(\Phi)]$ für verschiedene Zeiten während des Dehnungsprozesse berechnet. $\Phi$ ist dabei die Summe 
der Dihedralwinkel $\Phi_{3}$ von zwei benachbarten Monomeren, die zwischen $\Phi \approx-100^{\circ}$ ('Sessel'-'Sessel') und $\Phi \approx+100^{\circ}$ ('Wanne'-'Wanne') variiert. Abbildung 6.18 (a-e) zeigt fünf Freie-Energie-Landschaften $G(\Phi)=-\frac{1}{\beta} \ln p(\Phi, t)$, die aus den $\Phi$-Verteilungen in den Intervallen $[8000 j \ldots 8000 j+4000]$ ps mit $j=0,1,2,3,4$ berechnet wurden. Wenn man diese um die (linearisierte) Zugenergie $V_{\text {Feder }}=-k z v t$ korrigiert (d.h. die Zugkraft herausrechnet), dann weichen die fünf Landschaften nur leicht voneinander ab [Abbildung 6.18 (e)]. Auf Grundlage des zeitlichen Mittelwerts dieser Landschaften ergaben sich für $\Delta G \approx 3 \mathrm{kcal} / \mathrm{mol}$ und für $\Delta G^{*} \approx 5 \mathrm{kcal} / \mathrm{mol}$. Ausgehend von einer Ratenkonstante in Vorwärtsrichtung $k=0.5 \mathrm{ps}^{-1}$ bei $t=12 \mathrm{~ns}$, wo $\Delta G \approx 0 \mathrm{kcal} / \mathrm{mol}$, erhält man unter Verwendung von Gleichung (6.8) mit $\Delta G=3 \mathrm{kcal} / \mathrm{mol}$ für den Vorfaktor $\kappa=7 \mathrm{ps}^{-1}$.
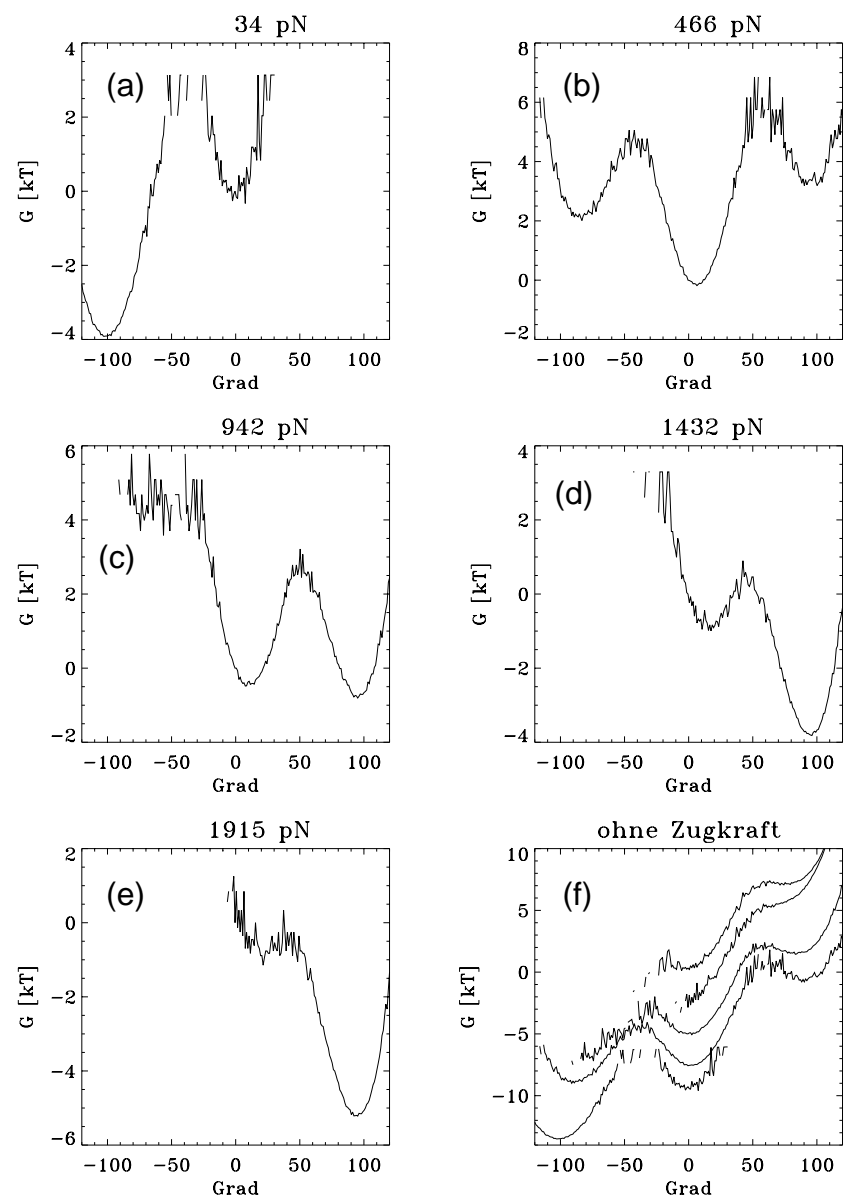

Abbildung 6.18: (a-e): Freie-Energie-Landschaften für die Dihedralwinkel $\Phi_{3}$ der Monomere 7 und 8, abgeleitet aus in den Simulationen beobachteten Wahrscheinlichkeitsverteilungen der Summe dieser beiden Dihedralwinkel. Diese Verteilungen wurden jeweils für die Intervalle $[0-8]$ (a), [8 - 16] (b), [16 - 24] (c), [24 - 32] (d) und [32-40] ns (e) bestimmt; (f): Überlagerung der Landschaften (a-e) nach Korrektur vom angelegten Zugpotenzial (siehe Text). Aus Gründen der Übersichtlichkeit sind hier die Landschaften vertikal gegeneinander verschoben.

Die bedingten Wahrscheinlichkeitsverteilungen $p_{i j}(t)(i, j=1,2)$ wurden für jeweils zwei benachbarte Monomere aus den Simulationen abgeleitet. Da sich die Wahrscheinlichkeitsverteilungen für die einzelnen Monomerpaare aus benachbarten Monomeren nur marginal 
voneinander unterscheiden, werden hier nur die Ergebnisse exemplarisch für ein Monomerpaar - Monomer 7 ('Ring A') und Monomer 8 ('Ring B') — gezeigt.

In Tabelle 6.1 sind die aus der Simulation abgeleiteten mittleren relativen Häufigkeiten sowie die Übergangsraten für das betreffende Monomerpaar aufgeführt. Desweiteren findet man in ihr die zugehörigen Werte für die Freie-Energie-Differenzen, wie sie unter Verwendung der Gleichungen (6.7), (6.15) sowie analoger Ausdrücke für die anderen drei Zustandskombinationen berechnet wurden. Auf der rechten Seite der Tabelle sind die Werte für die freie Energie, die aus den Simulationen abgeleitet wurden, graphisch dargestellt.

\begin{tabular}{|l|r|r|r|r|}
\hline$(i j)=$ & $(11)$ & $(12)$ & $(21)$ & $(22)$ \\
\hline$\left\langle p_{i j}\right\rangle_{t}$ & 0.13 & 0.11 & 0.18 & 0.58 \\
\hline \hline$(k j)=$ & $(\mathrm{A} 1)$ & $(\mathrm{A} 2)$ & $(\mathrm{B} 1)$ & $(\mathrm{B} 2)$ \\
\hline$\Delta G_{k j}$ & 3.5 & 9.7 & 3.9 & 10.0 \\
$\left\langle r_{k j}\right\rangle_{t}$ & 3.1 & 25.0 & 2.7 & 20.3 \\
$\Delta G_{k j}^{*}$ & 3.8 & 2.4 & 3.7 & 2.7 \\
\hline
\end{tabular}

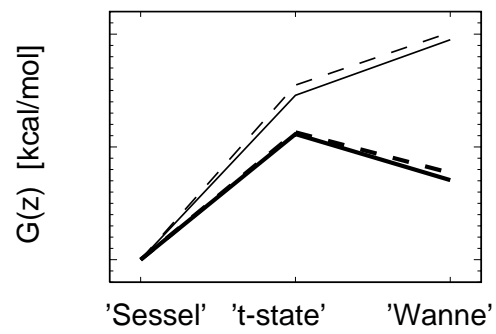

Tabelle 6.1: Links: mittlere Besetzungswahrscheinlichkeiten $\left\langle p_{i j}\right\rangle_{t}$ und daraus abgeleitete Freie-Energie-Differenzen $\Delta G_{i j}$ für die vier Zustände $(i, j)$ sowie die mittleren Übergangsraten $\left\langle r_{k j}\right\rangle_{t}$ und die daraus abgeleiteten Aktivierungsbarrierenhöhen $\Delta G_{k j}^{*}$ für die vier bedingten Übergänge $(k j)$. Raten sind in $1 / \mathrm{ns}$, Energien in $\mathrm{kcal} / \mathrm{mol}$ angegeben. Rechts: Skizze der Energielandschaft für den Sessel-Wannen-Übergang von Monomer A, falls Monomer B in der Sesselkonformation (fette, durchgezogene Linie) bzw. in der Wannenkonformation (dünne, durchgezogene Linie) ist. Die gestrichelten Linien zeigen in analoger Weise die Energielandschaft von B in Abhängigkeit der Konformation von Monomer A.

Wie aus diesem Bild ersichtlich, unterscheidet sich die Energielandschaft, die den Übergang von Ring A für den Fall beschreibt, dass Ring B in der Sesselkonformation verweilt (fette, durchgezogene Linie), nicht signifikant von dem umgekehrten Fall, in dem Ring B flippt und Ring A in der Sesselkonformation verbleibt (fette, gestrichelte Linie), wie es aus Symmetriegründen auch nicht anders zu erwarten ist. Dasselbe gilt für die Bedingung 'Wanne' (dünne Linien, durchgezogen und gestrichelt). Allerdings weisen die Energielandschaften für die Bedingung 'Sessel' und die Bedingung 'Wanne' untereinander erhebliche Unterschiede auf. Dies bedeutet, dass der Konformationszustand von Ring A stark beeinflusst ist von dem von Ring B und umgekehrt. Aus den Daten ergibt sich, dass die Wannenkonformation eines gegebenen Monomers durch einen Sessel-WannenÜbergang eines der benachbarten Monomere um etwa $6 \mathrm{kcal} / \mathrm{mol}$ destabilisiert wird. Dies erzwingt die Schlussfolgerung, dass Sessel-Wannen-Übergänge weitere Übergänge benachbarter Monomere stark unterdrücken. Ergebnis dieser quantitativen Analyse ist also, was wir schon in den in Abschnitt 6.1.2 beschriebenen Amylose-Dehnungssimulationen beobachtet hatten: eine kurzreichweitige, starke Antikooperativität der intramonomeren Konformationsübergänge, die das kontinuierliche Anwachsen der Steifigkeit über einen weiten Bereich von Zugkräften erklärt.

Welche Mechanismen auf der atomaren Ebene bewirken die ausgeprägte Antikooperativität? Warum stabilisiert die Wannenkonformation eines Monomers die Sesselkonforma- 
tion benachbarter Monomere? In Abschnitt 6.1.2 hatten wir bereits einen geometrischen Effekt in Betracht gezogen (siehe Abbildungg 6.11): Danach deformieren sich die in der Verbrückung zwischen zwei Monomeren befindlichen Bindungswinkel $\alpha, \beta$ und $\gamma$ stärker pro Längeneinheit, sofern zwei benachbarte Monomere jeweils in der Wannenkonformation sind.
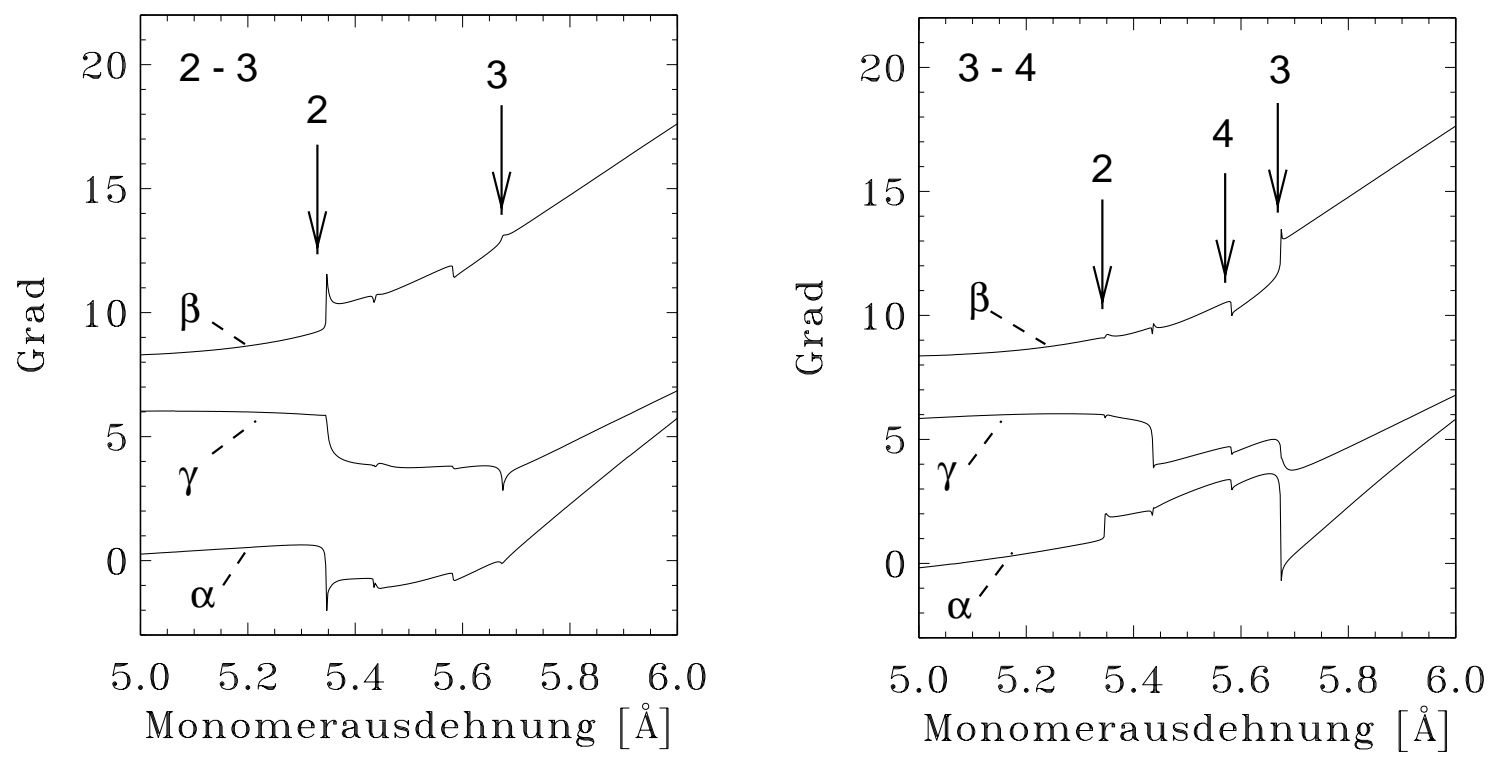

Abbildung 6.19: Verlauf der Bindungswinkel $\alpha, \beta$ und $\gamma$ in der Verbrückung zwischen zweitem und drittem Monomer (links) sowie in der Verbrückung zwischen dritten und viertem Monomer (rechts) als Funktion der Monomerausdehnung für einen Amylosepentamer, bei dem für alle Ausdehnungen zwischen 5.0 und $6.0 \AA$ pro Monomer die Struktur in Schritten von $0.1 \AA$ minimiert wurde. Die Pfeile markieren jeweils die Sessel-WannenÜbergänge in den darüber bezeichneten Monomeren. Zur Definition der Bindungswinkel siehe Abbildung 6.11.

Um diese Hypothese zu überprüfen, betrachten wir den jeweiligen Verlauf der Bindungswinkel in der Verbrückung in Abhängigkeit von der Ausdehnung pro Monomer. Dies ist in Abbildung 6.19 für einen Amylosepentamer gezeigt, für den die Struktur für jede Ausdehnung zwischen 5.0 und $6.0 \AA$ pro Monomer in Schritten von $0.01 \AA$ minimiert wurde. Es sind hier die Abweichungen der Bindungswinkel in der Verbrückung zwischen zweitem und drittem Monomer (links) bzw. zwischen drittem und viertem Monomer (rechts) von ihrer jeweiligen Gleichgewichtslage dargestellt. Die Pfeile markieren jeweils die Ausdehnung pro Monomer, bei der die mit Ziffern bezeichneten Monomere von der Sessel- in die Wannenkonformation geflippt sind. Es ist zu erkennen, dass, nachdem Monomer 3 als letztes bei einer Monomerausdehnung von knapp $5.7 \AA$ in die Wannenkonformationn geflippt ist und somit die Monomere 2, 3 und 4 die Konstellation 'Wanne'-'Wanne'-'Wanne' aufweisen, die Bindungswinkel $\alpha$ und $\gamma$ sowohl zwischen zweitem und dritten Monomer (links) als auch zwischen drittem und viertem Monomer (rechts) erheblich stärker mit der Monomerausdehnung ansteigen als es vorher der Fall war. Dabei ist der energetische Zustand nach dem Flip zwar zunächst teilweise günstiger — zwischen dem dritten und vierten Monomer bei $\alpha$ und $\gamma$-, da sich diese Winkel kurzzeitig wieder näher an ihrer Gleichgewichtslage befinden, doch dies ändert sich auf Grund des steilen Anstiegs schnell 
wieder. Bei dem Bindungswinkel $\beta$ nimmt die Steigung nach dem Flip zwar nicht zu, jedoch bewirkt hier der Flip selber einen energetisch ungünstigeren Zustand, was insofern eine erhebliche Rolle spielt, als dieser Bindungswinkel bereits vor dem Flip weit von seiner Gleichgewichtgslage im harmonischen Potenzial entfernt war.

Die hier gezeigten Bindungswinkel legen nahe, dass diese tatsächlich, wie vermutet, die Steifigkeit bestimmen, falls benachbarte Monomere in der Wannenkonformation sind. Dagegen rührt bei der Kombination 'Sessel'-'Sessel' oder 'Sessel'-'Wanne' die Steifigkeit im wesentlichen von der Verbiegung der Dihedralwinkel aus ihrer Gleichgewichtslage her. Vor diesem Hintergrund scheint es plausibel, dass die sehr viel „,weichere“ Konstellation 'Sessel'-'Wanne' bis zu hohen Zugkräften Bestand hat, bis zu einem Zustand, in dem eine weitere Deformation der Dihedralwinkel nicht mehr möglich ist, da sie dann in eine andere Gleichgewichtslage, die der Wannenkonformation entspricht, flippen.

Die überraschende Rolle der Seitengruppen und ihr daraus resultierender Einfluss auf die Polymerelastizität bietet eine Möglichkeit, die Materialeigenschaften von Polymeren gezielt zu beeinflussen. 


\subsection{Dehnungssimulationen von Polyethylenglykol (PEG)}

Nicht nur intramolekulare Eigenschaften bestimmen das elastische Verhalten von Polymeren. Auch ihre Umgebung - etwa die Art des umgebenden Lösungsmittels - kann darauf Einfluss nehmen, wie es etwa für PEG der Fall ist. So zeigten kraftmikroskpoische Experimente, dass PEG in einem polaren Lösungsmittel wie Wasser ganz andere elastische Eigenschaften aufweist als in einem apolaren Medium. Die im Folgenden beschriebenen Dehnungssimulationen zu PEG zielen darauf ab, die elastischen Eigenschaften von PEG in wässriger Lösung und in Gasphase zu studieren [70].

PEG ist ein synthetisches wasserlösliches Polymer, das aus einer Kette aus $\mathrm{CH}_{2} \mathrm{O}-$ Monomeren besteht. Es war bereits Gegenstand zahlreicher experimenteller und theoretischer Studien, vor allem wegen seiner zahlreichen industriellen, biotechnischen und klinischen Anwendungen [81,82], aber auch, weil es als Modellsystem für das Studium des komplexen Verhaltens von Polymeren in Lösung gut geeignet ist [239].

Die Eigenschaften von Makromolekülen stehen in engem Zusammenhang mit ihrer dreidimensionalen Struktur. Entsprechend gibt es zahlreiche Studien zu PEG in verschiedenen Lösungsmitteln. Aus Lichtstreuungsexperimenten ging hervor, dass PEG in Wasser und in Methanol nicht aggregiert [239], und infrarotspektroskopische Untersuchungen zeigten, dass mit wachsendem Lösungsmittelanteil die gauche-Konformation um die C-C-Bindung die trans-Konformation dominiert, was ein Indiz für die Ausbildung einer Superstruktur ist [240]. Es wurde angenommen, dass Wasserbrücken zwischen PEG-Sauerstoffatomen die Superstruktur stabilisieren.

Kürzlich durchgeführte kraftmikroskopische Einzelmolekülexperimente an PEG ergaben, dass für Zugkräfte bis zu 100 pN PEG-Polymere in dem apolaren Hexadekan elastischer sind als in Wasserlösung [24]. Für höhere Zugkräfte waren in Hexadekan gelöste PEGMoleküle hingegen steifer als die in Wasser gelösten. Während die Elastizität von PEG in Hexadekan sehr gut mit dem Verhalten einer einfachen Feder beschrieben werden konnte, erwiesen sich die elastischen Eigenschaften in Wasser als komplexer. Diese wurden in Ref. [24] mit der Deformation einer helikalen Superstruktur erklärt, welche durch ein elastisch gekoppeltes Markovsches Zwei-Zustands-System modelliert wurde. Quantenchemische Rechnungen unterstützten das Modell der Ausbildung dieser helikalen Strukturen [241]. Letztere ergaben eine günstigere Hydratisierungsenergie für den Fall, dass sich die $\mathrm{C}-\mathrm{C}$-Bindung in der (in einer helikalen Struktur anzutreffenden) gauche-Konformation befindet.

Mit Hilfe der hier beschriebenen MD-Dehnungssimulationen sollte der Frage nachgegangen werden, welche atomaren Mechanismen es sind, die diesen ausgeprägten Lösungsmitteleffekt hervorrufen. Die in Ref. [24] beschriebenen kraftmikroskopischen Dehnungsexperimente dienten hier vor allem dazu, die Resultate aus den Simulationen durch Vergleich mir den experimentellen Daten zu überprüfen.

\section{Methoden}

Viele methodische Details der PEG-Simulationen sind identisch mit denen in den Polysaccharidsimulationen (siehe letzter Abschnitt). Es werden daher hier nur die für PEG 
spezifischen Details erwähnt.

Ein Modell für ein linear verlaufendes PEG-18-mer wurde mit Hilfe des Molekül-Editors in Quanta [110] erstelllt. Die Kraftfeldparameter für die Dihedralwinkel, die entscheidend für die PEG-Konformation sind, wurden der CHARMM-Bibliothek entnommen. Im einzelnen wurden die Torsionen der zwei relevanten Dihedralwinkel um die $\mathrm{C}-\mathrm{C}$ - und die C-O-Bindungen durch sinusförmige Potenziale mit der Periodizität 3 beschrieben. Die Gleichgewichtswinkel lagen bei $-60^{\circ}\left(\right.$ gauche $\left.^{-}\right), 60^{\circ}$ (gauche $\left.^{+}\right)$bzw. $180^{\circ}$ (trans) für beide Dihedralwinkel; die Barrierenhöhen zwischen den Gleichgewichtslagen betrugen $1.6 \mathrm{kcal} / \mathrm{mol}$ für die Torsion um die $\mathrm{C}-\mathrm{C}$-Bindung und $0.2 \mathrm{kcal} / \mathrm{mol}$ für die Torsion um die $\mathrm{C}-\mathrm{O}-$ Bindung. Die Gleichgewichtswinkel stimmen gut mit denen in PEG-Kristallen überein [242].

Um PEG in Hexadekan bzw. Wasser zu beschreiben, wurden zwei Simulationssysteme erstellt. Die polare Wasserumgebung wurde explizit beschrieben, indem PEG mit Solvate [174] in einen Wassertropfen aus 1539 Wassermolekülen platziert wurde (siehe dazu Abschnitt 2.3). Da wir auf Grund seiner Apolarität den Einfluss des Lösungsmittels Hexadekan als gering einschätzten, wurden zur Beschreibung von PEG in Hexadekan Simulationen von PEG in Gasphase durchgeführt.

\section{PEG in Gasphase}

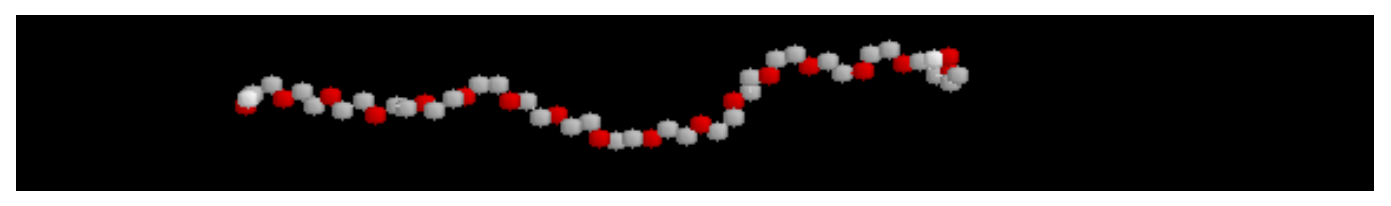

\section{PEG in Wasser}

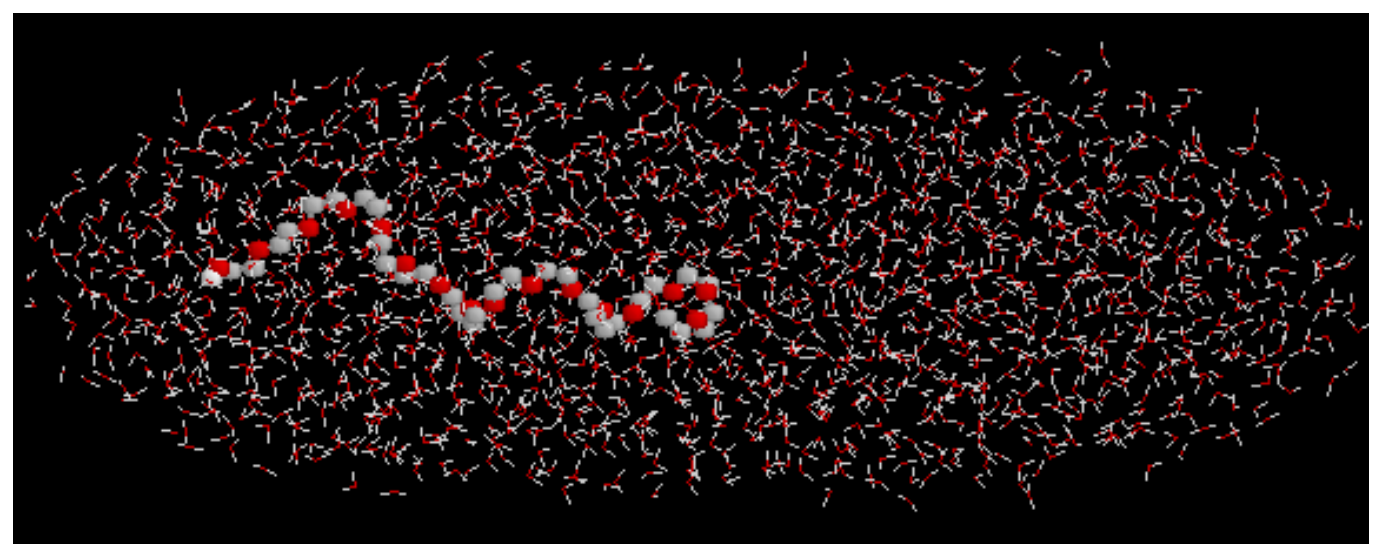

Abbildung 6.20: Simulationsmodell für PEG in Gasphase (oben) und für PEG in Wasser (unten).

Um Ausgangsstrukturen für die Dehnungssimulationen zu erhalten, wurden sowohl PEG in Gasphase als auch PEG in Wasser für 2000 ps equilibriert, wobei die Kopplungsskonstante an das Wärmebad $(T=300 \mathrm{~K}) 10^{-13} \mathrm{~s}^{-1}$ betrug. Wie in Abbildung 6.20 gezeigt, 
wurde das Sauerstoffatm O1 des einen terminalen Monomers (rechts in der Abbildung) an ein Zugpotenzial (Feder) gekoppelt, das mit $70 \mathrm{mN} / \mathrm{m}$ dieselbe Kraftkonstante aufwies wie der Cantilever in den kraftmikroskopischen Dehnungsexperimenten. Das Sauerstoffatom am anderen Ende des Polymers (links) wurde mit Hilfe eines steifen isotropen harmonischen Potenzials (Federkonstante $2.8 \mathrm{~N} / \mathrm{m}$ ) ortsfest gehalten.

In Analogie zu den weiter oben beschriebenen Dehnungssimulationen wurde das Zugpotenzial mit konstanter Zuggeschwindigkeit nach rechts bewegt, wobei die auf das Sauerstoffatom O1 wirkende Zugkraft als Funktion der Ausdehnung des PEG-18-mers in der Kraft-Ausdehnungs-Kurve aufgetragen wurde. Um den Einfluss der Zuggeschwindigkeit auf die Kraft-Ausdehnungs-Kurve zu studieren, wurde auch hier eine Reihe von Dehnungssimulationen mit unterschiedlichen Zuggeschwindigkeiten im Bereich von 50 bis $5 \mathrm{~m} / \mathrm{s}$ (entsprechend Simulationszeitspannen von 300 bis 3000 ps) durchgeführt.

Die PEG-Konformation während des Dehnungsprozesses wurde durch den End-zu-EndAbstand, den Trägheitsradius $R_{\text {gyr }}$ sowie die Helizität $\rho_{\text {helix }}$ charakterisiert. Der Trägheitsradius ist definiert durch

$$
R_{\text {gyr }}=\left[\frac{1}{N M} \sum_{i=1}^{N}\left(m_{i} r_{i}-\frac{1}{N M} \sum_{j=1}^{N} m_{j} r_{j}\right)^{2}\right]^{-1 / 2},
$$

wobei $N$ und $M$ Zahl bzw. Masse aller Atome im System sowie $r_{i}$ und $m_{i}$ Ort bzw. Masse von Atom $i$ sind. Die Helizität $\rho_{\text {helix }}$ wurde über die Anzahl der Tripel von benachbarten Dihedralwinkeln um die C-C-Bindung berechnet, die sich in derselben gaucheKonformation befanden. Diese Zahl wurde ins Verhältnis gesetzt zu der Gesamtanzahl der Tripel von benachbarten Dihedralwinkeln um die C-C-Bindung, so dass $\rho_{\text {helix }}$ Werte zwischen 0 und 1 annehmen konnte. Zur Bestimmung von $\rho_{\text {helix }}$ wurden Winkel zwischen $-120^{\circ}$ und $0^{\circ}$ der gauche ${ }^{-}$-Konformation und Winkel zwischen $0^{\circ}$ und $120^{\circ}$ der gauche ${ }^{+}$-Konformation zugeordnet. Entsprechend bedeutet eine Helizität von 1 eine perfekte helikale Struktur und eine Helizität von 0 keine helikale Struktur. Es sei betont, dass diese Definition für Helizität eher restriktiv ist, da kurze helikale Fragmente nur schwach zu $\rho_{\text {helix }}$ beitragen. Dazu betrachte man etwa zwei helikale Fragmente mit jeweils 4 Monomeren, die durch ein Monomer voneinander getrennt sind, das nicht in diese helikale Struktur passt. Diese insgesamt hochgradig helikale Struktur würde durch $\rho_{\text {helix }}=0.4$ beschrieben werden.

Für das in Wasser gelöste PEG wurden desweiteren das Ausbilden und das Brechen von Wasserstoffbrücken zwischen Wassermolekülen und PEG-Sauerstoffatomen betrachtet. Als Kriterium für Wasserstoffbrücken wurde ein Distanzkriterium $(<4 \AA$ zwischen den schweren Atomen) und ein Energiekriterium (Summe aus Van der Waals und elektrostatischer Energie $<-1 \mathrm{kcal} / \mathrm{mol}$ ) nach Ref. [148] verwendet. Als Wasserbrücken wurden Wassermoleküle bezeichnet, die gleichzeitig Wasserstoffbrücken zu wenigstens zwei PEGSauerstoffatomen ausbildeten.

Als weitere Observable wurde die gesamte Wechselwirkungsenergie von PEG mit Wassermolekülen in der direkten Umgebung in einem Abstand von weniger als $4 \AA$ herangezogen. Ferner wurde die durchschnittliche Zugänglichkeit $\alpha$ der Sauerstoffatome von PEG für Wasserbrücken betrachtet. Diese wurde bestimmt aus der mittleren Anzahl der Sauerstoffatome, die für ein Wassermolekül gleichzeitg „erreichbar“ waren, d.h. die hinreichend nah gelegen waren, so dass das jeweilige Wassermolekül Wasserstoffbrücken zu 
eben diesen Sauerstoffatomen gleichzeitig ausbilden konnte. Entsprechend impliziert ein Wert nahe bei 1, dass nur sehr wenige oder gar keine Wasserbrücken ausgebildet werden konnten, da meistens nur höchstens ein Sauerstoffatom in Reichweite jedes einzelnen Wassermoleküls lag, während etwa ein Wert von 1.5 darauf schließen lässt, dass es eine Reihe von Wassermolekülen gibt, die zwei oder mehr PEG-Sauerstoffatome „erreichen“ und Wasserbrücken zu ihnen ausbilden konnten.
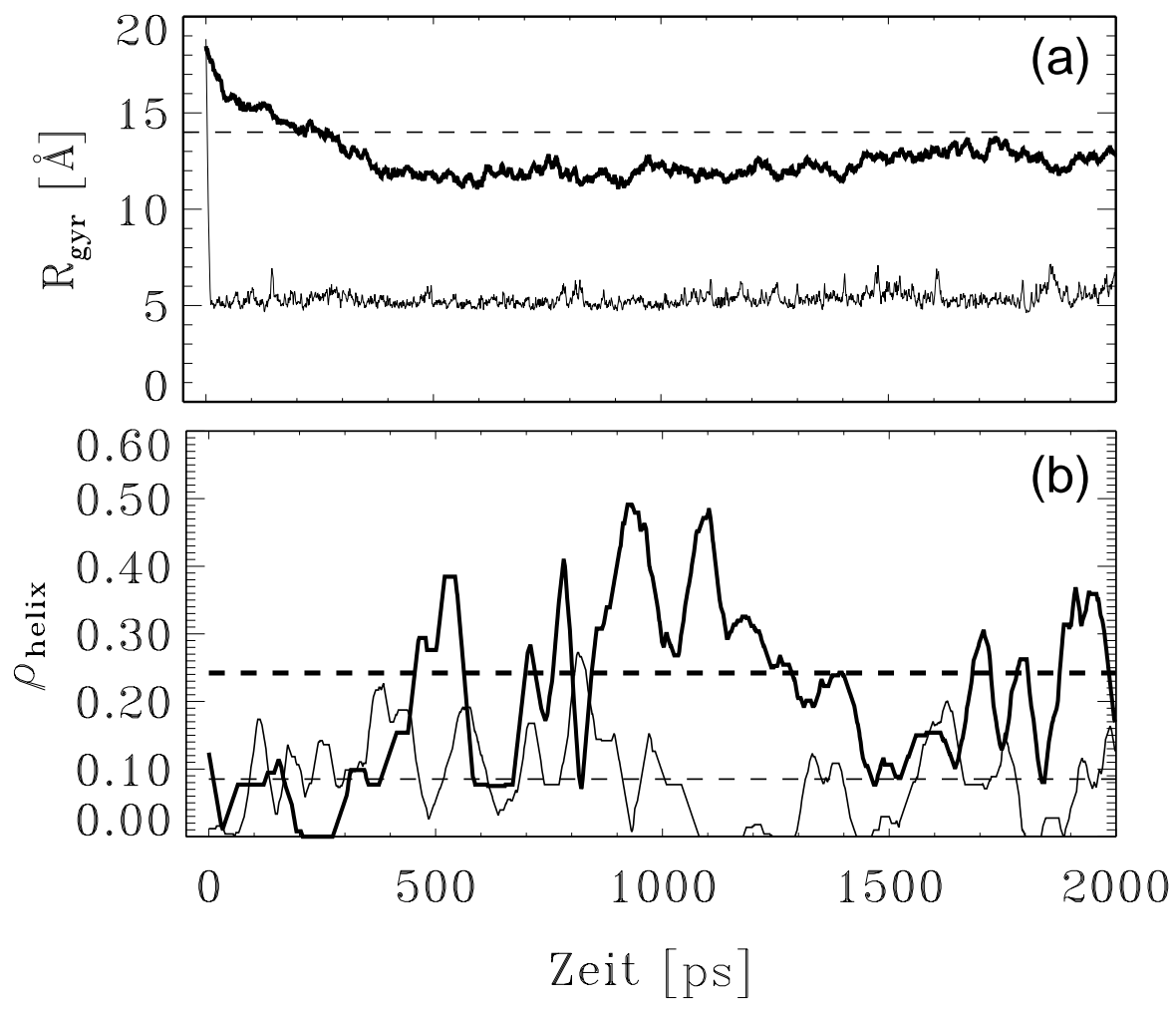

Abbildung 6.21: Trägheitsradius $R_{\text {gyr }}$ (a) und Helizität $\rho_{\text {helix }}$ (b) für PEG in Wasser (fette Linien) und in Gasphase (dünne Linien) während der Equilibrierung. Der Trägheitsradius für PEG mit einer perfekten helikalen Struktur ist anhand der gestrichelten Linie angedeutet (a). Die gestrichelten Linien in (b) zeigen die Mittelwerte der jeweiligen Helizitäten.

\section{Ergebnisse und Diskussion}

Während der Equilibrierung von PEG in Gasphase verringerte sich der End-zu-EndAbstand des anfänglich gestreckten PEG-Polymers innerhalb von weniger als $10 \mathrm{ps}$ auf einen Wert nahe bei $0 \AA$. Abbildung 6.21 (a) zeigt eine entsprechende Abnahme des Trägheitsradius $R_{\text {gyr }}$ auf etwa $5 \AA$ (dünne Linie). Im Gegensatz dazu stabilisierte sich die mittlere Ausdehnung eines Monomers des in Wasser gelösten PEG-Polymers nach einer Relaxationszeit von 400 ps bei $2.0 \AA$ und der Trägheitsradius $R_{\text {gyr }}$ bei $12 \AA$ [fette Linie in Abbildung 6.21 (a)]. Dieser Wert ist nur geringfügig niedriger als für PEG mit vollständig helikaler Struktur (gestrichelte Linie) und änderte sich während der restlichen 1600 ps der Equilibrierung nicht wesentlich. 
Abbildung 6.21 (b) zeigt die Helizität $\rho_{\text {helix }}$ während der Equilibrierung. Für PEG in Gasphase (dünne Linie) fluktuierte $\rho_{\text {helix }}$ zwischen 0 und 0.2 mit einem mittleren Wert von 0.08 (gestrichelte, dünne Linie), wohingegen die Helizität für das in Wasser gelöste PEG (fette Linie) in der Simulationszeitspanne zwischen 400 und 2000 ps um 0.25 (gestrichelte, fette Linie) im Bereich von 0.1 bis 0.5 variierte. Diese Werte zeugen von einer kaum vorhandenen Helizität von PEG in Gasphase, lassen dagegen häufig auftretende helikale Strukturelemente für PEG in Wasser vermuten. Der oberste Schnappschuss von PEG in Abbildung 6.25 zeigt ein repräsentatives Beispiel für eine solche helikale Struktur; darüber hinaus sieht man hier ausgewählte Wassermoleküle, die Wasserbrücken zwischen PEGSauerstoffatomen ausbilden. Diese Wasserbrücken betrachten wir als die entscheidende treibende Kraft für die Bildung einer helikalen Struktur. Wie zu sehen ist, können einzelne Wassermoleküle bis zu 4 PEG-Sauerstoffatome miteinander verbrücken.

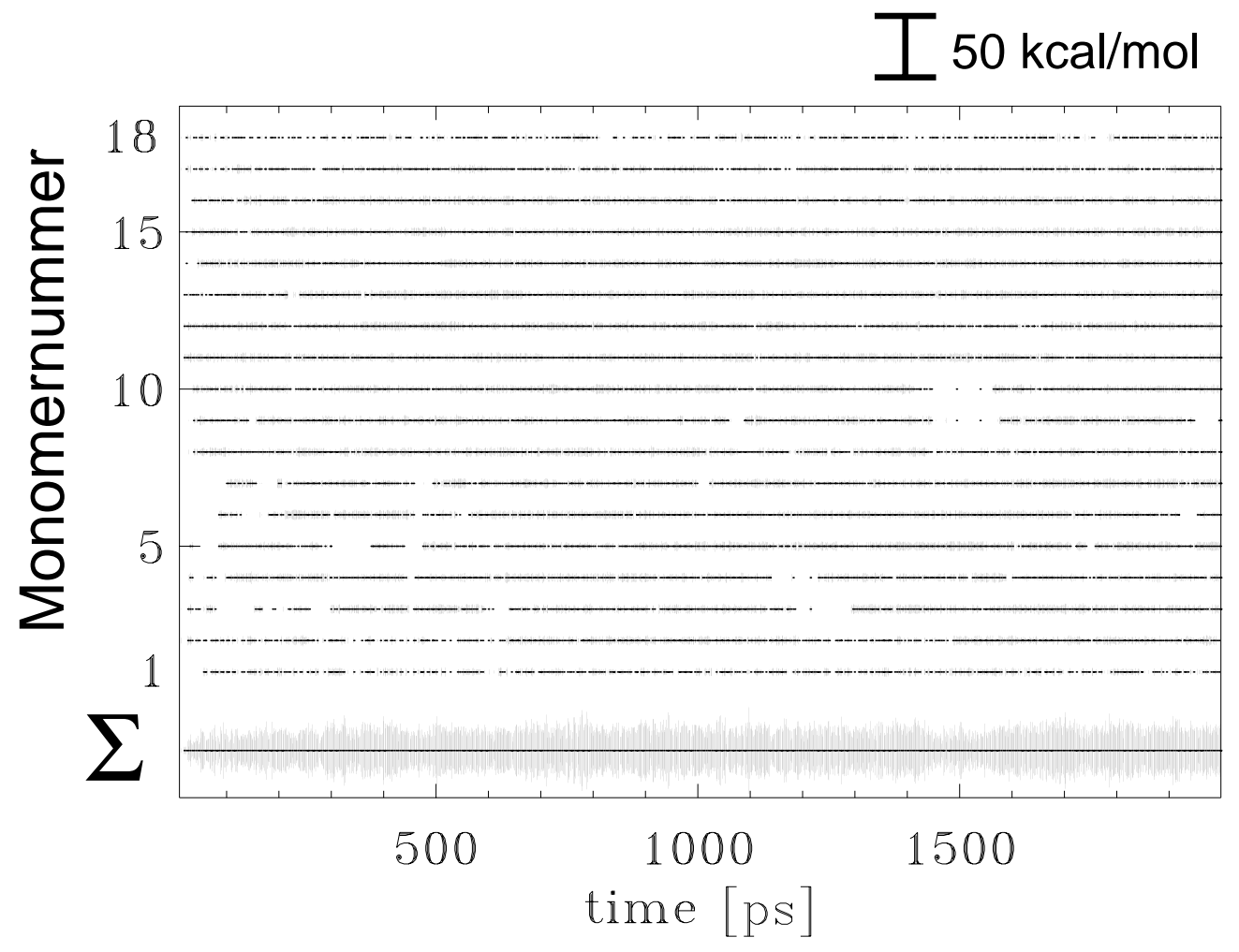

Abbildung 6.22: Stärke der Wasserbrücken zwischen PEG-Sauerstoffatomen für jedes Monomer während der Equilibrierung in kcal/mol. Die Dicke der 18 Balken ist ein Maß für die Stärke (siehe Skala oben in der Abbildung). Die Summe über alle Monomere ist unten gezeigt.

In Abbildung 6.22 ist die Stärke der Wasserbrücken für jedes der 18 Monomere während der Equilibrierungsphase quantifiziert: Diese ist definiert als die Wechselwirkungsenergie zwischen dem Wassermolekül und den an der Wasserbrücke beteiligten Sauerstoffatomen und spiegelt sich in der Abbildung in die Dicke der Balken wider. Man erkennt, dass sich die Stärke der Wasserbrücken nach einer Relaxationszeit von etwa 300 ps stabilisierte. Ebenfalls zu sehen ist, dass Wasserbrücken transient brachen und sich wieder neu bildeten (z.B. bei den Monomeren 9 und 10 nach einer Simulationszeit von 1400 ps). Die 
gesamte Wasserbrückenenergie (unterster Balken in der Abbildung) betrug $45 \mathrm{kcal} / \mathrm{mol}$, entsprechend im Mittel $2.5 \mathrm{kcal} / \mathrm{mol}$ pro Monomer.

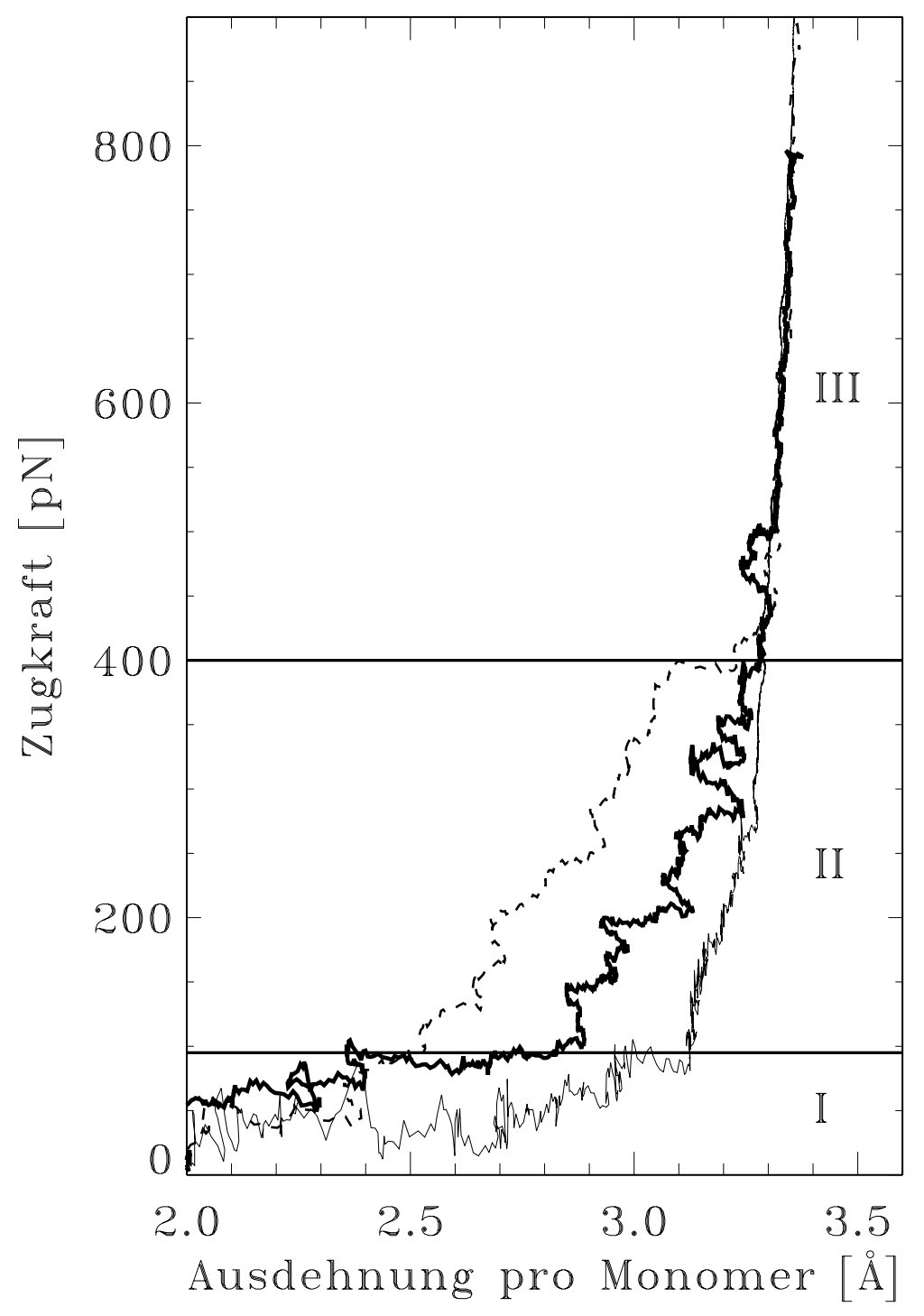

Abbildung 6.23: Kraft-Ausdehnungs-Kurven für PEG in Wasser mit Zuggeschwindigkeiten von $50 \mathrm{~m} / \mathrm{s}$ (gestrichelt) und $7.5 \mathrm{~m} / \mathrm{s}$ (fett) und für PEG in Gasphase (dünn). Die drei Regimes I, II, III werden im Text diskutiert.

Abbildung 6.23 zeigt die Kraft-Ausdehnungs-Kurven für in Wasser gelöstes PEG mit einer Zuggeschwindigkeit von $7.5 \mathrm{~m} / \mathrm{s}$ (fett) bzw. $50 \mathrm{~m} / \mathrm{s}$ (gestrichelt) und für PEG in Gasphase (dünne Kurve). Es können drei Kraftregimes unterschieden werden: ein Regime niedriger Kraft (I) für Zugkräfte unter 100 pN, ein intermediäres Regime (II) für Zugkräfte zwischen 100 und 400 pN und ein Regime hoher Kräfte für Zugkräfte über 400 pN. Während sich die Verläufe der Kraft-Ausdehnungs-Kurven für PEG in Wasser und PEG in Gasphase in den Regimes I und III nur geringfügig voneinander unterscheiden, weisen sie im mittleren Regime II signifikante Unterschiede auf. Hier erforderte die Dehnung von PEG in Wasser erheblich höhere Zugkräfte als die Dehnung von PEG in Gasphase.

Der Vergleich der Kraft-Ausdehnungs-Kurven von Simulationen mit unterschiedlichen 
Zuggeschwindigkeiten $\left[v_{\text {cant }}=7.5 \mathrm{~m} / \mathrm{s}\right.$ (fett) und $v_{\text {cant }}=50 \mathrm{~m} / \mathrm{s}$ (gestrichelt) $]$ zeigt, dass die Dehnung von gelöstem PEG bei hohen Zuggeschwindigkeiten erheblich höhere Zugkräfte erfordert, insbesondere in dem intermediären Regime. Wir erklären diesen Effekt mit Stokesscher Reibung. Für Zuggeschwindigkeiten unter 10 m/s konnte keine Geschwindigkeitsabhängigkeit der Dehnungskräfte mehr festgestellt werden (Daten nicht gezeigt), so dass Reibungskräfte hier bereits als vernachlässigbar gelten können. Dies ist in Übereinstimmung mit den in Kapitel 5 beschriebenen Dissoziationssimulationen zu AN02Hapten, bei denen für Zuggeschwindigkeiten unter $10 \mathrm{~m} / \mathrm{s}$ ebenfalls nur noch ein sehr geringer Beitrag der Reibungskräfte beobachtet wurde.

Am Beispiel der AN02-Hapten-Dissoziation hatten wir gesehen, dass zu den Reibungskräften eine weitere Kraftkomponente hinzukommt, die eine logarithmische Abhängigkeit von $v_{\text {cant }}$ zeigte und von der erzwungenen Überwindung der Energiebarrieren herrührte, die groß gegenüber $k_{B} T$ waren. Dies erschwert einen direkten Vergleich zwischen Nanosekundensimulationen und Millisekundenexperimenen (siehe dazu die ausführliche Diskussion in Kapitel 5). Da bei der Dehnung von PEG jedoch keine großen Barrieren überwunden werden müssen, erwarten wir hier keine signifikanten Unterschiede in den Kraft-Ausdehnungs-Kurven aus dem Experiment und der Simulation. In der Tat ergibt ein Vergleich der berechneten Kraft-Ausdehnungs-Kurven eine sehr gute Übereinstimmung mit den in kraftmikroskopischen Experimenten gemessenen (siehe Abbildung 4 in Ref. [24]). Daher stützt sich die nachfolgende Analyse der Struktur von PEG während des Dehnungsprozesses auf die Simulation, die mit einer Zuggeschwindigkeit von $7.5 \mathrm{~m} / \mathrm{s}$ durchgeführt wurde.

Wir konzentrieren uns nun auf die Frage, wie die beobachteten Dehnungskräfte mit molekularen Wechselwirkungen zusammenhängen. Um den Effekt des Lösungsmittels zu studieren, betrachten wir die Wechselwirkungen von PEG mit den Wassermolekülen in der Umgebung sowie die Helizität des Polymers. Die Ergebnisse sind in Abbildung 6.24 zusammengefasst. Man beachte, dass alle Observablen in Abhängigkeit von der angelegten Zugkraft aufgetragen sind. Die drei Pfeile oben in der Abbildung zeigen die jeweiligen Zugkräfte an, die bei den in Abbildung 6.25 dargestellten Schnappschüssen auf PEG wirken. Es fällt auf, dass alle Observablen in Abbildung $6.24 \mathrm{zu}$ Beginn des intermediären Regimes bei einer Zugkraft von etwa 100 pN eine abrupte Änderung aufweisen. Die Wechselwirkungsenergie zwischen PEG und denjenigen Wassermolekülen, die PEGSauerstoffatome miteinander verbrücken, nimmt erheblich ab, viele Wasserbrücken sind sogar gänzlich gebrochen, insbesondere zu den Monomeren 5 bis 10. Entsprechend verringert sich die gesamte Wasserbrückenenergie signifikant [Auftragung ganz unten in (a)]. Der zweite Schnappschuss in Abbildung 6.25 zeigt die PEG-Struktur unmittelbar nach dem Brechen bzw. der Abschwächung der Wasserbrücken. Der Vergleich mit dem ersten Schnappschuss (oben) zeigt, dass insbesondere die „Mehrfachwasserbrücken“ gebrochen sind, also diejenigen Wasserbrücken, in denen ein Wassermolekül zu wenigstens drei PEGSauerstoffatomen gleichzeitig Wasserstoffbrücken ausbildet. 


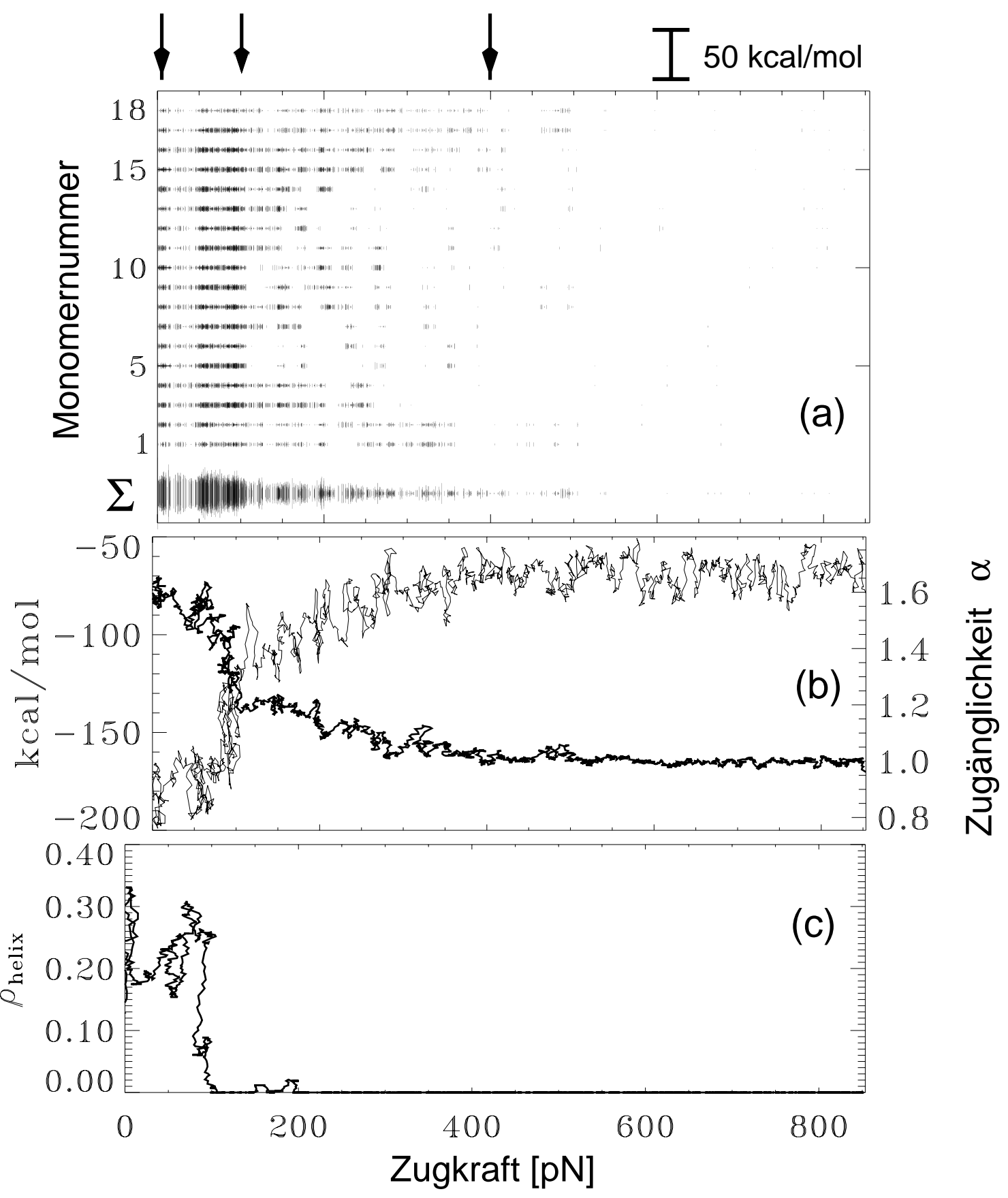

Abbildung 6.24: (a) Wechselwirkungsenergie der Wasserbrücken zu den einzelnen Monomeren als Funktion der Zugkraft während der Dehnungssimulation mit Zuggeschwindigkeit $7.5 \mathrm{~m} / \mathrm{s}$; (b) Gesamtenergie zwischen PEG und allen Wassermolekülen in einer $4 \AA$-Umgebung (dünn) sowie die mittlere Zugänglichkeit $\alpha$ der PEG-Sauerstoffatome zu Wasserbrücken (fett); (c) Helizität $\rho_{\text {helix }}$. 
Die Gesamtenergie, die zu einer solchen drastischen Konformationsänderung von PEG erforderlich ist, kann anhand des Sprungs in den Gesamtwechselwirkungen von PEG mit allen Wassermolekülen in einer Umgebung von $4 \AA$ grob zu etwa $40 \mathrm{kcal} / \mathrm{mol}$ abgeschätzt werden [dünne Linie in Abbildung 6.24 (b)], entsprechend etwa $2.2 \mathrm{kcal} / \mathrm{mol}$ pro Monomer. Es ist allerdings anzunehmen, dass dieser Wert die wirklich benötigte Energie überschätzt, da Wasserstoffbrücken, die sich zwischen PEG und einzelnen Wassermolekülen neu gebildet haben, nicht berücksichtigt sind. Eine grobe Abschätzung der mechanischen Arbeit, die auf Grund der Dehnung an jedem Monomer geleistet wurde, kann mit Hilfe von Abbildung 6.23 vorgenommen werden: Eine Dehnung um $0.9 \AA$ bei einer Zugkraft von etwa $100 \mathrm{pN}$ ergibt $0.9 \AA \cdot 100 \mathrm{pN} \approx 1.3 \mathrm{kcal} / \mathrm{mol}$ pro Monomer und somit etwa $23 \mathrm{kcal} / \mathrm{mol}$ für das gesamte 18-mer. Diese Abschätzung ist ein Indiz dafür, dass das Abreißen von Wasserstoffbrücken zwischen PEG und dem Lösungsmittel tatsächlich der wesentliche Effekt in diesem Stadium des Dehnungsprozesses ist. Dass an diesen in erheblichem Maße Wasserbrücken beteiligt sind, zeigt auch die mittlere Zugänglichkeit $\alpha$ der PEG-Sauerstoffatome zu Wasserbrücken, die von 1.5 auf 1.2 signifikant abnimmt [fette Linie in Abbildung 6.24 (b)].

Gleichzeitig verschwand die Helizität $\rho_{\text {helix }}$ [Abbildung 6.24 (c)] und das Polymer dehnte sich um etwa $0.5 \AA$ pro Monomer aus, wie aus Abbildung 6.23 und aus den Schnappschüssen in Abbildung 6.25 ersichtlich ist. Die betrachteten Oberservablen legen somit nahe, dass die drastische Konformationsänderung für die elastischen Eigenschaften von PEG in dem wässrigen Lösungsmittel verantwortlich ist, und dass diese Konformationsänderung wesentlich durch das Abreißen von Wasserbrücken induziert wird, insbesondere solchen, an denen mehr als zwei PEG-Sauerstoffatome beteiligt sind und die so eine helikale Struktur stabilisieren.

Weiter zunehmende Zugkräfte bis zu 400 pN sind erforderlich, um das Polymer um weitere $0.4 \AA$ pro Monomer auszudehnen. In diesem intermediären Regime brachen schließlich auch diejenigen Wasserbrücken, die nach der drastischen Konformationsänderung erhalten geblieben waren (siehe den zweiten Schnappschuss in Abbildung 6.25), was auch anhand des langsamen Anwachsens der Wechselwirkungsenergie von PEG zu den umgebenden Wassermolekülen zu sehen ist [Abbildung 6.24 (b)]. Auf Grund der Abwesenheit von Wasserbrücken in Gasphase ist PEG in diesem Regime bereits erheblich ausgedehnter und steifer.

In dem Regime hoher Zugkräfte $\left(F_{\text {Zug }}>400 \mathrm{pN}\right)$ sind die Kraft-Ausdehnungs-Kurven (Abbildung 6.23) für PEG in Gasphase (dünne Kurve) und in Wasser gelöstes PEG (fette Kurve) nahezu identisch. Hier tragen Wasserbrücken nicht mehr signifikant zu der Molekülelastizität bei. Vielmehr ist diese in diesem Regime dominiert durch intramolekulare Prozesse wie die Verbiegung von Bindungswinkeln oder die Verdrehung von Torsionswinkeln. Außerdem ändert sich hier die Gesamtwechselwirkungsenergie von PEG mit den Wassermolekülen in der direkten Umgebung in diesem Regime nicht mehr signifikant [dünne Linie in Abbildung 6.24 (b)]. Dies gilt ebenso für die Zugänglichkeit $\alpha$ der PEGSauerstoffatome zu Wasserbrücken (fette Linie), die sich auf eine Wert von annähernd eins stabilisierte. Dieser Wert besagt, dass in dieser fortgeschrittenen Phase des Dehnungsprozesse die Ausbildung von Wasserbrücken nahezu vollständig unterdrückt wurde, da der Abstand von benachbarten Sauerstoffatomen in der linear verlaufenden Polymerkette die Reichweite einzelner Wassermoleküle überstieg. 


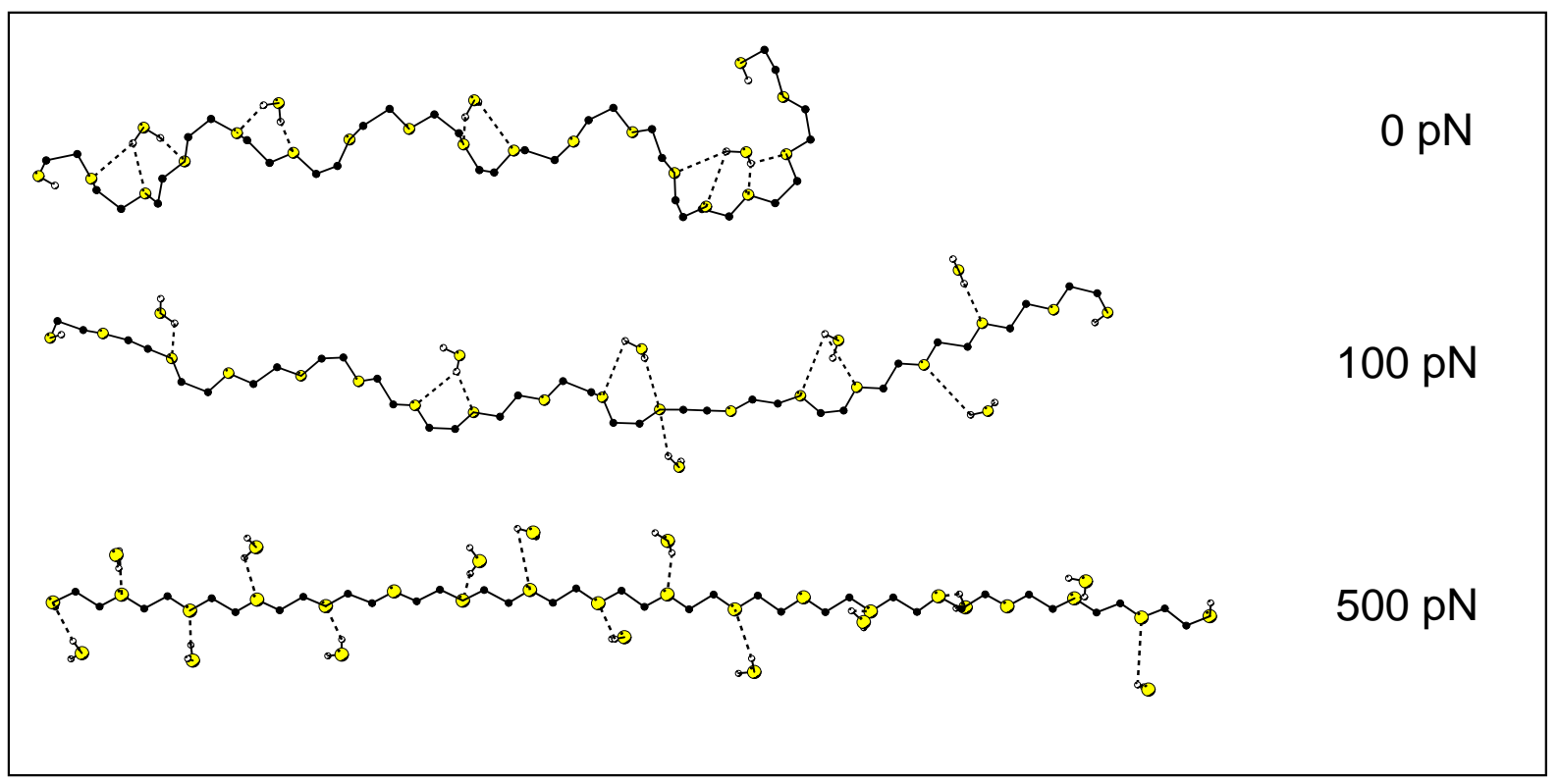

Abbildung 6.25: Drei repräsentative Schnappschüsse von in Wasser gelöstem PEG bei verschwindender (oben), mittlerer (Mitte) und hoher (unten) Zugkraft. Wasserstoffbrücken zwischen PEG -Sauerstoffatomen und Wassermolekülen sind durch gestrichelte Linien markiert. Es sind nur Kohlenstoffatome (schwarz), Sauerstoffatome (hell) und polare Wasserstoffatome (kleine weiße Kugeln) gezeigt; unpolare Wasserstoffatome sind nicht gezeigt.

\section{Schlussfolgerungen}

Die wichtigste Erkenntnis aus den MD-Dehnungssimulationen zu PEG ist, dass die elastischen Eigenschaften von PEG in Wasser maßgeblich durch die Ausbildung einer helikalen oder helixähnlichen Struktur bestimmt sind, die durch Wasserbrücken zwischen benachbarten Monomeren stabilisiert wird. Entsprechend werden bei der Dehnung von PEG in Wasser höhere Zugkräfte benötigt als bei PEG in Gasphase, um die Wasserbrücken zu brechen und somit das Polymer aus seiner helikalen Struktur zu entfalten. Bei PEG in Gasphase bildete sich keine solche Superstruktur aus. Für Zugkräfte über 100 pN lösten sich bei PEG in Wasser die helikalen Strukturelemente vollständig auf. Bei Zugkräften von mehr als $400 \mathrm{pN}$ wurden keine signifikante Unterschieden zwischen PEG in Gasphase und gelöstem PEG festgestellt, was ein Indiz dafür ist, dass hier nur noch intramolekulare Wechselwirkungen wie die Verbiegung oder Verdrehung von Winkeln zu der Elastizität beitragen. Die berechneten Kraft-Ausdehnungs-Kurven stimmen sehr gut mit denen aus kraftmikroskipischen Experimenten [24] überein, so dass die MD-Simulationen die elastischen Eigenschaften von PEG in Wasser offenbar gut beschreiben. Darüber hinaus zeigt der Vergleich mit dem Experiment, dass PEG in Gasphase ein gutes Modell für PEG in Hexadekan ist. 


\subsection{Zusammenfassung der Dehnungssimulationen}

Dehnungssimulationen zu den Polysacchariden Dextran, Cellulose und Amylose ermöglichten es, die in kraftmikroskopischen Einzelmolekülexperimenten gemessenen elastischen Eigenschaften auf atomarer Ebene zu interpretieren. Die aus den Simulationen abgeleiteten elastischen Eigenschaften stimmten mit den experimentellen Daten überein.

Für Dextran wurde anhand der Simulationen eine ausgeprägte Schulter in der KraftAusdehnungs-Kurve vorhergesagt, die später experimentell bestätigt wurde. Aus den Simulationen ergab sich, dass diese Schulter von dem Übergang eines Dihedralwinkels in der Verbrückung der Monomere von der einen in eine andere Gleichgewichtslage herrührt. Ein solcher Übergang bewirkt eine Verlängerung des Monomers von knapp $1 \AA$. Wenn man diese gemessenen und berechneten elastischen Eigenschaften auf einen makroskopischen Werkstoff überträgt, so könnte dieser als mechanische Sicherung oder mechanischer Schalter fungieren. Dieser Prozess hat darüber hinaus den Vorteil, dass er völlig verschleißfrei abläuft und deswegen beliebig oft wiederholbar ist. Schon heute wird das elastische Verhlaten von Dextran ausgenutzt, um Cantilever zu kalibrieren sowie deren Federkonstante zu bestimmen [23], da der Übergang von Dextran reproduzierbar bei etwa $750 \mathrm{pN}$ stattfindet.

Die Dehnungssimulationen zu Cellulose und Amylose, deren Monomere sich voneinander nur in der Orientierung der an das C1-Kohlenstoffatom gebundenen Hydroxylgruppe unterscheiden, zeigen, dass auch kleinste Änderungen in der molekularen Struktur von Polysacchariden dramatische Änderungen in den elastischen Eigenschaften mit sich bringen können. So weist die im Experiment verwendete Amylose, bei der an jedes Monomer noch eine Seitengruppe gebunden ist, welche eine kraftinduzierte parallele Ausrichtung benachbarter Monomere verbietet, ebenfalls eine Schulter in der Kraft-Ausdehnungs-Kurve auf, die von Sessel-Wannen-Übergangen in den einzelnen Monomeren herrührt. Bei Cellulose war dagegen keine Schulter in der Kraft-Ausdehnungs-Kurve zu beobachten - diese wies selbst bei niedrigen Zugkräften bereits eine hohe Steifigkeit auf. Hier blieben auch alle Monomere in ihrer anfänglichen Sesselkonformation. Insbesondere die Resultate zu Amylose weisen auf die Möglichkeit, elastische Eigenschaften von Materialien durch die gezielte Veränderung von molekularen Komponenten, wie etwa die Beschaffenheit von den Seitenketten an den Pyranoseringen, maßzuschneidern.

Schließlich haben die Dehnunssimulationen zu PEG gezeigt, dass elastische Eigenschaften auch stark von dem verwendeten Lösungsmittel abhängen können. Hier beteht also die Möglichkeit, elastische Eigenschaften über das Lösungsmittel zu regulieren. 


\section{Kapitel 7}

\section{Zusammenfassung}

In dieser Arbeit haben wir in enger Anlehnung an kraftmikroskopische Einzelmolekülexperimente die forcierte Dissoziation eines Haptenmoleküls von seinem AN02-Antikörper und die Dehnung von Polymermolekülen in Langzeit-Molekulardynamik-(MD)-Simulationen untersucht. Da MD-Simulationen und kraftmikroskopische Experimente auf sehr unterschiedlichen Zeitskalen stattfinden, haben wir eine Theorie entwickelt, die Zeitskaleneffekte in kraftinduzierenden Einzelmolekülexperimenten beschreibt.

Unsere Theorie sollte es erlauben, aus experimenell bestimmten Kraftspektren von Rezeptor-Ligand-Komplexen, in denen die Dissoziationskraft als Funktion der Zuggeschwindigkeit gemessen wird, Energielandschaften bzw. Kraftprofile, die die Trennung von RezeptorLigand-Bindungen beschreiben, zu rekonstruieren. Auf diese Weise könnte die begrenzte Ortsauflösung der Experimente, die eine direkte Messung von Kraftprofilen bislang nicht zulässt, umgangen und wesentlich detailliertere Informationen über die Energielandschaft bzw. das Kraftprofil gewonnen werden als es bisher experimentell möglich war.

Unsere Theorie ist allgemein in dem Sinne, dass sie im Unterschied zu bisherigen Verfahren keine Voraussetzungen hinsichtlich der Beschaffenheit der Energielandschaft erfordert und das ganze Spektrum von weichen bis zu harten Zugfedern einschließt. Es zeigte sich, dass weiche und harte Zugfedern dabei insofern komplementär wirken, als mit Hilfe der zugehörigen Kraftspektren unterschiedliche Abschnitte in der Energielandschaft bzw. des Kraftprofils rekonstruiert werden können. Damit sollte es möglich sein, einen recht großen Bereich der Energielandschaft und des Kraftprofils zu vermessen, indem verschiedene experimentelle Techniken kraftinduzierender Experimente, etwa BiomembranKraftmessungs-Experimente (weiche Federn) mit kraftmikroskopischen Experimenten (harte Federn), kombiniert werden.

Unsere Dissoziationssimulationen zu AN02-DNP-Hapten lieferten zum einen eine Vorhersage für die aus kraftmikroskopischen Dissoziationsexperimenten erwartete Dissoziationskraft. Auf Grundlage eines einfachen Modells, das durch thermische Fluktuationen getriebene aktivierte Prozesse, Reibung und die spontane Dissoziationsrate berücksichtigt, wurden die auf der Nanosekundenzeitskala berechneten Dissoziationskräfte auf die experimentelle Millisekundenzeitskala interpoliert, woraus sich eine erwartete experimentelle Dissoziationskraft von $65 \pm 25 \mathrm{pN}$ ergab. Zum anderen konnte aus unseren Simulationen ein detailliertes atomares Modell des Dissoziationsprozesses gewonnen werden. Dieses 
zeigt eine ausgeprägte strukturelle Heterogenität der Dissoziationspfade und der damit verbundenen Wechselwirkungen des Haptenmoleküls mit einzelnen Aminosäuren der Bindungstasche. Darüber hinaus haben Dissoziationssimulationen von AN02-Mutanten eine deutliche Konformationsflexibilität der Bindungstasche aufgezeigt. Wir konnten aus unseren Simulationen abschätzen, dass die strukturelle Heterogenität und die Konformationsflexibiltät einen überraschend großen entropischen Beitrag von etwa $4 \mathrm{kcal} / \mathrm{mol}$ zur freien Bindungsenergie des Komplexes von $16 \mathrm{kcal} / \mathrm{mol}$ leisten. Dies legt nahe, dass die Entropie bei der Optimierung der Bindung eine bedeutende Rolle spielt.

Unsere Simulationen zu AN02-Hapten unterstreichen, dass unsere Simulationsmethode sehr gut geeignet ist, auch variantenreiche Dissoziationsprozesse und Bindungsmechanismen von Rezeptor-Ligand-Komplexen zu charakterisieren und in ihnen komplexe Phänomene wie Konformationsflexibiltät und strukturelle Heterogenität zu erfassen. Dies lässt es uns als vielversprechend erscheinen, diese Methode auch auf komplexer aufgebaute Rezeptor-Ligand-Bindungen anzuwenden. Vorarbeiten zu umfangreichen Dissoziationssimulationen zum physiologisch relevanten Antikörper-Antigen-Komplex AntilysozymLysozym wurden vom Autor bereits begonnen.

Unsere Dehnungssimulationen zu dem Polysaccharid Dextran führten zur Vorhersage von zwei unerwarteten Elastizitätsregimes für hohe Zugkräfte, die inzwischen experimentell verifiziert wurden. In Dehnungssimulationen zu den Polysacchariden Cellulose und Amylose sowie zum Polymermolekül Polyethylenglykol (PEG) wurden die experimentell ermittelten elastischen Eigenschaften gut reproduziert. Aus den Simulationen ließen sich Modelle für die atomaren Prozesse ableiten, die die beobachteten Elastizitätscharakteristiken dieser Moleküle bestimmen.

Bei den Polysacchariden lieferten die Simulationen darüber hinaus eine Erklärung auf atomarer Ebene, warum minimale Unterschiede in der molekularen Struktur zu sehr unterschiedlichen Elastizitätscharakteristiken führen können. Die Dehnungssimulationen zu Amylose etwa zeigten, dass durch die Verwendung unterschiedlicher Seitengruppen an den einzelnen Monomeren die elastischen Eigenschaften des Polymers gezielt verändert werden können. Dies eröffnet die Möglichkeit, Materialeigenschaften auf molekularer Basis zu optimieren und neue Materialien mit gewünschten elastischen Eigenschaften herzustellen.

Die Dehnungssimulationen zu PEG erbrachten eine Erklärung auf atomarer Ebene für den aus kraftmikroskopischen Experimenten abgeleiteten Befund, dass PEG im ungestreckten Zustand in Wasser erheblich steifer ist als in einem apolaren Lösungsmittel oder in Gasphase: Im Gegensatz zu apolaren Lösungsmitteln begünstigt Wasser eine helikale Struktur, die durch Wasserbrücken stabilisiert wird und deren Aufbrechen bei der Dehnung des Moleküls einen zusätzlichen Kraftaufwand erfordert.

Unsere Simulationen zu dem Antikörper-Hapten-Komplex sowie zu den Polymermolekülen haben gezeigt, dass unsere Methode zur Simulation kraftinduzierender Einzelmolekülexperimente geeignet ist, Modelle für die atomaren Prozesse wichtiger Vorgänge in biologischen Systemen zu liefern. Inzwischen wurde diese Methode auch eingesetzt, um die forcierte Entfaltung von Proteinen zu simulieren $[61,67]$ und damit insbesondere die ersten Schritte bei der Proteinentfaltung zu charakterisieren. So scheint es absehbar, dass diese Methode einen Beitrag leisten kann, auch hochkomplexe Vorgänge wie den umgekehrten Prozess der Proteinfaltung in größerem Detail zu verstehen als es gegenwärtig der Fall ist. 


\section{Anhang A}

\section{Aminosäuresequenz von AN02}

Abbildung A.1 zeigt die Aminosäuresequenz von AN02 sowie die Positionen der $\beta$-Faltblätter und der hypervariablen Region. In Tabelle A.1 sind die Bezeichnungen der Aminosäuren, die wichtigsten Eigenschaften ihrer Seitengruppen für den pH-Wert 7 sowie ihre relative Häufigkeit in AN02 aufgeführt. Wir unterscheiden zwischen polar (p) und unpolar $(\mathrm{u})$ sowie zwischen positiv $(+)$ und negativ $(-)$ geladen. Für Aminosäuren mit titrierbaren Seitengruppen ist zusätzlich der pK-Wert der Seitenkette angegeben. 


\section{Aminosäuresequenz von AN02}

Leichte Kette:

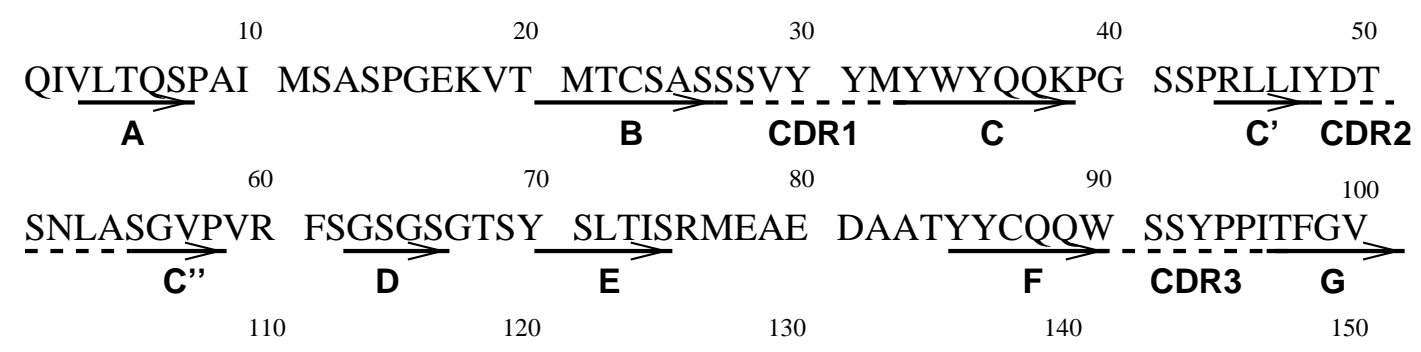

GTKLELKRAD AAPTVSIFPP SSEQLTSGGA SVVCFLNNFY PKDINVKWKI

$\begin{array}{rrrrr}160 & 170 & 180 & 190 & 200 \\ \text { DGSERQNGVL } & \text { NSWTDQDSKD } & \text { STYSMSSTLT } & \text { LTKDEYERHN } & \text { SYTCEATHKT }\end{array}$

210

STSPIVKSFN RNEC

Schwere Kette:

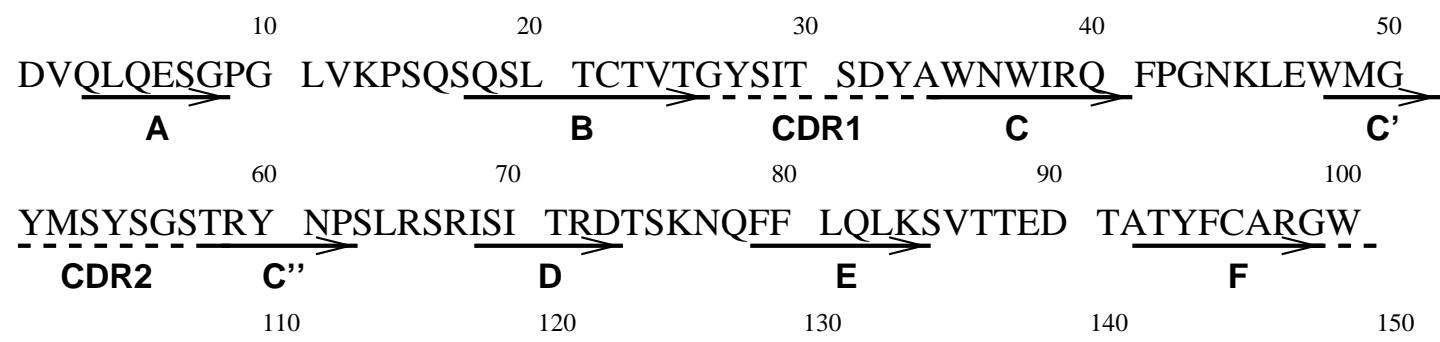

PLAYWGQGTQ VSVSEAKTTP PSVYPLAPGS AAQTNSMVTL GCLVKGYFPE CDR3 G

$180 \quad 190 \quad 200$

PVTVTWNSGS LSSGVHTFPA VLQSDLYTLS SSVTVPSSPR PSETVTCNVA

\section{0 \\ HPASSTKVDK KIVPRDC}

Abbildung A.1: Die Pfeile markieren die in Abbildung 5.2 gezeigten $\beta$-Faltblätter, die gestrichelten Linien die hypervaribalen Schleifen (CDR1 - CDR3), die die Eigenschaften der Bindungstasche bestimmen. Zum Ein-Buchstaben-Code der Aminosäuren siehe Tabelle A.1. 


\section{Eigenschaften der Aminosäuren}

\begin{tabular}{|c|c|c|c|c|c|}
\hline Name & $\begin{array}{l}\text { Aminosäu } \\
\text { 1-Buchstaben- } \\
\text { Symbol }\end{array}$ & $\begin{array}{l}\text { re } \\
\text { 3-Buchstaben } \\
\text { Symbol }\end{array}$ & $\begin{array}{c}\text { Polarität } \\
\text { bei pH } 7\end{array}$ & $\begin{array}{c}\text { Häufigkeit } \\
\text { in AN02 }\end{array}$ & $\begin{array}{c}\mathrm{pK} \text { der } \\
\text { Seitenkette }\end{array}$ \\
\hline Alanin & " $\mathrm{A}$ & " ALA & " u & ב 5.3 & \\
\hline Arginin & $\mathrm{R}$ & ARG & + & 3.5 & 12.5 \\
\hline Asparagin & $\mathrm{N}$ & ASN & $\mathrm{p}$ & 3.7 & \\
\hline Aspartat & D & $\mathrm{ASP}$ & - & 3.7 & 3.9 \\
\hline Cystein & $\mathrm{C}$ & CYS & $\mathrm{p}$ & 2.3 & \\
\hline Glutamin & $\mathrm{Q}$ & GLN & $\mathrm{p}$ & 4.6 & \\
\hline Glutamat & $\mathrm{E}$ & GLU & - & 3.7 & 4.3 \\
\hline Glycin & G & GLY & $\mathrm{p}$ & 6.0 & \\
\hline Histidin & $\mathrm{H}$ & HIS & $\mathrm{p}$ & 0.9 & 6.0 \\
\hline Isoleucin & I & ILE & $\mathrm{u}$ & 3.2 & \\
\hline Leucin & $\mathrm{L}$ & LEU & $\mathrm{u}$ & 6.3 & \\
\hline Lysin & $\mathrm{K}$ & LYS & + & 4.6 & 10.5 \\
\hline Methionin & $\mathrm{M}$ & MET & $\mathrm{u}$ & 1.9 & \\
\hline Phenylalanin & $\mathrm{F}$ & PHE & $\mathrm{u}$ & 2.8 & \\
\hline Prolin & $\mathrm{P}$ & $\mathrm{PRO}$ & $\mathrm{u}$ & 6.7 & \\
\hline Serin & $\mathrm{S}$ & SER & $\mathrm{p}$ & 15.5 & \\
\hline Threonin & $\mathrm{T}$ & THR & $\mathrm{p}$ & 10.2 & \\
\hline Tryptophan & W & TRP & $\mathrm{u}$ & 2.3 & \\
\hline Tyrosin & $\mathrm{Y}$ & TYR & $\mathrm{p}$ & 5.3 & 10.1 \\
\hline Valin & $\mathrm{V}$ & VAL & $\mathrm{u}$ & 7.2 & \\
\hline
\end{tabular}

Tabelle A.1: Bezeichnung und Eigenschaften der 20 Standardaminosäuren [219] sowie deren relative Häufigkeit in AN02. 


\section{Danksagung}

Diese Arbeit wurde am Institut für medizinische Optik der Ludwig-Maximilians-Universität München in der Arbeitsgruppe Theoretische Biophysik begonnen und zum größeren Teil am Max-Planck-Institut für biophysikalische Chemie in der von Dr. Helmut Grubmüller geleiteten Arbeitsgruppe für Theoretische molekulare Biophysik angefertigt. An erster Stelle möchte ich meinem direkten Betreuer, Helmut Grubmüller, besonders danken. Er stand mir während meiner gesamten Promotionszeit mit Rat und Tat zur Seite, brachte mir in ungezählten Diskussionen viele Anregungen und zeigte insbesondere bei den Korrekturen der Arbeit ein Höchstmaß an Geduld mit mir als wenn nicht uneinsichtigen, so doch hartnäckigen Doktoranden. Ihm ist es auch zu verdanken, dass mir ein exzellentes Arbeitsumfeld zur Verfügung stand, wozu eine hervorragende Rechnerausstattung zählt. Darüber hinaus hat mir die mehrjährige Zusammenarbeit großen Spaß gemacht.

Ganz herzlich möchte ich mich auch bei Prof. Dr. Erwin Neher bedanken, der sich nach meinem Wechsel von München nach Göttingen sofort bereit erklärte, die Doktorvaterschaft meiner Arbeit zu übernehmen und es mir damit ermöglichte, an der Universität Göttingen zu promovieren. Ich danke Prof. Neher auch für wertvolle Hinweise, die er mir bei der Korrektur der Arbeit gab.

Ebenso bin ich den Mitarbeitern unserer Gruppe zu Dank verpflichtet. Sie trugen alle zu einer sehr angenehmen Atmosphäre bei, in der es stets möglich war, Fragen und Probleme wissenschaftlicher wie technischer Art aufzuwerfen und sogar konstruktive Antworten zu erhalten. Darüber hinaus bin ich allen dankbar für das kritische Korrekturlesen, das zu einer deutlichen Verringerung inhaltlicher und orthografischer Fehler führte. Im Einzelnen bedanke ich mich bei Rainer Böckmann, Dr. Bert de Groot, Peer Geisendorf, unserer Sekretärin Eveline Heinemann, Volker Knecht, Dr. Peer Koch, Matthias Müller, Gunnar Schröder und Dr. Holger Wagner.

Großer Dank gebührt ebenfalls Dr. Matthias Rief (Stanford), Hongbin Li (Rochester) und Filipp Oesterhelt, die an dem von Prof. Dr. Hermann Gaub geleiteten Lehrstuhl für Angewandte Physik der Ludwig-Maximilians-Universität München die kraftmikroskopischen Dehnungsexperimente an den Polysacchariden und an Polyethylenglykol (Filipp Oesterhelt) durchgeführt haben, sowie Dr. Wolfgang Dettmann und Angelika Wehle, die die Messungen zu dem AN02-Antikörper-Hapten-Komplex vornehmen. Ich danke allen für eine aus meiner Sicht überaus fruchtbare und erfolgreiche Zusammenarbeit.

Ein persönlicher Dank gilt nicht zuletzt meinen Eltern, die einen wesentlichen Teil dazu beigetragen haben, dass ich unbeschwert studieren und promovieren konnte, und vielen Freunden, die mir alle zusammen ein sehr angenehmes und wichtiges Umfeld schufen. 


\section{Literaturverzeichnis}

[1] S. Khan and M. P. Sheetz. Force effects on biochemical kinetics. Ann. Rev. Biochem., 66:785-805, 1997.

[2] P. S. Stayton. May the force be with you. Nature (London), 397:20-21, 1999.

[3] J. T. Finer, R. M. Simmons, and J. A. Spudich. Single myosin molecule mechanics: piconewton forces and nanometre steps. Nature (London), 368:113-119, 1994.

[4] H. Yin, M. D. Wang, K. Svoboda, R. Landick, S. M. Block, and J. Gelles. Transcription against an applied force. Science, 270:1653-1657, 1995.

[5] S. C. Schuster and S. Khan. The bacterial flagellar motor. Ann. Rev. Biophys. Biomol. Struct., 23:509-539, 1994.

[6] S. B. Smith, L. Finzi, and C. Bustamente. Direct mechanical measurements of the elasticity of single DNA molecules by using magnetic beads. Science, 258:1122-1126, 1992.

[7] M. Rief, M. Gautel, F. Oesterhelt, J. M. Fernandez, and H. E. Gaub. Reversible unfolding of indinvidual titin Ig-domains by AFM. Science, 276:1109-1112, 1997.

[8] H. P. Erickson. Stretching single protein molecules: titin is a weird spring. Science, 276:1090-1092, 1997.

[9] M. S. Z. Kellermayer, S. B. Smith, H. L. Granzier, and C. Bustamante. Folding-unfolding transitions in single titin molecules characterized with laser tweezers. Science, 276:11121116, 1997.

[10] M. S. Z. Kellermayer, S. B. Smith, C. Bustamente, and H. L. Granzier. Complete unfolding of the titin molecule under external force. J. Struct. Biol., 122:197-205, 1998.

[11] L. Tskhovrebova, J. Trinck, J. A. Sleep, and R. M. Simmons. Elasticity and unfolding of single molecules of the giant muscle protein titin. Nature (London), 387:308-312, 1997.

[12] S. Smith, Y. Cui, and C. Bustamente. Overstretching B-DNA: the elastic response of individual double-stranded and single-stranded DNA molecules. Science, 271:795-799, 1996.

[13] D. Bensimon, A. J. Simon, V. Croquette, and A. Bensimon. Stretching DNA with a receding meniscus - experiments and models. Phys. Rev. Lett., 74(23):4754-4757, 1995.

[14] M. Carrion-Vazquez, A. F. Oberhauser, S. B. Fowler, P. E. Marszalek, J. Clarke, and J. M. Fernandez. Mechanical and chemical unfolding of a single protein: a comparison. Proc. Natl. Acad. Sci. USA, 96(7):3694-3699, 1999. 
[15] P. Marszalek, H. Lu, H. Li, M. Carrion-Vazquez, A. F. Oberhauser, K. Schulten, and J. M. Fernandez. Mechanical unfolding intermediates in titin modules. Nature (London), 402:100-103, 1999.

[16] M. Rief, J. Pascual, M. Saraste, and H. Gaub. Single molecule force spectroscopy of spectrin repeats: low unfolding forces in helix bundles. J. Mol. Biol., 286:553-561, 1999.

[17] M. Rief, F. Oesterhelt, B. Heymann, and H. E. Gaub. Single molecule force spectroscopy reveals conformational change in polysaccharides. Science, 275:1295-1297, 1997.

[18] H. Li, M. Rief, F. Oesterhelt, and H. E. Gaub. Single molecule force spectroscopy on xanthan by AFM. Advanced Materials, 3(4):316-319, 1998.

[19] H. Li, W. Zhang, X. Zhang, J. Shen, B. Liu, C. Gao, and G. Zou. Single molecule force spectroscopy on poly(vinyl alcohol) by atomic force microscopy. Macromol. Rapid Commun., 19:609-611, 1998.

[20] A. F. Oberhauser, P. E. Marszalek, H. P. Erickson, and J. M. Fernandez. The molecular elasticity of the extracellular matrix protein tenascin. Nature (London), 393:181-185, 1998.

[21] P. E. Marszalek, A. F. Oberhauser, Y. P. Pang, and J. M. Fernandez. Polysaccharide elasticity governed by chair-boat transitions of the glucopyranose ring. Nature (London), 396:661-664, 1998.

[22] H. Li, M. Rief, F. Oesterhelt, H. E. Gaub, X. Zhang, and J. Shen. Single-molecule force spectroscopy on polysaccharides by AFM - nanomechanical fingerprint of $\alpha$-(1,4)-linked polysaccharides. Chem. Phys. Lett., 305:197-201, 1999.

[23] H. Li, B. Liu, X. Zhang, C. Gao, J. Shen, and G. Zou. Single-molecule force spectroscopy on poly(acrylic acid) by AFM. Langmuir, 15:2120-2124, 1999.

[24] F. Oesterhelt, M. Rief, and H. E. Gaub. Single molecule force spectroscopy by AFM indicates helical structure of poly(ethylene-glycol) in water. New Journal of Physics, 1:6.1-6.11, 1999 .

[25] E.-L. Florin, V. T. Moy, and H. E. Gaub. Adhesion forces between individual ligandreceptor pairs. Science, 264:415-417, 1994.

[26] V. T. Moy, E.-L. Florin, and H. E. Gaub. Intermolecular forces and energies between ligands and receptors. Science, 266:257-258, 1994.

[27] G. U. Lee, D. A. Kidwell, and R. J. Colton. Sensing discrete streptavidin-biotin interactions with atomic force microscopy. Langmuir, 10:354-357, 1994.

[28] A. Chilkoti, P. H. Tan, and P. S. Stayton. Site-directed mutagenesis studies of the highaffinity streptavidin-biotin complex: Contributions of tryptophan residues 79, 108 and 120. Proc. Natl. Acad. Sci. USA, 92:1754-1758, 1995.

[29] U. Dammer, O. Popescu, P. Wagner, D. Anselmetti, and H.-J. Güntherodt. Binding strength between cell-adhesion proteoglycans measured by atomic-force microscopy. Science, 267:1173-1175, 1995.

[30] U. Dammer, M. Hegner, D. Anselmetti, P. Wagner, M. Dreier, W. Huber, and H.-J. Güntherodt. Specific antigen/antibody interactions measured by force microscopy. Biophys. J., 70:2437-2441, 1996. 
[31] P. Hinterdorfer, W. Baumgartner, H. J. Gruber, K. Schlicher, and H. Schindler. Detection and localizaton of individual antibody-antigen recognition events by atomic force microscopy. Proc. Natl. Acad. Sci. USA, 93:3477-3481, 1996.

[32] R. Ros, F. Schwesinger, D. Anselmetti, M. Kubon, R. Schäfer, A. Plückthun, and L. Tiefenauer. Antigen binding forces of individually addressed single-chain $F_{\mathrm{v}}$ antibody molecules. Proc. Natl. Acad. Sci. USA, 95:7402-7405, 1998.

[33] J. Fritz, A. G. Katopodis, F. Kolbinger, and D. Anselmetti. Force-mediated kinetics of single P-selectin ligand complexes observed by atomic force microscopy. Proc. Natl. Acad. Sci. USA, 95:12283-12288, 1998.

[34] J. K. Stuart and V. Hlady. Feasibility of measuring antigen-antibody interaction forces using a scanning force microscope. Colloid Surface B, 15:37-55, 1999.

[35] M. H. F. Wilkins, R. G. Gosling, and W. E. Seeds. Nucleic acid: an extensible molecule? Nature (London), 167:759-760, 1951.

[36] M. H. F. Wilkins, A. R. Stokes, and H. R. Wilson. Molecular structure of deoxypentose nucleic acids. Nature (London), 171:738-740, 1953.

[37] P. Cluzel, A. Lebrun, C. Heller, R. Lavery, J. L. Viovy, D. Chatenay, and F. Caron. DNA: an extensible molecule. Science, 271:792-794, 1996.

[38] J. M. Williams, T. Hon, and T. P. Beebe Jr. Determination of single-bond forces from contact force variances in atomic force microscopy. Langmuir, 12:1291-1295, 1996.

[39] D. Bensimon. Force: a new structural control parameter? Structure, 4:885-889, 1996.

[40] G. Binnig, C. F. Quate, and C. H. Gerber. Atomic force microscope. Phys. Rev. Lett., 56:930-933, 1986.

[41] D. Rugar and P. Hansma. Atomic force microscopy. Phys. Today, 43(10):23-30, 1990.

[42] M. B. Viani, T. E. Schäffer, A. Chand, M. Rief, H. E. Gaub, and P. K. Hansma. Small cantilevers for force spectroscopy of single molecules. J. Appl. Phys., 86(4):2258-2262, 1999.

[43] F. Reif. Fundamentals of Statistical Mechanics. McGraw-Hill Book Company, San Francisco, 1965.

[44] A. Chilkoti and P. S. Stayton. Molecular origins of the slow streptavidin-biotin dissociation kinetics. J. Am. Chem. Soc., 117:10622-10628, 1995.

[45] M. Levitt and S. Lifson. Refinement of protein conformation using a macromolecular energy minimization procedure. J. Mol. Biol., 46:269-279, 1969.

[46] W. F. van Gunsteren and H. J. C. Berendsen. Algorithms for macromolecular dynamics and constraint dynamics. Mol. Phys., 34(5):1311-1327, 1977.

[47] M. Karplus and D. L. Weaver. Protein folding dynamics. Nature (London), 260:404-406, 1976.

[48] J. A. McCammon, B. R. Gelin, and M. Karplus. Dynamics of folded proteins. Nature (London), 267:585-590, 1977. 
[49] H. J. C. Berendsen. Bio-molecular dynamics comes of age. Science, 271:954-955, 1996.

[50] D. A. Pearlman and P. A. Kollman. Free Energy Perturbation Calculations: Problems and Pitfalls along the Gilded Road, pages 101-119. ESCOM, Leiden, 1989.

[51] R. Elber. Calculation of the potential of mean force using molecular dynamics with linear constraints: An application to a conformational transition in a solvated dipeptide. $J$. Chem. Phys., 93(6):4312-4321, 1990.

[52] D. E. Smith and D. J. Haymet. Free energy, entropy, and internal energy of hydrophobic interactions: Computer simulations. J. Chem. Phys., 98:6445-6454, 1993.

[53] P. A. Kollman. Free energy calculations: Applications to chemical and biochemical phenomena. Chem. Rev., 93:2395-2417, 1993.

[54] I. Massova and P.A. Kollman. Computational alanine scanning to probe protein-protein interactions: A novel approach to evaluate binding free energies. J. Am. Chem. Soc., 121(36):8133-8143, 1999.

[55] H. Grubmüller, B. Heymann, and P. Tavan. Ligand binding: Molecular mechanics calculation of the streptavidin-biotin rupture force. Science, 271(5251):997-999, 1996.

[56] B. Heymann. Beschreibung der Streptavidin-Biotin-Bindung mit Hilfe von Molekulardynamiksimulationen. Master's thesis, Ludwig-Maximilians-Universität München, 1996.

[57] M. W. Konrad and J. I. Bolonick. Simulation of DNA stretching. J. Am. Chem. Soc., 118:10986-10994, 1996.

[58] S. Izrailev, S. Stepaniants, M. Balsera, Y. Oono, and K. Schulten. Molecular dynamics study of unbinding of the avidin-biotin complex. Biophys. J., 72:1568-1581, 1997.

[59] B. Isralewitz, S. Izrailev, and K. Schulten. Binding pathway of retinal to bacterio-opsin: a prediction by molecular dynamics simulations. Biophys. J., 73:2972-2979, 1997.

[60] S. Stepaniants, S. Izrailev, and K. Schulten. Extraction of lipids from phospholipid membranes by steered molecular dynamics. J. Mol. Model., 3:473-475, 1997.

[61] H. Lu, B. Isralewitz, A. Krammer, V. Vogel, and K. Schulten. Unfolding of titin immunoglobulin domains by steered molecular dynamics simulation. Biophys. J., 75:662-671, 1998.

[62] S. Marrink, O. Berger, P. Tieleman, and F. Jähnig. Adhesion forces of lipids in a phospholipid membrane studied by molecular dynamics simulations. Biophys. J., 74:931-943, 1998.

[63] D. Kosztin, S. Izrailev, and K. Schulten. Unbinding of retinoic acid from its receptor studied by steered molecular dynamics. Biophys. J., 76(1):188-197, 1999.

[64] H. Lu and K. Schulten. Steered molecular dynamics simulations of force-induced protein domain unfolding. Proteins, 35(4):453-463, 1999.

[65] H. Lu and K. Schulten. Steered molecular dynamics simulations of conformational changes of immunoglobulin domain I27 interpret atomic force microscopy observations. Chem. Phys., 247(1):141-153, 1999. 
[66] W. Wriggers and K. Schulten. Investigating a back door mechanism of actin phosphate release by steered molecular dynamics. Proteins, 35(2):262-273, 1999.

[67] A. Krammer, H. Lu, B. Isralewitz, K. Schulten, and V. Vogel. Forced unfolding of the fibronectin type III module reveals a tensile molecular recognition switch. Proc. Natl. Acad. Sci. USA, 96:1351-1356, 1999.

[68] B. Heymann and H. Grubmüller. AN02/DNP unbinding forces studied by molecular dynamics AFM simulations. Chem. Phys. Lett., 303:1-9, 1999.

[69] B. Heymann and H. Grubmüller. 'Chair-boat' transitions and side groups affect the stiffness of polysaccharides. Chem. Phys. Lett., 305:202-208, 1999.

[70] B. Heymann and H. Grubmüller. Elastic properties of poly(ethylene-glycol) studied by molecular dynamics stretching simulations. Chem. Phys. Lett., 307:425-432, 1999.

[71] M. Eichinger, B. Heymann, H. Heller, H. Grubmüller, and P. Tavan. Conformational dynamics simulations of proteins. In S. Reich and P. Deuflhard, editors, Lecture Notes in Computational Science and Engineering Vol 4: Algorithms for Macromolecular Modelling, pages 78-97. Springer, 1998.

[72] S. Izrailev, S. Stepaniants, B. Isralewitz, D. Kosztin, H. Lu, F. Molnar, W. Wriggers, and K. Schulten. Steered molecular dynamics. In S. Reich and P. Deuflhard, editors, Lecture Notes in Computational Science and Engineering Vol 4: Algorithms for Macromolecular Modelling, pages 39-65. Springer, 1998.

[73] A. Ashkin. Applications of laser radiation pressure. Science, 210:1081-1088, 1980.

[74] A. Ashkin, K. Schutze, J. M. Dziedzic, U. Euteneuer, and M. Schliwa. Force generation of organelle transport measured invivo by an infrared-laser trap. Nature (London), 348:346348, 1990.

[75] T. T. Perkins, D. E. Smith, and S. Chu. Direct observation of tube-like motion of a single polymer chain. Science, 264:819-822, 1994.

[76] F. Amblard, B. Yurke, A. Pargellis, and S. Leiber. A magnetic manipultor for studying local rheology and micromechanical properties of biological systems. Rev. Sci. Instr., 67(3):818-827, 1996.

[77] E. Evans, K. Ritchie, and R. Merkel. Sensitive force technique to probe molecular adhesion and structural linkages at biological interfaces. Biophys. J., 68:2580-2587, 1995.

[78] D. J. Leahy, T. R. Hynes, H. M. McConnell, and R. O. Fox. Crystallization of an anti2,2,6,6-tetramethyl-1-piperidinyoxyl-dinitrophenyl monoclonal antibody $\mathrm{f}_{\mathrm{ab}}$ fragment with and without bound hapten. J. Mol. Biol., 203:829-830, 1988.

[79] D. J. Leahy, G. S. Rule, M. M. Whittaker, and H. M. McConnell. Sequences of 12 monoclonal anti-dinitrophenyl spin-label antibodies for NMR studies. Proc. Natl. Acad. Sci. USA, 85:3661-3665, 1988.

[80] G. J. Wedemayer, P. A. Patten, L. H. Wang, P. G. Schultz, and R. C. Stevens. Structural insights into the evolution of an antibody combining site. Science, 276:1665-1669, 1997.

[81] P. Molyneux (Editor). Water Soluble Polymers, Synthetic Polymers: Properties and Uses. CRC Press, Boca Raton, 1983. 
[82] J. M. Harris. Poly(ethylene glycol) chemistry. Plenum Press, New York, 1992.

[83] R. Merkel, P. Nassoy, A. Leung, K. Ritchie, and E. Evans. Energy landscapes of receptorligand bonds explored with dynamic force spectroscopy. Nature (London), 397:50-53, 1999.

[84] E. Evans. Energy landscapes of biomolecular adhesion and receptor anchoring at interfaces explored with dynamic force spectroscopy. Faraday Discuss., 111:1-16, 1998.

[85] C. Yuan, A. Chen, P. Kolb, and V. T. Moy. Dynamic strength of ligand-receptor-complexes measured by atomic force microscopy, 1999. Eingesandt.

[86] G. I. Bell. Models for the specific adhesion of cells to cell. Science, 200:618-627, 1978.

[87] H. P. Erickson. Reversible unfolding of fibronectin type III and immunoglobulin domains provides the structural basis for stretch and elasticity of titin and fibronectin. Proc. Natl. Acad. Sci. USA, 91:10114-10118, 1994.

[88] E. Evans and K. Ritchie. Dynamic strength of molecular adhesion bonds. Biophys. J., 72:1541-1555, 1997.

[89] W. F. van Gunsteren and H. J. C. Berendsen. Computer simulation of molecular dynamics: Methodology, applications, and perspectives in chemistry. Angew. Chem. Int. Ed. Engl., 29:992-1023, 1990.

[90] P. W. Atkins. Molecular Quantum Mechanics. Oxford University Press, Oxford, 2nd edition, 1983.

[91] H. Haken and H. C. Wolf. Molekülphysik und Quantenchemie. Springer-Verlag, Berlin, 1991.

[92] A. Warshel. The consistent force field and its quantum mechanical extensions. In G. A. Segal, editor, Semiempirical Methods of Electronic Structure Calculation, Part A: Techniques, New York, 1977. Plenum Press.

[93] B. R. Brooks, R. E. Bruccoleri, B. D. Olafson, D. J. States, S. Swaminathan, and M. Karplus. CHARMM: A program for macromolecular energy, minimization, and dynamics calculations. J. Comput. Chem., 4(2):187-217, 1983.

[94] W. F. van Gunsteren and H. J. C. Berendsen. GROMOS Manual. BIOMOS b.v., Biomolecular Software, Groningen, The Netherlands.

[95] S. J. Weiner, P. A. Kollman, D. A. Case, U. C. Singh, C. Ghio, G. Alagona, S. Profeta Jr., and P. Weiner. A new force field for molecular mechanical simulation of nucleic acids and proteins. J. Am. Chem. Soc., 106:765-784, 1984.

[96] S. J. Weiner, P. A. Kollman, D. T. Nguyen, and D. A. Case. An all atom force field for simulations of proteins and nucleic acids. J. Comput. Chem., 7(2):230-252, 1986.

[97] A. Wallquist and G. Karlström. A new non-empirical force field for computer simulations. Chem. Scr., 29A, 1989.

[98] N. L. Allinger, Y. H. Yuh, and J. H. Lii. Molecular mechanics - the MM3 force-field for hydrocarbons. J. Am. Chem. Soc., 111(23):8551-8566, 1989. 
[99] N. L. Allinger, K. S. Chen, and J. H. Lii. An improved force field (MM4) for saturated hydrocarbons. J. Comput. Chem., 17(5-6):642-668, 1996.

[100] W. L. Jorgensen, D. S. Maxwell, and J. Tirado Rives. Development and testing of the OPLS all-atom force field on conformational energetics and properties of organic liquids. J. Am. Chem. Soc., 118:11225-11236, 1996.

[101] K. Rasmussen. Conformation and anomer ratio of D-glucosepyranose in different potentialenergy functions. Acta Chem. Scand. A, 36(4):323-327, 1982.

[102] S. Reiling, M. Schlenkirch, and J. Brickmann. Force field parameters for carbohydrates. J. Comput. Chem., 17:450-468, 1996.

[103] J. R. Maple, M. J. Hwang, T. P. Stockfisch, U. Dinur, M. Waldman, C. S. Ewig, and A. T. Hagler. Derivation of class-II-force fields. 1. Methodology and quantum force-field for the alkyl functional-group and alcane molecules. J. Comput. Chem., 15(2):162-182, 1994.

[104] H. Sun, S. J. Mumby, J. R. Maple, and A. T. Hagler. An ab-initio CFF93 all-atom force-field for polycarbonates. J. Am. Chem. Soc., 116(7):2978-2987, 1994.

[105] T. A. Halgren. MMFF VII. characterization of MMFF94, MMFF94s, and other widely available force fields for conformational energies anf for intermolecular-interaction energies and geometries. J. Comput. Chem., 20(7):730-748, 1999.

[106] E. J. Nystrøm. Über die numerische Integration von Differentialgleichungen. Acta Soc. Sci. Fenn., 50(13):1-54, 1925.

[107] L. Verlet. Computer 'experiments' on classical fluids. I. Thermodynamical properties of Lennard-Jones molecules. Physical Review, 159(1):98-103, 1967.

[108] W. H. Press, B. P. Flannery, S. A. Teukolsky, and W. T. Vetterling. Numerical Recipes in C. Cambridge University Press, Cambridge, 1988.

[109] R. H. Miller. A horror story about integration methods. J. Chem. Phys., 93:469-476, 1991.

[110] Molecular Simulations Inc. 1986-1998, University of York, York, England. QUANTA97.

[111] Molecular Simulations Inc. 1986-1998, University of York, York, England. Insight II (97.2).

[112] Cray Research Inc., 655 Lone Oak Drive, Eagan, Minnespta 55151. UniChem 3.0, 1997.

[113] Institut für Molekularbiologie und Biophysik, ETH Zürich, Fällanden, Switzerland. $M O L-$ MOL 2.6.

[114] F. C. Bernstein, T. F. Koetzle, G. J. B. Williams, E. F. Meyer, M. D. Brice, J. R. Rodgers, O. Kennard, T. Shimanouchi, and M. J. Tasumi. The protein data bank: A computerbased archival file for molecular structures. J. Mol. Biol., 112(3):535-542, 1977.

[115] M. Eichinger. Paralleler Fast-Multipol-Algorithmus mit multipler Schrittlänge zur Simulation von Langzeit-Proteindynamik. Master's thesis, Ludwig-Maximilians-Universität München, 1995.

[116] M. Eichinger, H. Grubmüller, and H. Heller. User Manual for EGO_VIII, Release 2.0. electronic access: http://www.mpibpc.gwdg.de/abteilungen/071/ego.html. 
[117] M. Eichinger, H. Grubmüller, H. Heller, and P. Tavan. FAMUSAMM: A new algorithm for rapid evaluation of electrostatic interaction in molecular dynamics simulations. J. Chem. Phys., 18:1729-1749, 1997.

[118] J. P. Ryckaert, G. Ciccotti, and H. J. C. Berendsen. Numerical integration of the cartesian equations of motion of a system with constraints: Molecular dynamics of n-alkenes. $J$. Comput. Phys., 23:327-341, 1977.

[119] W. F. van Gunsteren and M. Karplus. Effects of constraints one the dynamics of macromolecules. Macromolecules, 15:1528-1544, 1982.

[120] O. Teleman and B. Jönsson. Vectorizing a general purpose molecular dynamics simulation program. J. Comput. Chem., 7(1):58-66, 1986.

[121] J. E. Mertz, D. J. T., C. L. Brooks, and U. C. Singh. Vector and parallel algorithms for the molecular dynamics simulation of macromolecules on shared-memory computers. $J$. Comput. Chem., 12(10):1270-1277, 1991.

[122] N. S. Ostlund and R. A. Whiteside. A machine architecture for molecular dynamics: the systolic loop. In B. Venkataraghavan and R. J. Feldman, editors, Macromolecular Structure and Specificity: Computer-Assisted Modeling and Applications, pages 195-208. Annals of the N. Y. Acad. of Sciences 439, New York, 1985.

[123] D. C. Rapaport. Large-scale molecular dynamics simulation using vector and parallel computers. Computer Physics Reports, 9:1-53, 1988.

[124] H. Grubmüller. Dynamiksimulation sehr großer Makromoleküle auf einem Parallelrechner. Master's thesis, Technische Universität München, 1989.

[125] H. Heller, H. Grubmüller, and K. Schulten. Molecular dynamics simulation on a parallel computer. Mol. Sim., 5:133-165, 1990.

[126] E. D. Brooks III. Massive parallelism overcomes shared-memory limitations. Computers in Physics, 6(2):139-145, 1992.

[127] Bernhard R. Brooks and Milan Hodošcek. Parallelization of CHARMM for MIMD machines. Chem. Des. Autom. News, 7(12):16-22, 1992.

[128] W. Scott, A. Gunzinger, B. Bäumle, P. Kohler, U. A. Müller, H-R. Von der Mühll, A. Eichenberger, W. Guggenbühl, N. Ironmonger, F. Müller-Plathe, and W. F. van Gunsteren. Parallel molecular dynamics on a multi signalprocessor system. Computer Phys. Comm., 75(1-2):65-86, 1993.

[129] K.-T. Lim, S. Brunett, M. Iotov, R. B. McClurg, N. Vaidehi, S. Dasgupta, S. Taylor, and W. A. Goddard III. Molecular dynamics for very large systems on massively parallel computers: The MPSim program. J. Comput. Chem., 18(4):501-521, 1997.

[130] C. L. Brooks III, B. M. Pettitt, and M. Karplus. Structural and energetic effects of truncating long ranged interactions in ionic and polar fluids. J. Chem. Phys., 83(11):58975908,1985 .

[131] R. J. Loncharich and B. R. Brooks. The effects of truncating long-range forces on protein dynamics. Proteins, 6:32-45, 1989. 
[132] M. Saito. Molecular dynamics simulations of proteins in water without the truncation of long-range coulomb interactions. Mol. Sim., 8:321-333, 1992.

[133] H. Schreiber and O. Steinhauser. Cutoff size does strongly influence molecular dynamics results on solvated polypeptides. Biochemistry, 31:5856-5860, 1992.

[134] R. C. Y. Chin, G. W. Hedstrom, and F. A. Howes. Considerations on Solving Problems with Multiple Scales, chap. 1, pages 1-27. Academic Press, Orlando, Florida, 1st edition, 1985.

[135] A. Ahmad and L. Cohen. A numerical integration scheme for the $N$-body gravitational problem. J. Comput. Phys., 12:389-402, 1973.

[136] W. B. Streett, D. J. Tildesley, and G. Saville. Multiple time step methods in molecular dynamics. Mol. Phys., 35:639-648, 1978.

[137] Z. Jackiewicz. Quasilinear multistep methods and variable step predictor-corrector methods for neutral functional differential equations. SIAM J. Numer. Anal., 23(2):423-452, 1986.

[138] G. D. Quinlan and S. Tremaine. Symmetric multistep methods for the numerical integration of planetary orbits. Astron. J., 100(5):1694-1700, 1990.

[139] H. Grubmüller and P. Tavan. Multiple time step algorithms for molecular dynamics simulations of proteins: How good are they? J. Comput. Chem., 19:1534-1552, 1998.

[140] H. Grubmüller. Molekulardynamik von Proteinen auf langen Zeitskalen. PhD thesis, Technische Universität München, 1994.

[141] A. W. Appel. An efficient program for many-body simulation. Siam J. Sci. Stat. Comput., $6: 85-103,1985$.

[142] J. Barnes and P. Hut. A hierarchical $O(N \log N)$ force-calculation algorithm. Nature (London), 324:446-449, 1986.

[143] L. Greengard and V. Rokhlin. A fast algorithm for particle simulations. J. Comput. Phys., 73:325-348, 1987.

[144] L. Greengard and V. Rokhlin. On the evaluation of electrostatic interactions in molecular modeling. Chem. Scr., 29A:139-144, 1989.

[145] H.-Q. Ding, N. Karasawa, and W. A. Goddard III. The reduced cell multipole method for coulombic interactions in periodic systems with million-atom unit cells. Chem. Phys. Lett., 196(1,2):6-10, 1992.

[146] C. Niedermeier. Modellierung elektrostatischer Wechselwirkungen in Proteinen: Eine strukturadaptierte Multipolmethode. PhD thesis, Ludwig-Maximilians-Universität, München, 1995.

[147] D. Beglov and B. Roux. Finite representaton of an infinite bulk system: Solvent boundary potential for computer simulations. J. Chem. Phys., 100:9050, 1994.

[148] A. Kitao, F. Hirata, and N. Gō. Effects of solvent on the conformation and the collective motions of a protein. 2. Structure of hydration in melittin. J. Phys. Chem., 97:1022310230, 1993. 
[149] H. Nakamura and S. Nishida. Numerical calculations of electrostatic potentials of proteinsolvent systems by the self consistent boundary method. J. Phys. Soc. Jpn., 56:1609-1622, 1987.

[150] A. Warshel. Dynamics of enzymatic reactions. Proc. Natl. Acad. Sci. USA, 81:444-448, 1984.

[151] David J. E. Callaway. Solvent-induced organization: A physical model of folding myoglobin. Proteins, 20:124-138, 1994.

[152] S. C. Harvey. Treatment of electrostatic effects in macromolecular modeling. Proteins, 5:78-92, 1989.

[153] C. Niedermeier and K. Schulten. Molecular dynamics simulation in heterogeneous dielectrica and Debye-Hückel media - application to the protein bovine pancreatic trypsin inhibitor. Mol. Sim., 8(6):361-387, 1992.

[154] W. F. van Gunsteren, P. K. Weiner, and A. J. Wilkinson, editors. Methods for the evaluation of long range electrostatic forces in computer simulatios of molecular systems, pages 182-212. ESCOM, Leiden, 1993.

[155] M. E. Davis. The inducible multipole solvation model: A new model for solvation effects on solute electrostatics. J. Chem. Phys., 100(7):5149-5159, 1994.

[156] H. Sklenar, F. Eisenhaber, M. Poncin, and R. Lavery. Including solvent and counterion effects in the force field of macromolecular mechanics: the field integrated electrostatic approach (FIESTA). In D. L. Beveridge and R. Lavery, editors, Theoretical Biochemistry \& Molecular Biophysics, pages 317-335. Adenine Press, New York, 1990.

[157] M. Schäfer and C. Frömmel. A precise analytical method for calculating the electrostatic energy of macromolecules in aqueous solution. J. Mol. Biol., 216:1045-1066, 1990.

[158] B. Egwolf. Effiziente Beschreibung der Elektrostatik von Proteinen in ionenhaltigem Wasser. Master's thesis, Ludwig-Maximilians-Universität München, 1998.

[159] R. M. Levy, M. Karplus, and J. A. McCammon. Diffusive Langevin dynamics of model alkanes. Chem. Phys. Lett., 65(1):4-11, 1979.

[160] M. E. Tuckerman and B. J. Berne. Stochastic molecular dynamics in systems with multiple time scales and memory friction. J. Chem. Phys., 95(6):4389-4396, 1991.

[161] R. Brustein, S. Marianer, and M. Schwartz. Langevin memory kernel and noise from Lagrangian dynamics. Physica A, 175:47-58, 1991.

[162] F. H. Stillinger and A. Rahman. Improved simulation of liquid water by molecular dynamics. J. Chem. Phys., 60(4):1545-1557, 1974.

[163] O. Matsuoka, E. Clementi, and M. Yoshimine. CL study of water dimer potential surface. J. Am. Chem. Soc., 64(4):1351-1361, 1976.

[164] W. L. Jorgensen, J. Chandrasekhar, J. D. Madura, R. W. Impey, and M. L. Klein. Comparison of simple potential functions for simulating liquid water. J. Phys. Chem., 79:926, 1983. 
[165] A. Brünger. X-PLOR. The Howard Hughes Medical Institute and Department of Molecular Biophysics and Biochemistry, Yale University, version 3.1 edition, 1992.

[166] X. Daura, B. Jaun, D. Seebach, W. F. van Gunsteren, and A. E. Mark. Reversible peptide unfolding in solution by molecular dynamics simulations. J. Mol. Biol., 280:925-932, 1998.

[167] M. Berkowitz and J. A. McCammon. Molecular dynamics with stochastic boundary conditions. Chem. Phys. Lett., 90:215-217, 1982.

[168] C. L. Brooks III and M. Karplus. Deformable stochastic boundaries in molecular dynamics. J. Chem. Phys., 79:6312-6325, 1983.

[169] A. Brünger, C. L. Brooks III, and M. Karplus. Stochastic boundary conditions for molecular dynamics simulations of ST2 water. Chem. Phys. Lett., 105:495-500, 1984.

[170] R. Kossmann. Entwicklung eines effektiven Randpotentials für Molekulardynamiksimulationen wäßriger Lösungen. Master's thesis, Ludwig-Maximilians-Universität München, 1997.

[171] H. Mori. Transport, collective motion, and brownian motion. Prog. Theor. Phys., 33(3):423-455, 1965.

[172] H. J. C. Berendsen, J. P. M. Postma, W. F. van Gunsteren, A. Dinola, and J. R. Haak. Molecular dynamics with coupling to an external bath. J. Chem. Phys., 81(8):3684-3690, 1984.

[173] B. Heymann. Untersuchungen zum Sbound-Potenzial. (nicht veröffentlicht), 1997.

[174] H. Grubmüller. Solvate: A program to create atomic solvent models, 1996. (electronic publication, http://www.mpibpc.gwdg.de/abteilungen/071/hgrub/solvate/docu.html).

[175] J. D. Jackson. Classical Electrodynamics. John Wiley \& Sons, Inc., New York, 1975.

[176] J. H. Hoh, J. P. Cleveland, C. B. Prater, J.-P. Revel, and P. K. Hansma. Quantized adhesion detected with the atomic force microscope. J. Am. Chem. Soc., 114:4917-4918, 1992.

[177] M. Pierce, J. Stuart, A. Pungor, P. Dryden, and V. Hlady. Adhesion force measurements using an atomic force microscope with a linear position sensitive detector. Langmuir, 10:3217-3221, 1994.

[178] A. Chilkoti, T. Boland, B. D. Ratner, and P. S. Stayton. The relationship between ligandbinding thermodynamics and protein-ligand interaction forces measured by atomic force microscopy. Biophys. J., 69:2125-2130, 1995.

[179] J. K. Stuart and V. Hlady. Effects of discrete protein surface interactions in scanning force microscopy adhesion force measurements. Langmuir, 11(4):1368-1374, 1995.

[180] S. Allen, X. Chen, J. Davies, M.C. Davies, A. C. Dawkes, J. C. Edwards, C. J. Roberts, J. Sefton, S. J. B. Tendler, and P. M. Williams. Detection of antigen-antibody binding events with atomic force microscope. Biochemistry, 36:7457-7463, 1997.

[181] Y.S. Lo, N.D. Huefner, W.S. Chan, F. Stevens, J.M. Harris, and T.P. Beebe. Specific interactions between biotin and avidin studied by atomic force microscopy using the poisson statistical analysis method. Langmuir, 15(4):1373-1382, 1999. 
[182] T. Strunz, K. Oroszlan, R. Schäfer, and H.-J. Güntherodt. Dynamic force spectroscopy of single DNA molecules. Proc. Natl. Acad. Sci. USA, 96:11277-11282, 1999.

[183] H. A. Kramers. Brownian motion in a field of force and the diffusion model of chemical reactions. Physica (Utrecht), VII(4):284-304, 1940.

[184] G. U. Lee, L. A. Chrisey, and R. J. Colton. Direct measurement of the forces between complementary strands of DNA. Science, 266:771-773, 1994.

[185] M. Balsera, S. Stepaniants, S. Izrailev, Y. Oono, and K. Schulten. Reconstructing potential energy functions from simulated force-induced unbinding processes. Biophys. J., 73:12811287, 1997.

[186] J. Shillcock and U. Seifert. Escape from a metastable well under a time-ramped force. Phys. Rev. E, 57(6):7301-7306, 1998.

[187] J. Gullingsrud, R. Braun, and K. Schulten. Reconstructing potentials of mean force through time series analysis of steered molecular dynamics simulations. J. Comput. Phys., 151:190-211, 1999.

[188] H. J. Eyring. J. Chem. Phys., 3:107-115, 1935.

[189] D. R. Davies and S. Chacko. Antibody structure. Acc. Chem. Res., 26:421-427, 1993.

[190] D. R. Davies and H. Metzger. Structural basis of antibody function. Ann. Rev. Immunol., 1:87, 1983.

[191] A. T. Brünger, D. J. Leahy, T. R. Hynes, and R. O. Fox. $2.9 \AA$ resolution structure of an anti-dinitrophenyl-spin-label monoclonal antibody $\mathrm{f}_{\mathrm{ab}}$ fragment with bound hapten. $J$. Mol. Biol., 221:239-256, 1991.

[192] A. R. Rees, D. Staunton, D. M. Webster, S. J. Searle, A. H. Henruy, and J. T. Pedersen. Antibody design: beyond the natural limits. TIBTECH, 12:199-206, 1994.

[193] J. Anglister, T. Frey, and H. M. McConnell. Magnetic resonance of a monoclonal antispin-label antibody. Biochemistry, 23:1138-1142, 1984.

[194] T. Frey, J. Anglister, and H. M. McConnell. Nonaromatic amino acids in the combinig site region of a monoclonal anti-spin-label antibody. Biochemistry, 23:6470-6473, 1984.

[195] J. Anglister, T. Frey, and H. M. McConnell. Distances of tyrosine residues from a spin-label hapten in the combining site of a specific monoclonal antibody. Biochemistry, 23:5362$5375,1984$.

[196] J. Anglister, M. W. Bond, T. Frey, D. Leahy, M. Levitt, H. M. McConnell, G. S. Rule, J. Tomasello, and M. Whittake. Contribution of tryptophan residues to the combinig site of a monoclonal anti-dinitrophenyl spin-label antibody. Biochemistry, 26:6058-6064, 1987.

[197] E. A. Kabat et al. In Sequences of Proteins of Immunological Interest. National Institute of Health, Bethesda, MD, U.S.A, 4th edition, 1987.

[198] J. A. McCammon. Protein dynamics. Rep. Prog. Phys., 47:1-46, 1984.

[199] L. Stella and S. Melchionna. Equilibration and sampling in molecular dynmaics simulations of biomolecules. J. Chem. Phys., 109(13):10115-10117, 1998. 
[200] T. P. Theriault, D. J. Leahy, M. L. Levitt, H. M. McConnell, and G. S. Rule. Structural and kinetic studies of the $\mathrm{f}_{\mathrm{ab}}$ fragment of a monoclonal anti-spin label antibody by nuclear magnetic resonance. J. Mol. Biol., 221:257-270, 1991.

[201] A. Kitao, F. Hirata, and N. Gō. The effects of solvent on the conformation and the collective motions of a protein: normal mode analysis and molecular dynamics simulations of melittin in water and in vacuum. J. Phys. Chem., 158:447-472, 1991.

[202] A. Amadei, A. B. M. Linssen, and H. J. C. Berendsen. Essential dynamics of proteins. Proteins, 17:412-425, 1993.

[203] A. E. García. Large-amplitude nonlinear motions in proteins. Phys. Rev. Lett., 68:26962699, 1992.

[204] N. Ehrenhofer. Untersuchung der Konformationsdynamik eines vereinfachten Proteinmodells. Master's thesis, Ludwig-Maximilians-Universität München, 1994.

[205] H. Grubmüller, N. Ehrenhofer, and P. Tavan. Conformational dynamics of proteins: Beyond the nanosecond time scale. In M. Peyard, editor, Proceedings of the Workshop 'Nonlinear Excitations in Biomolecules', May 30-June 4, 1994, Les Houches (France), pages 231-240. Centre de Physique des Houches (France), Springer-Verlag, 1995.

[206] H. Grubmüller. Predicting slow structural transitions in macromolecular systems: Conformational flooding. Phys. Rev. E, 52:2893-2906, 1995.

[207] K. V. Mardia, J. T. Kent, and J. M. Bibby. Multivariate Analysis. Academic Press, London, 1979.

[208] Martin Karplus and Joseph N. Kushick. Method for estimating the configurational entropy of macromolecules. Macromolecules, 14:325-332, 1981.

[209] J. Schlitter. Estimation of absolute and relative entropies of macromolecules using the covariance matrix. Chem. Phys. Lett., 215:617-621, 1993.

[210] R. V. Hogg and A. T. Craig. Introduction to Mathmatical Statistics. Harper and Row, New York, U.S.A., 1970.

[211] L. Stryer. Biochemistry. W. H. Freeman and Company, San Francisco, 1988.

[212] N. Sharon. Carbohydrates, their Chemistry, Biosynthesis, and Function. Addison-Wesley, Reading, MA, 1975.

[213] R. P. McEver, K. L. Moore, and R. D. Cummings. Leukocyte trafficking mediated by selective carbohydrate interactions. J. Biol. Chem., 270:11025-11028, 1995.

[214] S. D. Rosen and C. R. Bertozzi. Leukocyte adhesion: two selectins converge on sulphate. Cur. Opin. in Struct. Biol., 6:261-264, 1996.

[215] R. Alon, D. A. Hammer, and T. A. Springer. Lifetime of the p-selectin-carbohydrate bond and its response to tensile force in hydrodynamic flow. Nature (London), 374:539-542, 1995.

[216] K. D. Puri, S. Chen, and T. A. Springer. Modifying the mechanical property and shear threshold of l-selectin adhesion independently of equilibrium properties. Nature (London), 392:930-933, 1998. 
[217] D. J. Cosgrove. Relaxation in a high-stress environment: the molecular bases of extensible cell walls and cell enlargement. Plant Cell, 9:1031-1041, 1997.

[218] J. J. Thwaites and N. H. Mendelson. Biomechanics of bacterial walls: studies of bacterial thread made from Bacillus subtilis. Proc. Natl. Acad. Sci. USA, 92:2163-2167, 1985.

[219] A. L. Lehninger. Biochemistry. Worth, New York, U.S.A., 2nd edition, 1975.

[220] N. V. Joshi and V. S. R. Rao. Flexibility of the pyranose ring in $\alpha$ - and $\beta$-D-glucose. Biopolymers, 18:2993-3004, 1979.

[221] G. M. Brown and H. A. Levy. $\alpha$-D-glucose: Precise determination of crystal and molecular structure by neutron-diffraction analysis. Science, 147:1038-1039, 1965.

[222] G. M. Brown and H. A. Levy. $\alpha$-D-glucose: Further refinement based on neutrondiffraction data. Acta Crystallogr., B35:656-659, 1978.

[223] S. C. Chu Shirley and G. A. Jeffrey. The refinement of the crystal structures of $\beta$-D-glucose and cellobiose. Acta Crystallogr., B24:830-838, 1968.

[224] J. W. Brady. Molecular dynamics simulations of $\alpha$-D-glucose. J. Am. Chem. Soc., 108:8153-8160, 1986.

[225] J. W. Brady. Molecular dynamics simulations of $\beta$-D-glucopyranose. Carbohydr. Res., 165:306-312, 1987.

[226] G. I. Csonka, K. E. Éliás, and I. G. Csizmadia. Relative stability of ${ }^{1} C_{4}$ and ${ }^{4} C_{1}$ chair forms of $\beta$-D-glucose: a density functional study. Chem. Phys. Lett., 257:49-60, 1996.

[227] M. Fixman and J. Kovac. Polymer conformational statistics. 3. Modified gaussian models of stiff chains. J. Chem. Phys., 58(4):1564-1568, 1973.

[228] C. Bustamante, J. F. Marko, E. D. Siggia, and S. Smith. Entropic elasticity of lambdaphage DNA. Science, 265:1599-1600, 1994.

[229] J. F. Marko and E. D. Siggia. Stretching DNA. Macromolecules, 28:8759-8770, 1995.

[230] J. Hutter, P. Ballone, M. Bernasconi, P. Focher, E. Fois, S. Goedecker, D. Marx, M. Parrinello, and M. Tuckerman. CPMD Version 3.0. MPI für Festkörperforschung and IBM Zurich Research Laboratory 1995-96.

[231] M. Eichinger, P. Tavan, J. Hutter, and M. Parrinello. A hybrid method for solutes in complex solvents: Density functional theory combined with empirical force fields. $J$. Chem. Phys., 110(21):10452-10467, 1999.

[232] D. Vanderbilt. Soft self-consistent pseudopotentials in a generalized eigenvalue formalism. Phys. Rev. B, 41:7892-7895, 1990.

[233] I. Tvaroška and J. P. Carver. Ab initio molecular orbital calculation of carbohydrate model compounds. 4. Flexibility of $\Psi$-type glycosidic bonds in carbohydrates. J. Mol. Struct., 395:1-13, 1997.

[234] H. Eibl, 1999. Private Mitteilung.

[235] M. Grandbois and H. Li, 1998. Private Mitteilung. 
[236] M. Rief, J. M. Fernandez, and H. E. Gaub. Elastically coupled two-level systems as a model for biopolymer extensibility. Phys. Rev. Lett., 81(21):4764-4767, 1998.

[237] W. Nadler, A. T. Brünger, K. Schulten, and M. Karplus. Molecular and stochastic dynamics of proteins. Proc. Natl. Acad. Sci. USA, 84:7933-7937, 1987.

[238] S. Chandrasekhar. Stochastic problems in physics and astronomy. Rev. Mod. Phys., 15(1):1-89, 1943.

[239] K. Devanand and J. C. Selser. Polyethylene oxide does not necessarily aggregate in water. Nature (London), 343:739-741, 1990.

[240] R. Begum and H. Matsuura. Conformational properties of short poly(oxyethylene) chains in water studied by IR spectroscopy. J. Chem. Soc. Faraday Trans., 93(21):3839-3848, 1997.

[241] R. L. C. Wang, H. J. Kreuzer, and M. Grunze. Molecular conformation and solvation of oligo(ethylene glycol) terminated self-assembled monolayers and their resistance to protein adsorption. J. Phys. Chem. B., 101:9763-9773, 1997.

[242] H. Tadokoro. Structure of crystalline polymers. Krieger, Malabar, 1990. 